\title{
It's All One Curriculum: Guidelines for a Unified Approach to Sexuality, Gender, HIV, and Human Rights Education
}

International Sexuality and HIV Curriculum Working Group

Nicole Haberland

Population Council

Deborah Rogow

Follow this and additional works at: https://knowledgecommons.popcouncil.org/departments_sbsr-pgy

Part of the Demography, Population, and Ecology Commons, Family, Life Course, and Society Commons, Gender and Sexuality Commons, International Public Health Commons, and the Medicine and Health Commons How does access to this work benefit you? Let us know!

\section{Recommended Citation}

International Sexuality and HIV Curriculum Working Group. 2009. "It's All One Curriculum: Guidelines for a Unified Approach to Sexuality, Gender, HIV, and Human Rights Education," edited by Nicole Haberland and Deborah Rogow. New York: Population Council. 



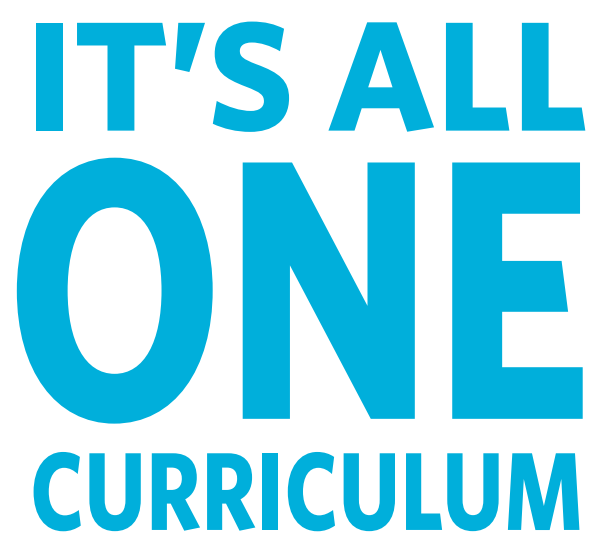

VOLUME 1: GUIDELINES FOR A UNIFIED APPROACH TO SEXUALITY, GENDER, HIV, AND HUMAN RIGHTS EDUCATION 

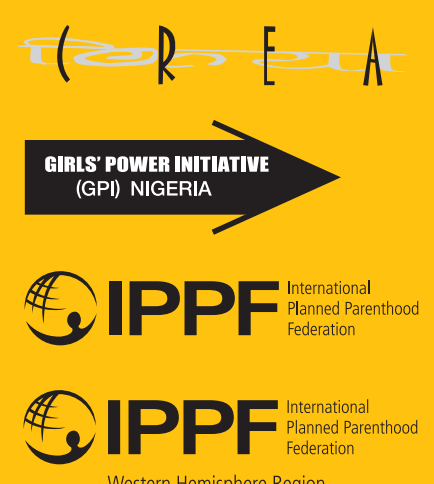

Western Hemisphere Region

$\bigcirc$

INTERNATIONAL WOMEN'S

HEALTH COALITION

\section{Mexfam \\ Salud para tu familia}

1 Population Council
It's All One Curriculum: Guidelines and Activities for a Unified Approach to Sexuality, Gender, HIV, and Human Rights Education was developed by an international working group comprised of representatives from the following organizations (listed alphabetically):

CREA (India): Caroline Earle, Sunita Kujur, Geeta Misra

Girls Power Initiative (Nigeria): Bene Madunagu, Grace Osakue

International Planned Parenthood Federation: Doortje Braeken

IPPF/Western Hemisphere Region: Jessie Clyde, Denise Kohn

International Women's Health Coalition: Kelly Castagnaro, Corinne Whitaker

Mexfam (Mexico): Ofelia Aguilar

Population Council: Nicole Haberland, Deborah Rogow

The working group brought a range of perspectives and relevant technical expertise in adolescent sexuality/HIV education, including in areas of rights and gender, program management, research, and advocacy. Andrea Irvin also helped draft a number of sections.

\section{Written by the International Sexuality and HIV Curriculum Working Group Edited by Nicole Haberland and Deborah Rogow}

Project Coordinators: Michelle Skaer and Jonah Stuart Brundage

Design: Emanuela Frigerio, Hyun Auh, C\&G Partners, New York City

Production: Mike Vosika, Christina Tse, Michelle Skaer, Susan Shapiro

Copyeditor: Karen Tweedy-Holmes

Reading-level editor: Gina Duclayan

Coordination of 2011 revision: Amy Handler

Photo credits for cover images: Introduction, Jacob Silberberg, courtesy of IPPF/WHR; unit 1, Manoocher Ceghati, courtesy of IRIN; unit 2, Michael Newman, courtesy of PhotoEdit; unit 3, Gabe Cooney, courtesy of IPPF/WHR; unit 4, Maura Carroll; unit 5, Melissa May; unit 6, Ronn Aldaman; unit 7, Neil Thomas, courtesy of IRIN; unit 8, Eugene Martin; fact sheets, Helen Cole, courtesy of Photoshare. All other photo credits are identified next to the image.

Published by the Population Council, New York.

Available for free download at: www.itsallone.org

Copyright (c) 2009 The Population Council, Inc. Revised first edition, printed 2011.

Any part of this volume may be photocopied without permission from the authors or publisher, provided that publication credit is given and copies are distributed free. Any commercial reproduction requires prior written permission from the Population Council. Please also credit any original sources as noted for selected activities.

ISBN: Guidelines: 978-0-87834-117-7; Activities: 978-0-87834-118-4; Set: 978-0-87834-119-1 


\section{In memory of Enofe Duncan Osakue}


RESEARCHERS have identified gender inequality as a key factor driving the AIDS pandemic.

POLICYMAKERS have called for sexuality and HIV education that emphasizes gender equality and human rights.

EDUCATORS want to teach young people the critical thinking skills needed to build compassionate and just societies. 


\section{IT'S ALL ONE CURRICULUM}

responds to these calls. 


\section{acknowledgments}

It's All One Curriculum: Guidelines and Activities for a Unified Approach to Sexuality, Gender, HIV, and Human Rights Education is the product of contributions from individuals around the world. Our heartfelt thanks to each and every person who contributed to this effort.

Wendy Baldwin, Carmen Barroso, Kate Bourne, Judith Bruce, Vicente Díaz, Beth Fredrick, Adrienne Germain, Naana Otoo-Oyortey, Tim Shand, and Victoria Ward provided invaluable guidance and advice. Maggie Díaz and Juan Díaz at Reprolatina reviewed the GUIDELINES volume for technical and clinical accuracy. Evan Read created the original illustrations, and Jared Stamm developed the website. Nell Timreck and Ernestine Heldring contributed substantially during final revisions. We are particularly indebted to Mike Vosika and Karen Tweedy-Holmes for their extraordinary support throughout the production process. Thanks as well to the many friends and colleagues who generously shared their photographic images with us.

Michelle Skaer, and later Jonah Stuart Brundage, coordinated this project with great intelligence and equal cheer; their contributions were critical at every stage. More than 50 experts reviewed the manuscript during its development, and eight organizations assisted in field testing original sample activities. These individuals and organizations are listed on the following page (institutional affiliations are noted for identification purposes only and refer to affiliation at the time of review). We are deeply grateful for their technical support, time, and insights; this document would not be what it is without them. The editors alone are responsible for errors or omissions.

Finally, we thank our donors, whose financial and collegial support made It's All One Curriculum possible. Our sincere thanks to the Ford Foundation, the William and Flora Hewlett Foundation, The Libra Foundation, the John D. and Catherine T. MacArthur Foundation, the UK Department for International Development (DfID), and the United Nations Population Fund (UNFPA). We also benefited greatly from financial support provided by the International Planned Parenthood Federation, IPPF/Western Hemisphere Region, International Women's Health Coalition, and the Population Council. 
ADVISORY REVIEW

Aziza Ahmed (International Community of Women Living with HIV/AIDS)

Lucy Atkin (Colibri Consulting and Hesperian)

Doris Bartel (CARE)

Marina Bernal (MULABI)

Jennifer Catino (EngenderHealth)

Esther Corona (Mexican Association for Sex Education and WAS)

Sarah Hawker Costa (Global Fund for Women)

Jane Cottingham (WHO)

Karen Fazekas (Family Health International)

Gill Gordon (International HIV/AIDS Alliance)

Nik Hartley (Students Partnership Worldwide)

Christine Heritier (Afghanistan Libre)

Rachel Jacobson (Global Youth Coalition on HIV/AIDS)

Magaly Marques (Planned Parenthood of Los Angeles)

Rafael Mazin (PAHO)

Alexander McKay (SIECCAN)

Prabha Nagaraja (TARSHI)

Rick Olson (UNICEF)

Christine Ricardo (Instituto Promundo)

Saira Shameem (Asian Pacific Resource and Research Centre for

Women - ARROW)

Robert Thomson (UNFPA)

Nell Timreck (Students Partnership Worldwide)

\section{ACTIVITIES FIELD TESTING TEAM}

Aahung (Pakistan)

Asociación Demográfica Costarricense (Costa Rica)

Association for Sexual and Reproductive Health XY (Bosnia)

Belize Family Life Association (Belize)

Fundación Mexicana para la Planeación Familiar (MEXFAM) (Mexico)

Girls Power Initiative (Nigeria)

Lesotho Planned Parenthood Association (Lesotho)

Reprolatina (Brazil)

\section{TECHNICAL REVIEW}

Anonymous (individual)

Gautam Bhan (individual)

Yvonne Bogaarts (World Population Foundation)

Jeff Buchanan (individual)

Margarita Díaz (Reprolatina)

Uyi-Oni Ekhosuehi (Optimal Health and Development Project)

Nadine Dimodi Ekotto (ALVF)

Chris Fung (USAID)

Tamara Gonçalves (CLADEM/Brazil Member)

Angela Heimburger (Human Rights Watch)

Ernestine Heldring (Scenarios USA)

Patty Herrera (Latino Community Solutions)

Laura Katzive (Center for Reproductive Rights)

Scott Kellerman (Population Council)

Martha Kempner (SIECUS)

Tang Kun (China Family Planning Association)

Katarina Lindahl (RFSU)

Eugenia López Uribe (Balance Promoción para el Desarrollo y Juventud)

Veronica Magar (CARE)

Lori Michau (Raising Voices)

Carmen Murguia (UNFPA)

Ratidzai Ndlovu (UNFPA)

Karen Newman (individual)*

Suzyo Nthazie (Young African Advocates for Rights)

Sabina Rashid (BRAC University)

Nell Rasmussen (Danish National Board of Social Services)

Sundari Ravindran (Achutha Menon Centre for Health Science

Studies)

Meredith Sheehy (Population Council)

Joann Stemmermann (individual)*

John Townsend (Population Council)

Lita Townsend (Cleveland Metropolitan Schools)

Wijit Wong (World Population Foundation)

Margot Zimmerman (individual)*

*Provided early technical input. 


\section{table of contents}

INTRODUCTION 1

SEXUAL HEALTH AND WELL-BEING REQUIRE HUMAN RIGHTS 17

how we treat each other: values and society

what are "human rights"?

sexual and reproductive rights

promoting human rights, including sexual and reproductive rights

glossary (basic concepts about human rights)

\section{GENDER}

defining gender

gender identity

gender norms and roles solidify during childhood and adolescence

gender and education

gender stereotypes in the media

how gender affects mobility, social connection, and safe public spaces

how gender affects civic and political participation

gender, work, and economic resources: inside and outside the home

gender and marriage

gender and religion

gender and bodily autonomy

gender and violence

sexual coercion is a form of gender-based violence

responding to gender-based violence

gender norms and roles change over time

gender: our own decisions and actions

changing the world around us

glossary (basic concepts about gender) 
about sexuality

sexual rights

sexuality and society

sexual norms vary according to gender roles: the "double standard" for sexual behavior

sexual desire

sexual diversity

anatomy and sexual pleasure

sexual expression and enjoyment

sexual behavior

motivations for having and not having sex

sexual consent and coercion

creating mutually respectful and responsible sexual relationships

concerns about sexual function

sexual well-being and advocacy

glossary (basic concepts about sexuality)

\section{INTERPERSONAL RELATIONSHIPS}

introduction to interpersonal relationships

relationships in our lives

how can our relationships be more satisfying and respectful?

romantic relationships: courtship and dating

romance: what is falling in love? what is "true love"? what about jealousy?

sexual activity in relationships

long-term intimate relationships

difficulties in relationships

ending a relationship

norms about relationships are changing

\section{COMMUNICATION AND DECISIONMAKING SKILLS}

factors affecting communication

tips for effective communication

direct versus indirect communication styles

talking to your partner about sex and sexual health issues

making decisions

acting on our decisions 
body image

puberty

knowing about one's body

sexual and reproductive organs

fertility and reproduction ("where babies come from")

when pregnancy continues

learning about one's body: a global movement

\section{SEXUAL AND REPRODUCTIVE HEALTH}

the right to health services

PART 1: SEXUALLY TRANSMITTED INFECTIONS, INCLUDING HIV AND AIDS

about sexually transmitted infections (STIs) and HIV and AIDS

methods of protection against STIs and HIV

why people don't use protection and why gender equality is key to fighting AIDS

living with HIV and AIDS

rights and responsibilities related to preventing STIs and HIV

reproductive tract infections (RTIs)

PART 2: DECISIONS ABOUT ONE'S OWN FERTILITY:

CONTRACEPTION AND ABORTION

about contraception

different contraceptive methods

unintended pregnancy and abortion

ADVOCATING FOR SEXUAL HEALTH, RIGHTS, AND GENDER EQUALITY

reflecting on our own attitudes

recognizing whether something is fair or unfair

changing the world around us

obstacles faced in advocating for social change

the meaning and power of advocacy in people's lives

taking action: project-based learning 


\section{INTRODUCTION}

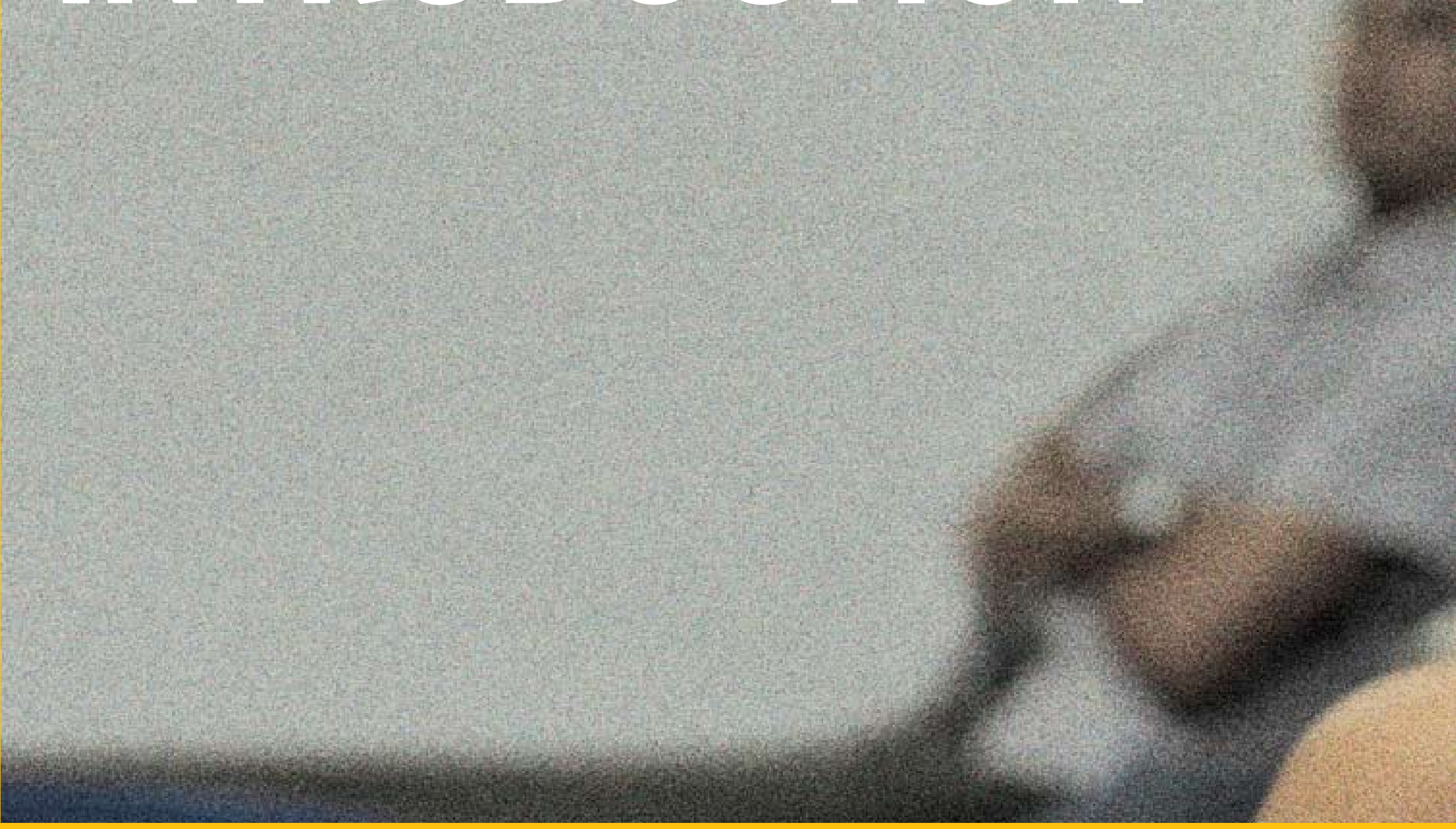




\title{
It's All One Curriculum: what is it?
}

\author{
This is a practical resource for curriculum development, particularly in \\ the areas of gender, sexuality, and HIV.
}

It's All One Curriculum offers content on almost any topic you might want to include in teaching young people about gender, sexual health, HIV, sexuality, relationships, communication, intimate-partner violence, puberty, reproduction, contraception, abortion, or advocating for their own rights. It is intentionally comprehensive, so that you can select the content and activities that meet your needs.

It's All One Curriculum is not simply comprehensive, however. It takes an integrated approach to these topics. Research shows that young people's social context, individual factors, and health outcomes are profoundly interconnected. Hence, this resource helps you think about and teach about a range of related topics — as one curriculum.

Importantly, It's All One Curriculum also brings a critical thinking approach to the learning process — thereby strengthening education overall. Moreover, it helps countries respond to the Millennium Development Goals. In all these ways, it brings a fresh and practical approach to educating young people in a diverse and rapidly changing world.

It's All One Curriculum has seven key features, described on the opposite page. These features are based on the strategies and priorities established by a number of global health and education agencies, including the United Nations General Assembly, ${ }^{1}$ UNAIDS, ${ }^{2}$ the World Health Organization, ${ }^{3}$ UNESCO, ${ }^{4}$ and the World Association for Sexual Health. ${ }^{5}$ It's All One Curriculum was developed by an international group of experts to ensure that its perspective is relevant for educating young people globally — from Africa to the Pacific, from Asia to the Americas, from Europe to the Arab World.

The ultimate goal of It's All One Curriculum is to develop the capacity
of young people to enjoy - and advocate for their rights to - dignity,
equality, and responsible, satisfying, and healthy sexual lives. 


\section{SEVEN KEY FEATURES OF It's All One Curriculum}

1 Evidence-based, that is, it builds on curricular standards articulated by global researchers, ${ }^{6}$ while also integrating important findings about the links between gender dynamics and sexual health outcomes;

2 Comprehensive, including accurate information about all the psychosocial and health topics needed for a thorough curriculum covering sexuality, HIV prevention, the right to abstain from sex, and family life education; ${ }^{7}$

3 Based on core values and human rights, that is, it promotes principles of fairness, human dignity, equal treatment, opportunities for participation, and human rights for all as the basis for achieving sexual and reproductive health and well-being; ${ }^{8}$

4 Gender-sensitive, emphasizing the importance of gender equality ${ }^{9}$ and the social environment in general for achieving sexual and reproductive health and overall well-being for both boys and girls;

5 Promotes academic growth and critical thinking, fostering habits of mind necessary for understanding relationships between self, others, and society and how these relationships affect all of our lives. Thus, it provides a basis for extending sexuality and HIV education into civics, social studies, and language-arts classrooms;

6 Fosters civic engagement by championing the idea that each person matters and can make a positive difference in his or her world. It helps build advocacy skills that are crucial to creating a more just and compassionate society; and

7 Culturally appropriate, reflecting the diverse circumstances and realities of young people around the world.

\section{ONE CURRICULUM, MULTIPLE GOALS}

INCREASING YOUNG PEOPLIEIS

Ability to make responsible decisions and act upon their own choices

Ability to participate in society and exercise their human rights

Critical thinking, and overall educational achievement

Sense of self-efficacy and agency

Sense of sexual well-being and enjoyment

REDUCING ADOLESCENTS'

RATES OF

Unintended pregnancy

Sexually transmitted infections, including HIV

Coerced or unwanted sex Gender-based violence 


\section{It's All One Curriculum: why is it needed?}

\section{FACT}

Young people who have developed egalitarian gender norms have better sexual health outcomes than their peers.

\section{FACT}

International agreements call for sexuality education and gender equality.

"... we know what it takes to turn the tide against this [AIDS] epidemic ... It requires real, positive change that will give more power and confidence to women and girls, and transform relations between women and men at all levels of society."

- Former United Nations Secretary-General Kofi Annan
The global community has prioritized the fight against AIDS. Most governments have also signed international agreements honoring the principles of gender equality and of human rights. But how are these linked? Why are gender equality and human rights crucial for achieving sexual health and well-being?

The fact is that gender norms profoundly affect young people's ability to make and implement decisions regarding their own sexual lives. For example, the unforgiveable reality is that sex, marriage, and pregnancy remain neither voluntary nor informed for tens of millions of girls. Boys, too, often experience intense pressures to live up to unrealistic and harmful expectations of manhood.

The consequences are real. Studies from both developing and developed countries confirm that young people who believe in gender equality have better sexual health outcomes than their peers. In contrast, those young people who hold less egalitarian attitudes tend to have worse sexual health outcomes. For example, young people who believe that males should be "tough" and should hold more power than females are less likely to use condoms or contraception and more likely to have multiple sex partners. They are also more likely to be in intimate relationships that involve violence. Females in relationships with a high level of male control are also more likely to report HIV and unintended pregnancy. Similarly reflecting this constellation of gender inequality and poor sexual health are studies showing that intimate partner violence is associated with higher rates of unintended pregnancy, STIs, and HIV. ${ }^{10}$ These findings make clear that young people need chances to learn about gender equality and human rights, particularly because these issues affect their sexual lives, and indeed, their happiness.

\section{Unfortunately, sex education programs have lagged in applying these findings. Few sex education curricula address issues of gender and rights in a meaningful way. This deficiency is particularly worrisome because few sex or HIV curricula have demonstrated a statistically significant impact either on unintended pregnancy or on sexually transmitted infections. ${ }^{11}$}


The lesson — which we ignore at adolescents' peril — is that gender equality and human rights are not just lofty goals. Rather, they are key to preventing the spread of HIV and to enabling young people to grow up to enjoy good health, as well as responsible and satisfying sexual lives. Indeed, it is in response to such research findings, and as a matter of human dignity, that the global community — governments, civil society, and international agencies — is increasingly asking for sexuality and HIV education that addresses issues of gender and human rights. Today's educators need resources for presenting these concepts in meaningful and effective ways.

Happily, there are groundbreaking new sexuality and HIV education programs around the world that are paying greater attention to gender equality and to human rights. What is compelling is that such approaches are now showing exciting results; ${ }_{i}^{12}$ it is high time to implement and test such approaches more widely.

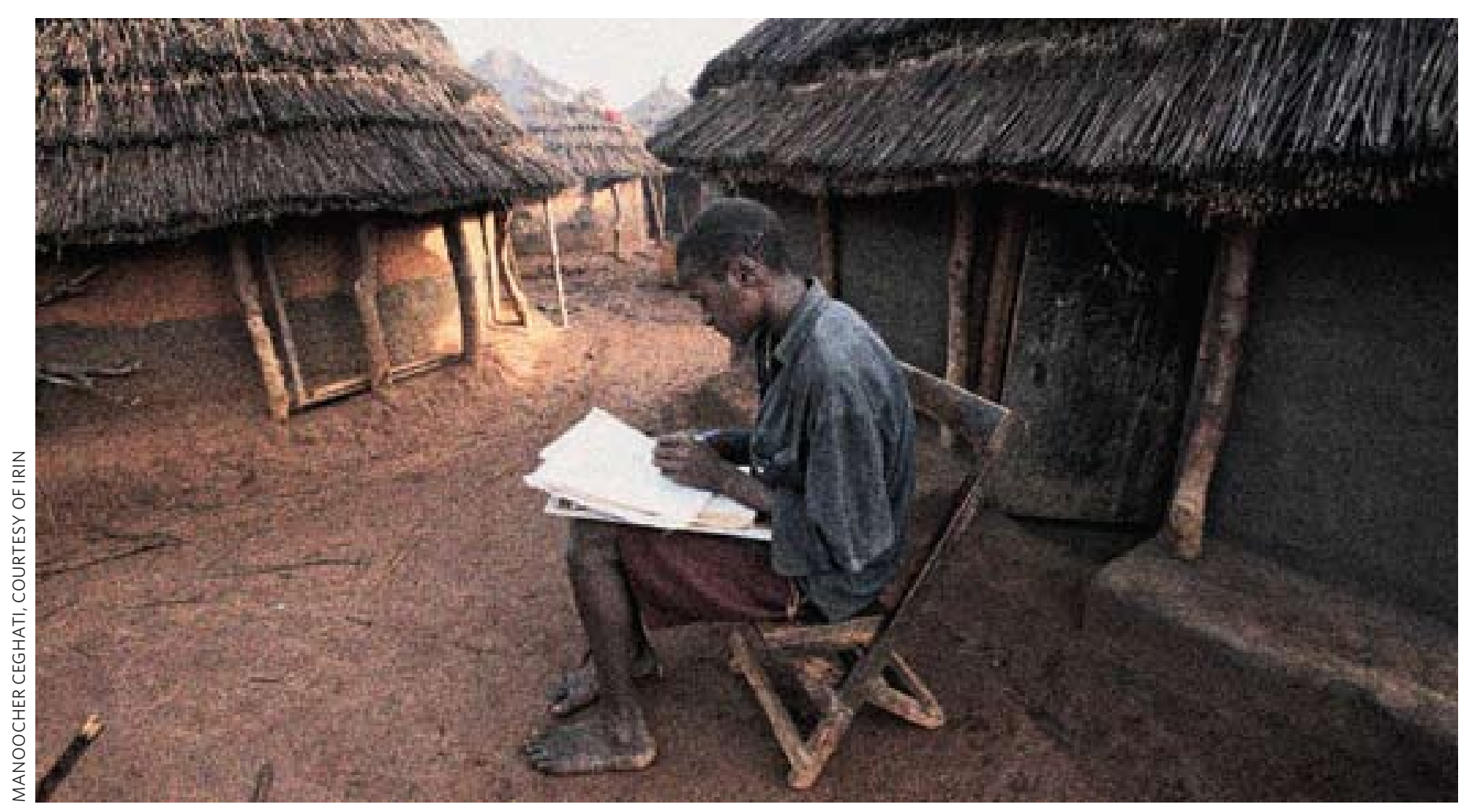




\section{It's All One Curriculum: who can use it?}

\section{It's All One Curriculum is designed primarily for curriculum developers,}

schoolteachers, and community educators responsible for education in the areas of sexuality/sexual health (including AIDS) and civics or social studies. Users may draw on the guidelines and activities in this kit to meet their needs, for example:

- to develop or modify comprehensive curricula (of any duration) appropriate for their setting;

- to design more narrowly focused teaching units (for example, on gender or sexual health); and

- to use as a resource for single-topic lesson plans (for example, gender and the media, deciding about sex, protecting oneself and one's partners from HIV, reflecting on masculinity).

\section{A second audience for the It's All One Curriculum kit includes health and education} policymakers and school administrators. This kit can help these professionals ensure that their sexuality and HIV education initiatives respond to the learning needs of young people and to the policy statements of such bodies as the United Nations General Assembly (Millennium Development Goals ${ }^{13}$ ), UNAIDS, UNESCO, the World Health Organization, and other agencies. ${ }^{14}$ Moreover, the methods that are the heart of It's All One Curriculum support higher-order thinking skills (such as research, reflection, and analysis) and foster students' connectedness to school. As such, schools can use sex/HIV education to strengthen education overall, rather than to compete with other valuable academic goals.

Around the world, sexuality education takes place in a great variety of cultural and political contexts. It's All One Curriculum: Guidelines and Activities is designed to present sensitive information appropriately in a wide range of such contexts in Africa, the Americas, the Arab world, Asia, Europe, and the Pacific. The material includes many examples from various cultural settings. The next section, (It's All One Curriculum: Where and How to Use It) offers guidance to educators and policymakers on how to adapt these materials easily for their particular setting. 


\section{It's All One Curriculum: where and how to use it}

IN RESPONSE TO EDUCATORS' REQUESTS

It's All One Curriculum provides the basis for curricula to be offered in various settings. It may be used to design curricula to be taught in schools in subjects ranging from health and biology to social studies and literature. It is also useful for afterschool classes or educational programs in community settings. These could include health services, youth programs, and other informal education venues. It may also be adapted for adult-education curricula.

Sexuality and HIV education programs vary widely in terms of substantive emphasis and duration. Hence, It's All One Curriculum is highly flexible and is designed to let users quickly identify the information and level of detail they need. For example, the content is broken down into eight units, each with subtopics. Within each subtopic is a series of key statements, and many of these statements are supplemented with further detail or concrete examples from various cultural settings. Users can easily select which units, which subtopics, and what level of detail best meet their needs. The most comprehensive curriculum will draw from all eight units. However, users who have limited time to plan a curriculum or to teach these topics may wish to refer to the gold margin on the right for a recommended sample of selected content and activities.

The content of It's All One Curriculum was developed for young people aged 15 and older, whether in or out of school. More and more, though, experts and policymakers see the necessity of starting this type of education at earlier ages. Puberty and early adolescence signal a time when attitudes and behaviors related to gender become more distinct and established, and when a large proportion of adolescent girls are still reachable through the formal education system. Many educators who teach children younger than 15 can draw on this kit to create an appropriate curriculum. Care must be taken, of course, to consider the particular educational requirements of a younger audience. [For a list of those activities most easily and appropriately adapted for younger learners, see the opening pages of the ACTIVITIES volume.] $]^{15}$

Finally, It's All One Curriculum: Guidelines and Activities is designed flexibly, to be used in many cultures. It applies universal principles to the varied cultural and social circumstances in which people live. Naturally, educators may wish to emphasize certain sections over others for cultural or political reasons or because of the particular needs of special groups. A worldwide review suggests that It's All One Curriculum is useful for guiding the design of curricula for a broad range of populations.
We provide a sampling of recommended activities for those who have fewer than 14 hours of teaching time but still wish to draw from all the units:

\section{unit 1 activity 4}

unit 2 activities 5, 9 (plus 7 or 14)

unit 3 activities 18, 23

unit 4 activity 32

unit 5 activities 35,36

unit 6 activities 41, 42, 44

unit 7 activity 50 (plus homework at start of 51)

unit 8 activity $\mathbf{5 3}$ 


\section{It's All One Curriculum: what does it contain?}

This two-book kit provides the essential elements for developing a rights-based, gender-sensitive, and participatory curriculum for sexuality and HIV education.

\section{Book 1: GUIDELINES}

An introduction that includes an evidence-based policy argument

Seven content units (each with Learning Objectives, Key Content, and Points for Reflection)

A final project-based unit (to support advocacy and apply lessons learned)

22 fact sheets

\section{Book 2: ACTIVITIES}

Effective teaching methods

54 sample activities

Additional resources

Each of these books is described briefly on the following pages. 
桌

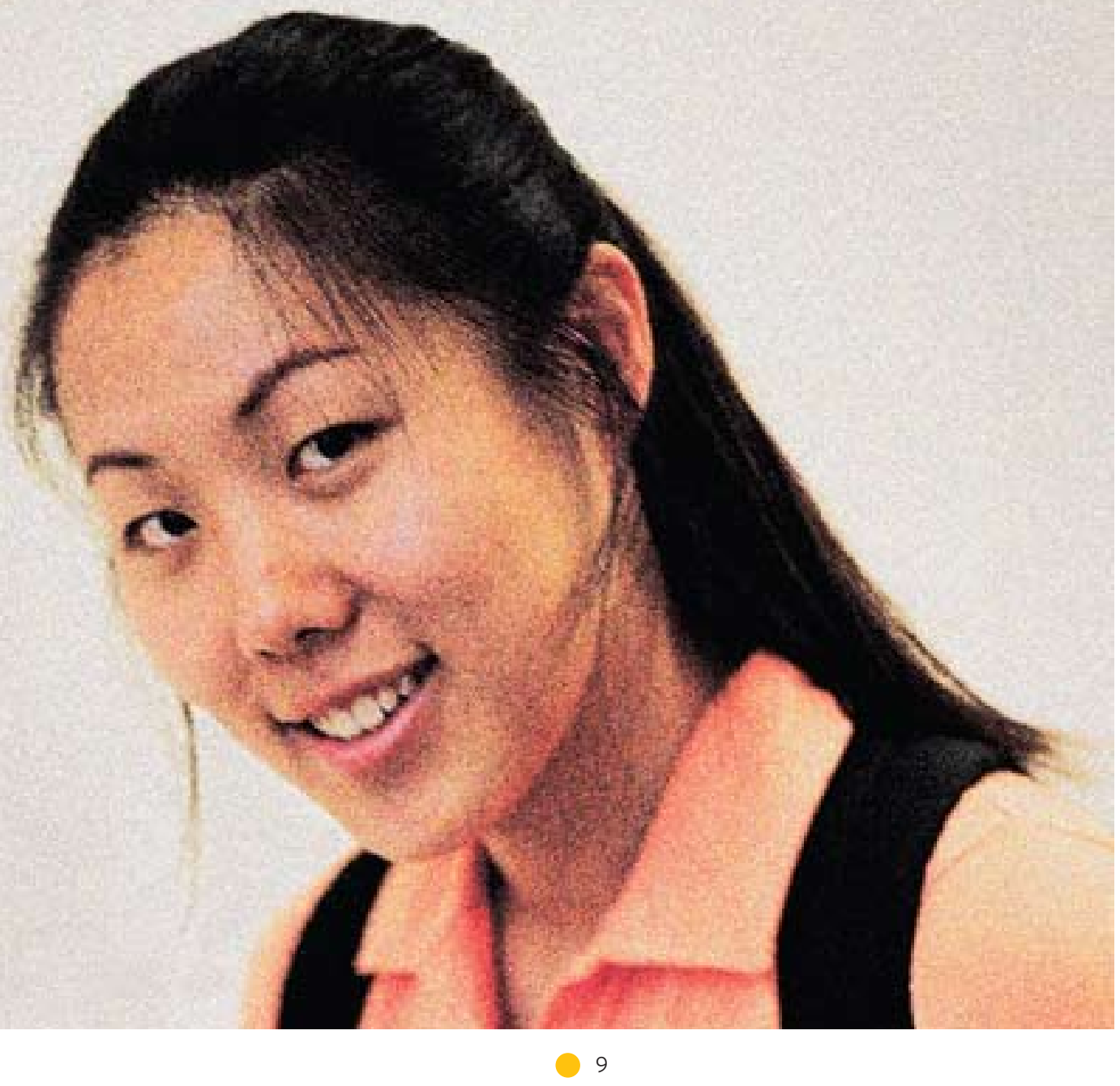




\section{guidelines book}

CONTENT UNITS: The first seven units of the GUIDELINES book provide the necessary information for a comprehensive curriculum that integrates the issues of gender, human rights, sexuality, sexual health, and HIV. You will also see special "Points for Reflection" in the gold-colored margins. These Points for Reflection illustrate ways to use the material to stimulate learners' critical thinking skills. These questions may also help educators think about the content in creative ways. You will also see orange boxes that link selected content to innovative classroom activities (found in the companion ACTIVITIES book). Finally, Unit 8 provides background and guidelines for project-based learning in the area of advocacy and social change.

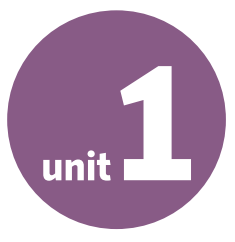

\section{SEXUAL HEALTH AND WELL-BEING REQUIRE HUMAN RIGHTS}

Why should sexuality and HIV-prevention education include content about human rights? This unit explains how people's sexual health and emotional well-being are connected to their ability to exercise their human rights (for example, their rights to education and freedom of expression). These rights extend to protecting one's body, sexuality, and health. This unit stresses the importance of being able to exercise one's rights with confidence. It describes actions young people can take to promote respect. It shows how they can protect their own and their partners' sexual and reproductive health and rights.

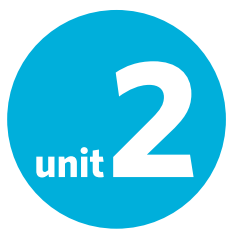

\section{GENDER}

Achieving gender equality is a moral imperative and a key Millennium Development Goal. This unit enables educators to address gender issues effectively, supporting both boys and girls. It provides information about how gender norms function in society - in family relations, in schooling, in people's experience of violence, in the media, and elsewhere. This unit also explains how gender roles affect sexuality and sexual health. It helps boys and girls to think critically and to reflect upon their own attitudes about gender in a meaningful way.

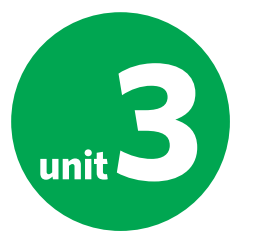

\section{SEXUALITY}

Although this unit includes basic biological information about sexuality, it also emphasizes the social underpinnings of sexuality in people's lives and communities. The content examines how cultural and gender norms affect sexual attitudes, practices, experiences, and pleasure. It also reviews some of the common concerns people experience with regard to their sexual lives, including feeling pressure to have unwanted or unsafe sex.

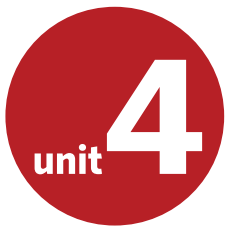

\section{INTERPERSONAL RELATIONSHIPS}

Sexual well-being and health depend on individual or personal factors as well as broader social influences. This unit aims to help adolescents gain a measure of understanding and confidence in their relationships. Specifically, it provides resources to help them reflect and strengthen their communication in all kinds of relationships. It focuses especially on ways of making their way through the emotional thicket of intimate and romantic relationships. 


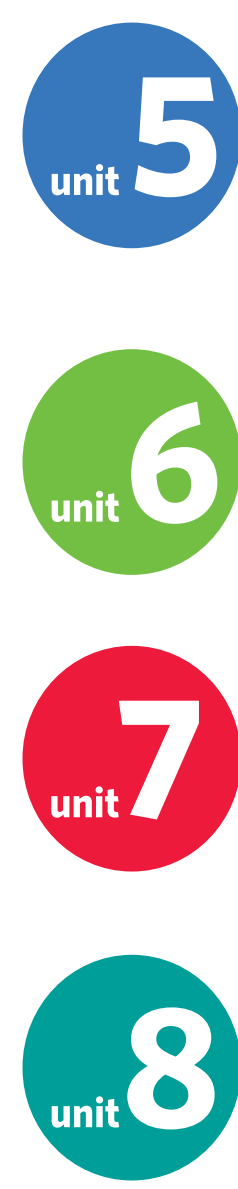

\section{COMMUNICATION AND DECISIONMAKING SKILLS}

People who speak with their partners about sexual issues have more satisfying relationships and better sexual health. Young people would like to learn ways of having conversations about intimate topics in which they can feel at ease and self-assured. Yet they rarely have an opportunity to learn how to handle these sensitive conversations. This unit focuses on strengthening communication skills. It focuses on sexuality, contraception, and HIV and AIDS. It also includes a section on making and acting on decisions.

\section{THE BODY, PUBERTY, AND REPRODUCTION}

Knowing about their bodies empowers young people to protect their health and sexuality. Unit 6 includes basic information that has usually been a part of school-based sex education. For example, it explains puberty and how the body and its parts work. The material is presented, however, with an eye to social context and human rights, rather than within a narrow "clinical" framework.

\section{SEXUAL AND REPRODUCTIVE HEALTH}

\section{(including HIV prevention and contraception)}

This unit provides information in two parts. The main topics in Part 1 are sexually transmitted infections, HIV and AIDS, and reproductive tract infections. Part 2 covers contraception and abortion. Preventive health is highlighted throughout this unit.

\section{ADVOCATING FOR SEXUAL HEALTH, RIGHTS, AND GENDER EQUALITY}

Many young people can, and want to, help promote the social changes that will lead to better sexual health and well-being, changes that will also work toward greater justice and equality for all. This module guides educators, including civics and social studies teachers, in ways to use learner-centered methods to promote young people's involvement in their communities. Such hands-on experiences can complement and deepen the knowledge gained in the preceding units. It can offer young people the satisfaction of seeing how they can make a positive difference in the world.

\section{FACT SHEETS}

At the end of the GUIDELINES book, you will find 22 fact sheets that serve as further technical reference sources on certain topics. Each fact sheet supports, and is linked to, specific subtopics in Units 1-7 of the GUIDELINES. These sheets are ordered alphabetically. 


\section{activities book}

\section{EFFECTIVE TEACHING METHODS}

Around the world, sexuality and HIV education programs have often led the way in using participatory teaching methods that go beyond the usual lectures or readings. Engaging young people more actively in their own learning, such methods involve personal reflection, critical thinking, and discussion. These processes can foster more egalitarian attitudes as well as behavior change, including in the areas of gender and sexual health. More broadly, they also help equip young people to address their changing world with imagination and confidence.

Hence, the ACTIVITIES book of It's All One Curriculum begins with a section explaining and offering guidance on interactive, learner-centered teaching approaches. (The GUIDELINES book also includes relevant "Teaching Tips" at the beginning of each content unit.) These resources, however, cannot substitute for adequate training of and support for educators.

\section{SAMPLE ACTIVITIES}

The ACTIVITIES book includes 54 sample activities that correspond to specific content in the GUIDELINES book (indicated by the orange boxes throughout the GUIDELINES book). These learner-centered activities have been tested and are easy to adapt across cultures. They can help young people to see links between what they have learned and their own experiences and feelings. The sample activities are creative and engaging for young people.

Teachers can use the activities as they are presented, or they can adapt them. They can also model new activities on them. Many of the activities involve reading or writing, but the great majority are adaptable for nonliterate learners.

\section{ADDITIONAL RESOURCES LIST}

The ACTIVITIES volume concludes with a list of selected technical and material resources from around the world. Each entry includes a brief description and contact information. 
Policymakers and international organizations have asked for sex, HIV, and family life education that is gender-equitable and rights-based.

It's All One Curriculum: Guidelines and Activities responds to that call. It draws on research findings about the factors that drive sexual behavior. It fosters the development of selfconfident, thinking individuals who can help build compassionate and just societies. 


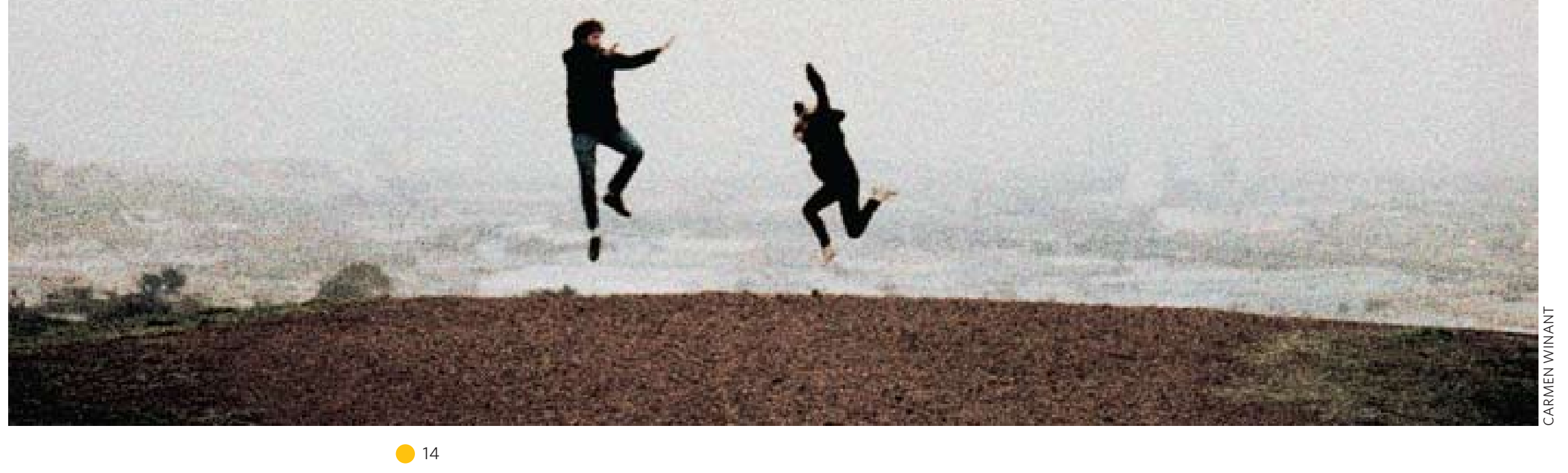




\section{ENDNOTES}

$1<$ http://www.un.org/millenniumgoals/>

$2<$ http://data.unaids.org/pub/InformationNote/2008/20081031

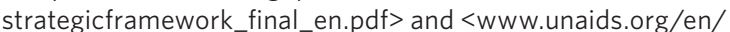
KnowledgeCentre/Resources/PolicyGuidance/OperationGuidelines/ gender_operational_guidelines.asp>.

$3<$ www.who.int/reproductive-health/strategy.htm>

4 <http://portal.unesco.org/en/ev.php-URL_ID=33618\&URL_DO=DO_ TOPIC\&URL_SECTION=201.html>. Also, see UNESCO emphases for Human Rights and Gender Empowerment Education at: <http://portal. unesco.org/en/ev.php-URL_ID=33525\&URL_DO=DO_TOPIC\&URL_ SECTION=201.html>

5 World Association for Sexual Health. 2008. Sexual Health for the Millennium. A Declaration and Technical Document. Minneapolis: World Association for Sexual Health.

6 Senderowitz, J. and D. Kirby. 2006. "Standards for curriculum-based reproductive health and HIV education programs." Arlington, VA: Family Health International/YouthNet.

7 In different settings, education programs may use such terms as "life skills," "family-life education," "health education," or "population education." It's All One Curriculum enables professionals to develop or modify curricula (or lesson plans) for education under any of these rubrics.

8 These human rights have been formally endorsed by most nations and are cited throughout this document.

9 This document uses the term "gender equality" to refer to the concept that all human beings - regardless of gender - are equal and have the right to equal treatment. Other documents also refer to similar concepts under the term "gender equity."

10 Dunkle, K., R. Jewkes, H. Brown, G. Gray, J. Mclntyre, and S. Harlow. 2004. "Gender-based violence, relationship power, and risk of HIV infection in women attending antenatal clinics in South Africa," The Lancet 363: 1415-1421; Jewkes, R., C. Vundule, F. Maforah, and E. Jordaan. 2001 "Relationship dynamics and teenage pregnancy in South Africa," Social Science \& Medicine 52: 733-744; Karim, A.M., R. Magnani, G. Morgan, and K. Bond. 2003. "Reproductive health risk and protective factors among unmarried youth in Ghana," International Family Planning Perspectives 29: 14-24; Koenig, M., I. Zablotska, T. Lutalo, F. Nalugoda, J. Wagman, and R. Gray. 2004. "Coerced first intercourse and reproductive health among adolescent women in Rakai, Uganda," International Family Planning Perspectives 30: 156-163; Martin, S., L. Matza, L. Kupper, J. Thomas, M. Daly, and S. Cloutier. 1999. "Domestic violence and sexually transmitted diseases: The experience of prenatal care patients," Public Health Reports 114: 262-268; Pleck, J.H., F.L. Sonenstein, and L.C. Ku. 1993. "Masculinity ideology: Its impact on adolescent males' heterosexual relationships," Journal of Social Issues 49: 11-29; Pulerwitz, J. and G. Barker. 2008. "Measuring attitudes toward gender norms among young men in Brazil: Development and psychometric evaluation of the GEM scale," Men and Masculinities 10(3): 322-338; Stephenson, R., M.A. Koenig, R. Acharya, and T.K. Roy. 2008. "Domestic violence, contraceptive use, and unwanted pregnancy in rural India," Studies in Family Planning 39(3): 177-186; Zambrana, R.E., L.J. Cornelius, S.S. Boykin, and D.S. Lopez. 2004. "Latinas and HIV/AIDS risk factors: Implications for harm reduction strategies," American Journal of Public Health 94(7): 1152-1158.

11 See, for example, Kirby, D., B. Laris, and L. Rolleri. 2007. "Sex and HIV education programs: Their impact on sexual behaviors of young people throughout the world." Journal of Adolescent Health 40: 206-217. Kirby et al. find that two-thirds of programs result in students' self-reporting a change in their behavior; however, most of the evaluations that looked at the effect of a sex/HIV education program on sexual health outcomes (specifically, unintended pregnancy or sexually transmitted infections) fail to demonstrate a statistically significant impact.

12 DiClemente, R., G. Wingood, E. Rose, et al. 2009. "Efficacy of sexually transmitted disease/human immunodeficiency virus sexual riskreduction intervention for African American adolescent females seeking sexual health services: A randomized controlled trial," Archives of Pediatrics and Adolescent Medicine 163(12): 1112-1121; Haberland, N. 2010. "What happens when programs emphasize gender? A review of the evaluation research." Presented at the UNFPA Global Consultation on Sexuality Education, 30 November-2 December, Bogotá, Colombia; Jewkes, R., M. Nduna, J. Levin, et al. 2008. "Impact of Stepping Stones on incidence of HIV and HSV-2 and sexual behaviour in rural South Africa: Cluster randomized controlled trial," British Medical Journal 337:a506, doi: 10.1136/bmj.a506; Pulerwitz, J., G. Barker, M. Segundo, and M. Nascimento. 2006. "Promoting more gender-equitable norms and behaviors among young men as an HIV/AIDS prevention strategy," HORIZONS Final Report. Washington, DC: Population Council.

13 The MDGs are a list of eight goals (including eradicating extreme poverty and hunger, achieving universal primary education, promoting gender equality and empowering women, and improving maternal health) adopted by the UN General Assembly. The MDGs commit the international community to an expanded vision of development and have been commonly accepted as a framework for measuring developmental progress.

14 See endnotes 1-5.

15 Pending demand, a separate version may be developed for teaching younger students. Please contact the publishers for further information. 
SEXUAL MEALH

AND WEMIDBET

REOU/RE

HUMAN RIGHTS 


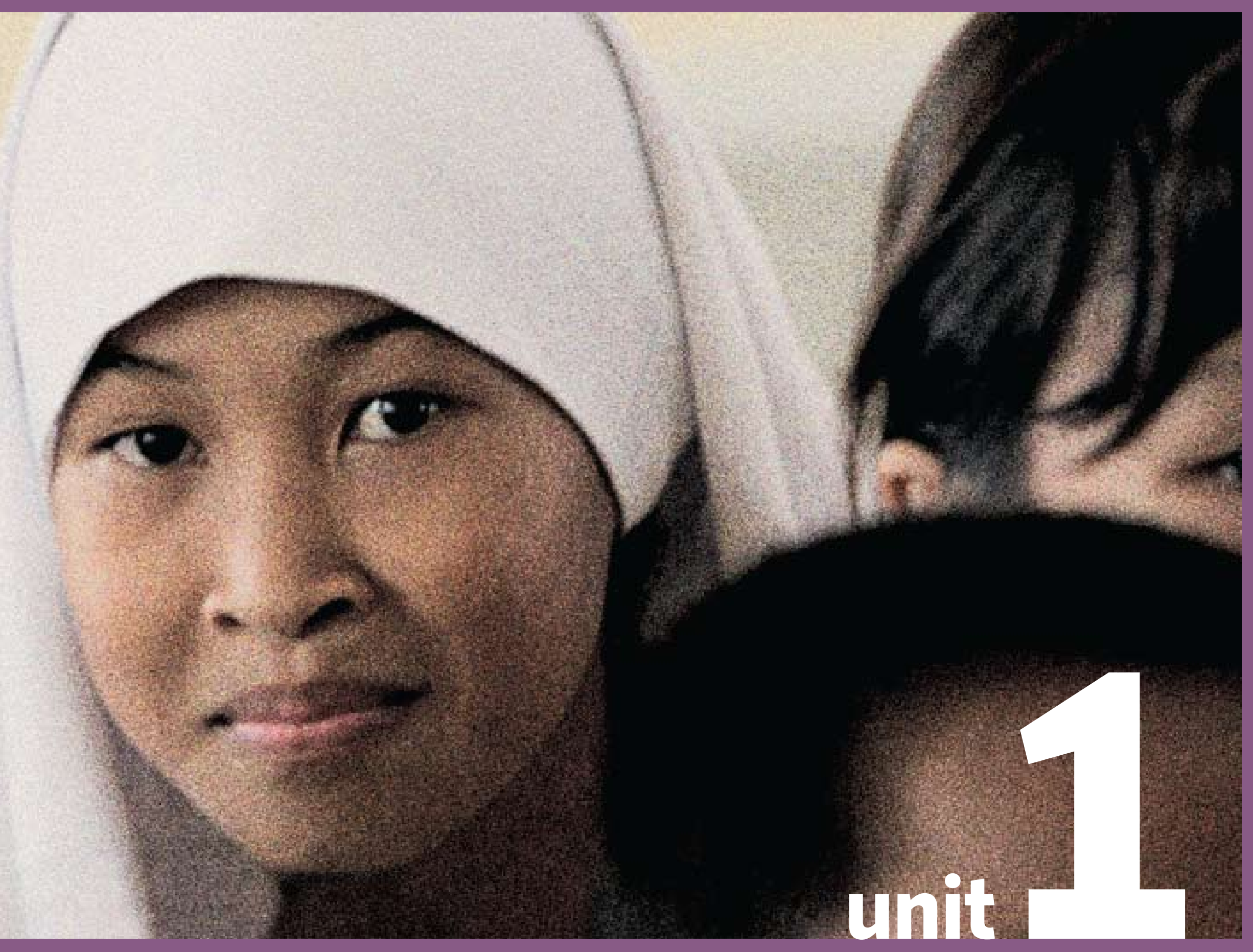




\section{overview}

Why would sexuality and HIV education emphasize human rights? To enjoy safe and satisfying sexual lives, young people must be able to exercise their basic human rights. For example, everyone has a right to dignity, bodily safety, and access to health information and services. Only when people can exercise these rights can they really choose whether or not to have sex, negotiate condom and contraceptive use, and seek the services they need. Promoting sexual and reproductive rights also encourages young people to take responsibility for protecting the well-being and rights of others. Unfortunately, hundreds of millions of people, especially young people, still remain vulnerable to such abuses as forced sex (often increasing their risk of acquiring HIV or becoming pregnant), violence, child marriage, and stigma related to their sexual behavior. When people's rights are violated, their capacity for safe and satisfying sexuality is undermined for their whole lifetime.

Knowing about human rights allows young people to gain a sense that they matter in the world. This unit provides a basic overview of sexual and human rights and explores their link to sexual experience and health. 


\section{SEXUAL HEALTH AND WELL-BEING REQUIRE HUMAN RIGHTS}

The concepts of human rights and sexual rights are internationally recognized. They apply to all regions of the world, including Africa, the Americas, Asia, Europe, the Arab World, and the Pacific. But many people do not know what these concepts mean, or how they affect their own lives. You can familiarize yourself with these topics by reading through this short unit.

Be aware of your own biases. Constantly ask yourself what forms the basis of your opinions about other people.

Remember that human rights apply to all people. Hence they cannot be taken away from any person. Not everyone is able to experience these rights fully, however.

Emphasize that human beings also have responsibilities, including respecting other people and the rights of all.

Be prepared to be honest about the ways that social institutions, such as social clubs, religious organizations, and other groups may undermine people's rights or allow discrimination.

Conduct some background research to identify human rights violations that are related to sexuality issues in your country - for example, forced marriage, sexual violence, or the situation of people living with HIV and AIDS.

Draw on concrete examples of human rights issues - either from the activities presented in the ACTIVITIES book or from your own environment. Emphasizing real situations can help ensure that students understand that human rights are more than an abstract idea.

As part of teaching human rights, help students appreciate that they are powerful and that they matter in the world!

A number of the fact sheets at the end of this book provide additional details on these topics. 


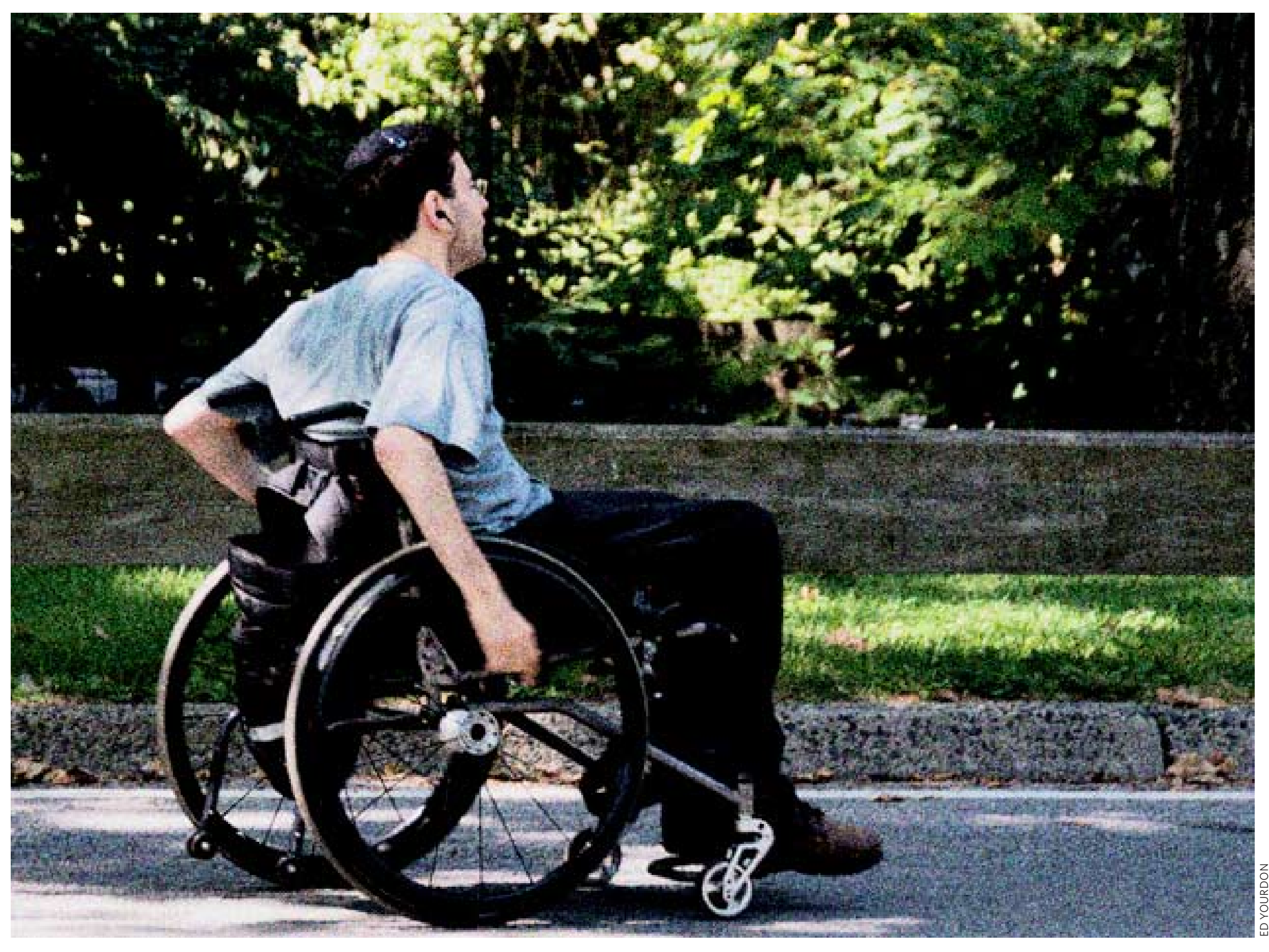




\section{SEXUAL HEALTH AND WELL-BEING REQUIRE HUMAN RIGHTS}

The material in this unit prepares learners to:

\section{Cognitive Objectives}

Identify five basic rights of every human being, including two that are sexual or reproductive rights.

Discuss at least two circumstances in which people are able to exercise their sexual or reproductive rights and two in which they cannot do so. Explain how their situation may affect their sexual or reproductive health.

Describe an example of a change in a law or policy affecting people's sexual or reproductive lives. Indicate a person or organization to go to or call if someone's sexual rights are being ignored.

Discuss, for at least two rights, what responsibilities the state has for protecting, respecting, and fulfilling these rights, and what responsibilities individuals have.

\section{Affective Objectives}

Understand the importance of respect in human interaction, including in romantic and sexual relationships.

Discuss their own feelings about whether treating people unequally is fair.

Discuss their own feelings and attitudes about a violation of a sexual or reproductive right that they care about and the consequences of this violation.

Describe what they consider to be a full and satisfying life for themselves.

\section{Skill-based Objectives}

Speak effectively about their ideas related to equality, discrimination, and other aspects of human rights. 


\section{how we treat each other: values and society}

We can pose many questions about how we treat each other in society. These questions apply regardless of what region of the world we live in. Some of these questions are listed below.

1 What do most people, including young people, want?

- Most young people want a good quality of life. This is sometimes called "well-being."

- For most of us, well-being means having a chance to be healthy and happy. We want to be safe and respected. We want to have opportunities to grow up and to learn. We want to matter in the world and to pursue our dreams. And we want to live together in peace. We want these things for ourselves, our families, and our communities.

- Sexual health and well-being are an important part of overall well-being.

\section{POINTS FOR REFLECTION}

Does everyone have the right to pursue happiness and to pursue his or her dreams?

What does it mean for someone to "matter" to others?

What is our responsibility to treat everyone with respect?

Should everyone be safe?

Should everyone have a fair say in establishing rules and laws?

Should resources be divided fairly?

Should everyone be able to make basic decisions to protect his or her own body and future?

These questions also apply to people's intimate and sexual lives.
2 How do we need to live together - in our families, communities, and societies - to ensure that all people have a chance for a good quality of life and well-being? 
3 Where do we learn our ideas about how we should behave and treat each other?

Where do we learn what responsibilities we have toward each other?

- Each of us has our beliefs about what is right or wrong. These beliefs include values and attitudes that have to do with the body, sexuality, and intimate relationships.

- We often tend to think of our own values and beliefs as "natural." However, they are deeply influenced by our families, communities, and society.

- The attitudes of our families, communities, and society are called "social norms" [see glossary].

- Societies enact laws that reflect norms and specify which behaviors are permitted and which are not. Those individuals or groups who have the most power often have the greatest influence in determining both social norms and laws. Some laws, norms, and individual values are concerned with sexuality.

- Social norms change over time. They also vary across and within cultures.

- Although we are all influenced by social norms, each of us can also develop her or his independent ideas about the fairest way to behave and treat others. We may gather ideas from many sources, including role models, books, and personal reflection.

\section{Some ethical principles about how people should treat each other are widely viewed as universal. These principles are called human rights.}

[See the following section.]

\section{SEE ACTIVITIES BOOK Activity 1 \\ why fairness matters}

Students think about the issue of fairness by responding to quotations from prominent people. 


\section{what are "human rights"?}

1 Every single human being is entitled to basic rights and protections.

These rights include, but are not limited to:

- equal treatment under the law;

- food, water, shelter, and clothing;

- being treated with respect and dignity;

- freedom from torture;

- freedom of expression;

- freedom of thought, conscience, and religion;

\section{SEE ACTIVITIES BOOK}

Activity 2

\section{introduction to human rights}

Students develop a list of rights for a new country and compare their

list with the Universal Declaration of Human Rights. They interview adults about their understanding of the term "human rights."

\section{SEE ACTIVITIES BOOK}

Activity 3

power, privilege, and

equality

Students identify and reflect on the relationship between social power and the experience of privilege or discrimination.
- the right to assemble and to participate in society;

- the right to education; and

- the right to health, including access to health information and services.

2 These human rights are universal. This means they apply to all of us, regardless of our sex, age, marital status, sexual identity or behavior, gender identity, race, ethnicity, national or social origin, political beliefs, citizenship, religious beliefs, social or economic status, where we live, our physical and mental ability, or our health status. ${ }^{1}$ These rights are not conditional and cannot be taken away.

- Many people have heard about human rights in discussions concerning torture, for example.

- Human rights also extend to economic rights and social rights. These include the right to education and to health care. They also include specific sexual and reproductive rights. 
3 Basic human rights have been agreed upon by the global community of states (through the United Nations). They are formalized in international agreements and formally ratified by most governments. ${ }^{2}$

[See fact sheet on United Nations Agreements.]

4 Children have human rights. Children's rights have been established in international agreements, including the Convention on the Rights of the Child (CRC). The rights in the CRC apply to all people under the age of 18.

5 Although all of us should be able to enjoy our human rights, we cannot always do so.

6 Part of the responsibility for protecting, respecting, and fulfilling human rights rests on governments. In reality, however, countries vary in the degree to which they fulfill this responsibility.

For example, some governments have passed laws that restrict the rights of certain people, for example, by:

- outlawing political protest;

- prohibiting labor-union organizing;

- criminalizing same-sex sexual activity between consenting adults; and

- pardoning or treating lightly the murder of a woman or girl by her male partner or family member when he perceives his action as a matter of "honor."

2 Important, legally binding, human rights documents include: the International Covenant on Economic, Social and Cultural Rights (ICESCR, 1966); International Covenant on Civil and Political Rights (ICCPR, 1966); Convention on the Elimination of All Forms of Discrimination Against Women (CEDAW, 1979); Convention on the Rights of the Child (CRC, 1989). Another important, but nonbinding, human rights document is the Universal Declaration of Human Rights (UDHR). For a copy of the UDHR see Activity 2 in the companion volume. [See references to specific rights in relevant sections throughout units 1-7.]

\section{POINTS FOR REFLECTION}

What basic human rights do children (including adolescents) share with adults?

What additional rights do you think children have that must be honored, specifically because they are still children? For example, what basic opportunities do children need to be able to feel happy?

What kinds of opportunities do children need in order to have a better chance at a full and satisfying life? Do children sometimes experience dangers or hardships that they should be protected from?

How do children's capacity and responsibility to understand and protect their own rights and the rights of others develop with maturity? Give an example or two. 
7 Individuals' social and economic status also may limit their ability to enjoy their rights.

For example, their nationality, sex, race, religion, age, class/caste, political view, sexual identity, HIV status, or physical or mental ability typically influences their opportunity to:

- obtain an education and earn a good living;

- receive equal and just treatment under the law;

- live free from violence;

- feel respected and be treated with dignity; and

- feel that they can pursue and achieve their dreams.

\section{Every single person has a responsibility to respect the rights of every other person. ${ }^{3}$}

- When we grow up learning to respect every human being equally, we come to respect human rights.

- Often, when we grow up learning to hold negative attitudes toward certain groups of people, we may treat them unfairly and deny them their rights.

- Sometimes people attach a set of characteristics to a certain group of human beings. This is called "stereotyping." Common examples of stereotyping include the attitudes that boys are naturally better than girls at math and that certain groups are lazy or unclean. Stereotypes are typically inaccurate or highly distorted. Stereotyping makes us less able to see others as fully human. It makes us more likely to condone unfair treatment of others.

- Some people may be subject to severe social disapproval because of their personal characteristics. This disapproval is called stigma. For example, in some places people may be subject to stigma because of their weight, their sexual behavior, their religion, their health status, or even their lack of ability in sports.

- When people are treated unfairly because of their presumed (or known) identity, such treatment is called "discrimination." People have a right to live free of discrimination. Discrimination occurs in families, at school, at work, in the community, and in society at large.

- Discrimination is not only an individual matter. Governments and whole social systems (such as schools, religions, or the job market) also discriminate.

- Regardless of our personal attitudes, we all have a responsibility to respect people's human rights. 


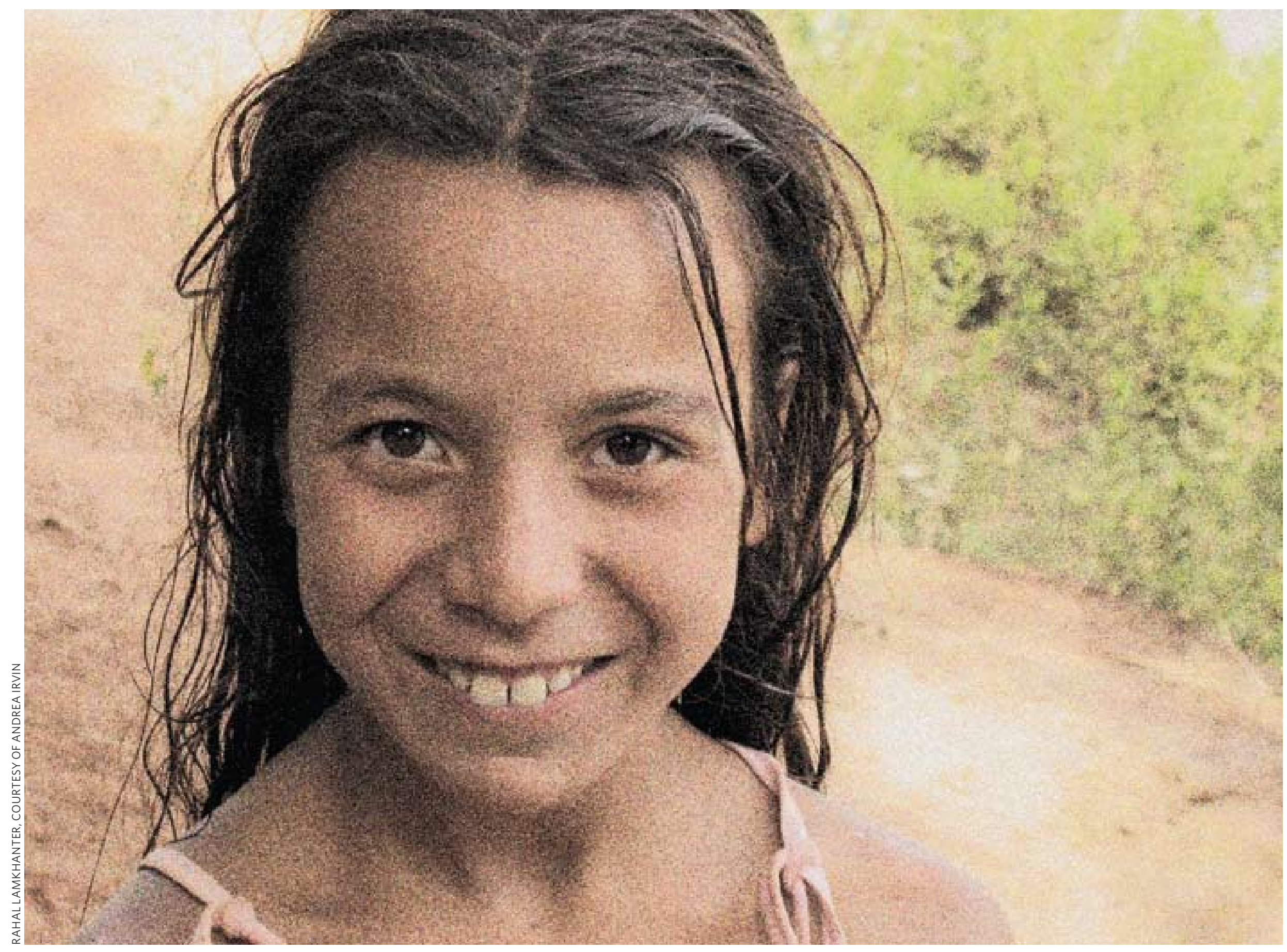




\section{sexual and reproductive rights}

1 People's romantic and sexual experiences can become human rights issues. Only when our basic rights are honored (both by governments and by other individuals) can we make optimal decisions about intimate relationships, sex, and childbearing.

For example:

- Individuals can make decisions about if, when, and with whom they will form a romance, a long-term relationship, or a marriage. They can avoid being married too young or against their will. Or they can have an intimate relationship with someone of the same sex.

- They can decide if, when, with whom, and under what circumstances to have sex (free from sexual abuse and coercion). They can negotiate condom use to prevent infection. They are free to have sex with someone of the same sex.

- They can decide whether or when to become pregnant or have children. They can obtain contraceptive information and services. They can have a safe abortion. They can adopt a child regardless of their marital status or sexual identity.

2 When human rights relate to people's sexuality or reproduction, we call them "sexual rights" or "reproductive rights."

- Sexual rights and reproductive rights sometimes overlap. However, sexual rights generally include individuals' control over their sexual activity and sexual health. Reproductive rights usually concern controlling the decisions related to fertility and reproduction.

- The principle of consent between adults is central to sexual and reproductive rights. Access to information and services is also critical.

- Many of these rights are acknowledged in international agreements. ${ }^{4}$

4 Such agreements include, for example, the Convention on the Elimination of All Forms of Discrimination Against Women (CEDAW), the International Conference on Population and Development (ICPD) Programme of Action, and the Platform for Action of the Fourth World Conference on Women (FWCW)

\section{Sexual and reproductive rights also apply to young people.}

- Children have the right to develop a positive sense of their own bodies and sexuality. Children have the right to be free of abuse and inappropriate touching.

- Younger children need help in making decisions. The direction and guidance provided by caring adults must take into account the best interests of children. It must also consider the capacity of children to exercise rights on their own behalf.

- As children grow and develop their capacities, their rights and responsibilities continue to evolve.

- Young people have the right to obtain information to protect their health, including their sexual and reproductive health. 
4 In the real world, people - male and female - face many barriers to exercising their sexual and reproductive rights. The consequences of these barriers are often serious.

- Millions of people experience sexual violence (violence or assault that includes, but is not limited to, sex that is forced or that takes place without consent or under threat of violence). [Also see Unit 2, pages 70-71 and Unit 3, pages 106-107.]

- Sexual violence affects people of all walks of life, and both sexes. Girls and women are disproportionately affected, however.

- People experience sexual violence in many environments. It occurs inside the home, as well as within such institutions as prisons, refugee camps, houses of worship, brothels, and unsafe school environments.

- Poverty often increases young people's (especially girls') risk of experiencing sex that is unwanted, abusive, or unsafe. Young people living in poverty are more likely to need to exchange sex for favors or material goods in order to survive.

- Girls living in poverty are more likely than other girls to suffer early or forced marriage, unwanted pregnancy, unsafe abortion, and sex trafficking (coercive relocation of people for purposes of sexual exploitation). [See fact sheet on Sex Trafficking.]

- Some people's sex partners (including some who pay for sex with cash or gifts) refuse to wear a condom.

- Some people suffer stigma, shame, fear, or violence because their sexual identity (or behavior) does not fit in with local social norms. For example, individuals perceived as homosexual or people who adopt a different gender identity (transgender people) may be subject to such treatment or feelings.

- Physical violence against pregnant women is particularly common in some settings.

- In some settings, many or most girls are forced to have their genitals cut. [See fact sheet on Female Genital Mutilation.]

- Many people face discrimination when they try to seek necessary sexual health information and services. This problem is particularly severe among young people and among people living with HIV and AIDS.

5 Unfortunately, such economic and social barriers and violations are so common that they are typically excused, overlooked, or seen as culturally "normal." These barriers and violations take different forms around the world.

6 To control and protect our own bodies, we all need to be treated with dignity and respect. This is everyone's right as a human being. 


\section{POINTS FOR REFLECTION}

Our attitudes about male and female roles affect our sexual behavior and our sexual health.

Research shows that young people who believe in "traditional" or "conservative" gender roles (for example, that boys should act tough or that females should be submissive to males) tend to have more sexual health problems. They are less likely to use condoms or contraceptives.

They are more likely to be involved in an intimate relationship that is violent. Those in relationships with a high level of male control are more likely to be infected with HIV and to report unintended pregnancy. Similarly, intimate partner violence is associated with higher rates of unintended pregnancy, STIs, and HIV.

Conversely, individuals who have more "liberal" attitudes about gender roles or who believe in equality are less likely to suffer these consequences. They generally enjoy better sexual health outcomes than their peers.

How might these consequences be explained?

5 Pleck et al., 1993; Martin et al., 1999; Jewkes et al., 2001; Karim et al., 2003; Dunkle et al., 2004; Koenig et al., 2004; Zambrana et al., 2004; Stephenson et al., 2006; Pulerwitz and Barker, 2008.
7 Everyone deserves the chance to learn about the issues that affect his or her sexual feelings, experiences, and health. Young people, especially, benefit from having the chance to think about and discuss these issues in depth. They deserve to develop the ability to make informed choices. Everyone deserves to play a role in his or her own well-being.

These issues include:

- gender norms and roles;

- human rights, especially sexual rights and reproductive rights;

- responsibilities of the state, and of every person, to honor these rights;

- the human body and sexuality (including puberty and reproduction, intimacy and pleasure, ways to prevent and end unintended pregnancy, and information about HIV and AIDS);

- developing greater comfort with our own bodies and with our own evolving values; and

- strengthening our ability to act on behalf of ourselves, our families, and our communities.

8 Learning about our rights and being able to exercise them can have a profound effect on our sexual and reproductive health. 


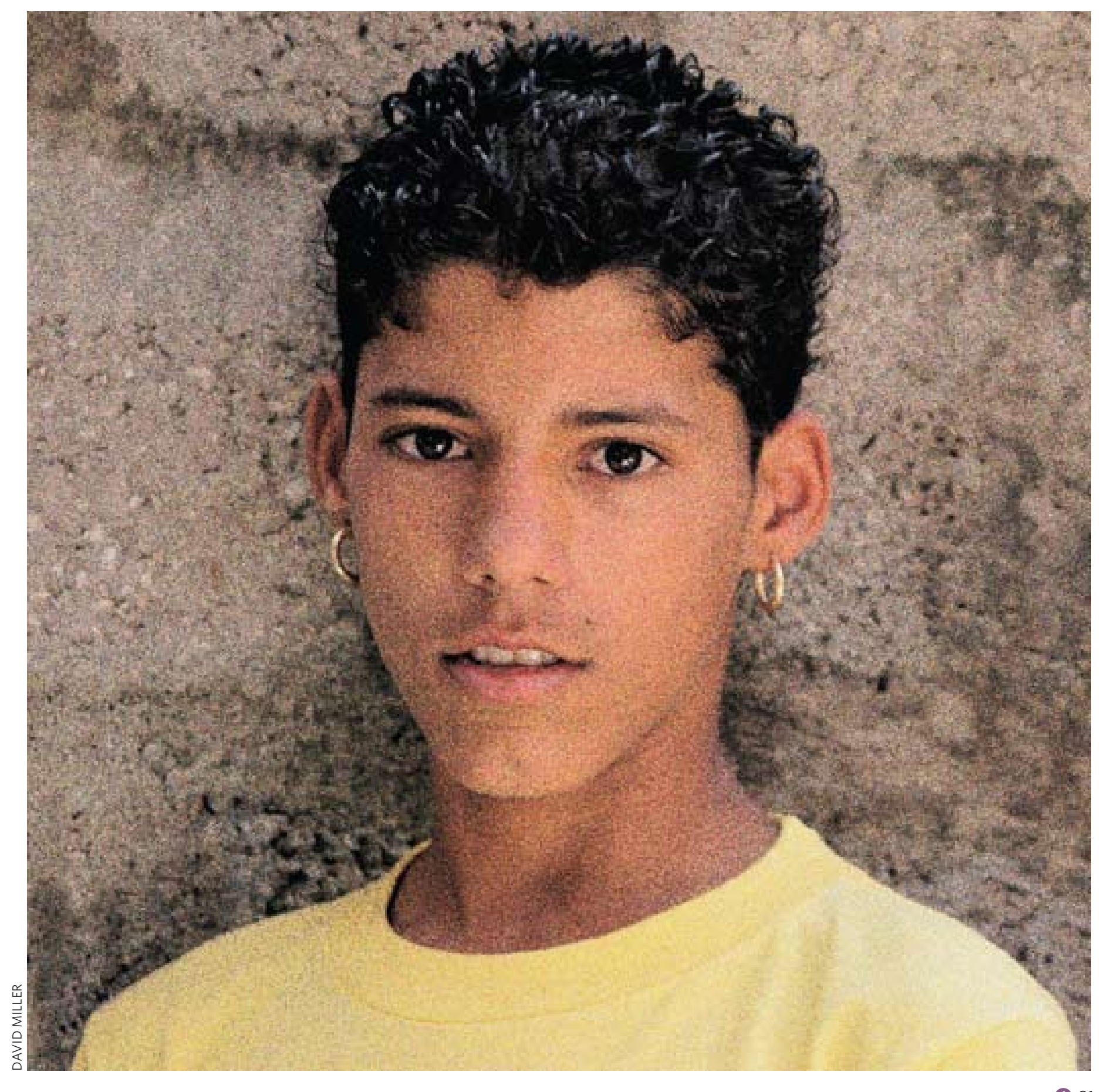

SEE ACTIVITIES BOOK

Activity 4

case studies concerning sexual and reproductive rights

Students examine and discuss true stories involving violations of sexual or reproductive rights. 


\section{promoting human rights, including sexual and reproductive rights}

\section{POINTS FOR REFLECTION}

Think about your own values and about fairness in your own life.

Ask yourself: What do I want? What do I need? What do I enjoy? What are my values? What do I admire in others? What do I want to become? What barriers do I face in reaching my goals? How can I overcome those barriers?

What stereotypes do I have toward certain groups of people?

Confronting our own biases can be difficult. But everyone is capable of self-reflection, growth, and change. As we reflect and grow, we become more comfortable with ourselves and with others.

Can you think of a time when your own or someone else's rights were being violated?

Does speaking out against a human rights abuse seem easy or difficult? What might make it difficult to do? What might make it easier?

\section{1 Many people care about fairness and about the basic rights of human beings.}

2 We can promote fairness and human rights in everyday life, including in sexual and reproductive life.

- We can stand up for a friend or classmate who is being treated unfairly. We can defend a classmate who is ridiculed because he is perceived to be homosexual, or a girl expelled from school because she is pregnant, or a teacher who faces discrimination because he or she is living with HIV or AIDS.

- We can help others realize that they have opportunities or choices in life other than the ones being presented to them. We can support a classmate who feels pressured to marry or to join a gang.

- We can identify trusted individuals (or organizations) who can help respond to incidents of discrimination.

3 We can also promote fairness and human rights in our communities, including sexual and reproductive rights. Sometimes we can do this on our own; other times we can do this within an organization.

- We can accompany a friend on a visit to a school official, the police, a health clinic, or another service.

- We can talk to people we know in the community about human rights and about the issues we care about.

- We can ask a local leader to speak out on an issue such as domestic violence.

- We can make sure that everyone in the community (including ourselves) knows about human rights and understands that everyone in the community matters. 
See unit 8 for more detailed background and guidelines for taking action.

4 We can join organizations or groups that fight for sexual and reproductive rights using various tactics.

Examples include:

- marching against hate crimes;

- adolescents' theater projects focusing on living with HIV or AIDS;

- community-awareness campaigns about female genital mutilation; and

- community "watch groups" that monitor and intervene on such issues as domestic violence.

5 Organizations also advocate for laws to protect human rights, including sexual and reproductive rights - especially for the most marginalized or vulnerable members of society. In virtually every country, people have formed groups that are working for such laws.

Examples of such laws (which in some settings also come under religious jurisdiction) include:

- ensuring every citizen's right to vote;

- outlawing child labor and protecting workers' safety;

- protecting community members against police brutality;

- criminalizing "hate crimes" (threats and violence based upon a person's identity);

- ensuring physical access to public space, including for people with disabilities;

- outlawing violence against women (outside and within marriage);

- ensuring women's rights within marriage;

- guaranteeing widows' inheritance rights;

- outlawing child marriage;

- criminalizing sex trafficking; and

- protecting the rights of everyone to form a civil union, marriage, or family, whether with someone of the same or of the other sex. 
6 Some organizations work to have an impact on human rights at the global level.

For example:

- They seek to expand the list of human rights recognized by the United Nations.

- They use the Internet for global petitions against human rights abuses.

7 Adolescents can, and do, help create change - including change in their own lives.

Young people around the world can respond to issues they care about in many ways. For example:

- They are educating others in their families and communities.

- They are helping promote the policies and practices that they believe are just.

- They are helping plan and implement programs.

- They are encouraging their friends to join campaigns. 


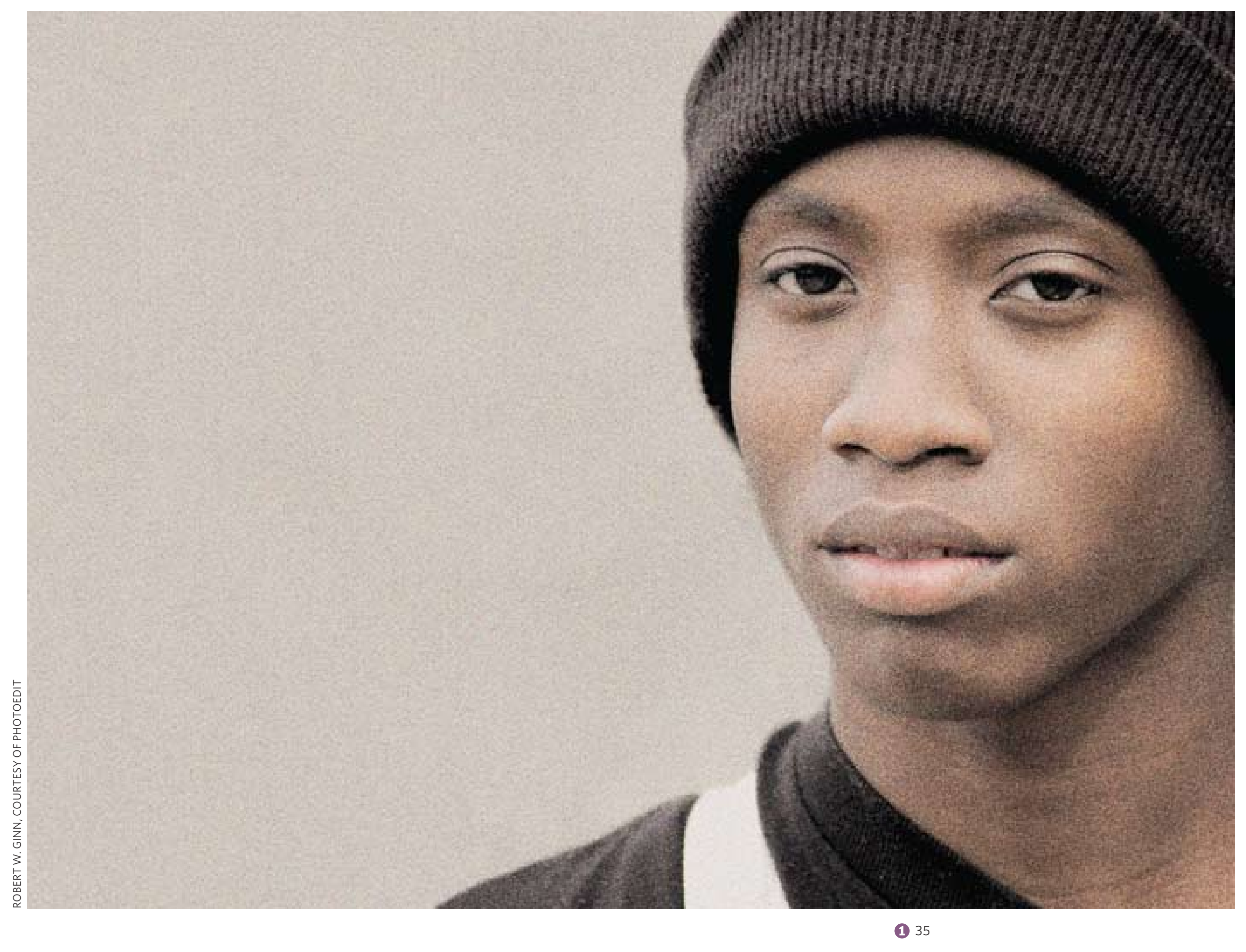




\title{
basic concepts about individuals and communities, values, and rights
}

\author{
The following brief explanations aim to help users clarify important terms regarding \\ society and human rights. These terms are used throughout this document. Around \\ the world, educators bring creativity and sensitivity to the task of adapting these \\ concepts in their own cultural and political context.
}

Communities: groups of people who may share certain characteristics. These include beliefs, needs, living or work environment, and identity. Various kinds of communities exist. As members of a community, people have both rights and responsibilities for how they treat each other.

Discrimination: unfair or unequal treatment of people based on their appearance, behavior, or (presumed or real) identity.

Gender: differences in the social roles that societies and families expect from males and females. Gender is not the same as biological differences by sex. People often experience differences in power in their families and societies by virtue of their gender.

Human rights: the basic protections and entitlements due to every human being. These rights are inalienable. That is, they cannot be taken away from anyone. A partial list includes the rights to: food and shelter; education; health care; civic participation and expression; equal treatment before the law; and treatment with respect and dignity. People's ability to fully exercise their human rights affects virtually every aspect of their lives.

Governments have responsibilities to respect, protect, and fulfill these rights. Most governments have endorsed international agreements to that effect. People, in turn, have the right to demand that governments uphold these obligations and responsibilities. People also have the right to make sure that governments fulfill these obligations. 
Identity: the way people think of themselves, or describe themselves to others. The way that others perceive someone's appearance or behavior does not necessarily match that person's own sense of his or her identity. People typically have more than one aspect to their identity. For example, a person can identify as a boy, a Hindu, and also as a student. Identity can come from belonging to a community. The way people identify themselves may change over time. ("Identity" may also refer to formal recognition of a person by the state, such as having a name, birth registration, and nationality.)

Social norms: expectations for how people in a community should act or think. Growing up, people come to think of the prevailing norms as "natural" or "normal." In fact, norms vary from place to place and over time. Prevailing norms often pressure people to meet social expectations. They influence people's attitudes and behavior. People who act or think in ways that are different from the norm may be viewed as inferior rather than independent.

Stereotypes: generalizations and assumptions about individuals and communities based on their identity or behavior. For example, the idea that girls are weak at math is a stereotype. Such generalizations are often highly inaccurate, or may be completely invented. Stereotypes can lead to stigma, discrimination, and other harmful outcomes.

Stigma: severe social disapproval based on an individual's personal characteristics. It may also arise when a person's beliefs or actions do not comply with social norms. For example, in some places people face stigma because of their weight, sexual behavior, religion, or health status.

Values: the set of beliefs that govern what people view as right and wrong. Values vary across individuals, families, and cultures. Some values, however, are accepted virtually universally as characteristic of ethical human behavior. 


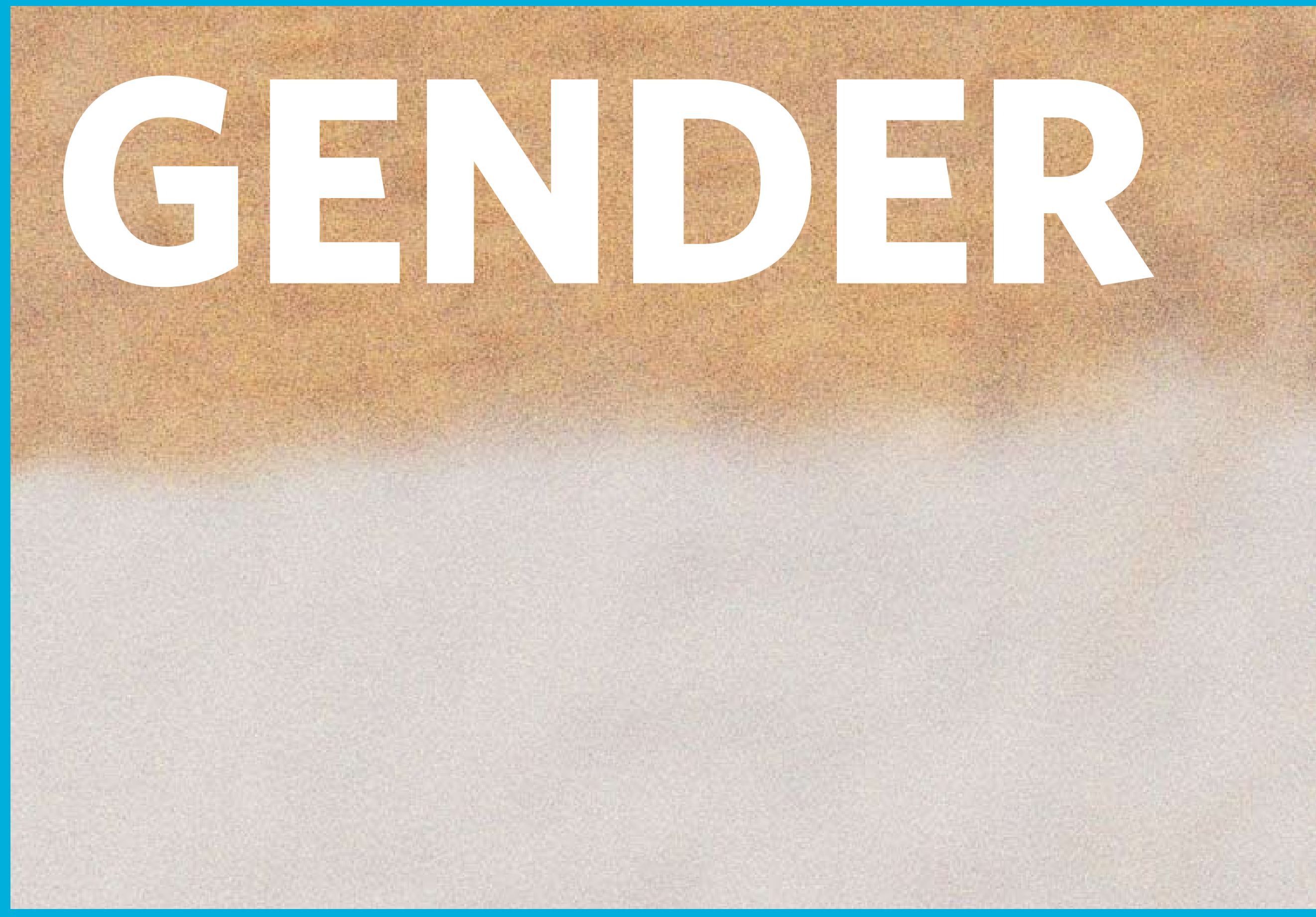




\section{overview}

Gender norms affect everyone's well-being, including sexual health and risk of HIV. Most countries have identified the achievement of gender equality as a moral imperative and as key to fighting AIDS and to strengthening families and societies. Around the world, gender norms and roles are changing rapidly. Raising adolescents' awareness about gender issues is vital, because interventions during this formative period can alter later life outcomes dramatically.

This unit defines gender and explores how gender norms affect the lives and health of both boys and girls. It suggests ways to enable adolescents to imagine the kind of people they want to be, the kinds of relationships they hope to form, and the type of society they view as fair and happy. 


\section{GENDER}

Emphasize that the term "gender" refers to boys as well as to girls.

Use concrete examples of gender issues - from the ACTIVITIES book or from your own setting. Recognizable examples help students understand that gender is more than an abstract idea.

Keep emphasizing that boys, as well as girls, can benefit from less rigid gender norms and arrangements. Remember that many students have already chosen less conventional gender roles and feel good about themselves.

Within a given culture, as well as between cultures, gender dynamics take different forms. Be sensitive to the nature (and variability) of gender dynamics in your local cultural setting.

Start with examples of inequality and discrimination that students recognize (like racism or stigma associated with HIV and AIDS). Such examples help students understand inequality and discrimination as they relate to gender.

The topic of gender roles may generate defensiveness or hostility. Plan ways to diffuse potential arguments and maintain open and respectful discussion.

Recall that many learners have experienced violence. Discussing the topic calls for sensitivity and planning. Establish a safe learning environment. Provide appropriate support and referral as needed.

Support learners' efforts to process their feelings. Challenging our own attitudes, or the norms of people around us, can be difficult or confusing. But it is possible and can be empowering.

Foster a safe environment for open discussion. Consider separating girls and boys for some activities. Later you can bring them together for shared discussion.

For definitions of basic terms, see the glossary at the end of Unit 2. The fact sheets at the end of this book provide additional detail on selected topics. 


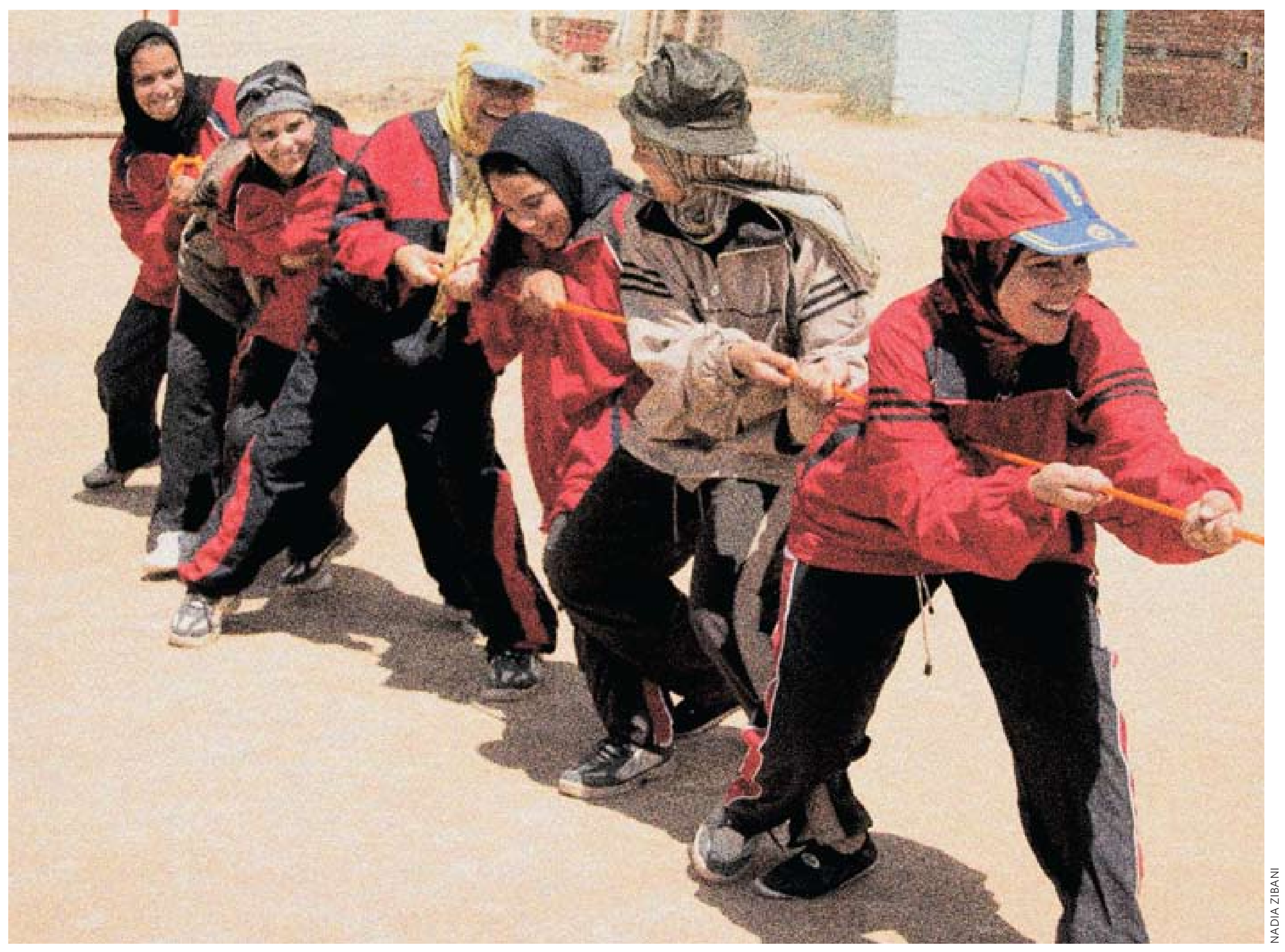




\section{GENDER}

The material in this unit prepares learners to:

\section{Cognitive Objectives}

Distinguish between sex and gender.

Give an example of how male and female gender roles are changing. Describe steps people take to promote positive changes in gender roles.

Discuss how gender inequality affects opportunities, including access to education, public space, health services, civic participation, and employment.

Give three examples of how children learn their gender roles from families and communities.

Discuss how institutions (marriage, family, media, religion, schools) reinforce gender norms.

Discuss how gender norms perpetuate child marriage, female genital mutilation, and violence (including sexual violence).

Explain how conventional gender roles can increase the likelihood that women and girls will face HIV or other sexually transmitted infections and unintended pregnancy.

\section{Affective Objectives}

Understand that gender norms can undermine the well-being of both boys and girls.

Discuss gender roles they have challenged or would like to challenge.

Clarify their beliefs about intimate partner violence and sexual coercion.

Describe how gender socialization can affect feelings of security and self-esteem.

Skill-based Objectives

Demonstrate analytical and critical thinking skills in explaining their ideas. 


\section{defining gender}

\section{POINTS FOR REFLECTION}

What messages about how to behave do girls receive at home? At school? From religious leaders? From the media? Do boys receive the same messages?

What are typically "female" jobs that men could do?

What are typically "male" jobs that women could do?

Do females have all the same opportunities as males in your society? In every society? Do males face some pressures simply because they are male?

Do women have exactly the same role in your society that they had one hundred years ago? What are some differences?

What do boys today think about gender equality, compared with the attitudes their fathers or grandfathers hold?
1 In every society, gender norms and gender roles influence people's lives, including their sexual lives.

2 Gender roles are learned. They are not innate or "natural." In fact, almost everything that males can do, females can also do. And almost everything that females can do, males can also do.

3 Within any culture or society, people have varying attitudes about gender roles and gender equality.

4 Beliefs about gender also vary from one culture (or society) to another.

5 Gender roles change over time, and in many settings people - especially young people - are embracing greater gender equality. 
See the glossary at the end of this unit for a simple introduction to these concepts.
6 Greater equality and more flexible gender roles give everyone more opportunities to develop to his or her full capacity as a human being. In contrast, restrictive gender roles can limit opportunities.

7 Despite gender inequality (or similar barriers), every day millions of individuals seek to fulfill their dreams. Although everyone does not automatically enjoy the same opportunities, many individuals achieve their dreams by fighting for a fair chance and working hard to take advantage of the opportunities they obtain.

8 The achievement of gender equality is a key goal around the world. ${ }^{1}$

- Equality between males and females is a matter of human rights.

- Achieving gender equality is a key part of combating HIV and AIDS, ending child marriage, reducing unwanted pregnancy, and making pregnancy safer.

- Gender equality fosters the growth of healthy and prosperous communities and societies.

- The United Nations has identified gender equality as one of eight key development goals for nations to pursue.

- Millions of people are actively promoting gender equality — in families, schools, workplaces, communities, and countries. [See the last section in this unit; see also Unit 8.]

1 See, for example, the Universal Declaration of Human Rights (UDHR, 1948); Convention on the Elimination of All Forms of Discrimination Against Women (CEDAW, 1979); and the Millennium Development Goals (MDGs, 2000).

\section{SEE ACTIVITIES BOOK}

Activity 5

male $\&$ female word webs

Students work in groups to create word webs about what it means

to be a "man" or a "woman," and to discuss where their ideas come from. 


\section{gender identity}

1 At birth, newborns are identified as male or female based on their sex organs. In many settings, people indicate a baby's sex through the use of specific names, jewelry, clothing, and so forth.

2 Some babies whose genitals are not clearly male or female are termed intersex. Some children (regardless of whether or not they are intersex) come to feel ambiguous about their gender identity, or clearly identify with the gender other than the one with which they were reared.

3 Almost all children behave in ways that do not match the stereotypes associated with their gender.

Two examples are:

- Many girls enjoy sports, excel at math, and have dreams of leading their country — and still feel like girls.

- Many, if not most, boys enjoy developing close interpersonal relationships, creating art, and feeling free from constant pressures to achieve and be brave — but still feel like boys. 


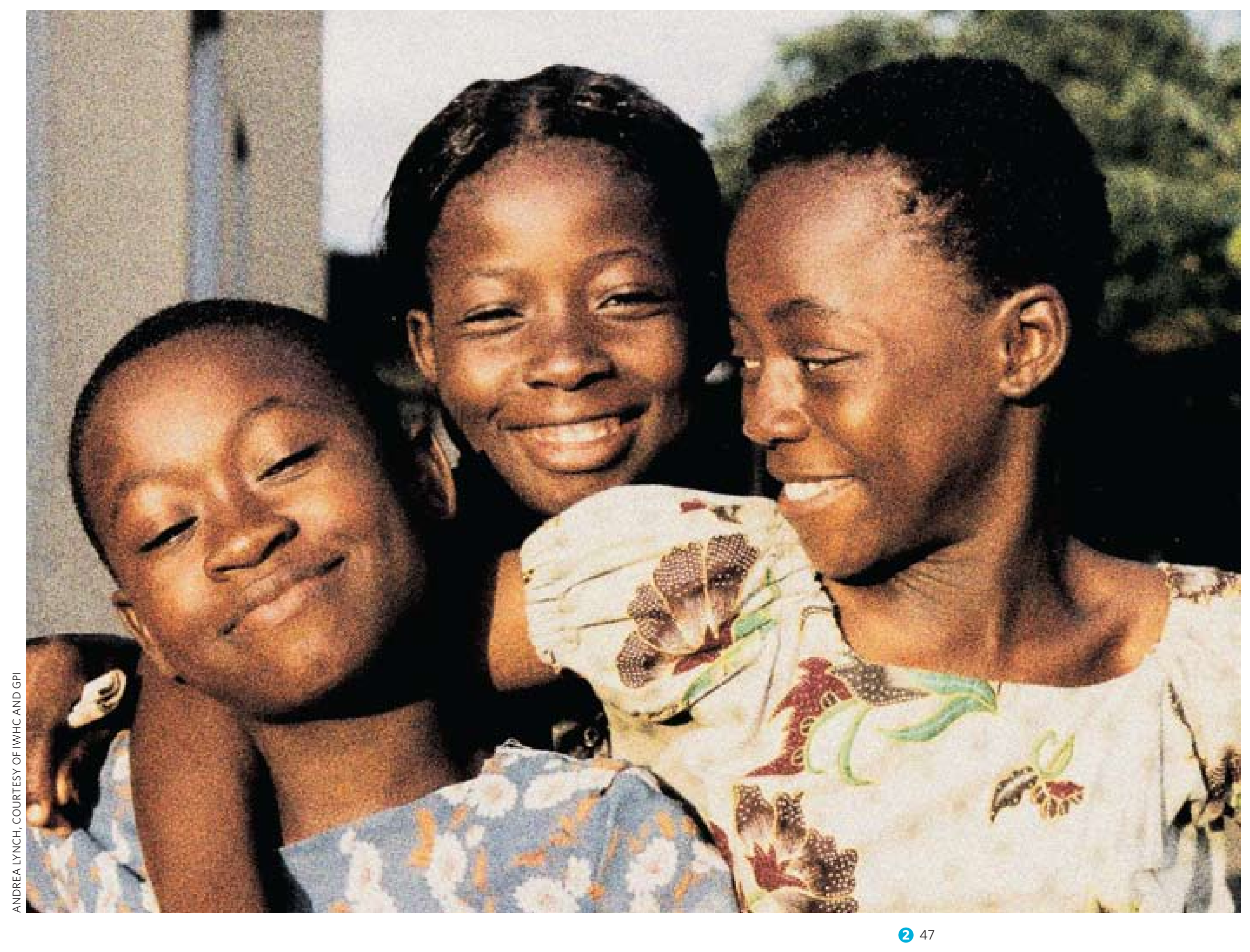




\section{gender norms and roles solidify during childhood and adolescence}

1 Expected gender roles are apparent in many aspects of family life.

For example:

- Family members model gender norms in their own roles and behaviors. Depending on the culture and the family, male and female roles might be similar or they might be distinct.

- Males and females typically have different responsibilities and roles regarding infant and child care. Thus, as infants, children begin to observe and absorb gender norms.

\section{Some families treat boys and girls equally.}

For example, both sons and daughters are encouraged and permitted to:

- seek success in the public sphere;

- express feelings of vulnerability; and

- share equally in household chores.

\section{However, many families do not treat girls and boys equally.}

For example, even in early childhood:

- In settings with food shortages, infant girls may not be fed as well as their brothers.

- Girls are often dressed differently from boys and given different toys.

- Particularly where resources are scarce, families may work harder to make sure that their sons are educated. [See the following section on Gender and Education.]

- In some societies, females are viewed as the property of their husbands. In these places, families may be less likely to invest precious resources in feeding and educating girls, whom they assume will grow up and leave the family.

- Although many boys have household chores, girls tend to be given more domestic responsibilities and have less free time than their brothers.

- Boys may be discouraged from crying or from expressing feelings of vulnerability.

- Girls may be discouraged from asserting themselves or from playing "rough" sports.
4 People - including parents - often reinforce expectations about gender through language.




\section{As young people approach adolescence, they feel more pressure to conform to culturally determined gender roles.}

\section{Despite cultural variation, many adolescent boys share similar experiences.}

Around the world, boys enjoy more independence and freedom outside the home than do girls, and have more opportunities to participate in public life. Boys also often suffer pressure to prove their heterosexuality and manhood, for example, to:

- be brave and assertive;

- have money and prepare to become providers;

- suppress certain emotions (for example, vulnerability and tenderness) or behaviors that may appear "feminine";

- engage in physical violence (against people they know or do not know);

- perform as an athlete and have a muscular body;

- avoid seeking health care, or even admitting that they are sick or have been harmed,

- "prove" their heterosexuality, for example, by having heterosexual intercourse or even fathering a child;

- take risks by engaging in unsafe sex (thus increasing their risk of acquiring HIV infection); and

- take physical risks (including with drugs, alcohol, or with a vehicle).

Boys may face harassment or brutality by police. This is especially true for boys from minority or marginalized groups or from low-income neighborhoods. Some boys face severe beatings for relatively minor misbehavior.

\section{Despite cultural variation, many adolescent girls share similar experiences.}

Around the world, girls tend to enjoy greater opportunity than boys to develop and practice one-to-one interpersonal skills. Girls also suffer pressures to comply with norms of femininity, for example, to:

- be caregivers;

- be docile and submissive to males, underplay their intelligence, undervalue or withhold their opinions and ideas;

- accept having their rights limited;

- accept close monitoring of their dress, friendships, and their comings and goings;

- be careful not to hurt people's feelings;

- avoid having sex before marriage, even if they wish to; and

- give in to having unwanted sex [see section on Sexual Coercion in this unit; also see Unit 3, pages 106-107]. 
8 Rigid gender roles also affect how people treat each other and contribute to suicide, violence, and many other social problems.

- People who do not conform to dominant gender norms may be teased, isolated, or threatened.

- People who may be particularly subject to such stigma include: individuals perceived as homosexual, boys who are perceived as having feminine traits, women with multiple sexual partners, or people who adopt a gender identity different from the one with which they were reared (transgender people).

9 Despite social norms, millions of young people are determined to "be themselves" and to realize more of their potential as human beings. They believe in greater gender equality and in diversity.

- Many young people are able to resist pressures to conform to an idealized body image.

- Many girls have confidence in themselves and their own power. They know that they can fight for opportunities to work hard, achieve, and pursue their dreams.

- Many boys feel confident to resist conventional pressures to prove their manhood.

- Many boys feel free to express a range of emotions, including vulnerability and tenderness. Later in life, this freedom may also enhance their capacity and satisfaction as fathers.

- Many young people celebrate diversity and difference.

10 Around the world, gender norms are changing. Young people who work for equality and justice are helping to bring about that change.

[See the section in this unit titled Gender: Our Own Decisions and Actions.] 


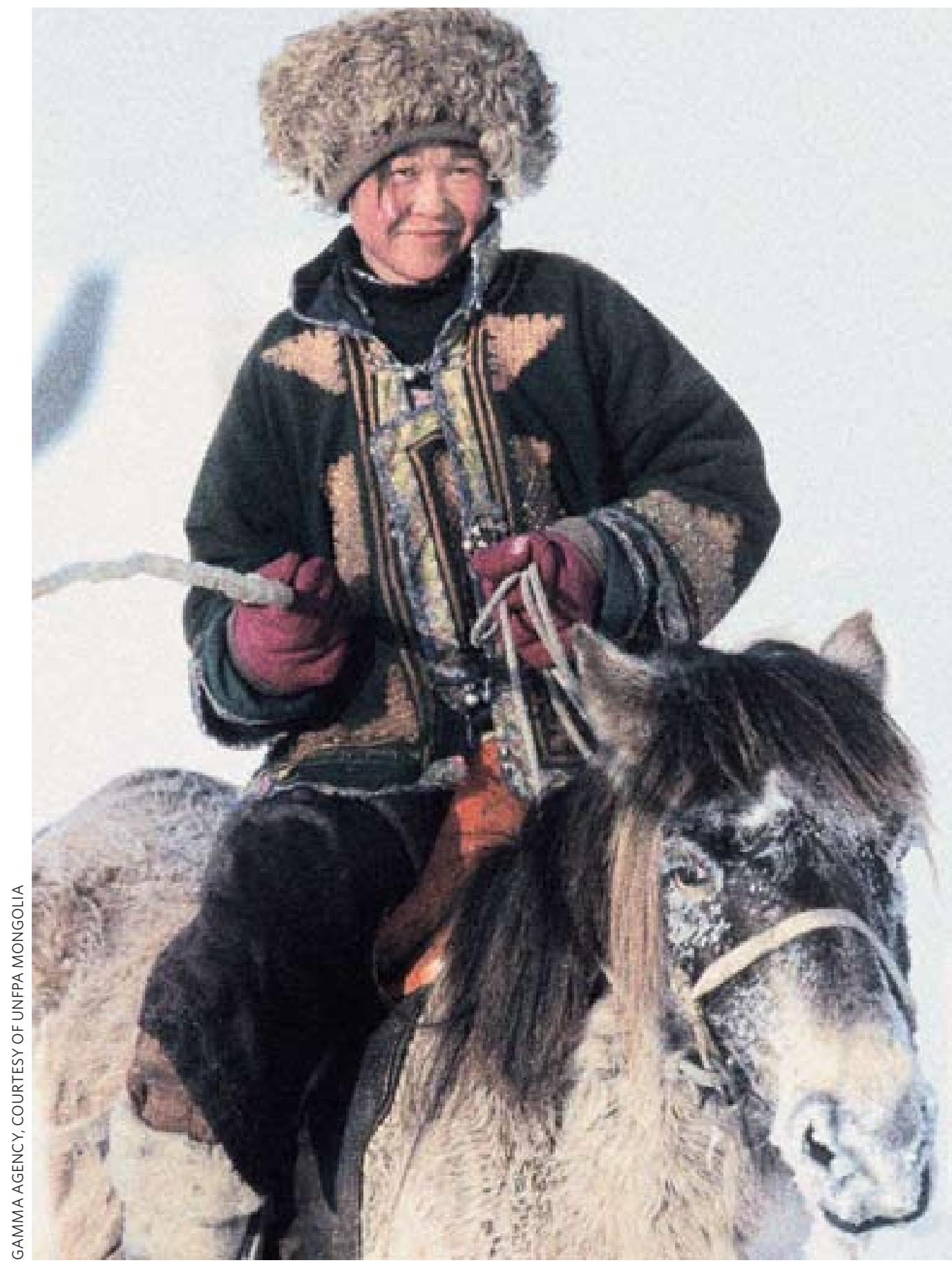

SEE ACTIVITIES BOOK Activity 6

memory journey: learning about gender as a child

Students share a memory of a time when they were treated a certain way because of their sex; they recall their feelings about those experiences.

SEE ACTIVITIES BOOK Activity 7

images of fatherhood

Students write about their fathers or about a male caregiver. They discuss how gender roles limit men's role as caregivers. 


\section{gender and education}

\section{SEE ACTIVITIES BOOK}

\section{Activity 8}

research project: gender in the school environment

Students conduct research on the role of gender in schooling and report on their findings.
Everyone - without distinction of any kind, such as race, sex, language, religion, social origin, or other status - has the right to education (Article 26.1, Universal Declaration of Human Rights [UDHR], 1948; Article 13.1, International Covenant on Economic, Social and Cultural Rights [ICESCR], 1966; Article 10, Convention on the Elimination of All Forms of Discrimination Against Women [CEDAW], 1979; Article 8.1, Convention on the Rights of the Child [CRC], 1989).

1 Education is a universal right. Yet, in many countries, boys are more likely than their sisters to attend school (at all grades), and to go to schools of better quality.

Obstacles to girls' schooling may include:

- the lower value placed on developing girls' capacities;

- economic priorities of the family;

- fears that travel to school will endanger girls' safety (and reputation);

- concerns about sexual harassment or violence toward girls from teachers or male students;

- expectations that girls should help with domestic work;

- inadequate resources for girls to manage menstruation;

- local norms about early marriage and childbearing; and

- lack of equal opportunity in the workforce for educated females.

2 Access to education is critical for achieving gender equality. Yet, in many places, school environments tend to reinforce unequal gender roles and choices.

For example:

- Boys typically demand more of the teacher's time and attention than do girls. They are also more likely to assume leadership roles.

- School staff may tolerate degrading language and "jokes" about females or minorities.

- Students, especially girls, may be sexually harassed (by male students and/or teachers).

- Students who do not conform to prevailing gender norms may be socially marginalized.

- Girls may be discouraged from pursuing traditionally masculine subjects (in some settings, science and math).

- Boys may be directed away from activities perceived to be more feminine (such as certain sports and the arts).

- Many boys are pressured to succeed in athletics or to demonstrate their masculinity by using derogatory language and showing off in the classroom.

- Some sex- and HIV-education programs may even reinforce negative gender stereotypes.

- In some settings, female students may not attend school if they are pregnant. 


\section{Some school environments are actually unsafe.}

- In some schools, girls face a risk of forced sex, sometimes by adults.

- Young people perceived as homosexual and transgender youth often face violence and bullying.

- Gangs may present a risk to all young people, particularly boys.

- Teachers may face these risks as well.

\section{Educational materials also often reinforce unequal gender roles and choices.}

\section{Around the world, people are working to promote gender equality in education and} to expand access to schooling for all.

- Young people are insisting on girls' right to stay in school for as many terms as their brothers do.

- Some governments provide stipends to families in exchange for keeping their daughters in school.

- Educators are revising textbooks and curricula to make them more gender-equitable.

- Some communities sponsor programs to keep boys from joining gangs, using drugs, and engaging in other behaviors that often lead them to drop out of school.

\section{More young people around the world are going to school and staying in school} longer than ever before.

- Throughout history, learning has been one of humankind's great pleasures.

- Education is crucial to providing the skills young people need to find meaningful work and to face the challenges of a changing and globalizing world.

- All young people have the right to education.

\section{POINTS FOR REFLECTION}

Is it the school's responsibility to provide a safe environment for all students and teachers? Does everyone at our school feel safe?

Schoolchildren learn about people who have made contributions to society - for example, to history, science, art, and literature. How much do they learn about the contributions of women? What about the contributions of racial or ethnic minorities?

What do your lessons or schoolbooks include about the contributions of all people to society? If you work with schoolbooks, consider the text, as well as the images and photographs.

What attitudes do schoolchildren absorb if a curriculum excludes the contribution of certain groups of people? 


\section{gender stereotypes in the media}

1 Both children's stories and the media exert a powerful and wide-ranging influence on the gender norms and expectations of young people. Such media include radio, television, movies, newspapers, magazines, the Internet, and advertising.

2 Media images and messages can promote and expose people to values of equality, respect, and dignity - or to those of disrespect and inequality.

3 Children's stories and the media often reinforce gender inequality and disrespect.

Some of the ways they do this include:

- portraying stereotypical male and female roles (for example, depicting men as heroes and women as victims) and stereotypes of racial and ethnic groups, people in same-sex relationships, and others;

- depicting and glorifying idealized body types;

- representing women and girls in highly sexualized ways; and

- reserving for men the more senior and more visible positions in news programs and in film and television.

\section{POINTS FOR REFLECTION}

How do local media portray males and females?

What messages do fairy tales send to children about masculinity and femininity?

What alternative media, if any, exist to give a voice to people who have been ignored, depicted negatively, or otherwise stereotyped in the mainstream media?
4 Around the world, young people are creating their own media and telling their own stories about their lives. Many groups promote public awareness about messages in the mainstream media. 


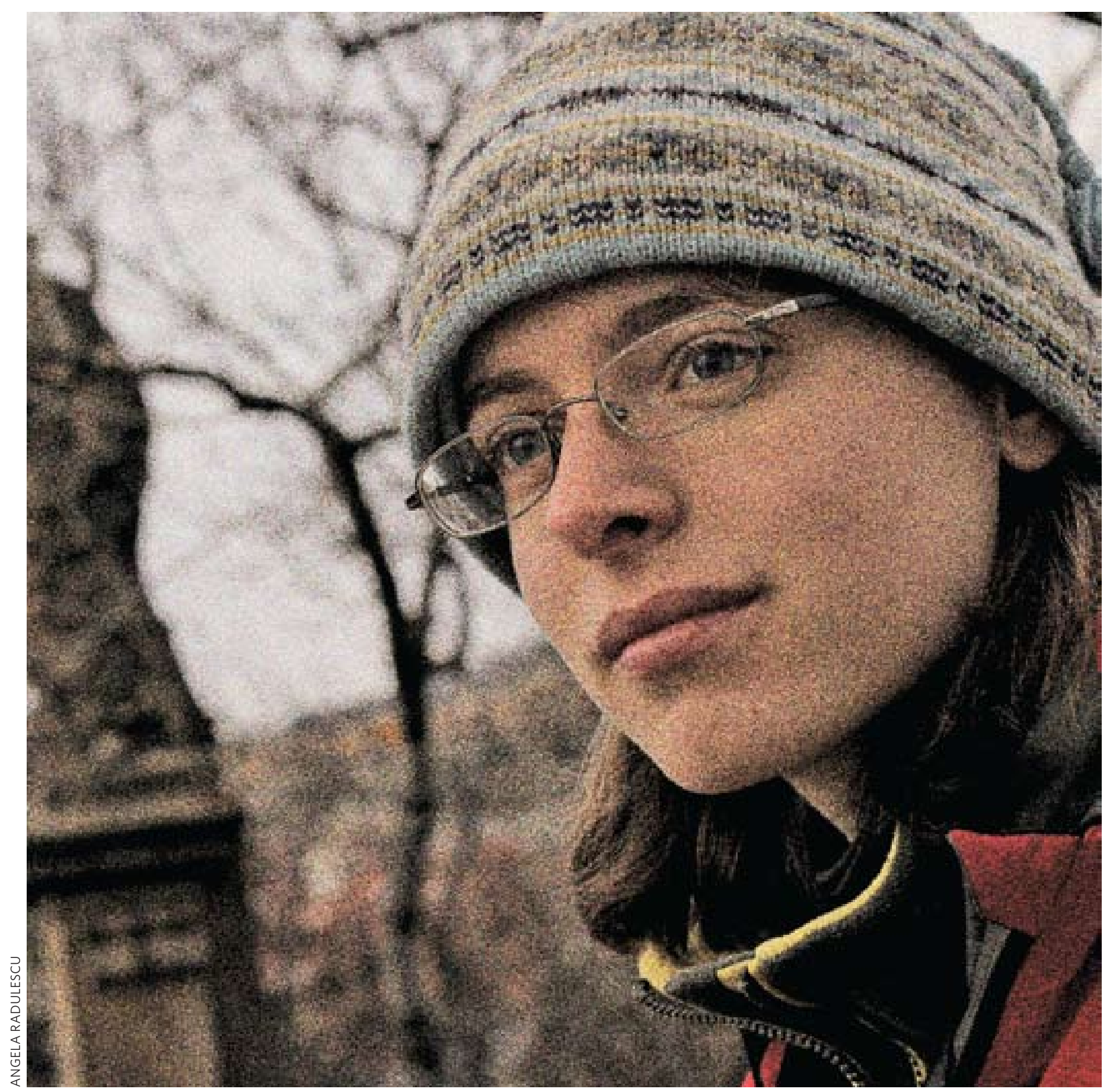

SEE ACTIVITIES BOOK

Activity 9

selling stereotypes:

analyzing advertising

Students make a collage of female and male images from advertisements, analyze the ads' messages about gender, and create ads that break stereotypes. 


\section{how gender affects mobility, social connection, and safe public spaces}

Everyone has the right to freedom of movement and residence within the borders of each state (Article 13.1, UDHR, 1948). Everyone has the right to participate in the cultural life of the community (Article 27.1, UDHR, 1948; Article 15.1, ICESCR, 1966).

1 Being able to move freely and safely around a community is important. It helps people to gain access to information, services, and jobs, as well as to form social support networks. Being able to connect socially outside the home is enjoyable and helps people expand their horizons. Being isolated at home leads some people to feel depressed.

2 In many settings, gender norms restrict females' ability to move about freely in their communities.

For example:

- Adolescent girls are generally allowed much less freedom than boys to leave home and move about in their communities. As a result, girls often cannot play sports, visit friends, access services, or prepare to participate fully in society.

- In some settings, females who go outside their homes by themselves risk being labeled as "bad" or "loose." They may encounter sexual harassment or violence.

- In some settings, adult women are forcibly secluded in their homes. They must be accompanied by a male relative to destinations such as a friend's house, health clinic, or store. 
3 In some contexts, public spaces are unsafe and carry significant danger.

For example:

- In many low-income and minority communities, boys face violence and police harassment or brutality, and incarceration.

- Some communities have high levels of gang activity and lack options for decent jobs or advanced education. In such places, boys may be drawn to gang membership or to dealing in drugs.

- Boys are disproportionately drawn into warfare or other forms of combat.

- Women and girls living in camps for refugees or internally displaced persons, new migrant-labor zones, or other unstable communities, typically face a high risk of violence, including sexual violence.

- In many places, individuals perceived as homosexual or transgender suffer physical assaults that may be lifethreatening.

4 Despite social taboos, many young people refuse to be isolated. Where they can, they create safe spaces to meet each other. Just a few examples of people who have formed such safe spaces include married girls; female domestic workers; people attracted to others of the same sex; transgender youth; girls who want an opportunity to play sports; and sex workers.

\section{SEE ACTIVITIES BOOK}

Activity 10

the gendered space

Students draw maps of their communities, showing which spaces are safe and accessible to people of which sex. They analyze how participation in civic life is affected by gender roles. 


\section{how gender affects civic and political participation}

\section{SEE ACTIVITIES BOOK}

\section{Activity 11}

\section{women of action:}

a make-a-book project

Students create children's books about a female leader.
Everyone has the right to participate in the political and public life of one's country, including the right to vote, to be eligible for election, and to have equal access to public service (Article 21, UDHR, 1948; Article 25, International Covenant on Civil and Political Rights [ICCPR], 1966; Article 7, CEDAW, 1979).

1 Although everyone has the right to participate in public life, everyone is not equally able to exercise this right.

2 Members of some groups often face obstacles to participating in society. This may include women and girls, poor people, people with disabilities, people living openly in same-sex relationships, elderly people, and ethnic and racial minorities.

For example:

- In some places, women cannot vote and rarely hold positions of public leadership. They may have less access to government programs and be less able to participate in society.

- Even in settings where women hold high office, most women may still suffer serious gender inequality and limited opportunity to participate in society.

3 Although a significant gender gap is still widespread in civic and political life, in some places women are breaking such barriers.

- Women serve as leaders at the local, state, and national levels. In some countries, political parties must name women to at least 30 to 50 percent of their electoral slate.

- Women also lead nongovernmental organizations of all sizes.

- Despite the challenges they face, strong female leaders are visible in community and public life in every region of the world.

- Women have organized into effective and vibrant groups. These groups foster discussion and promote women's empowerment, equality, and human rights.

- Many men are working actively to increase women's equal access to civic and political life.

4 Dream big and work hard. You can scale mountaintops and make important differences in the world! 


\section{gender, work, and economic resources: inside and outside the home}

Everyone has the right to work, to free choice of employment, to just and favorable conditions of work, and to protection against unemployment; and everyone - without discrimination - has the right to equal pay for equal work (Article 23, UDHR, 1948; Articles 6, 7, ICESCR, 1966; Article 11, CEDAW, 1979).

1 Everyone - both male and female - is capable of nurturing and caring for children, carrying out domestic chores, and working in paid jobs outside the home.

2 Nevertheless, in most settings, economic pressures - and opportunities (including access to cash) - vary according to sex.

3 Around the world, women - and many men — are seeking to expand women's and girls' access to and control over resources.

They are doing this, for example, through:

- policies that enable women to own property or that promote hiring and promotion of females and other underrepresented groups in the workplace;

- microfinance and savings programs that provide women with cash to participate in the informal economy, especially in places where such resources go mainly to men;

- efforts by sex workers to improve and control their working conditions;

- programs that reach women who must remain in their home or compound;

- education and vocational training that can expand women's options in the formal and informal job markets; and

- affordable childcare that allows parents to seek potentially higher-paying jobs.

4 All of us benefit when everyone can develop and apply her or his talents and caring in families, at work, and in the community.

For example:

- Being an engaged and loving father or mother can provide great emotional rewards to parents and their children.

- As women enter the workforce, men often become more involved fathers.

- Equal access to education and employment allows young people more job options. 


\section{gender and marriage}

At the age of majority, men and women have the right to marry and found a family; they are entitled to equal rights as to marriage, during marriage, and at its dissolution (Article 16.1, UDHR, 1948; Article 16.1, CEDAW, 1979).

Marriage shall be entered into only with the free and full consent of intending spouses (Article 16.2, UDHR, 1948; Article 16.1, CEDAW, 1979). The betrothal and the marriage of a child shall have no legal effect ... (Article 16.2, CEDAW, 1979).

1 Many people form long-term (even lifelong) relationships in which they live together. These are called domestic relationships or domestic partnerships. People have various reasons for forming such relationships.

For example:

- they love each other, and being together makes them happy;

- they desire companionship;

- they need economic security;

- they want to have children; and

- their communities or families expect them to have children.

2 Some people in long-term committed domestic relationships marry formally under the laws of their state or religion. People have various reasons for marrying.

For example:

- They want to honor or legitimize an intimate relationship in the context of the values of either or both partners or of their families, community, or society.

- They want to honor or legitimize childbearing in the context of the values of the individual or of his or her family, community, religion, or society.

- They need benefits that may not be granted to people who are not married or not allowed to marry, such as health and survivor benefits and social approval of sexual relations.

- They comply with their parents' wishes and plans. (In some settings, parents typically arrange marriages for their children. They do this to ensure good matches for their children. They may have concerns for a child's reputation. They may also marry off a daughter in order to relieve economic pressures on the family.) Child marriage (marriage before the age of 18) is a serious violation of human rights but remains common in some parts of the world. 


\section{Some people in long-term committed domestic relationships do not marry}

formally. People have various reasons for not marrying.

For example:

- Personal choice: A couple may feel comfortable foregoing formal approval by the state or by a religious institution.

- They are denied the right to marry. A family or society may prohibit same-sex marriage or marriage between people of different races, religions, or social castes.

- The couple may lack economic resources (income, dowry, or brideprice) needed to marry.

\section{Marriage is a complex and deep-rooted social institution.}

- Marriage may provide many mutual benefits and supports. In many marriages, both partners work to support each other and to support the rights of the other.

- Marriage may also reinforce gender norms, including in ways that are unfair and harmful.

\section{Certain social movements promote greater equality and dignity within marriage.}

These include:

- movements to legalize same-sex marriage;

- campaigns against dowry and child marriage; and

- legal reforms that ensure a just inheritance, allow both parties to initiate divorce, and criminalize marital violence, including rape. 


\section{gender and religion}

Governments should take steps so that tradition and religion and their expressions are not a basis for discrimination against girls (Paragraphs 24 and 276.d, FWCW Platform for Action, 1995).

1 Religions hold a wide range of perspectives about gender and sexuality. These perspectives may change over time. Attitudes also vary within any religion.

2 Many people find that they do not always agree with their religious leader on issues related to gender and sexuality. Nevertheless, religious perspectives influence the beliefs and behavior of many people.

3 Religion or religious leaders may influence gender (and sexual) norms in various ways. [Also see Unit 3, page 88.]

- Some religious traditions are more egalitarian (equal-minded) with regard to gender. Others are more patriarchal (based on a system of male power).

- Religions vary in the degree to which they influence or seek to influence gender norms, sexuality, and fertility. Religious texts may also be interpreted selectively to justify or oppose certain practices.

- Some religious leaders support information about and access to contraception, condom use, abortion, and sex education. Others oppose such access.

- Some religions support equal rights for all people, regardless of sexual identity. (This includes permission to be ordained as a religious leader.) Other religions oppose homosexuality and the rights of people who are homosexual.

- Some religions or religious leaders reinforce a double standard of sexuality. They do this by blessing both female virginity and faithfulness within marriage while condoning polygyny (the practice whereby men have multiple wives). However, others do not.

- Some religions and religious leaders support gender equality in divorce, inheritance, and community life. In other settings, religious laws or practices may restrict women's movement, or forbid them equal (or any) rights in terms of divorce, inheritance, or other family matters. Religious laws sometimes conflict with civil law. 
4 Women are often denied the opportunity to participate equally with men in religious life.

-Women typically assume many of the community-support activities for religious institutions, but have limited opportunities for leadership within those institutions.

- In some religious institutions, women are not allowed to pray together with men.

5 Around the world, people, including many religious leaders, are working to promote values of human rights and gender equality within their communities.

- Examples of such organizations doing this work include: Women Living Under Muslim Laws and Catholics for Choice. 


\section{gender and bodily autonomy}

Everyone has the right to life, liberty, and the security of person (Article 3, UDHR, 1948; Articles 6.1 and 9.1, ICCPR, 1966). No one shall be subjected to . . cruel, inhuman or degrading treatment (Article 5, UDHR, 1948; Article 7, ICCPR, 1966; Article 37.a, CRC, 1989). States shall take measures to abolish traditional practices harmful to the health of children (Article 24.3, CRC, 1989).

Marriage shall be entered into only with the free and full consent of intending spouses (Article 16.2, UDHR, 1948; Article 16.1, CEDAW, 1979). The betrothal and the marriage of a child shall have no legal effect ... (Article 16.2, CEDAW, 1979).

1 We all deserve to have basic control over our own bodies. This includes being free from violence and sexual abuse and from pressure to engage in violence toward others. Control over one's body also refers to deciding whether and when to have sex, whether and when to become pregnant, whether to continue a pregnancy, and even whether and how to alter one's appearance.

2 Such control promotes confidence, safety, health, pleasure, and the opportunity to explore one's identity. Unfortunately, both boys and girls may feel that other people are exercising physical or sexual power and control over them. Feeling you have lost control over your body can be deeply disturbing, even traumatic.

\section{SEE ACTIVITIES BOOK}

Activity 12

altering bodies

Students identify the idealized appearance for males and females in their culture and examine practices people engage in to make their appearance conform to this ideal.
3 Our control of our bodies is influenced by our family values, by our social and religious institutions and norms, and by formal laws. 


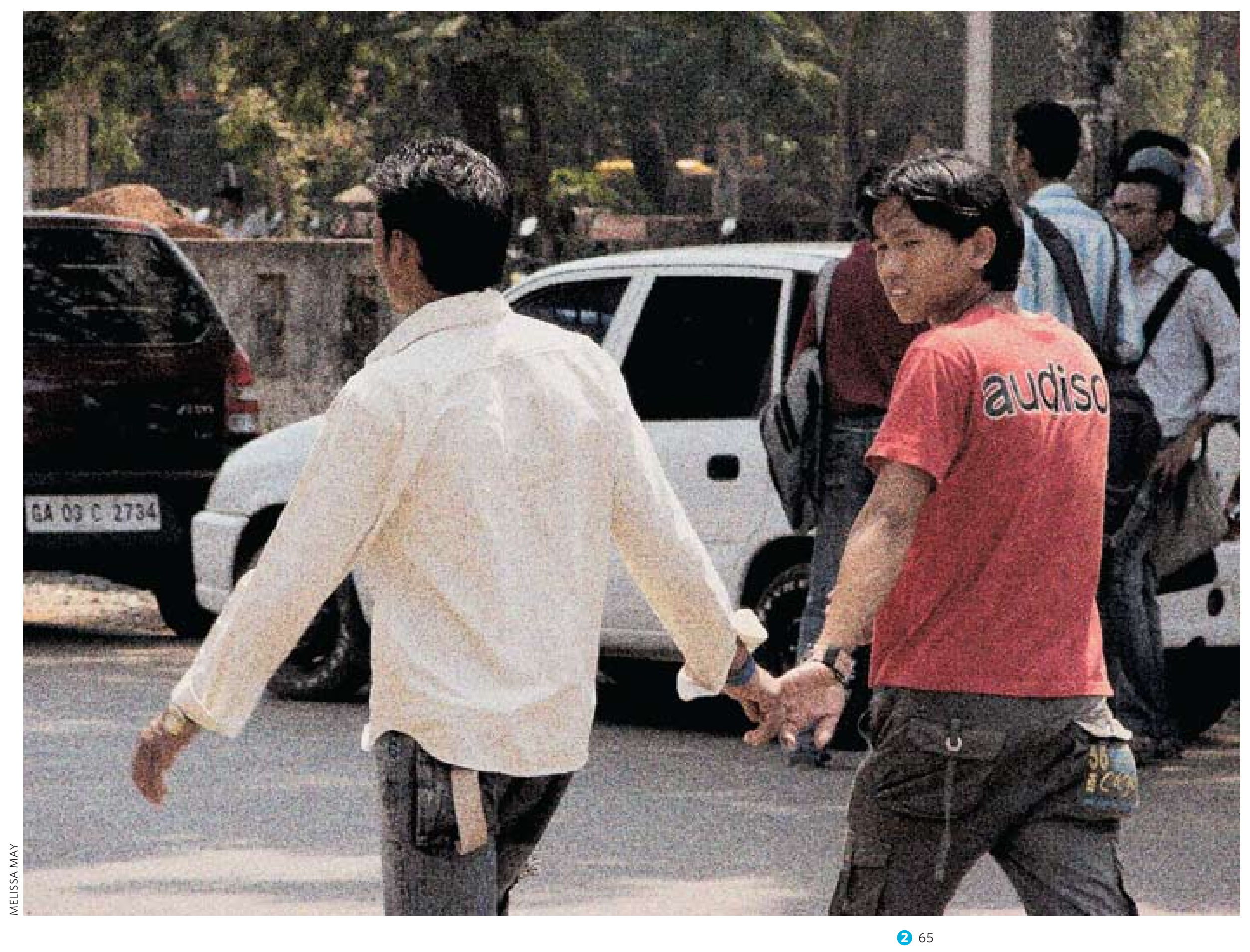




\section{POINTS FOR REFLECTION}

Apart from coercive practices such as genital mutilation, millions of women and girls voluntarily undergo risky medical procedures (or engage in practices that jeopardize their health) to achieve an appearance that fits a cultural ideal. What are some of these procedures and practices? How does society determine ideals of female attractiveness?

What are the reasons that some people use skin-lightening creams? Where does the idea that one skin color is more appealing than another come from?

Why (in some settings) do some girls and women severely restrict their food intake, and why (in some settings) do some put drying agents into their vaginas?

\section{Almost everywhere, females experience stricter regulation and control over their} bodies than do males.

For example, girls are more likely to:

- be reared to expect to have little control over their own bodies;

- experience limits on their sexual expression. Many suffer rape and sexual harassment (such as unwelcome advances, requests for sexual favors, or other unwanted verbal or physical conduct of a sexual nature).

- be limited in their movements (such as not being able to walk around the community) or their dress and have fewer opportunities to play sports.

\section{5 In some places girls are subject to extreme control over their bodies.}

Examples include:

- genital mutilation [see fact sheet at the end of this book]; and

- early or forced marriage.

\section{Males are also pressured to engage in potentially harmful practices.}

For example:

- Some young men consume dangerous drugs to increase their muscle size.

- In some settings, boys undergo traditional, often dangerous, rites to earn adult status. They may undergo such rites as wilderness survival rituals, circumcision carried out under unsafe conditions, or obligatory sexual initiation in a brothel. 
7 Families, communities, religions, and governments often regulate and punish behavior (including sexual behavior) that does not conform to expectations regarding gender roles.

[See Unit 3 on Sexuality.]

Such punishment may range in severity; for example, people might:

- call sexually active girls by derogatory names (such as "slut"), when no derogatory equivalent exists for heterosexual boys;

- approve harsh legal and social consequences for females who engage in extramarital sexual activity, while condoning — or even rewarding — similar behavior among males;

- criminalize and abuse sex workers, while enforcing no legal consequences for those who pay for sex; and

- criminalize homosexuality.

8 Around the world, many parents and children defend the right of young people to bodily autonomy and dignity. Many organizations are also working toward this goal by educating communities and advocating legal changes.

9 Each person's body belongs to him or her. No one has the right to abuse, injure, or violate someone else's body in any way. 


\section{gender and violence}

Everyone has the right to life, liberty, and the security of person (Article 3, UDHR, 1948; Articles 6.1 and 9.1, ICCPR, 1966). No one shall be subjected to ... cruel, inhuman or degrading treatment (Article 5, UDHR, 1948; Article 7, ICCPR, 1966; Article 37.a, CRC, 1989).

1 Everyone wants to feel safe from violence. Most of us also feel better about ourselves if we are not perpetrating violence against others.

2 The incidence of violence varies dramatically by place and over time.

3 People commit many kinds of violence, including physical force, threats, intimidation, and psychological abuse. Such violence may be carried out by - or in the name of - individuals, groups, institutions, or the state.

4 Males are more likely than females to commit violence and to be victims of violence.

- Many young men are socialized (or pressured) to act violently.

- Young men are particularly vulnerable to becoming victims of violence outside the home — in war and civil conflict, in prisons, and in gangs.

- Women are often subject to interpersonal violence, frequently in the home.

- People who are perceived as not conforming to conventional gender norms may be subject to interpersonal violence.

5 Violence against women and girls, or against individuals who do not conform to dominant gender norms, is called gender-based violence.

- Females are particularly vulnerable to violence perpetrated by people they know, including their intimate male partners.

- Such violence may be of a sexual nature, such as unwanted touching or forced sex. [See the following section titled Sexual Coercion.]

- Such violence ranges in severity and may include beatings, burning, or murder.

- Some people face violence because they are perceived (correctly or not) as homosexual or transgender. Violence based on a person's identity is sometimes referred to as "hate crime."

- All gender-based violence is a violation of human rights. 
6 Gender-based violence reflects and reinforces cultural norms about masculinity and male control and dominance.

Examples include:

- Girls are often reared to expect to have little control over their own bodies.

- Boys are often brought up to believe that males are superior to females and that men should dominate women.

- Many females are brought up to accept that men are entitled to be violent or that violence is an expression of a man's love. Some people even blame the victim rather than holding a man responsible for being violent.

- When communities tolerate violence against individuals who do not conform to expected gender roles (such as people who are attracted to the same sex, transgender people, and openly feminist women in conservative settings), "hate crimes" can become a common aspect of the culture.

7 In addition to being a violation of human rights, violence against women is also a public health problem of epidemic proportion.

- The incidence of gender-based violence varies dramatically in response to different historical circumstances and social contexts.

- Violence against women is also often associated with men's consumption of alcohol or certain drugs.

- Such violence may also lead to short- or long-term physical health problems. It may also lead to mental health problems such as depression and isolation. Gender-based violence is also associated with higher prevalence of HIV and other STIs.

8 Men, women, and young people are working locally, nationally, and internationally to reduce interpersonal violence, including all forms of gender-based violence.

Such activities include: legal reforms, community watch groups, education campaigns, and efforts to change norms.

\section{POINTS FOR REFLECTION}

Young men who believe in gender equality are less likely to be violent toward their female partners. Similarly, young women who believe in gender equality are less likely to be involved with male partners who are violent. How might this be explained?

Consider whether violence toward a homosexual person is a sign of one's confidence or of one's lack of confidence.

What long-term health consequences might result from gender-based violence? 


\section{sexual coercion is a form of gender-based violence}

See unit 3, pages 106-107:

Sexual consent and coercion.
Every person has the right to be free from all forms of sexual violence and coercion (Paragraph 96, FWCW Platform for Action, 1995).

1 Sexual coercion occurs when someone forces (or attempts to force) another individual to engage in sexual activity against her/his will. Sex is coercive if one person senses a lack of choice to refuse sex without facing significant social or physical consequences.

2 Sexual coercion is a form of violence. It reflects and reinforces gender inequality.

- Both males and females may be coerced to have unwanted sex, but females are more often the victims.

- Some communities or laws tolerate sexual coercion, rather than understanding it as a type of violence.

3 People may be subject to sexual coercion by different means, including emotional manipulation, deception, physical force or threats, verbal insistence, cultural expectations, or economic inducements. 


\section{Sexual coercion can occur in many different contexts.}

For example:

- Sexual coercion often takes place in a setting or situation normally considered safe, such as at one's home or the home of friends or relatives, at school, in a religious institution, at work, within a dating relationship, or within marriage.

- Sexual coercion also may occur in other situations, for example, with a stranger, as a material exchange (with older partners or peers, for cash or material gifts), in war and conflict situations, and in prisons.

\section{Sexual coercion is a violation of human rights, no matter what the context.}

\section{Like other forms of violence, sexual coercion has serious consequences.}

- Such violence may lead to emotional problems, such as feelings of insecurity, isolation, low self-esteem, and severe depression. It may also lead to physical injury or even death.

- When sex is coerced it often takes place without protection. In fact, coerced sex is linked with increased risks of unintended pregnancy and STIs, including HIV. [See Unit 7.] 


\section{responding to gender-based violence}

\section{POINTS FOR REFLECTION}

What are some of the reasons that women remain in relationships in which they are being physically abused? What role might be played by economics? By fears for one's safety? Concerns for the family? Worries about community attitudes? Lack of alternatives? Not being aware of their rights?
1 In some cases, men may stop being physically abusive to their partners. In other cases, women may leave a violent partner. However, many people remain in violent relationships. [See Unit 4.]

2 Much can be done to reduce the incidence of gender-based violence, such as ensuring that people know that they have the right to live free of violence, including sexual coercion. [See Units 3 and 8.]

3 All people can strengthen their own commitment to and skills for communicating with their friends, family members, and sex partners about problems related to gender-based violence, including sexual coercion. They can encourage their friends to do the same.

4 More and more people (males as well as females), organizations, communities, and country governments are working to reduce violence.

They do this by:

- teaching people ways to resolve conflicts without violence, including ways of expressing their feelings respectfully and effectively;

- supporting survivors of gender-based violence, including providing a safe haven where they can seek help and safety;

- working to change attitudes that tolerate or excuse violence or blame it on the victim;

- promoting norms that honor diversity and difference and that support boys and young men who choose not to adopt aggressive male roles;

- educating people about violence, including the gender norms that foster violence, the wide range of contexts in which violence takes place, the rights of all people to live free of violence, and the importance of shared responsibility for reducing violence; and

- advocating for the passage and enforcement of effective laws against violence. 


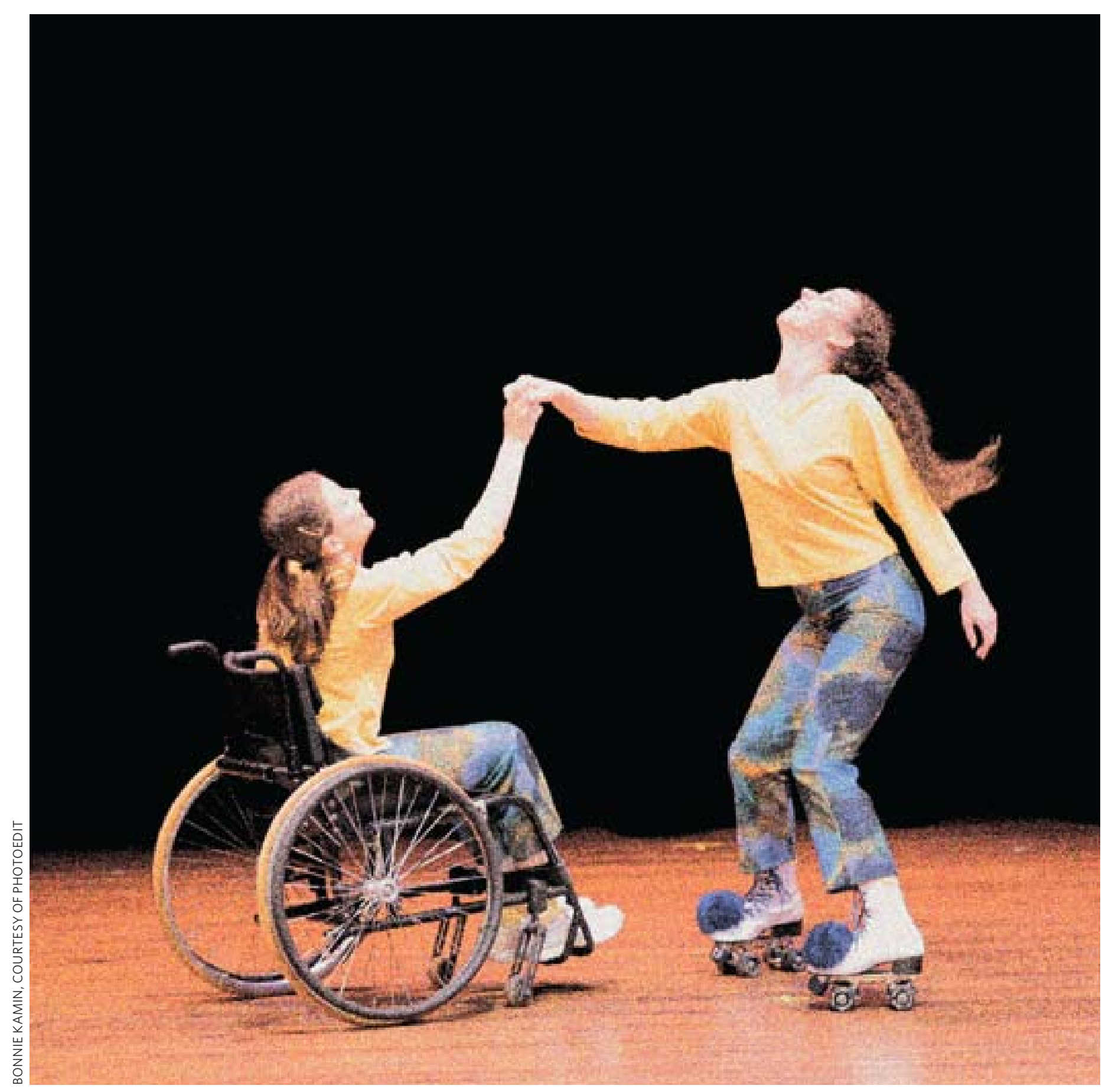

SEE ACTIVITIES BOOK

Activity 13

from violence to respect in intimate relationships

Students develop skits exploring respect and violence in intimate relationships. They discuss how to promote respect in their own relationships.

SEE ACTIVITIES BOOK Activity 14

action against gender-based violence

In small groups, students develop strategies for eliminating violence against women and present their strategies as television newscasts. 


\section{gender norms and roles change over time}

1 Societies and cultures are constantly evolving. The conditions of human beings change, sometimes for the better and sometimes for the worse.

Gender roles are also changing.

- Around the world, millions of people are working actively in their families, schools, and communities to change gender norms.

2 Girls' roles are changing in most parts of the world, rapidly in some places.

- In many places, girls are slowly gaining access to their rights.

- In a few, however, girls are finding their lives more and more restricted.

3 Boys' roles are also evolving, but more slowly.

- Boys' opportunities to discuss and modify their identities and roles continue to be limited.

- Many boys feel conflicting pressure to act like "real men," as traditionally defined. Yet, they are also expected to become more respectful and caring in their relationships with women.

- Organizations of men are working globally to eliminate violence against women. They are also redefining masculinity in ways that allow boys and men to lead fuller lives as individuals, partners, fathers, and members of a just society.

\section{SEE ACTIVITIES BOOK}

Activity 15

images of changing gender roles \& norms

Students interview older relatives about the gender roles and norms of their youth. They discuss how gender roles change.
4 Attitudes toward homosexual and transgender individuals are changing rapidly in some settings.

5 Awareness of sexual violence is increasing rapidly in some places, but more efforts are needed to reduce the prevalence of such violence. 


\section{gender: our own decisions and actions}

States shall take all appropriate measures to eliminate prejudices and customary and other practices that are based on the idea of the inferiority of women (Article 5, CEDAW, 1979).

1 Most of us want to develop our full potential as human beings.

2 Our ability to develop and interact fully is limited, however, by the norms and stereotypes we have absorbed.

3 In order to challenge stereotypes in our own lives, we must identify how they have affected our identity, personal development, and life choices.

4 In order to reduce gender-based discrimination, people must be able to recognize it and act upon it.

5 Recognizing gender-based discrimination is sometimes easy and sometimes difficult. It may be obvious: for example, giving key leadership positions or other privileges to boys, or making an insulting remark about someone in a same-sex relationship. Or it can be more subtle and difficult to notice: for example, ignoring someone's opinion because of her or his gender.

[See Unit 8 for more detailed background and for guidelines for taking action.] 


\section{changing the world around us}

1 Around the world, millions of people, including adolescents, are working to achieve gender and social equality. They do this to help create greater happiness in their own relationships and lives, in their communities, and in the broader society.

2 Young people can help to promote gender and social equality by:

- taking care not to use degrading language or tell demeaning jokes;

- speaking out against discrimination and gender-based violence;

- reaching out to a person who is being marginalized — this can help a person significantly;

- helping to ensure that people living with HIV or AIDS are treated fairly in the community;

- working to reform laws that punish people based on their sexual identity; and

- joining organizations such as the White Ribbon Campaign (a global movement of men working to end violence against women).

SEE ACTIVITIES BOOK

Activity 16

speaking truth to power

By writing songs and poetry, students practice speaking up for gender equality in relationships. 


\section{basic concepts about gender}

The following brief explanations aim to help users clarify important terms regarding gender. These terms are used throughout this document. Around the world, educators bring creativity and sensitivity to the task of adapting these concepts in their own cultural and political context.

Gender: socially or culturally defined ideas about masculinity (male roles, attributes, and behaviors) and femininity (female roles, attributes, and behaviors). Gender is not the same as sex.

Gender equality/inequality: equal (or unequal) opportunities, burdens, and social, political, and economic power of males and females. (The term gender equity has a similar meaning.)

Gender norms: the widely held expectations or beliefs within a community about how people should act or think as males or females. Gender norms also refer to views on how strictly or consistently people should comply with one gender role or another.

Gender roles: the social roles assigned to males or females by the society or family in which they live. Such roles include, for example, how they should behave or what jobs they should have.

Patriarchy: a system of male domination across society, based on belief in the superiority of males.

Sex: Sex is the difference in biological characteristics of males and females, determined by a person's genes. For example, only males produce sperm. Only females produce eggs and can become pregnant. [See also definition of intersex in Unit 3 glossary.] Sex is not the same as gender. 


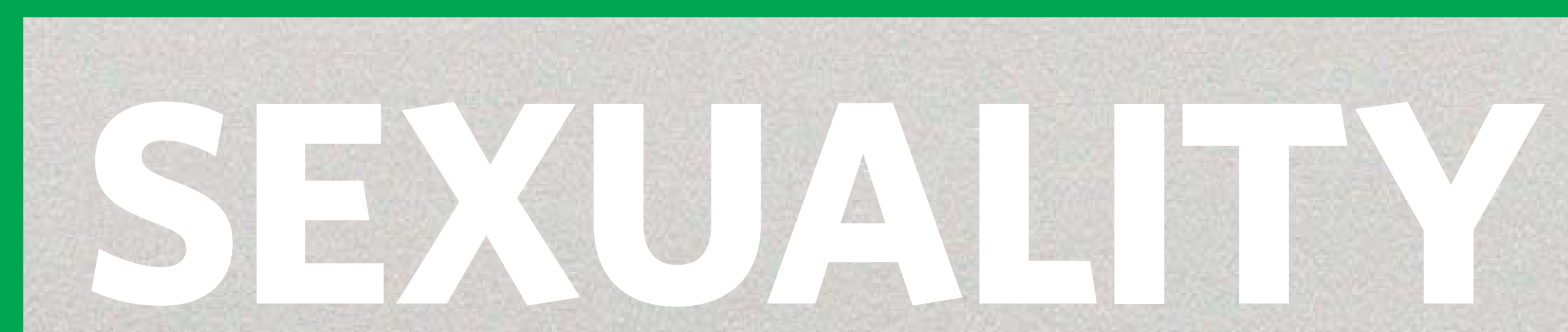




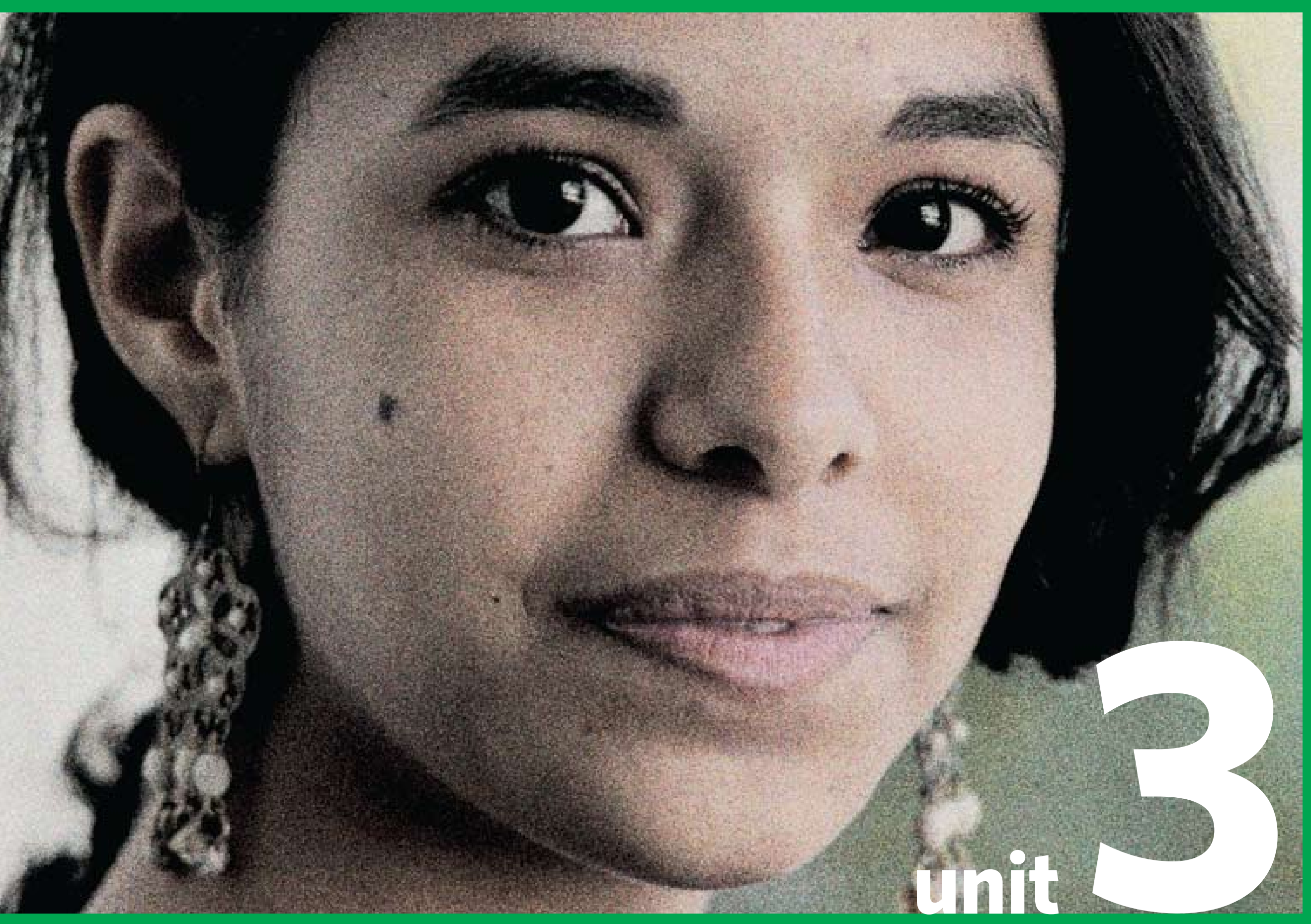




\section{overview}

Sexuality can be a source of great pleasure and meaning in life. Sexual activity is only one aspect of sexuality. People experience sexuality through their physical feelings, emotions, thoughts, identity, and relationships. Cultural norms, individual experiences, and hormones all influence the way we understand and experience sexuality.

This unit helps young people understand what sexuality is and what factors affect the way we experience and understand sexuality. It helps young people to understand why sexual relationships require a level of maturity and to become more comfortable discussing sexual issues. It highlights the importance of consent, mutuality, and respect in sexual relationships. 


\section{SEXUALITY}

Educators can help young people understand how sexuality relates to well-being and health.

Address the positive aspects of sexuality, but keep in mind that many adolescents do not want to have intercourse, and many are simply not yet developmentally or socially ready to have sex. Be clear that a safe and comfortable sexual relationship requires a certain maturity and power to negotiate for oneself; emphasize especially the importance of mutuality and respect.

Plan time to discuss sexual consent in a meaningful way. Many young people feel ambivalent about what they want or confused about their partner's wishes. Explore ways to ensure mutual consent.

An educator's own values should not interfere with teaching about sexuality. Remain neutral and avoid imposing your personal values on learners. You may wish to look for resources or support to help you reflect on your areas of discomfort or conflict regarding sexuality.

Educators may feel moments of embarrassment in discussing sexuality. Thorough preparation helps.

Help your students understand and feel comfortable with the correct terms for body parts. If you are teaching in a language that lacks scientific terms for certain body parts, using the most appropriate term with ease is helpful.

Use respectful terms and avoid hurtful language, particularly in regard to same-sex attraction, sexually active girls, and young people who do not conform to conventional gender norms.

Topics related to sexuality - for example, sexual abuse and AIDS - may raise disturbing or intense feelings. Students should not feel pressured to disclose information about their own sexual experiences. Teachers must support students appropriately and respect their confidentiality. They must also be aware, however, of legal reporting requirements related to disclosure of abuse of a minor.

To foster a safe environment for open discussion, consider separating girls and boys for some activities and then bringing them back together for shared discussion.

Some topics may be viewed as controversial in your setting. Consult as needed about your curriculum.

A number of the fact sheets at the end of this book provide additional details on these topics. 


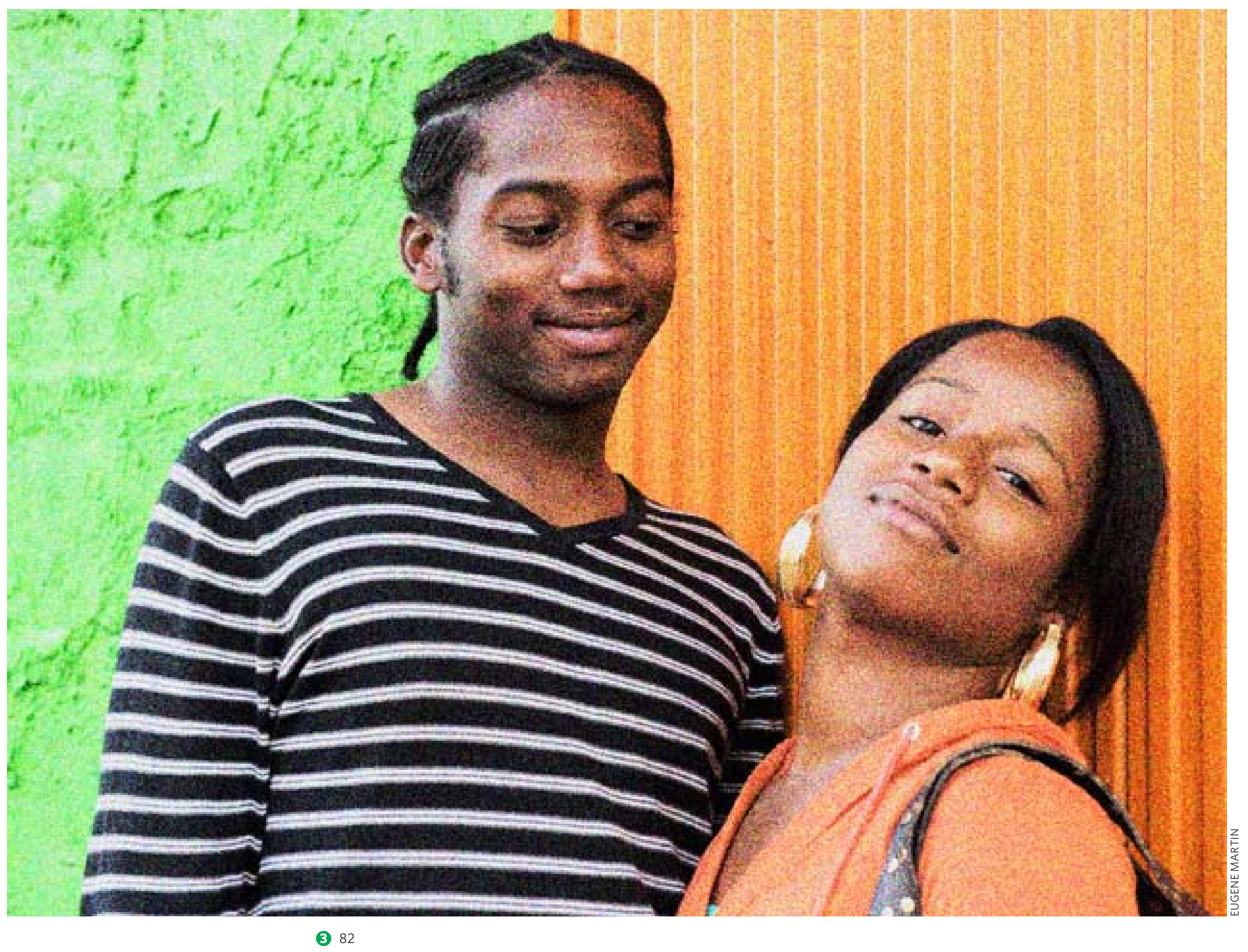




\section{SEXUALITY}

The material in this unit prepares learners to:

\section{Cognitive Objectives}

Discuss at least three reasons that people want to have sex and at least three reasons that people have sex when they don't want to.

Define the concepts of respect, mutuality, and enjoyment as they apply to sexual relationships.

Define and discuss at least three sexual rights, including the right to refuse unwanted sex in any circumstance.

Explain at least two ways that social norms and laws affect people's attitudes about, and experience of, sexuality.

Discuss social norms regarding diverse forms of sexual expression and how such standards have changed or are changing.

Define the concepts of consent and abuse as they apply to sexual relationships.

Identify body parts that play a role in sexual pleasure.

Affective Objectives

Reflect upon ways to promote and protect a positive and responsible sense of their sexuality. Reflect upon their own feelings, motivations, and experiences about sexual decisionmaking.

Define and express attitudes toward the different standards for sexual behavior and pleasure for males and females.

Clarify their own attitudes about sexual diversity. 


\section{about sexuality}

1 Sexuality is a dimension of life. Sexuality is experienced in thoughts, feelings, and practices.

- Sexuality may be expressed by oneself or with others.

- Sexuality includes desires or practices involving someone of the other sex, the same sex, or both.

- People are sexual beings throughout their lives. At some periods in their lives, however, most people experience little or no sexual desire.

- At different times most of us will experience various emotions related to sexuality. We may feel excitement, confusion, anguish, happiness, or many other feelings. Such emotions may be intense or, at other times, mild.

2 Developing comfort and confidence about sexuality is part of growing up. Such comfort is also influenced by individual, family, and social factors and experiences. [See section titled Sexuality and Society in this unit.]

3 Sexuality - expressed alone or in a mutually consensual and respectful situation with a partner - can be a source of pleasure and meaning in life. It can enhance happiness, well-being, health, and the quality of life. It can also foster intimacy and trust between partners. 


\section{sexual rights}

The human rights of women include their right to have control over and decide freely and responsibly on matters related to their sexuality, including sexual and reproductive health, free of coercion, discrimination and violence. Equal relationships between women and men ... including full respect for the integrity of the person, require mutual respect, consent and shared responsibility for sexual behaviour (Paragraph 96, FWCW Platform for Action, 1995).

\section{All people should be able to enjoy their sexuality.}

\section{A critical aspect of sexual experience is that it be voluntary and wanted by both} partners.

[See section titled Sexual Consent and Coercion in this unit.]

- Sexual consent involves deciding freely and voluntarily to engage in sexual activity with another person.

- Because people may have conflicting or confusing feelings about whether they want to have sex, or about whether they can comfortably refuse unwanted sex, ensuring consent can be a complicated matter.

- As young people mature, their capacity to give meaningful consent evolves.

\section{Some aspects of sexuality are matters of human rights; these are often called sexual rights.}

Sexual rights are based on international agreements and covenants. Sexual rights include the right to:

- choose sex partners and to form relationships based on choice and consent;

- say yes or no to sex;

- express sexuality, including the right to seek pleasure, in the context of consent;

- enjoy bodily autonomy, free from sexual violence or exploitation;

- obtain full and accurate information, education, and services; and

- protect oneself against unwanted pregnancy and infection, including HIV.

\section{People also have responsibilities regarding their sexuality.}

For example, these responsibilities include:

- ensuring consent; and

- protecting their own health and that of their partners. [See Unit 7, pages 200-201.] 


\section{sexuality and society}

\section{POINTS FOR REFLECTION}

Social expectations and laws affect what we learn and think about sexuality. For example:

How much open discussion about the body and feelings of sexual pleasure exists - in sex education classes, in families, and in the community?

Do policies ensure adolescent girls' access to safe abortion?

How respectfully do most people treat same-sex couples?

How are people who live with a disability generally treated, especially with regard to their sexual desires and rights?

How are people living with HIV or AIDS generally treated?

When women are raped, how are they treated by their families and communities?
1 All people can grow up to enjoy sex lives that are safe and satisfying and that are characterized by dignity, equality, responsibility, and mutual respect.

๑ 2 A person's ability to develop a safe and satisfying sex life depends on the family, community, and society in which he or she grows up. Social norms and even laws related to sexuality can promote - or undermine - everyone's feelings of selfworth, dignity, health, and sense of belonging and well-being.

[See following section, Sexual Norms Vary According to Gender Roles.]

\section{Whether young people attend school and the quality of their schooling can affect} their sexual experiences and health.

- In many settings, one of the best things girls can do to protect their sexual and reproductive health is to stay in school.

- In some places, girls who become pregnant are forced to leave school.

- Many schools promote gender equality and girls' empowerment. However, many girls also face sexual harassment (and even coercion) at school or on their way to and from school. Young people who are perceived as homosexual or as transgender also face harassment in many school settings. Increasingly, adolescents are forming support groups. In some settings such groups call themselves "gay-straight" alliances.

- All young people have a right to obtain information. ${ }^{1}$ An increasing number of schools are trying to provide meaningful education to enable their students to have safe and responsible sex lives and to avoid HIV infection. Some young people also receive accurate information about sexuality, gender, and human rights from their families, communities, and the media [see number 4, below]. 1 Various international human rights agreements have mandated governments to provide young people with education that will enable them to make
decisions about and take responsibility for their own health and to achieve mutual respect in matters concerning sexuality and fertility, with attention to
promoting gender equality (Paragraphs 107.a, 107.e, 281.e, FWCW Platform for Action, 1995; Articles 13.1 and 28.1, CRC, 1989; Article 26.1, UDHR, 1948; Article
13.1, ICESCR, 1966; Article 10, CEDAW, 1979). [See previous section on Sexual Rights.] 
4 The media - including books, television, films, and music videos - generate images that influence our attitudes, feelings, and expectations about sexuality.

- These images can promote positive and accurate notions about sexuality. Often, however, media images reflect narrow and misleading notions about sexuality.

- In terms of sex, no one way to look or behave is correct, so long as consent and safety are assured. Rather, sexual diversity exists everywhere.

\section{All people should be able to participate in political, professional and civic life without discrimination. Sexual norms should not present obstacles to such participation.}

- Unfortunately, some people may face discrimination, humiliation, or job loss because they do not follow prevailing sexual norms. For example, someone with a same-sex partner, an unmarried female who is sexually active or has more than one partner, or someone living with AIDS may suffer such bias.

- Such discrimination is a violation of the rights defined in many human rights documents. ${ }^{2}$

\section{Around the world, young people grow up with different attitudes and laws} regarding sexual relationships and marriage.

- Most but not all young people want to form a relationship and to marry.

- In some settings, broad or increasing support exists for same-sex relationships, including the right to marry or to form a legally recognized union. In many settings, however, no such support exists.

- People living with HIV or AIDS may face fears or discrimination about marrying, but millions of couples have successful marriages in which HIV is a reality.

- In some settings, laws still allow or do not recognize marital rape (marital sex without spousal consent). 
7 Religions and religious leaders hold a range of perspectives on sexuality and may seek to influence norms and policies regarding sexuality and sexual rights issues.

These norms and policies include, for example, those related to [also see Unit 2, pages 62-63]:

- sex education;

- abstinence and virginity;

- contraception and abortion;

- homosexuality;

- genital mutilation; and

- marriage.

8 Cultural norms and local laws concerning sexuality are not static. They vary from place to place and change over time.

9 Individuals interact with society, and many young people bring their independent attitudes about sexuality and rights into their society. Young people should feel proud of themselves and know that they matter in society.

\section{SEE ACTIVITIES BOOK}

Activity 17

sex education debate

Students debate whether young people should learn about

sexuality, gender, and sexual

health - or should learn only to

abstain from sex until marriage. 


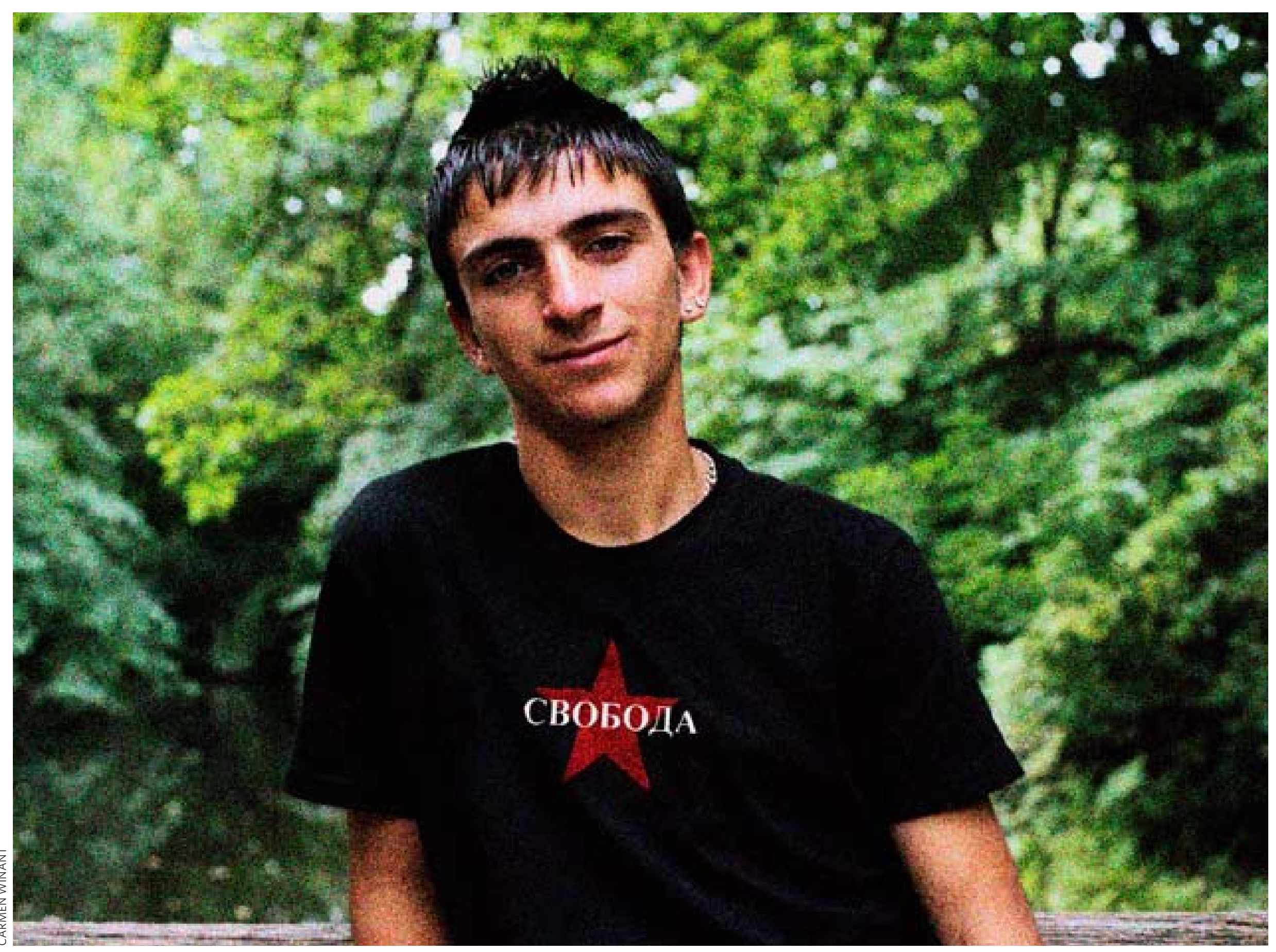




\section{sexual norms vary according to gender roles: the "double standard" for sexual behavior}

1 Boys are often permitted, or even pressured, to be sexually active, as long as their sexual desires are directed toward females.

For example:

- Some boys are encouraged to, and may wish to, delay sexual activity. Often, however, they feel significant pressures to "prove their manhood" through early, repeated, and sometimes even aggressive, heterosexual experience.

- Taking risks (including sexual ones) is commonly expected of boys and men in many settings.

2 Girls often receive negative or contradictory messages about sex.

- Many girls are taught that they should not be sexually active prior to marriage. They may even be punished for being sexually active.

- At the same time, girls are expected to be sexually appealing. Media images may 'sexualize' girls at a young age.

- Girls are often socialized to be submissive to their boyfriends and husbands and to men in general.

- Some girls experience pressure to have sex in order to prove their fertility.

3 Certain expectations are placed on both boys and girls.

- People whose appearance or behaviors depart from social expectations may be harassed or threatened. Boys and men whose behavior is perceived as feminine are often treated disrespectfully or cruelly.

- Many people feel pressure to alter their appearance or bodies to conform to cultural ideals of sexual attractiveness. Girls typically are subject to these pressures more intensely than boys.

SEE ACTIVITIES BOOK

Activity 18

\section{first impressions}

Students examine their response to a character in a story based on their assumptions about whether the character is male or female. 
4 Sexual norms often reflect and reinforce narrow or misinformed attitudes about the sexuality of other groups. For example, such attitudes may be aimed at the elderly, those who live in poverty, those from certain ethnic or racial groups, those with a disability, or those who are attracted to others of the same sex.

5 Each of us can decide how fully we agree with local norms related to sexuality. If we disagree with certain norms and expectations, we can think about whether we will comply with them or whether we can live according to our own beliefs.

\section{POINTS FOR REFLECTION}

The experience of being male or female is not the same everywhere or for every group. For example:

How are older women viewed by society in terms of their sexuality?

Are males in certain ethnic groups labeled as highly sexual or asexual?

A person perceived as homosexual may be subject to stigma. Is that stigma less if that person also happens to be wealthy?

Why are mentally disabled girls more likely than others to be sexually abused?

Think of a person you know and admire who lives according to his or her own beliefs and values, even though these values differ from those of the larger society. Do you think that person suffers hardship for living in that way? Why do you admire that person? 


\section{sexual desire}

1 There are many ways that people experience sexual desire (a longing for sexual expression or a feeling of sexual attraction). There is no one "normal" way to experience sexual desire.

- Virtually every person experiences sexual desire, sometimes of an intense nature. People may feel desire for another person (of the same sex, of the other sex, or both). Or they may feel generalized desire that is not necessarily attached to another person.

- Within an intimate relationship, one person may feel sexual desire more than the other.

- People's level of sexual desire may change over a short time or over the course of their lives. They may experience sexual desire until the end of their lives, although their physical response may change with age.

- People experience sexual desire in response to a wide range of stimuli. Personal preferences, life experiences, and cultural norms all influence these responses.

\section{Various social, emotional, and physical factors shape people's desire to express} themselves sexually. These factors often are interrelated.

- Some factors are related to the body, such as hormone levels, alcohol and certain drugs, fatigue, or illness.

- Some factors are related to emotions, such as feeling respected and understood in a relationship or having suffered an experience of sexual abuse.

- The social environment can also influence the expression of desire. For example:

- A lack of privacy or feelings of nervousness and shyness can make it harder to express desire.

- Gender norms make some boys feel that they are supposed to want sex even when they do not. In contrast, females, young people, people with disabilities, and those attracted to the same sex may be taught that expressing their sexual desire is somehow wrong. 


\section{People often confuse sexual desire or attraction with other emotional or physical}

experiences.

- Sexual desire is not the same as love, although it is often confused with love. A person can experience sexual desire with or without love. For example, a person may feel sexual desire for someone whom he or she barely knows.

[See Unit 4.]

- Sexual desire is not the same as a physical sexual response. For example, a boy or man may have an erection without feeling desire. Or he may experience desire without having an erection.

- Sexual desire is not the same as sexual activity. A person experiencing sexual desire may choose to act on it or not. Sexual activity may or may not spring from desire. Engaging in sexual activity may or may not increase desire.

\section{For many people, fantasy may create or increase desire.}

- Thinking about a sexual act is normal, not shameful.

- Fantasizing about an act does not necessarily mean wanting to engage in that act. It does not mean the person having the fantasy is going to act upon it.

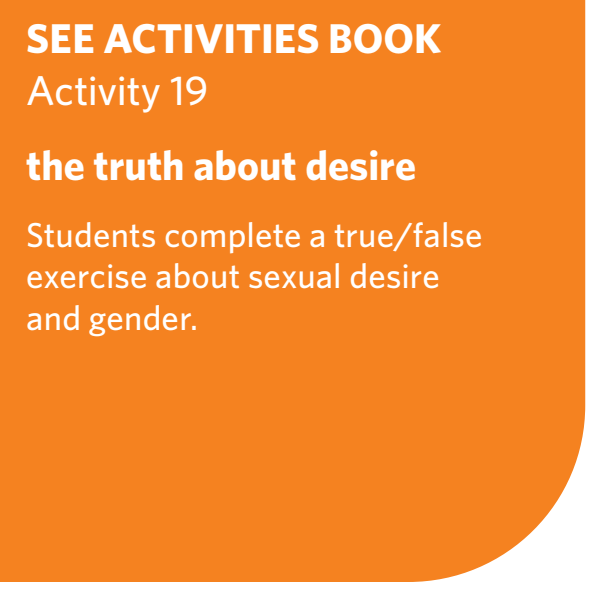

SEE ACTIVITIES BOOK

Activity 19

the truth about desire

Students complete a true/false exercise about sexual desire

and gender. 


\section{sexual diversity}

Note on terminology: Attraction to the same or the other sex may be called sexual orientation, sexual identity, or some other term. This document uses the terms sexual identity and sexual diversity to refer to the broad range of sexual expression. People who are attracted to others of the same sex also use different terms to describe themselves; some prefer the term homosexual, while others use gay and lesbian, or another term. What is considered appropriate and respectful in one setting may be considered offensive in another setting. This document uses same-sex attraction and homosexual interchangeably. For your curriculum, please use what is appropriate in your setting.
1 First and foremost, we are all people. All of us have similarities and differences compared with others in our families, school, workplace, and communities. For example, there is wide variation in how we look and what we think, in our talents, and in our sexuality. This diversity of human experience exists everywhere.

2 Variation in people's sexual desires, behaviors, and identities is referred to as sexual diversity.

3 People may experience feelings of love, attraction, and sexual desire for the other sex, the same sex, or both. This variation has always been true throughout history. It is true in all societies, whether or not the society accepts same-sex attraction.

- The term heterosexual is used to describe people who desire people of the other sex. The term homosexual is used to describe people who desire people of the same sex. In some settings these terms are preferred, in other settings other terms are used (see Note).

- Like everyone else, transgender people (people whose gender identity differs from the sex they were assigned at birth) may be attracted to people of the same sex, the other sex, or both.

- People may or may not identify as heterosexual, homosexual (gay or lesbian), or bisexual (attracted to people of both the same and the other sex).

- People may be labeled with a sexual identity that they do not claim for themselves. Some people do not want to be labeled or categorized in terms of their sexuality or sexual identity, regardless of their desires.

- What determines whether a person experiences desire for the same sex, the other sex, or both, is not well understood. These desires cannot be changed by religion, therapy, or medical intervention. A person's desires, behavior, or identity may shift over time and from situation to situation.

4 People who are heterosexual, homosexual, bisexual, or transgender may be found in every kind of family, community, religion, and profession. 


\section{As a matter of human rights, people may enter into relationships that they choose and that are consensual.}

6 In every society, individuals' feelings about sexual diversity and homosexuality vary.

- Some people are comfortable with, and celebrate, sexual diversity. Others may experience fear or even hatred toward people who are homosexual. Some have mixed feelings. Fear of or aversion to homosexuals is called homophobia.

- People's feelings often reflect local norms. Such norms vary across a continuum that includes: stigma and discrimination (for example, refusing someone housing or employment); rejection (for example, teasing); tolerance; acceptance; respect; and, finally, valuing and embracing diversity.

7 Unfortunately, rejection, stigma, and discrimination toward people who desire or engage in same-sex experiences or relationships is widespread. Such stigma and discrimination harm people and violate their human rights.

- Ridiculing someone for being attracted to others of the same sex can cause that person to feel isolated or ashamed.

- Where homosexuality is stigmatized, people who are attracted to others of the same sex may find it difficult or frightening to acknowledge their own sexual feelings or to be open with others about those feelings.

- Some people identify publicly as heterosexual, even though they feel sexual desire mostly (or exclusively) for individuals of their own sex.

- Boys who do not act "masculine enough" may be intimidated into behaving in ways that are uncomfortable for them. 
SEE ACTIVITIES BOOK

Activity 20

feeling different

Students identify how it feels to be similar to or different from other

people and reaffirm the human

rights of minority groups, including sexual minorities.

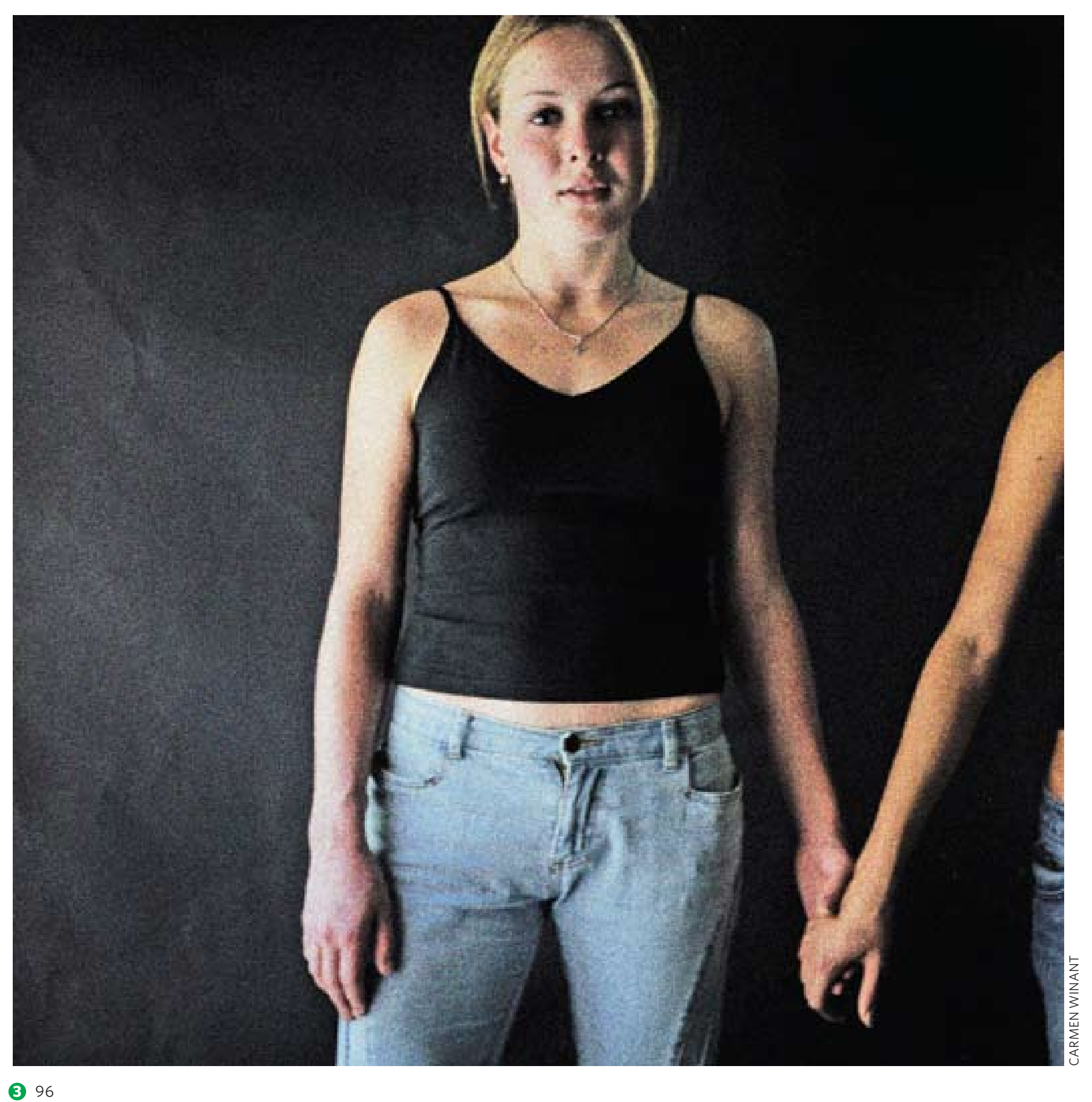


8 All people should be able to participate in political, professional, and civic life without discrimination. Sexual norms should not present obstacles to such participation.

9 The shift toward acceptance of sexual diversity is gradually occurring in many parts of the world.

- Millions of people — both homosexual and heterosexual — are working to support people's right to choose their sex partners, and to form relationships based on mutual consent.

- In secondary schools around the world, students have formed "gay-straight" alliances to oppose homophobia and to educate others about sexual diversity.

- Many human rights, civil rights, and public health institutions have issued declarations regarding the rights of all persons. These declarations support people's right to choose their sex partners and to form relationships based on mutual consent.

- In some cases the media are also helping to generate changes in social attitudes and laws about sexual diversity.

- Even in conservative settings where same-sex relationships have been taboo, people are finding ways to engage in respectful and compassionate discussions about this issue.

10 Discrimination against a person based on that person's sexual identity, desire, or consensual behavior is a violation of human rights.

\section{SEE ACTIVITIES BOOK}

Activity 21

feeling sexually attracted to someone of the same sex: personal stories

Students read three stories of adolescents who realize that they are not heterosexual and discuss these adolescents' reactions. Misinformation is corrected. 


\section{anatomy and sexual pleasure}

\section{POINTS FOR REFLECTION}

The brain mediates many functions related to sex. What are some of the ways that the brain (or mind) influences a person's sexual experience and pleasure?

Something that feels sexual or erotic in one situation may feel unstimulating or even unpleasant in another situation. How might you explain that?
1 The brain is deeply involved in sexual experience and pleasure. It responds to input from hormones and processes emotions. Some people would say that the brain is the most important sexual organ.

2 Any area of the body can respond to sexual stimuli. For example, a person may feel sexual pleasure from a touch to the face, stomach, nipples, ears, legs, or anywhere else. Each person has different responses, and each person's response depends on the situation.

3 Certain parts of the body that contribute to sexual pleasure are specific to males or to females:

[See fact sheets on Anatomy and Sexual Pleasure and on Sexual and Reproductive Systems.]

- In boys and men, they include the penis, testes, scrotum, and prostate.

- In girls and women, these parts include the clitoris, vulva, vagina, and breasts.

- The clitoris (not the vagina) is the part of the female body that is most responsive to sexual stimulation. Most females reach orgasm (sexual climax) as a result of stimulation of the clitoris (rather than from penile penetration of the vagina). Unfortunately, many people do not understand this basic fact.

4 The way the body actually responds to sexual stimulation involves various physiological processes.

For example:

- Heart rate increases.

- Blood flows to the genital area. In males, this bloodflow may cause an erection.

- The body secretes fluids. In females, the vagina may become wet. In males, the penis may release a few drops of pre-ejaculate (not the same fluid as that of ejaculation).

- How the body responds to sexual stimulation varies according to the situation and from person to person. 


\section{sexual expression and enjoyment}

1 Emotional and physical pleasure are important parts of sexual well-being. Public health and rights organizations have issued declarations regarding the rights of all persons to sexual expression. These rights include the right to seek pleasure in the context of safety and of mutual and meaningful consent.

2 What feels sexually pleasurable varies by person.

- People can experience sexual pleasure by touching themselves or through a shared experience (with someone of the same or the other sex). They can also experience sexual pleasure with no touching at all.

- Sources of sexual pleasure may include fantasies, words, reading, watching a film, caressing, kissing, or genital contact.

- For sex to be enjoyable, people must know what feels good to them and to their partners.

3 Touching or stroking oneself (especially one's own genitals) for sexual pleasure is called masturbation.

[See the following section titled Sexual Behavior.]

- Masturbation is an important way that people learn about their bodies and sexuality.

- Most people seek pleasure through masturbation throughout their lives, including periods when they have a sexual partner or are married.

- Masturbation is a safe sexual behavior. It is neither physically nor mentally harmful. 


\section{POINTS FOR REFLECTION}

How do attitudes about female virginity compare with attitudes about male virginity?

How do people treat boys who have had more than one sex partner? How do people treat girls who have had more than one sex partner?

What messages do abstinenceonly education, child marriage, and female genital mutilation send about sexual pleasure?

Do you think that most young men understand the way that most women reach orgasm (through stimulation of the clitoris, rather than through intercourse)?
4 Sexual arousal may reach a peak or climax, called orgasm. Along with a feeling of euphoria, orgasm involves involuntary contraction and release of muscles and secretion of fluid (ejaculate, with semen, in males; genital lubrication in females.)

[See previous section titled Anatomy and Sexual Pleasure.]

- Many females reach orgasm only through stimulation of the clitoris. As part of knowing her own body, a girl should have the opportunity to learn about the function of the clitoris.

- Part of what makes us feel pleasure with orgasm is an increase in the level of endorphins. These are chemical substances produced in our brains that reduce pain and make us feel good.

- People can experience orgasm without intercourse and intercourse without orgasm.

- Feeling pressured to have an orgasm may reduce sexual pleasure and make having an orgasm difficult or impossible.

- Women who have undergone genital mutilation may still experience sexual pleasure. [See fact sheet on Female Genital Mutilation.]

5 Ideally, both partners in a sexual relationship are concerned about ensuring pleasure for their partner as well as for themselves. However, both men and women may have been taught that men (particularly heterosexual men) have a greater right than women to seek sexual pleasure.

6 As long as sexual activity is undertaken with mutual and meaningful consent and is not harmful, there is no one true or better way to enjoy it.

7 Most people want their sex partner to experience pleasure. Without adequate information about their own or their partner's body, however, many people are unsure about how to foster such pleasure. For example, they may not know about the clitoris. Or they may not feel comfortable talking about what feels best. 


\title{
sexual behavior
}

1 People - regardless of their sexual identity, gender, or physical ability - can express and experience their sexuality through a variety of sexual behaviors. One sexual practice is not better (or worse) than another - as long as the partners respect each other, no one is harmed, and both partners fully consent.

2 Children are curious about bodies and reproduction.

- Most children touch their genitals because it feels good; this is called masturbation. Young children do not masturbate with sexual intent. [See previous section titled Sexual Expression and Enjoyment.]

- Although masturbating is safe, it is discouraged or even stigmatized within some cultures and religions. As a result, many parents are unsure about what to tell their children concerning the practice.

- As children become aware of their bodies, they may explore their sexuality with friends of either sex.

\section{Sexual behavior ranges widely.}

Below are descriptions of some common sexual behaviors:

- Masturbation (touching oneself) remains a common practice throughout life for most people. Masturbation is a safe sexual behavior. It is neither physically nor mentally harmful.

- Caressing, kissing, sharing erotic fantasies, stimulating a partner's genitals with one's hand, and rubbing against each other are practices that may lead to orgasm and do not involve penetration.

- Oral sex is mouth-to-genital contact.

- Intercourse is sexual activity in which the penis enters the vagina or anus. Other forms of penetrative sex may involve using the fingers or an object.

4 People can share an intimate sexual experience without touching each other. Nonpenetrative practices (without exchange of bodily fluids) do not carry the same health risks as do intercourse and oral sex.

\author{
SEE ACTIVITIES BOOK \\ Activity 22 \\ sexual behavior - myths \\ and facts \\ Students play a game in which they \\ decide whether statements about \\ sexual behavior are true or false. \\ Misconceptions are corrected in \\ discussion.
}




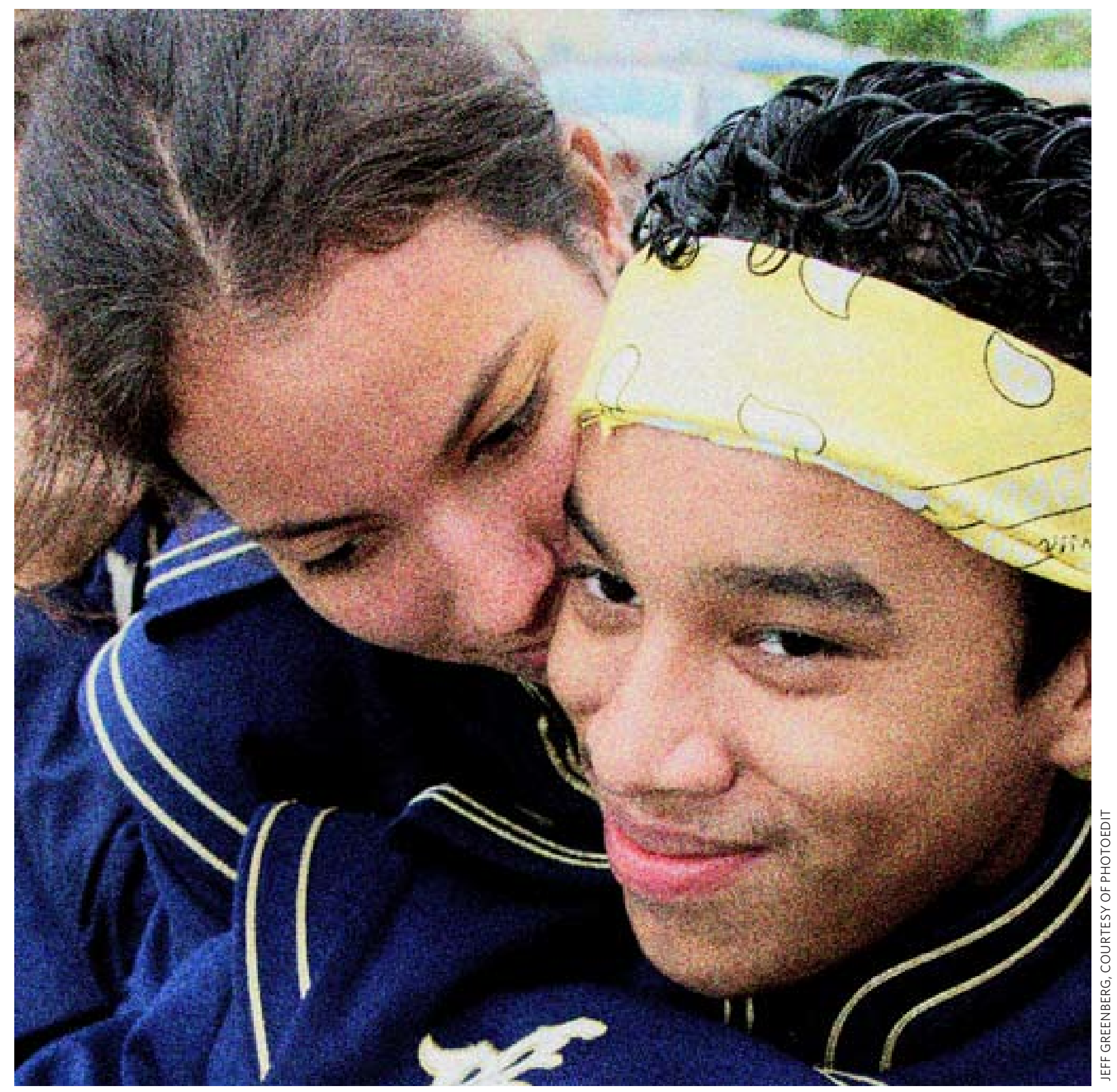




\section{motivations for having and not having sex}

1 As with other activities, people have sex for many different reasons. They may have more than one reason at any time.

- The reasons people feel motivated to have (or not have) sex are often affected by their age, sex, economic status, the status of their relationship, or other circumstances.

- People often have conflicting feelings about sex. They may want to have sex and not want to have sex at the same time.

- People, including young people, may be clear about wanting to have sex and about the reasons why they want it.

Often, however, people (especially young people) may feel confused about these issues.

\section{People may want to have sex in response to genuine desire.}

For example:

- to give or to receive pleasure;

- to learn about their own sexuality and feelings; and

- to express intimacy, connectedness, and love.

3 People sometimes want to have sex primarily as a means to a different end. Even if having sex is consensual and safe, a person might decide to do so primarily to try to fulfill some other need or social obligation.

For example:

- to "win" or "keep" someone's love;

- to avoid an argument or potential violence;

- to achieve greater social status;

- to prove their masculinity or femininity;

- to experiment or fulfill curiosity;

- to challenge adults' authority;

- to demonstrate their power over someone else;

- for material benefit (gifts or cash) or for food or basic survival;

- to fulfill expectations of marital duty; and

- to produce children. 


\section{A person may have any of a number of common and acceptable reasons for not}

having sex.

For example:

- They just do not want to, even if they do not have a particular reason.

- They feel that they are too young to have sex.

- They feel that their relationship is not yet at the stage where they should have sex. They may feel their partner is not committed enough. They may not be "in love." Or they may not want to marry.

\section{SEE ACTIVITIES BOOK}

Activity 23

why we do it (or don't)

Students choose whether they agree or disagree with a

series of statements about why people choose to have - or not to have - sex.

\section{SEE ACTIVITIES BOOK}

Activity 24

where on the line? the continuum between sexual choice and coercion

Students place case studies on the continuum between forced sex and voluntary and desired sex and discuss the right to say no.
- They don't trust or feel comfortable or intimate enough with the other person to have sex. Or they don’t feel enough respect and mutuality in the relationship.

- They don't feel comfortable with the situation.

- Boys, especially, may be anxious about their sexual performance. They may worry about maintaining an erection or about ejaculating too soon.

- They are worried about pregnancy.

- They are worried about HIV or other STIs or about giving such an infection to their partner.

- They fear consequences to their social status.

- Having sex in their particular situation is against their own values or morals.

- Their religion, parents, or community urges them to wait to have sex until they are married.

- They may be afraid to act on their attraction to a member of the same sex.

- They haven't enjoyed their past sexual experiences. Sex has become routine or boring in their relationship.

- They are feeling unwell, tired, worried, upset, or angry. 
5 People sometimes have sex because they are coerced or forced to do so against their wishes. Such abuse is commonly referred to as rape, sexual violence, sexual coercion, or sexual assault. It is a violation of human rights. It is always wrong, and the victim is never guilty.

[See Unit 2, pages 70-71.]

- People of either sex can be coerced to have unwanted sex. However, girls and women are forced to have unwanted sex more often than are boys and men.

- Young people — including small children — are also vulnerable to sexual coercion.

6 The line between voluntary, wanted sex and forced sex is sometimes hard to distinguish. It is more like a continuum.

Think about the following circumstances:

- when the desire to respond to a partner's needs becomes an unwelcome obligation or duty;

- when a person does not know how to assert her or his own desire or needs, or does not feel that he or she has the right to say no; or

- when a person fears that refusing sex will lead to serious consequences: violence (being beaten or raped), losing a relationship, or losing a job.

- Sometimes sex is voluntary but is not wanted.

\section{POINTS FOR REFLECTION}

What are some of the situations in which a person might agree to have sex, even if he or she does not want to?

What do you think are the best reasons for having sex? What are some poor reasons?

How easy is it to be sure that a partner's consent is truly felt? 


\section{sexual consent and coercion}

See unit 2, pages 70-71: Sexual coercion is a form of gender-based violence.

\section{SEE ACTIVITIES BOOK}

Activity 25

\section{the matter of consent}

Students learn about the concept of sexual consent. They explore this concept in case studies, short skits, and discussion.
1 Consenting means agreeing to do something. Giving sexual consent means agreeing to have sex. All people have the right to give or withhold sexual consent. All people have the responsibility to respect their partners' right to give or withhold such consent.

2 Sexual coercion occurs when someone forces (or attempts to force) another individual to engage in sexual activity against her/his will. In a coercive situation, a person may be physically forced to have sex. Or he or she may fear social or physical consequences for refusing unwanted sex.

- Anyone can be coerced into unwanted sexual activity. Most commonly, however, girls and women are the victims of coercion.

- People may be sexually coerced in different ways: by emotional manipulation, deception, physical force or threats, intimidation, and economic inducements, to name a few.

- Forced sex and rape can happen anywhere (including at home or within families and in intimate relationships, as well as in settings normally considered safe, such as schools and religious institutions).

- The prevalence of forced sex rises even higher in certain situations: during war, in refugee camps, in prisons, in sex work, and in situations of sex trafficking or slavery. [See fact sheet on Sex Trafficking.]

- Touching someone's body without her or his consent can also be a form of coercion. If someone touches you in a way that makes you feel uncomfortable, you have the right to tell that person to stop.

3 Regardless of the circumstances under which it occurs, sexual coercion may have serious consequences.

- Sexual coercion may lead to emotional problems, such as feelings of insecurity, isolation, and severe depression. It can also lead to physical injury.

- Coerced sex is more likely than consensual sex to result in unintended pregnancy, HIV infection, or other sexually transmitted infections. 
4 Many people feel confused about the issue of sexual consent. They want to understand the limits of what behavior is appropriate or inappropriate in terms of ensuring consent.

- At any moment, you are entitled to change your mind about what feels acceptable or to speak up if you believe you are not being fully understood and respected. You can say no to a sexual experience even after it has started.

- Consenting to one act or experience does not mean that you agree to any other act or experience. A person who consents to an experience one time has the right to say no to the same experience in the future.

- Because they have been taught to obey adults, boys and girls sometimes feel they must say yes if an adult asks for sex. Because girls are often taught to defer to boys and men, they may feel that they must agree to have sex regardless of their own desires. Such instances are not examples of meaningful, informed, and freely given consent. - Sometimes it is difficult to speak up if someone touches you in a way that makes you uncomfortable. If you find it difficult to speak up, speak to a trusted adult.

\section{Many factors affect a person's ability to consent to sex in a way that is meaningful} and real. For example, personal maturity, awareness of one's rights, and control over the basic aspects of one's life are all important. Being able to communicate fully and openly about preventing infection and unwanted pregnancy is also part of meaningful consent.

\section{Selling sex may be consensual or not.}

- Some people enter sex work by choice. Others sell sex because they are unable to make a living by other means, or they may be forced into sex work through deception or other pressures. [See fact sheet on Sex Trafficking.]

- Some people advocate for the right to engage in paid sex between consenting adults and oppose the stigma and legal consequences attached to such work.

7 Sexual coercion is always a violation of human rights, no matter where, when, or how it happens. In many countries, educators can provide an existing list of hotlines and support services for young people who have experienced sexual coercion.

\section{POINTS FOR REFLECTION}

What is required for consent to be meaningful and real?

What level of emotional judgment, maturity, and capacity does someone need to make informed sexual decisions?

Do people always realize that they have the right to refuse sexual activity?

Why might some people need additional time to sort out and express their feelings?

How easy is it for young people to express their sexual desires and to ensure that their partners can do the same?

How meaningful is consent if a person does not know his or her partner's HIV status?

Some people - including young people - have sex in exchange for cash or gifts. Is their consent valid and meaningful?

How can drugs or alcohol impair someone's judgment or ability to be clear-minded when making sexual decisions? 


\section{creating mutually respectful and responsible sexual relationships}

1 Various factors contribute to having mutually satisfying, responsible, and safe sexual experiences. This is true throughout your life.

These factors include:

- knowing that you and your partner both have the same rights, and cooperating to ensure mutual respect, consent, and responsibility;

- treating each other as equals, and as people, not just as bodies;

- feeling comfortable in communicating what each partner wants or does not want;

- respecting a partner's right not to do anything that feels uncomfortable or unsafe;

- being honest with each other;

- feeling intimacy;

- feeling cared for;

- using safe and effective ways to protect yourself and your partner from unwanted pregnancy and sexually transmitted infections, including HIV;

- working to protect yourself and your partner from emotional harm;

- being aware of your own desires and comfort level and those of your partner; and

- being able to give and to accept pleasure.

2 All of us can learn to develop greater respect, responsibility, and satisfaction in our sexual relationships. 


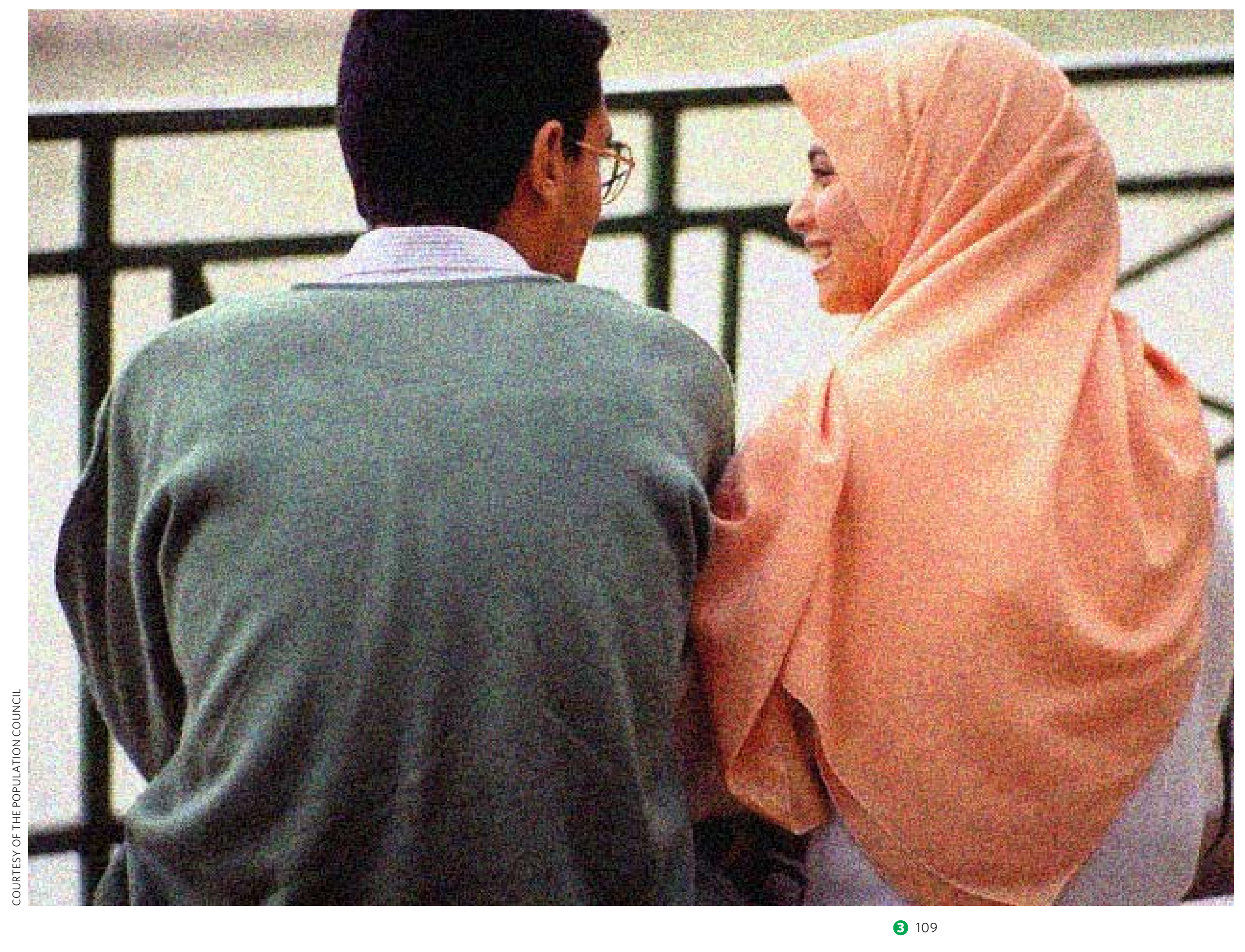




\section{concerns about sexual function}

1 Many people develop concerns at some point about whether their sexual responses are functioning the way they should.

- Most concerns about sexual function relate to a person's feelings and situation. For example, people may worry about their body parts, attractiveness, or ability to "perform" sexually. They may have learned negative attitudes about sex or have had disturbing sexual experiences. They may have negative feelings toward their partner. They may be worried about STIs, AIDS, or pregnancy, or they may be distracted by a lack of privacy. They may not know about normal variation in sexual response or may not be willing or able to talk about sexual needs.

- Less often, problems in sexual function are caused by physical factors, such as illness, alcohol, drugs, or medication.

\section{Certain sexual concerns or problems are fairly common among men and boys.}

These include:

- not being able to have or maintain an erection adequate for sexual intercourse. Almost every man experiences this concern at some time in his life;

- ejaculating too soon and feeling that ejaculation is not under control;

- not being able to have an orgasm or taking longer to climax (have an orgasm) than desired; and

- not being able to help their partner reach orgasm.

3 Certain sexual concerns or problems are fairly common among women and girls.

These include:

- not being able to have an orgasm or taking longer to climax than desired;

- not responding to sexual stimulation; and

- experiencing persistent pain during intercourse (which may be caused by infections).

4 Many people (regardless of their gender or sexual identity) experience periods where they lack interest in sex. It may become a concern for a couple if both partners do not have a similar desire for sex.

5 Communicating honestly and respectfully with one's partner may restore comfort and enjoyment. If a concern continues or interferes with a person's sexual enjoyment, speaking with a trusted counselor may be helpful. 


\title{
sexual well-being and advocacy
}

1 Everyone should have the opportunity to develop the capacity for having a safe, consensual, and enjoyable sex life, when they are ready for it in their lives.

2 We can advocate for health, pleasure, and respect in our own sexual relationships.

Promoting safe and respectful relationships involves, for example:

- learning to respect our sex partners and to express our own needs, which takes skill and experience;

- communicating our feelings to help ensure mutual health, pleasure, and understanding; and

- waiting to have sex until both partners have the maturity, the power to negotiate for themselves, and the skills to ensure communication, mutual respect, consent, safety, and comfort.

3 All around the world, sexual and reproductive rights advocates - community groups, health care providers, young people, and others - are promoting greater respect, mutuality, and consent within sexual relationships. Some of the changes they are working toward include:

- better sex education;

- promotion of gender equality;

- elimination of laws that criminalize consensual sex between adults, such as same-sex sexual activity;

- recognition of the sexual rights of people with disabilities; and

- improved access to sexual and reproductive health services, such as access to contraception and to safe and legal abortion, as well as to confidential testing, counseling, and treatment for HIV.

\author{
SEE ACTIVITIES BOOK \\ Activity 26 \\ hot policy topics and \\ personal responses \\ Students select a news headline \\ that reflects changing norms about \\ sexuality and write a personal \\ response.
}




\section{basic concepts about sexuality}

The following brief explanations aim to help users clarify important terms regarding sexuality. These terms are used throughout this document. Around the world, educators bring creativity and sensitivity to the task of adapting these concepts in their own cultural and political context.

Bisexuality: having both same-sex and other-sex attraction or desire, behavior, or identity.

Heterosexuality: sexuality between males and females.

Homosexuality: sexuality between people of the same sex. In some settings, attraction to the same or the other sex is called sexual orientation, or some other term; this document uses the terms sexual identity and sexual diversity to refer to the broad range of sexual expression, including attraction to the same or the other sex.

Intercourse: sexual intercourse often refers to vaginal penetration by the penis. Oral intercourse involves the mouth at or on a partner's sex organ. Anal intercourse involves insertion of the penis into a partner's anus.

Intersex: having sex chromosomes, genitalia, and/or secondary sex characteristics that are neither exclusively male nor female.

Sexual and reproductive rights: human rights that apply to sexual and reproductive life and health. For example, they include: whether, with whom, and under what circumstances a person has sex; whether to carry a pregnancy to term; and the right to protect one's body from sexual violence or coercion. 
Sexual desire: a longing for sexual expression or a feeling of sexual attraction.

Sexual diversity: the wide variation in people's sexual desires, identities, and behaviors.

Sexual function: physiological responses that are part of one's sexuality.

Sexual identity: how people identify themselves in terms of various aspects of their sexuality, which may include their sexual preferences and attractions. It may also include the kinds of relationships they wish to form. A person's sexual identity may or may not be the same as their sexual desire or behavior.

Sexual norms: social standards that shape our understanding, attitudes, and experiences related to sexuality.

Sexual well-being: a sense of well-being related to one's sexuality and sexual life.

Sexuality: how people experience and express themselves as sexual beings. Many factors contribute to people's sexual behaviors, relationships, feelings, identity, desires, and attitudes. One of these factors is biology, especially sex hormones. Another factor is individual personality and experience. Yet another factor is culture, which influences people's attitudes, expectations, and experiences related to sexuality. Cultural norms also affect laws and policies about sexuality. All of these factors interact throughout life. 


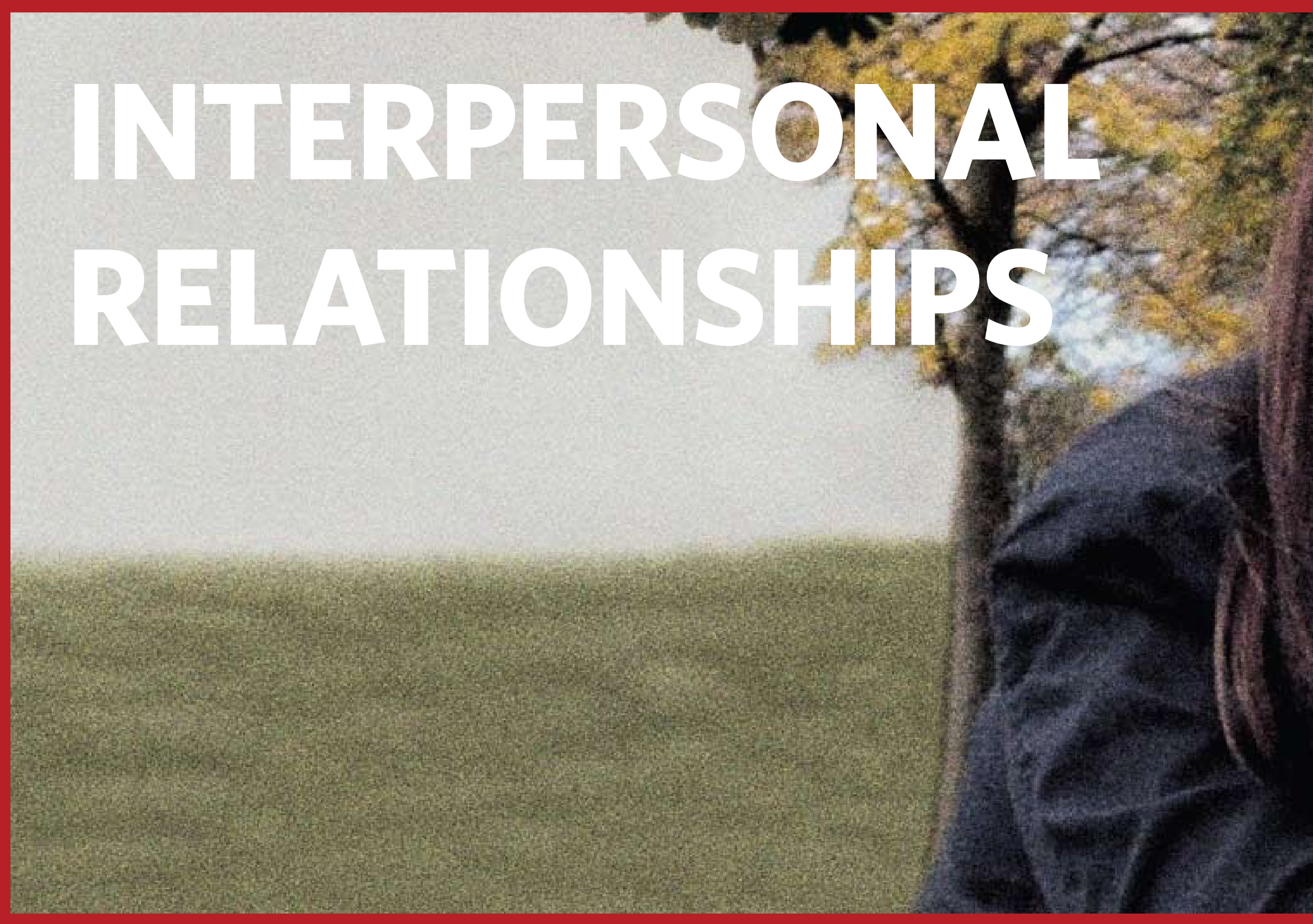




\section{overview}

In thinking about our interpersonal relationships, most of us think about individual personality or experience. Our relationships, however, are also influenced by society. For example, power differences between people, media portrayals of relationships, and other factors strongly influence our ideas about personal relationships. During adolescence, young people may experience different, often intense, feelings as aspects of their relationships undergo dramatic change.

This unit explores different kinds of relationships that people have, including romantic or sexual relationships. It encourages young people to think about the qualities they seek in intimate personal relationships in their own lives. 


\section{INTERPERSONAL RELATIONSHIPS}

Although personal interaction involves the best and the worst of human experience, caring relationships give many people's lives meaning and represent much of what life is about.

Focus first on the different kinds of relationships people have. Then emphasize romantic or intimate relationships.

The connection between teachers and students is also one kind of interpersonal relationship. Although teachers hold authority, basic principles of respect and dignity still apply to the teacherstudent interaction.

Validate your students' knowledge: Every person has experience of human relationships.

Allow students to share their experiences or to keep them private.

Invite your students to think about the need for respect, compassion, and human rights in relationships with people who are HIV positive. These relationships can be at school, in the community, in the extended family, or elsewhere. This consideration is particularly important in settings with a high prevalence of HIV.

This unit touches on topics about which young people typically have many questions and feelings. Budget enough time to allow for exercises and ample discussion. 


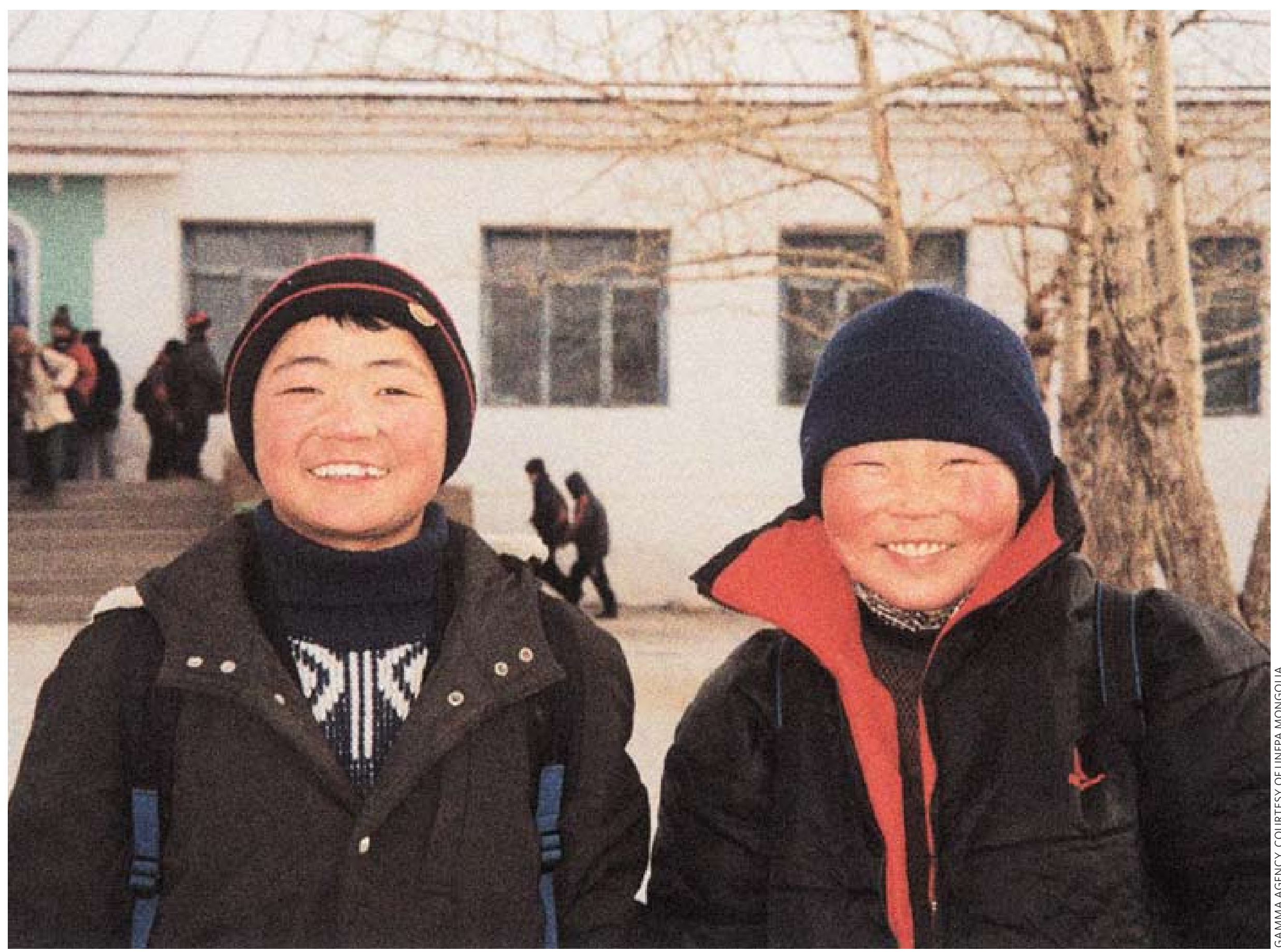




\section{INTERPERSONAL RELATIONSHIPS}

The material in this unit prepares learners to:

\section{Cognitive Objectives}

Describe the basic right to form relationships and the right to be treated with respect and dignity. Describe different types of relationships and family structures.

Describe two personal and two societal or cultural factors that may contribute to, or block, satisfying and mutually respectful relationships.

Discuss the kinds of issues that people need to be able to talk about with comfort and maturity to ensure safe, respectful, and consensual sexual relationships.

Discuss at least two key challenges that many young people face in intimate relationships.

Affective Objectives

Reflect upon the difference between love and infatuation, with examples from their own lives.

Reflect upon the nature of their relationships and the kind of relationships that they want to have in their own lives.

Reflect honestly about their own maturity level and comfort in communicating with a partner to ensure that intimate experiences are wanted, safe, respectful, and enjoyable.

Appreciate the importance of knowing one's rights and responsibilities; having communication skills; and having personal or professional support to address or end a troubled relationship.

Identify what they believe to be their sources of power and powerlessness and how they bring these perceptions into their interpersonal relationships.

[For related skill-based objectives, see Unit 5: Communication and Decisionmaking Skills.] 


\section{introduction to interpersonal relationships}

Equal relationships [including] between women and men in matters of sexual relations and reproduction, ... require mutual respect, consent, and shared responsibility. ... (Paragraph 96, FWCW Platform for Action, 1995).

1 Interpersonal relationships are social associations, connections, or affiliations between two or more people.

- For most people, having interpersonal relationships is an important part of being happy.

- Human relationships can fulfill various emotional, social, physical, intellectual, and economic needs.

- Our culture shapes the way we see our world and the relationships in it. People's relationships change as their culture changes.

2 Every person, in every society, has many different kinds of relationships.

- These include links with family members, friends, coworkers, neighbors, acquaintances, boyfriends and girlfriends, teachers, fellow students, and others.

- Interpersonal relationships also vary in their quality. For example, different relationships may be characterized by more or less openness, trust, communication, intimacy, sharing, power, respect, affection, and feeling.

- Relationships may or may not be centered around some thing(s) shared in common. For example, people in relationships may be neighbors; classmates; coworkers; members of the same club; congregants at the same church, mosque, or temple; members of an AIDS support group; or users on the same social networking website.

- People express their feelings for each other in many different ways.

\section{SEE ACTIVITIES BOOK}

Activity 27

my relationships

Students create a visual representation of their

relationships.
3 People may start new relationships throughout life. They may also end relationships. Sometimes, a relationship can be harmful to one or both people's well-being. People are not obligated to remain in a relationship. 


\section{relationships in our lives}

1 People have various personal relationships, including loving relationships, throughout their lives. For most people, important early relationships are formed with members of their family. Young children look to their parents or to other trusted adults or older family members for unconditional love.

- Families take many forms. Family members may, or may not, be biologically related.

- An extended family typically includes relatives other than those of the immediate family, and may include individuals who are not biologically related.

- Many families include one or more adopted children.

- Family members may live together in the same home or may be separated, either by choice or by circumstances. Some common circumstances that separate families include: work, migration, military service, and imprisonment. These situations can separate members of a family for extended periods or permanently.

- In families with children, the children may live with two parents (in a male-female or a same-sex relationship), with one parent, with extended family members, or with adult guardians.

- Some children grow up without reliable adult protection, but may be nurtured by older children.

\section{Like all relationships, family relationships are changing.}

For example:

- In many parts of the world, more women are heads of households than has been the case in the past.

- In many places, social attitudes about fatherhood are changing. Increasingly, as a result, more fathers are building close relationships with their children and sharing responsibility for child care. This is especially true where women are entering the formal workforce.

- In places where large numbers of people have died as a result of AIDS, war, or other reasons, many orphaned children live with other relatives or in orphanages.

- As cultural attitudes in many places become more accepting of diverse family arrangements, more same-sex couples are living openly and many are rearing children. These parents may bring children from previous marriages, may adopt, or may use assisted-reproduction technologies such as artificial insemination or surrogacy.

3 Friendship is one of the most important kinds of interpersonal relationships.

\section{POINTS FOR REFLECTION}

Why do we form friendships?

What qualities define friendship? Trust? Affection? What else?

In some cultures, young people often form comfortable, nonsexual friendships with people of the other sex. In other cultures, they do so less often. How can we explain this variation?

What can we gain from becoming friends with someone from a different background or group? 


\section{SEE ACTIVITIES BOOK}

Activity 28

what's going on between these two?

Students read case studies of relationships characterized by societal inequalities; they identify the inequalities and discuss their effect on the relationships.

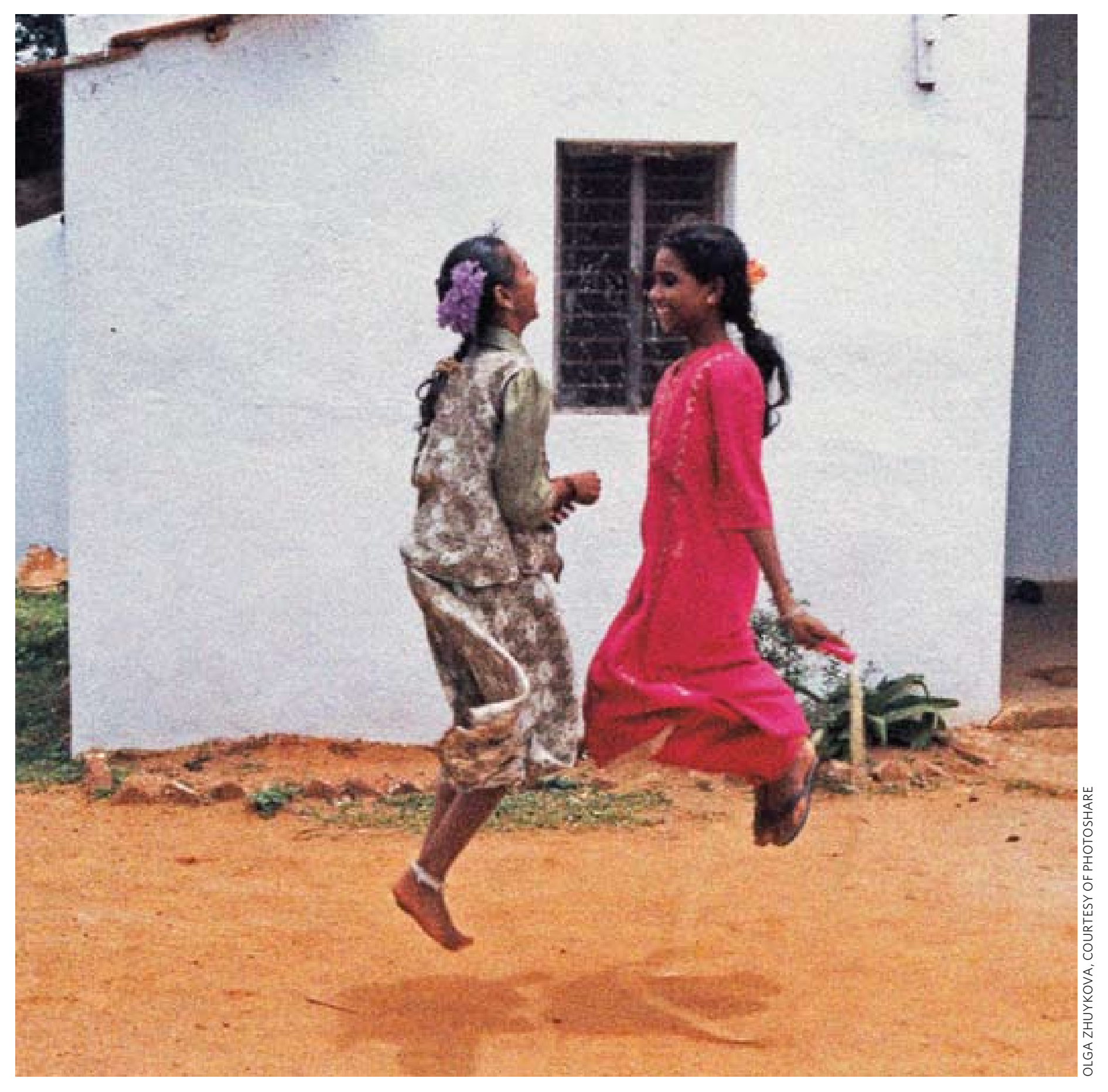

(4) 122 


\section{how can our relationships be more satisfying and respectful?}

1 All of us want relationships that are satisfying and mutually respectful.

2 Certain personal qualities help build satisfying and mutually respectful relationships:

- respect for oneself and an awareness of and comfort with one's own feelings and values;

- sensitivity to other people's feelings and respect for their dignity and rights;

- shared expectations;

- honesty and authenticity;

- good communication skills [see Unit 5 for more on what this entails];

- "give and take" (reciprocity); and

- caring for, spending time with, and paying attention to each other.

3 Support from the broader society can also promote positive relationships. However, societal inequality can undermine mutual respect and comfort in people's relationships.

- Parents, religious leaders, and the media can teach young people to respect each other as equals — regardless of their race, religion, ethnicity, gender, economic status, physical ability, HIV status, or other categories.

- Schools and community organizations can bring young people from different backgrounds together so that they do not grow up isolated and unfamiliar with people from other walks of life.

- Schools and families can teach young people to notice when things are not equal and to understand how power differences between people can undermine a satisfying and mutually respectful relationship.

\section{POINTS FOR REFLECTION}

Can you recall a situation in which one person considered himself or herself superior to others, or was in a position to mistreat another person?

What kinds of experiences have you shared with someone who is different from yourself, and what did these experiences teach you? 


\section{romantic relationships: courtship and dating}

1 Courtship and dating refers to social interaction with others who could become romantic or sex partners.

2 Norms and practices about courtship and dating vary enormously around the world.

- In many settings, courtship or dating is the custom. Not all cultures, however, practice courtship and dating, and not all people court or date.

- In settings where people cannot date in person, they may find other means of communicating such as the Internet.

- In places where arranged marriage is customary, people may wed without having courted or dated. In such settings, parents (or the community) may arrange a marriage or identify a potential marriage partner for their child.

- Many, although not all, people whose marriages were arranged may come to feel that they have grown together and have a loving marriage.

\section{What do courtship and dating offer?}

- They give people a chance to develop interpersonal skills. These skills include recognizing, honoring, and expressing their own feelings; recognizing the feelings of others; and developing an understanding of what they value, enjoy, and appreciate in another person.

- They give people a chance for companionship and new experiences.

- They give people a chance to gradually get to know a potential romantic or sex partner.

\section{At what age do people start dating or courting?}

- The age at which young people begin dating varies widely from person to person and across cultures and societies.

- The age at which parents permit young people to begin dating or courting varies widely — both within communities and across communities and cultures.

- Many adults also date. 


\section{Whom do people court, date, or "go out" with?}

- Often a person dates someone of about the same age, but not always. In some settings, adult men seek girls as dating partners. This age discrepancy often contributes to an unequal division of power in the relationship.

- Often people date someone from their same social group, but not always. In some cases a person may date someone of a different race, ethnicity, religion, socioeconomic level, or caste. Some, but not all, families and communities are comfortable and supportive of such interpersonal relationships.

- People may date someone of the same or the other sex.

\section{How do dating and courtship start?}

- People meet in a variety of ways, including through work, school, family, mutual friends, social networks, in the community, on the Internet, or elsewhere.

- In many heterosexual contexts, boys and men are expected to initiate dating. In some places, however, this convention has been relaxed, and girls and women also initiate dating. Many people feel nervous about asking someone out on a first date.

\section{What do people do on a date or as part of courtship?}

- What people do on dates varies. For example, they may sit and talk, take a walk or a bicycle ride, share a cup of coffee or tea, see a movie, attend a community event or party, or visit with friends or family members.

- Two people may engage in these activities on their own, with a larger group of friends, or accompanied by family members or a chaperone. These customs tend to be shaped by local norms.

- Some people court, even over an extended period, via the Internet or other means of communication.

- People may feel comfortable, excited, nervous, or anxious about going on a date with a particular person.

- People may go out with each other only one time or they may continue dating or courting for many years.

- Courtship can be an opportunity to develop trust and friendship. For example, young people may share their values, their hopes and dreams, or difficult experiences or worries they are facing. 


\section{Who pays for expenses on a date?}

- A date does not have to entail spending money. When it does, practices vary. Many people share the costs of a date. Sometimes the boy or man is expected to pay for the date. Sometimes the person with greater resources pays.

- The financial arrangement should be mutually comfortable. Cash outlays by one person do not require the other person to fulfill uncomfortable or otherwise unwanted obligations, including sexual activity.

\section{Is sexual or intimate physical contact part of dating?}

- Sometimes people who are dating find that they are physically attracted to each other and both may desire sexual contact, which may include holding hands, kissing, caressing, or other intimate activity.

- In a context of trust, mutuality, and respect, such experiences may be wonderful and exciting. They may offer chances for young people to learn about their own sexual feelings and responses.

- For many people, sharing a sexual experience always involves affection, intimacy, or love. For others, love is not always part of sex. Even in the absence of love, sex partners can share trust, respect, care, and pleasure.

- Some people feel comfortable anticipating having sex. They may make sure to have condoms or another contraceptive in advance. (Both male and female condoms can prevent pregnancy and protect against HIV and other infections.) Others may have sex without having planned for it or discussed it with their partner. They may not have thought to have any form of protection ready.

- Talking with one's partner about having sex is important for ensuring mutual consent. Such discussions can enhance both partners' comfort and help ensure their safety. [See Unit 5, page 150.]

\section{What if you are pressured to have sex during dating or courtship?}

- Nobody is ever obligated to have unwanted sexual contact for any reason. This is true even if the other person spent money on the date, or if the date or courting has gone on for a long time.

- Unfortunately, sexual coercion is common in the context of dating and even at some group social events. This serious social problem is sometimes called "date rape." Date rape is even more frequent when the date involves excessive drinking of alcohol, when there is little or no social accountability for one's behavior, or when no trusted friends are nearby to turn to. Young people should learn about where and how date rape may occur in their own communities. 


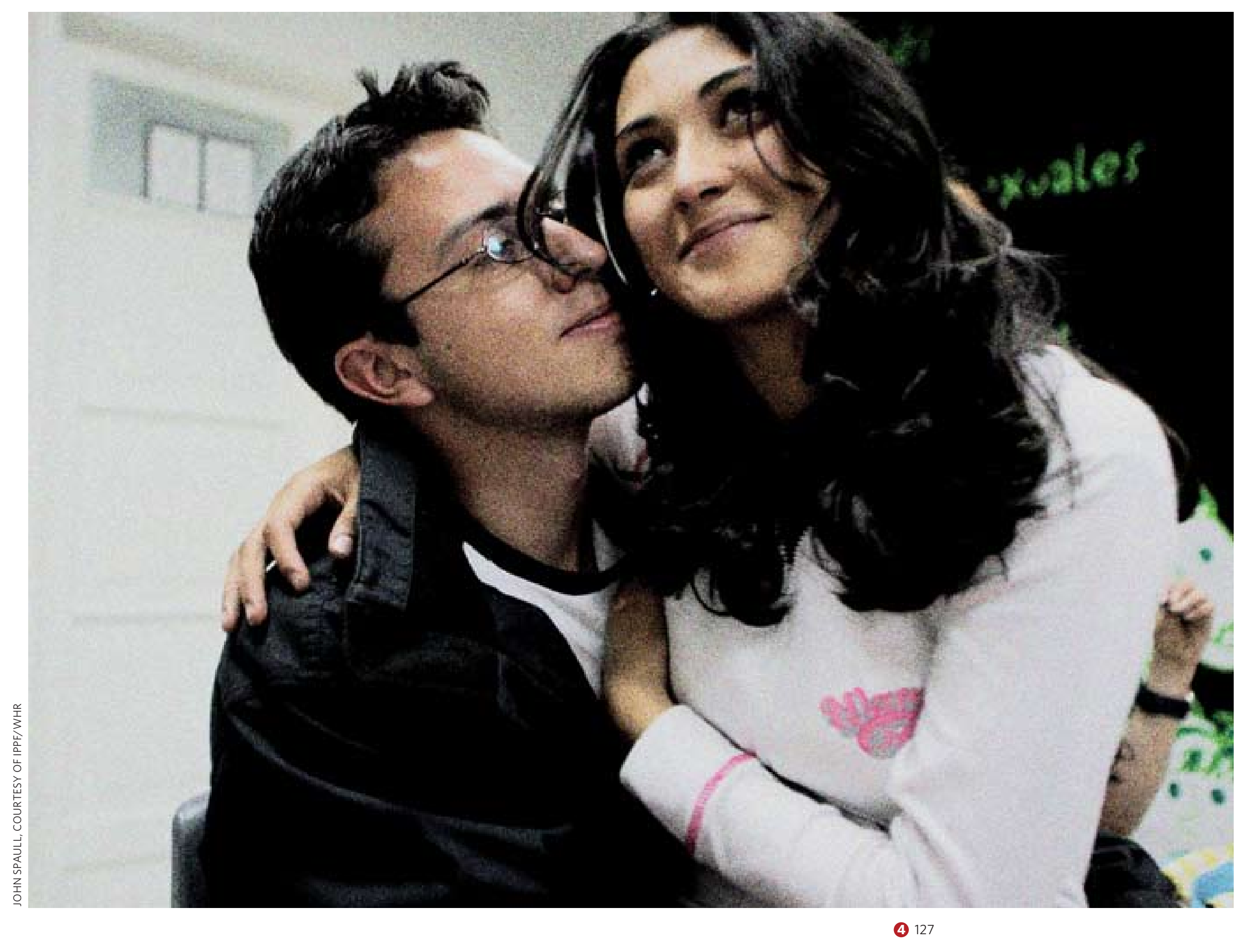




\section{romance: what is falling in love? what is "true love"? what about jealousy?}

1 Ideas about "romance" and "love" vary in different settings.

2 Typically, "falling in love" involves feelings of passion, sexual attraction, and excitement. Sometimes this feeling is called a "crush," "romance," or "infatuation."

- Falling in love is often a thrilling experience.

- A romantic relationship sometimes (although not always) involves feelings of commitment and intimacy.

- Falling in love can be a one-sided experience; the object of the love may not feel the same.

- Everyone can fall in love. Adults, as well as adolescents, fall in love.

- People may fall in love only once, more than once, or many times in their lives.

\section{POINTS FOR REFLECTION}

What are the main messages about romance in children's fairy tales? In music videos?

How realistic are these messages? What kind of expectations do they place on young men? On young women?

How necessary is romantic love for happiness in life?
3 Children grow up absorbing many messages about romance and love.

4 What is "true love"? Loving someone is caring deeply for that person and being committed to his or her well-being and happiness. Loving and being loved can be the source of deep joy and meaning in life.

- Love is one of the most powerful emotions that people experience. It has inspired great works of art, literature, and music.

- There are many different ways to love somebody.

- People may feel love for members of their immediate or extended family, for close friends, and for their partners or spouse of the same or the other sex.

- The terms "true love" or "real love" often refer to an intimate partner bond that has moved beyond the "falling in love" or infatuation stage.

- Sorting out feelings of affection, romantic love, sexual desire, and "true love" is often difficult and confusing.

- Everyone receives messages from her or his culture about what love is, whom we should (or should not) love, and how we should express (or not express) our love. 


\title{
5 When people feel that a valued relationship is threatened, they may become
} jealous.

- Jealousy (in any kind of relationship, including a romantic one) refers to feelings of envy, possessiveness, vulnerability, anger, and resentment.

- Most people have feelings of jealousy at one time or another.

- In romantic relationships, people may feel jealous of a real or imagined romantic rival. However, a person may also feel that a relationship is threatened by a partner's commitments to family, friends, or work.

\section{Some people express jealousy with threats, violence, or controlling or} manipulative behavior.

- Such behaviors are not love and are never an expression of love.

- Violence and coercion are demonstrations of power over another person. They always violate the human rights of the person they are used against, regardless of whether they express jealousy or other feelings.

- Both the person who feels jealous and his or her partner can benefit from talking honestly and respectfully about their feelings with each other. Each of them may also benefit from speaking with a trusted friend, adult, or counselor.

\author{
SEE ACTIVITIES BOOK \\ Activity 29 \\ is it love? \\ Students distinguish love from \\ related emotions.
}




\section{sexual activity in relationships}

1 What does a satisfying sexual relationship offer to people?

- Satisfying sexual relationships can bring people closer together, be pleasurable, and enrich life.

- Having sex should feel safe, desirable, and pleasurable.

- Nobody is ever obligated to have unwanted sexual contact.

\section{POINTS FOR REFLECTION}

Even if they are sexually aroused, people often have mixed feelings about having intimate sexual contact. They may not be sure of what it might entail.

What might happen if people acknowledge their mixed feelings and their questions about sex?
2 Does a person always know if he or she wants to have intimate sexual contact?

3 For a person who is sexually active, what factors contribute to having a sexual relationship that is emotionally satisfying to both partners, responsible, and safe?

In addition to factors that contribute to any interpersonal relationship (see page 123), sexual relationships in particular are often more comfortable, satisfying, and safe when both partners:

- feel intimate and cared for, and not that they are just a convenient body;

- ensure mutual consent, respect, and responsibility;

- are able to give and to accept sexual pleasure;

- feel comfortable communicating what they want or do not want;

- respect each other's right not to do anything that feels uncomfortable;

- share in the responsibility for using safe and effective methods to prevent unwanted pregnancy and sexually transmitted infections, including HIV;

- know your own and your partners' status with regard to HIV (and other STIs); and

- talk about whether or not they will have sex partners outside their relationship. When people have only one sex partner, their relationship is described as monogamous or "being faithful." 


\section{In what ways do young people sometimes feel pressured by their boyfriend or}

girlfriend to have sex?

Some of the reasons that people have sex that they do not want include:

- to give in to peer pressure;

- to prove love or to try to gain commitment in a relationship;

- to avoid hurting the other person's feelings or ego;

- because dating or courting has gone on for some time;

- because of having previously agreed to have sex even though one has subsequently changed one's mind;

- because the other person is in a position of power, status, or authority (for example because of age, social popularity, resources, or gender);

- because of pressure from family members, elders, or community leaders;

- in order to obtain money or gifts; and

- because alcohol or drugs have impaired their judgment or ability to resist an unwanted sexual advance.

Unfortunately, even in relationships, many people experience sexual coercion, abuse, or violence. Anyone may be subject to such abuse, although girls and women are more frequently the victims. Sexual abuse is harmful and always wrong. It is never the fault of the victim. Coercive sex is also associated with a higher risk of HIV transmission. [See Unit 2, pages 70-71 and Unit 3, pages 106-107.]

\section{Developing a high level of comfort, communication skills, and maturity in sexual} relationships is a learned process and takes time.

- Because many young people enter sexual relationships while they are still growing in these areas, they are particularly likely to feel awkward and embarrassed; anxious or ashamed; and fearful about HIV or pregnancy.

- Boys and men, particularly, may feel pressured to "perform" sexually. They may feel they cannot admit that they lack knowledge or experience. In turn, girls and women may feel it is not proper for them to talk about such topics as condom use or their own sexual desires.

- Practice and encouragement can help all young people overcome such pressures and learn to communicate with greater confidence.

\section{SEE ACTIVITIES BOOK \\ Activity 30 \\ deciding whether to have sex \\ Students examine the indicators of maturity, self-awareness, self-efficacy, and the ability to communicate that are part of what a young person needs to negotiate a safe and comfortable sexual relationship.}




\section{long-term intimate relationships}

\section{People form different kinds of long-term, committed, loving relationships.}

- Most people are brought up to expect that they will form a relationship with a partner of the other sex, marry that person, have children, and remain in that marriage for the rest of their lives.

- The reality for many millions of people, however, is more complex. People may form many different kinds of long-term, committed relationships. They may have more than one fulfilling long-term relationship in their lives. Or they may remain single, either by circumstance or by choice. They may form male-female or same-sex relationships.

- Either as a matter of choice or because of circumstances beyond their control, people may: live together some or all of the time; agree to be mutually monogamous or have other sex partners; rear children alone or with other family members; marry; and/or make a lifelong commitment to each other.

\section{POINTS FOR REFLECTION}

Various factors contribute to long-term compatibility between people.

How important to you are shared values? Friendship? Intellectual compatibility? Sexual attraction? A shared sense of responsibility? An ability to communicate? Honesty? Shared commitment? Harmony with in-laws and extended family? Shared spiritual or religious life? Mutual respect for each other's rights? $\odot 2$ A long-term and committed intimate relationship may develop as a result of different circumstances. For example, it may spring from an infatuation, a friendship, or an arrangement between families.

\section{The nature of marriage and long-term intimate relationships varies from place to} place and over time.

- In many places, a significant proportion of couples form unions outside of marriage.

- In many societies, people find their own intimate partners or spouse. In other places, families choose a spouse for their child — someone they feel will be a suitable partner, or who will strengthen social kinship structures, or both.

- Most societies prohibit being married to more than one person at a time. Where polygamy exists, it virtually always involves one man with multiple wives, not the reverse.

- Although rates of child marriage are declining, this custom continues to affect millions of girls around the world.

- In some societies, women are choosing to marry later or not at all.

- In some settings, men are marrying at later ages than they did in the past because they cannot afford to support a family. 
4 Around the world, some couples are creating marriages or long-term relationships based on gender equality and human rights. They are doing this even where the decision challenges local norms.

[See Unit 2, pages 60-61.]

- In many settings, openness is increasing in attitudes toward marriage between people from different backgrounds (for example, from different religions, races, or castes).

- Some societies are discussing, or voting on, the right of same-sex couples to marry or to form civil unions that carry many of the same legal rights and responsibilities as marriage.

5 Many people within long-term relationships have concerns about transmitting HIV to a partner or spouse. One partner may be infected with HIV while the other is not, or either or both of them may have sex partners outside of the relationship. Information, access to condoms, and confidential testing and counseling are critical for helping couples to develop transmission-prevention strategies.

[See Unit 7, Part 1.]

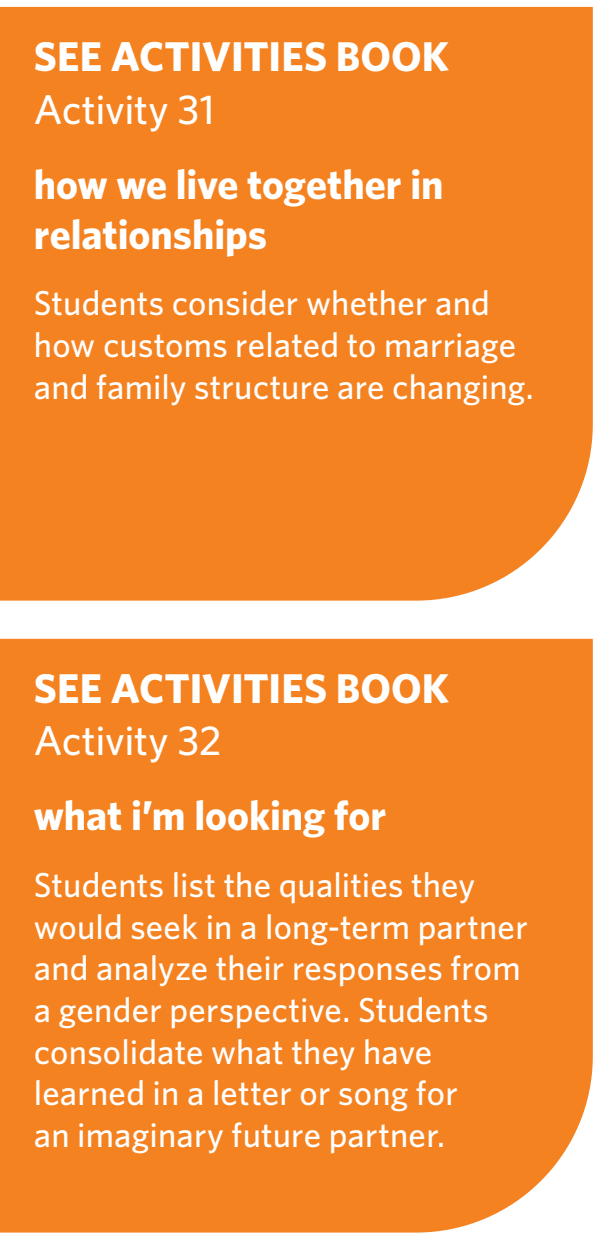




\section{difficulties in relationships}

1 All relationships - even stable, happy ones - have periods of difficulty or moments of frustration. Some relationships are more deeply or chronically troubled than others, however.

Some signs of a troubled relationship may include:

- a serious imbalance in respect for each other's dignity and rights;

- feelings of inauthenticity about oneself ("not being able to be yourself" in a relationship);

- ongoing feelings of loneliness and isolation;

- absence of shared values or common interests;

- ongoing feeling of contempt for one's partner;

- episodes involving physical, sexual, or psychological violence, or the threat of such violence; and

- a partner's unexpected outside sexual relationship.

Resolving problems in a productive and nonviolent way requires effort and skill. [See Unit 5.]

\section{SEE ACTIVITIES BOOK}

Activity 33

love troubles

Students finish stories about relationships that show signs of

trouble and reflect on what would

make them end a relationship. 


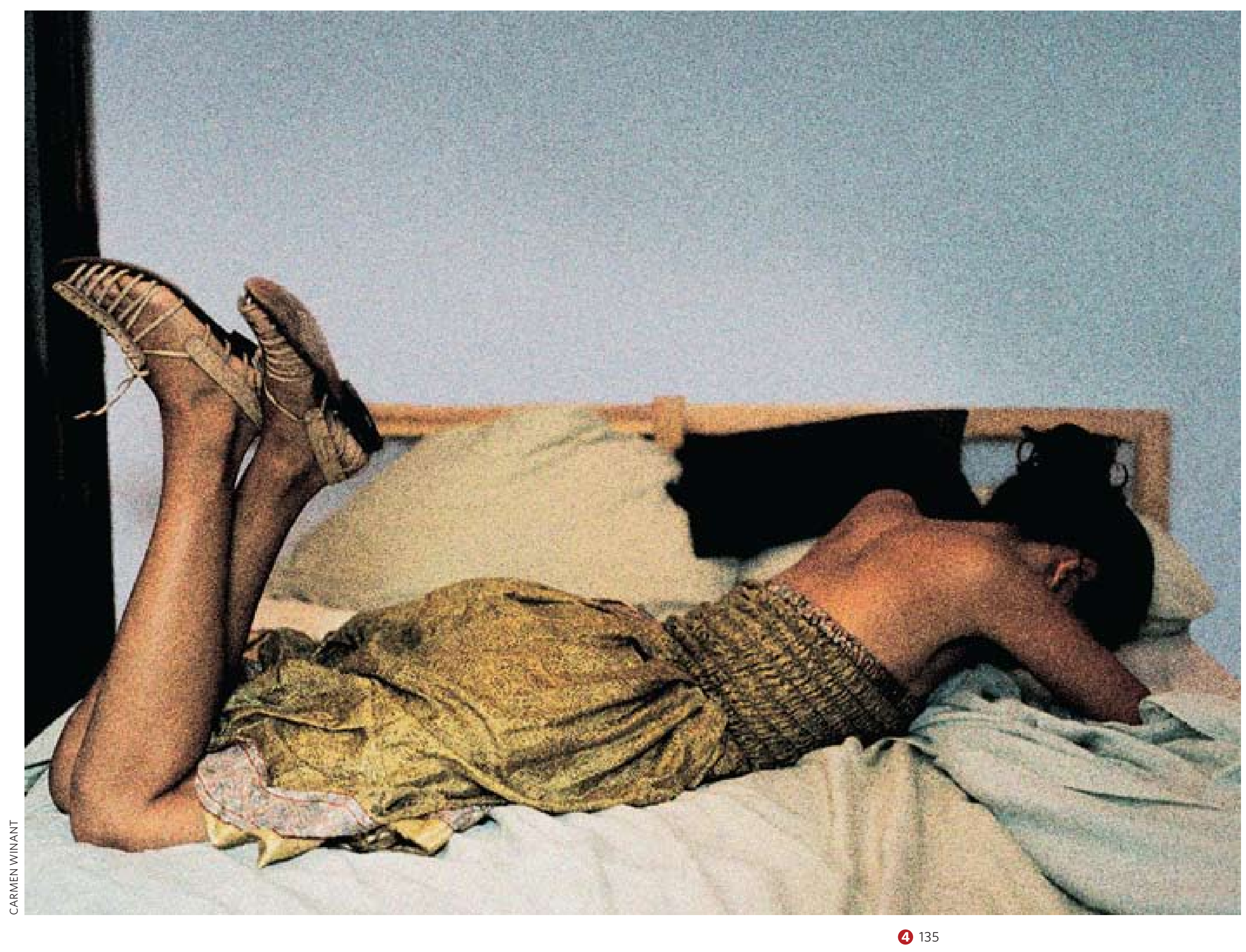




\section{ending a relationship}

1 No one should be forced to enter a relationship, to marry, or to remain in a relationship.

- The end of a relationship is not always mutual. Even for marriage, most countries recognize the right of one partner to end a relationship.

- People should have the right to seek a divorce. People may seek divorce for many reasons. For example, they may be in a marriage in which their rights are being violated. They may have tried hard over a long period of time to clear up serious incompatibilities, but failed.

- The end of a relationship may be associated with strong feelings of sadness, hurt, loneliness, anger, and failure. It may also bring feelings of relief or happiness. 


\section{norms about relationships are changing}

1 Attitudes and norms about interpersonal relationships are constantly changing.

2 We make choices every day about how we relate to other people. Those choices create and recreate the meaning of relationships in our lives.

3 Today, people talk with their friends and family members about what a respectful and safe relationship means to them.

For example:

- Many people talk to family members and friends about nontraditional relationships, such as same-sex relationships or relationships across religion, caste, or race.

- Many young people urge their friends and sisters to avoid older men or "sugar daddies" who offer money or gifts in exchange for sex.

- A respectful and honest conversation can also help people to think about their own biases.

4 Many people take public action to promote safer and more respectful relationships across society.

For example:

- Young people are playing important roles in raising awareness about such issues as date rape and the stigma related to HIV infection.

- Campaigns to improve access to drugs and services for people with HIV are enabling those people to live longer, and giving them hope and confidence to develop and nurture their personal relationships over the long term.

- Many thousands of men have joined campaigns to end violence against women and to build more peaceful and harmonious interpersonal relationships.

[See Unit 8 for more detailed background and guidelines for taking action in one's own life or community.] 


\section{COMMUNICATION}

AND

DECISIONMAKING

SKILLS 


\section{overview}

Knowing how to express yourself so that you are understood, and being able to understand what other people are trying to say, are important and empowering skills. These skills can help you develop relationships that are based on mutual understanding and satisfaction. They can help people resolve conflicts respectfully and without violence.

Some people find that their status in a community influences their ability to express their needs, desires, and feelings to another person. It may also affect their ability to put their decisions into action. Everyone can learn to communicate more effectively.

This unit explores difficulties that young people often experience in communicating and making decisions related to sexuality. It teaches related skills and provides opportunities for strengthening such skills. 


\section{COMMUNICATION AND DECISIONMAKING SKILLS}

Pair students off to learn and practice communication skills; role-playing is also useful and fun.

When teaching communication and decisionmaking skills, be sure to have a number of concrete examples that relate to your students' lives.

Most students need extra skills, practice, and support in learning to communicate their feelings about sex and sexuality without embarrassment. Topics that may be particularly sensitive include: communicating one's HIV status, sharing what feels pleasurable and what does not, or deciding whether and how to communicate one's experience of same-sex attraction.

Modeling communication skills, such as active listening and nonjudgmental responses, is an important part of teaching those skills.

Remember the importance of nonverbal communication. Be aware of your own body language. A person's body can send a message that conflicts with what that person is saying.

Create a safe environment in which all students can communicate openly, including those students who typically hold back in front of others. However, avoid pressuring anyone to communicate about a personal or sensitive topic. 


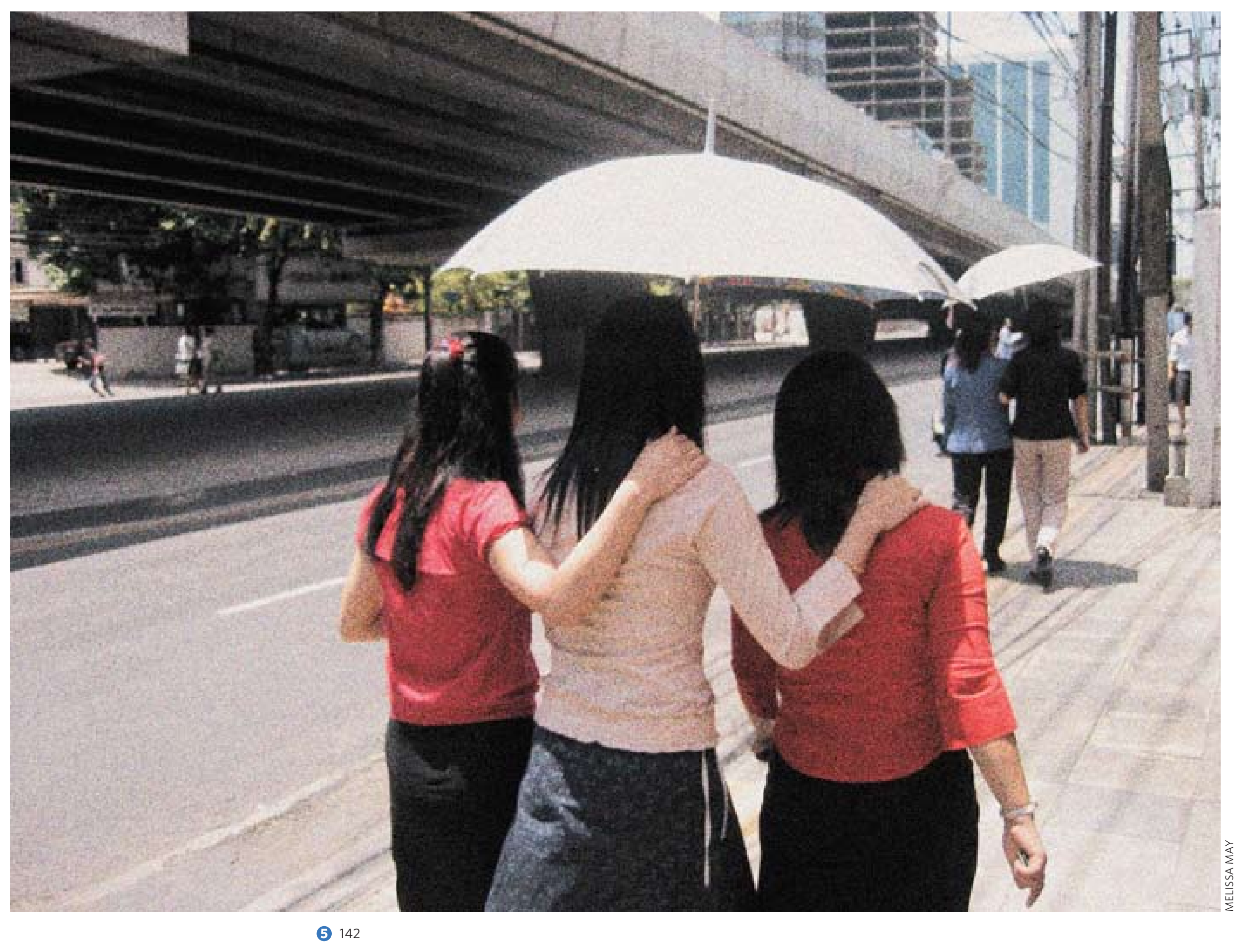




\section{COMMUNICATION AND DECISIONMAKING SKILLS}

The material in this unit prepares learners to:

\section{Cognitive Objectives}

Explain why talking about sexuality or HIV may be difficult.

Identify a common sexual decisionmaking situation that might be uncomfortable for someone who lacks adequate communication or decisionmaking skills.

\section{Affective Objectives}

Appreciate the importance of good communication skills for interpersonal relationships.

Reflect honestly about their own maturity level and comfort in communicating with a partner to ensure that intimate experiences are wanted, safe, respectful, and enjoyable.

Appreciate why it is difficult for many young people to communicate clearly and assertively that they do not want sex.

\section{Skill-based Objectives}

Demonstrate the use of at least three basic communication skills and at least three behaviors that can impede clear communication.

Demonstrate increased ability to communicate clearly in a conversation about whether both partners actually want intimate physical activity.

Demonstrate increased ability to communicate clearly in a conversation about how to protect themselves against infection (including HIV) and unwanted pregnancy.

Demonstrate understanding of basic steps in decisionmaking. 


\section{factors affecting communication}

1 Knowing how to express yourself so that you are understood, and being able to understand what other people are trying to say, are important and empowering skills.

- These skills can help you develop relationships that are based on mutual understanding and satisfaction.

- They can help people resolve conflicts respectfully and without violence.

- These skills can help you feel good about yourself and about your relationships.

2 People have different styles and skills in communicating.

- Different cultures vary in terms of their oral and expressive tradition.

- Communication styles also depend on a person's individual temperament and the communication style that he or she learned as a child.

- Gender norms often affect a person's ability and style of communicating. Men and women may communicate in different ways.

- Strengthening personal communication skills can help people to convey their opinions, needs, and feelings clearly.

- People can develop the ability to communicate effectively and comfortably across cultural and other divides.

\section{POINTS FOR REFLECTION}

In a conversation between a wealthy person and a person from a lower socioeconomic class or caste, who is likely to feel freer to express ideas and feelings? Who is likely to feel freer in a conversation between a man and a woman?

How can we make sure that someone's needs, feelings, and right to communicate are respected without regard to social status?
3 If one person is perceived as having less "social power" or social status than another, this perception may profoundly affect his or her ability and style in communicating.

4 Most people can learn effective communication skills. With practice everyone can communicate more effectively. 


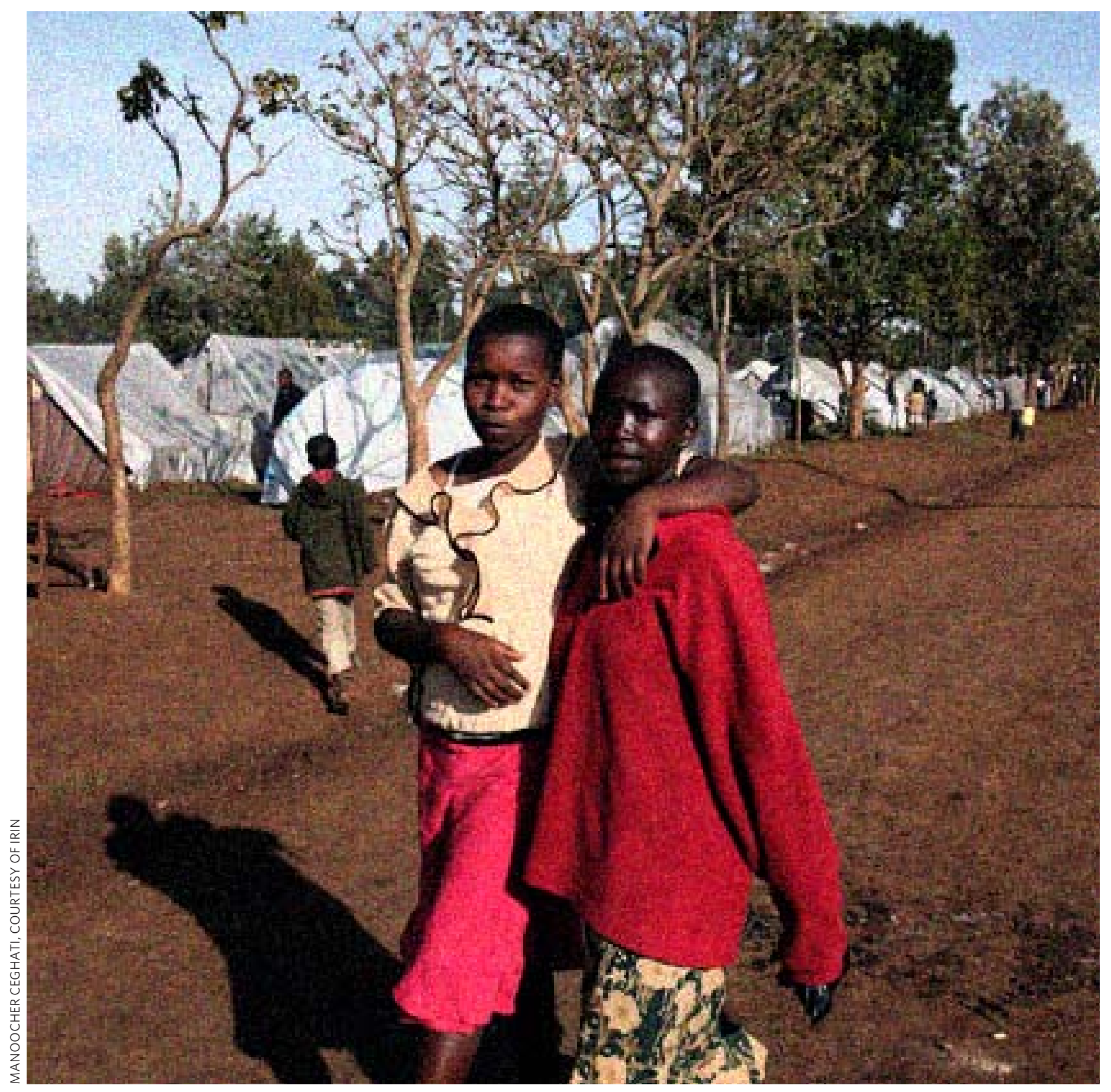

SEE ACTIVITIES BOOK Activity 34

did i say that? different styles of communication

Students examine alternate ways to respond verbally in an uncomfortable situation and discern between aggressive, assertive, and passive communication. 


\section{tips for effective communication}

1 Clear communication occurs when the message the sender intends to convey is the same as the message that the receiver understands.

- People communicate both verbally and nonverbally.

- It is important to check that your message was understood correctly, especially if it involves a difficult or emotional topic.

2 In every situation, one of the most important behaviors for good communication is listening well and with respect. However, cultural norms influence what kind of communication is considered appropriate.

3 Active and nonjudgmental listening can enhance communication.

When you are listening it is helpful to:

- try to understand the other person(s);

- say things that validate the other person, such as "I can understand how you feel," or "Good point";

- make eye contact;

- give positive nonverbal cues, such as a smile, nod, or pat on the back; and

- ask for clarification.

SEE ACTIVITIES BOOK

Activity 35

\section{active listening}

Students demonstrate behaviors that enhance (or impair)

communication. 
4 Specific behaviors can enhance communication when you speak.

Common constructive behaviors include:

- stating one's feelings and starting sentences with "I" rather than with "You";

- acknowledging that all people have a right to their feelings and opinions;

- avoiding being too directive, judgmental, or controlling;

- stating as clearly as you can what you want or what you do not want; and

- helping identify possible solutions to problems.

\section{Many behaviors can impair communication.}

\section{POINTS FOR REFLECTION}

When you are trying to communicate, how does it feel to: Be interrupted or not be heard? Be criticized, called a name, or labeled?

Be judged or made to feel guilty?

Sense that the other person is trying to control the conversation?

Receive negative nonverbal messages, such as being frowned at? 


\section{direct versus indirect communication styles}

1 Some people tend to communicate in a way that is direct and firm. Others tend to communicate in ways that are indirect.

2 Direct and firm communication may be verbal or nonverbal, but generally sends a clear message.

For example:

- A person who communicates assertively expresses his or her feelings or thoughts in a straightforward way.

- A person may use "I statements" that express his or her feelings and thoughts (for example, "I feel bad when you speak that way to me" or "I'm glad that you came with me to the health clinic").

- A person may make eye contact or use other nonverbal messages to communicate directly.

practicing assertive communication

Students review assertive behaviors, discuss cultural implications, and practice using assertive communication in situations where rights are being abused.

\section{SEE ACTIVITIES BOOK} Activity 37

five steps for communicating about a conflict

Students learn and practice a five-step model for communicating about an interpersonal conflict with clarity and respect.
3 Indirect communication may also be verbal or nonverbal, but often sends a less specific or less defined message.

For example:

- A person may avoid specific expressions of their own opinion or feelings (for example, "I heard that you can become pregnant the first time," rather than "I won't have sex if you don't use a condom").

- A person may avoid finishing a sentence or making eye contact.

4 Sometimes knowing the best way to express oneself - directly or indirectly - is difficult.

- A person who communicates indirectly may be following cultural norms about politeness, social status, or expectations about gender roles. Understanding how to assert oneself effectively in one's own culture is important. - Indirect communication may not always be clear to the listener or receiver.

- Sometimes people are in situations in which they do not feel that they are being heard. They may need to practice expressing themselves more clearly, directly, and repeatedly than they are used to doing.

- Communicating directly and firmly is not the same as being aggressive. A person can communicate clearly and directly while still respecting the feelings and thoughts of others. 


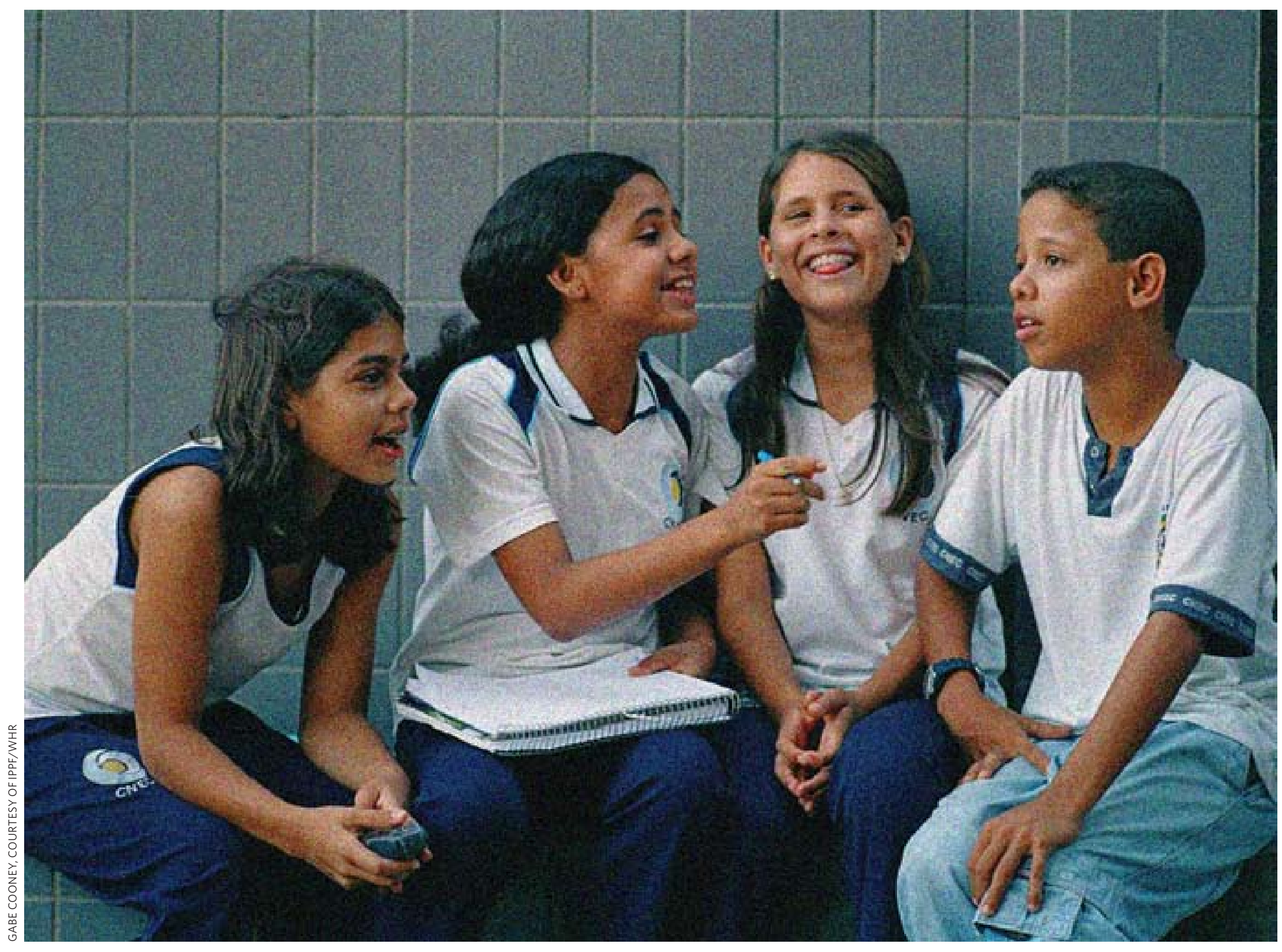




\section{talking to your partner about sex and sexual health issues}

1 Communication is an important part of a sexual relationship.

2 Communication with a sex partner is important for ensuring that both people are consenting to engage in sexual activity.

3 Effective communication can help people protect their own and their partners' well-being.

This protection includes:

- guarding against sexually transmitted infections, including HIV;

- protecting against unwanted pregnancy; and

- reducing the likelihood of a conflict that could lead to violence.

4 Communication can also increase mutual trust and pleasure.

5 Communication is important for clarifying expectations and limits.

Such expectations and limits may relate to:

SEE ACTIVITIES BOOK

- feelings;

- the exchange of money or material goods; or

- other factors.

talking about sex and

sexual health

Through discussion and roleplaying, students practice verbal and nonverbal skills that are

6 Gender norms often affect the way people communicate - or do not communicate - about sex.

7 Everyone can learn to communicate comfortably and effectively about sexuality. Practicing helps! 


\section{making decisions}

An important part of growing up is learning to bring good judgment to making decisions. Certain steps generally help people to make decisions with which they are more satisfied. These steps include:

\section{Step 1: Consider all of the options.}

- For many decisions there are options we have not thought of.

- Other people may be able to help identify more options.

Step 2: Identify the benefits and disadvantages of each option carefully.

- Include every option's potential harm to oneself or another.

- Write down a list of the potential consequences of each option.

Step 3: Where appropriate, seek information or advice from people you trust.

Step 4: Make a tentative decision.

- Consider whether your decision is one that will be easy or hard to change later.

Step 5: Reconsider the decision if necessary.

Try to take as much time as you need to go through all the steps of decisionmaking. We often feel happier with decisions that we have made thoughtfully.

\section{POINTS FOR REFLECTION}

Many decisions related to sex can be complicated. Imagine thinking over these decisions:

whether to have sex;

whether to insist on condom use with a partner who is reluctant to use condoms;

whether to end a relationship;

whether to have sex in order to obtain a gift or money for school fees;

whether to disclose an HIV test result;

whether to continue or end an unintended pregnancy; and

whether to tell one's parents about having romantic or sexual feelings toward someone of the same sex. 


\section{acting on our decisions}

After a decision is made, make a plan for carrying out the decision.

Clarify all the steps necessary for acting on the decision. These steps include:

\section{Step 1: Consider what will make the decision easiest to carry out.}

For example:

- talking to your parents when they are not under pressure;

- finding out about peers who have made and carried out similar decisions (for example, girls who took a stand to continue their schooling, a friend who asked someone out on a date, or people who decided to get an HIV test); and

- finding ways to gather the money or other resources necessary for carrying out the decision.

Step 2: Think about likely barriers to carrying out a decision. This step is important, because some decisions are very difficult to put into action. Examples of potential barriers include:

- not having enough money (for example, for bus fare to a clinic or for schoolbooks);

- not having access to services (for example, hard-to-reach schools and clinics);

- legal limits (such as laws restricting abortion or contraceptive products and services for unmarried adolescents);

- fears about social consequences (for example, of coming out as homosexual, opposing genital mutilation, resisting early marriage, being seen at a family planning clinic, or working at a job that is usually performed by the other sex); and

- worries about personal costs (for example, being rejected by a partner for refusing to have sex or for insisting on condom use, or facing a possible life-changing diagnosis).

\section{Step 3: Rehearse your decision safely or privately.}

\section{For example:}

- write down or practice telling a trusted adult about sexual abuse;

- practice using a (male or female) condom;

- practice with a friend (if you have a friend whose judgment you trust and who you know will respect your privacy); and

- consider whether and how to communicate your decision respectfully to anyone else whom it will affect. 
Step 4: Discuss the decision and plan with a supportive person.

For example, you could:

- talk with a counselor about ending a pregnancy;

- talk with a person who has already obtained an HIV test; or

- find a hotline, drop-in center, or online community where people can talk with someone who is thinking about changing gender.

Step 5: Figure out how to carry out your decision in the safest way.

For example, you could:

- bring someone with you to confront a violent partner; or

- find an ally in the community leadership before starting a campaign for sex education.

Step 6: Where appropriate, seek information or advice from people you trust.

Step 7: If barriers arise in carrying out a decision, develop a different plan of action or rethink the decision.

Step 8: Be aware that even when people do not encounter a barrier, they have the right to re-evaluate decisions and change their minds.

\section{SEE ACTIVITIES BOOK}

Activity 39

carrying out difficult

decisions

Students learn basic steps for implementing a decision and create comic strips that depict a person implementing a difficult decision. 


\section{THE BODY,}

PUBERTY, AND

REPRODUCTION 


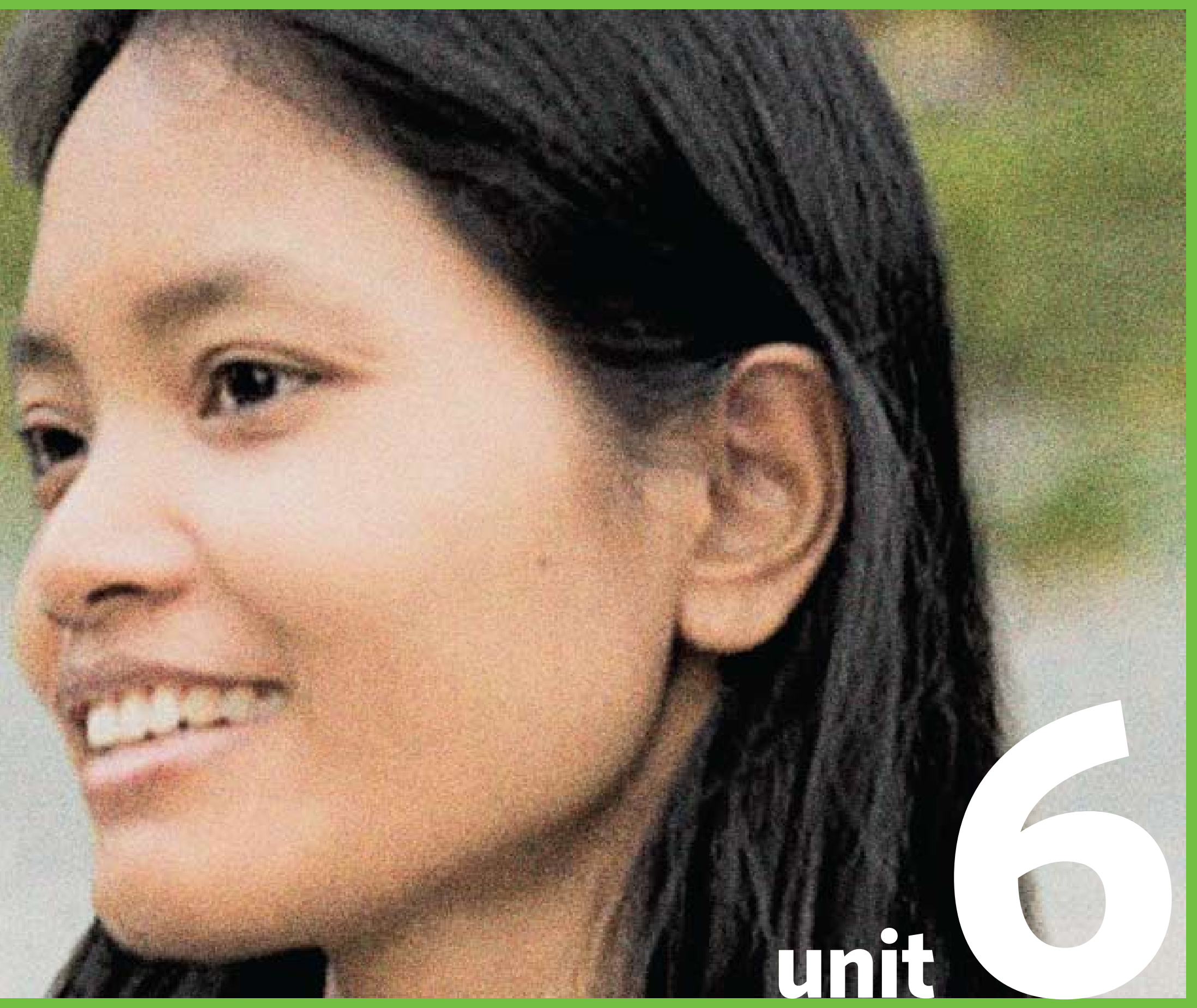




\section{overview}

The human body is beautiful in all its forms. Young people deserve to grow up with a sense of familiarity and confidence about their own bodies. Such familiarity and confidence also enable them to take better care of their own sexual health. In addition, young people need good nutrition, exercise, information, and health services to keep their bodies well.

\section{This unit explains these keys to good health for young people and some barriers they may face in taking care of their bodies.}




\section{THE BODY, PUBERTY, AND REPRODUCTION}

When discussing such topics as puberty, body types, and the reproductive system, keep in mind that young people are often sensitive about whether they are "normal." Focus on the wide range of what is natural and avoid using such words as "abnormal" and "unnatural."

Using the technical terms for body parts will help your students feel more comfortable.

Keep in mind that your students' sexual behavior is greatly influenced by social factors such as their attitudes about gender issues. Many teachers are more accustomed to presenting technical information. However, resources such as fact sheets can convey such information efficiently, allowing teachers to use their limited time to focus on topics that require thinking and dialogue.

A number of the fact sheets at the end of this volume provide additional details on the topics covered in this unit. 


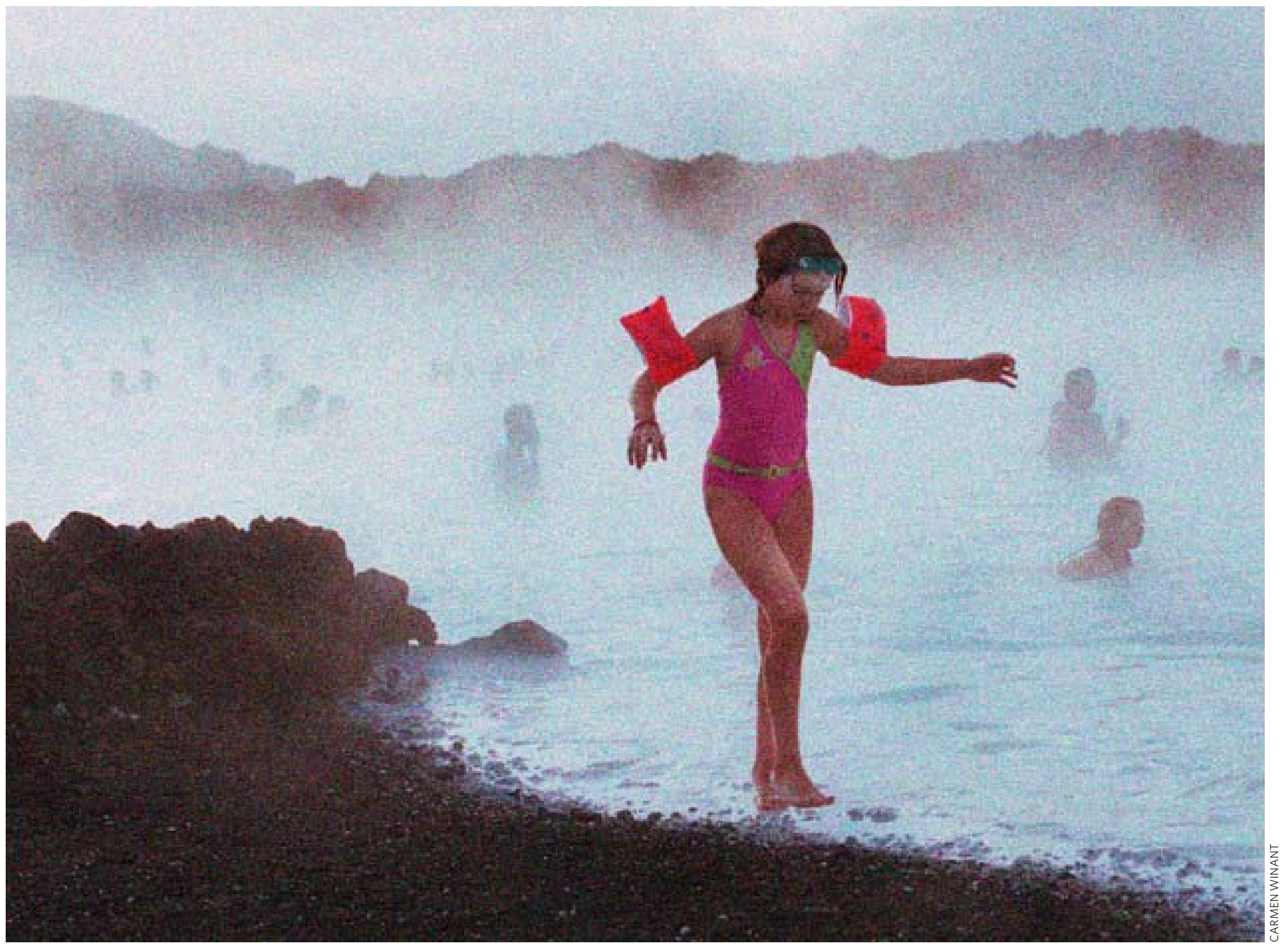




\section{THE BODY, PUBERTY, AND REPRODUCTION}

The material in this unit prepares learners to:

\section{Cognitive Objectives}

Discuss at least two physical changes, and two cultural or social changes that young people experience at puberty and how these vary for girls and for boys.

List at least two ways that knowing about their bodies can promote sexual health and well-being.

Describe the male and female sexual and reproductive systems and how fertilization and reproduction occur.

Explain the roles of males and females in infertility.

\section{Affective Objectives}

Discuss (or write about) how gender norms affect body image.

Identify something about their own bodies that they feel positive about.

Identify and discuss (or write about) at least one concern or fear about being able to protect their sexual health. 


\section{body image}

1 People's bodies differ in appearance. There is no "perfect" or "normal" body type or appearance, despite cultural and media messages to the contrary.

\section{Learning to be comfortable with one's own body - having a positive body} image - is an important element of self-esteem.

- Experimenting with one's appearance can be fun and creative; it can be one way to explore one's identity.

- People's body image affects their degree of comfort with social life, with physical activity, and with sexuality.

- Developing this comfort can be a particular challenge for those living in communities that stigmatize physical disabilities.

\section{POINTS FOR REFLECTION}

Various factors can undermine our confidence about our bodies or our appearance. For example, consider the following questions:

How realistic and flexible are the messages and images we receive from the media about what kinds of bodies are attractive, desirable, and acceptable? What about messages we receive from advertising? From our community? From our families and friends? How does it feel to cope with pressure to meet cultural ideals about the body or about our appearance? Is coping with such pressure easier or harder during adolescence?

How does it feel to be teased about our bodies or ridiculed about our appearance?

\section{Social and individual factors affect people's confidence about their bodies.}

Such factors include:

- knowing about one's own body;

- understanding that one's body is one's "own";

- internalizing social norms that celebrate or stigmatize bodies' different appearances and abilities;

- understanding that "ideal" appearances vary across cultures and time;

- receiving positive or negative feedback about one's body, regardless of how closely it resembles or diverges from the cultural ideal;

- being physically active and maintaining good health;

- understanding one's physical desires, including avoiding sexual relationships that are unwanted, uncomfortable, disrespectful, coercive, or violent; and

- having laws and support systems in place that enable people with disabilities to live full lives, whether independently or aided by respectful assistance. 


\section{Girls and women often feel intense social pressure related to their physical}

appearance.

- Girls' and women's social status often depends significantly on their appearance.

- Cultural practices (from beauty contests to genital mutilation) reinforce the pressure on young women to achieve cultural ideals of beauty.

- Girls and women are often subject to sexual comments and harassment that can be upsetting, uncomfortable, and threatening.

- Women, and especially girls, are more vulnerable than boys to negative feelings about their bodies; such feelings can lead to eating disorders.

- Some girls who have a poor body image (or low self-esteem in general) feel that they must agree to have sex in order to gain love and approval.

\section{Men and boys also may feel anxious about their appearance.}

- They may feel pressure to be physically strong or athletic in order to be seen as masculine.

- Boys and men are also subject to sexual comments and harassment.

- Some boys develop eating disorders.

- Boys often find that acknowledging or seeking support for these concerns is less acceptable socially for them than it is for girls. 
6 Nearly all people with a physical disability or chronic illness can still experience all aspects of their life, including their sexuality. Oftentimes, however, they suffer discrimination and physical and social isolation because of their physical or health status.

- This stigma undermines people's confidence in their bodies and their ability to have full social (and sexual) lives.

- Such discrimination or stigma also affects people's ability to obtain housing, work, and access to public spaces.

- Around the world, people with disabilities (as well as people living with HIV and AIDS) have organized to eliminate such stigma and discrimination, and to expand their ability to attain satisfying sex lives and participate fully in society.

7 With encouragement, all young people can be comfortable with their physical appearance. They can also develop other sources of self-esteem and self-worth. For example, they can focus on academic achievement, creative talents, and other traits.

\section{SEE ACTIVITIES BOOK}

Activity 40

what you see in me

Students discuss pressures related

to appearance. They write about

physical characteristics that they

like in themselves and hear about

nonphysical characteristics that

others admire in them. 


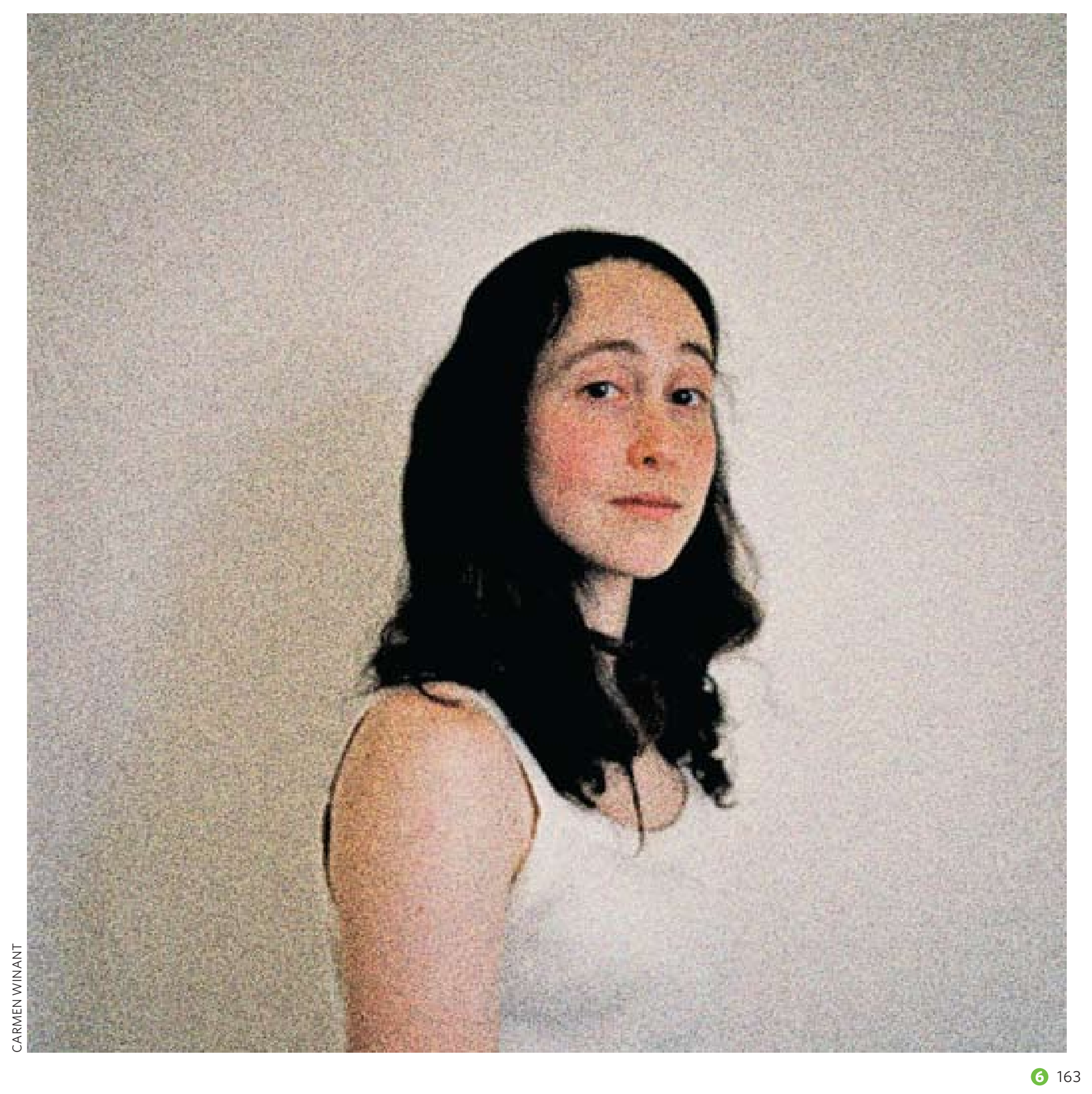




\section{puberty}

See fact sheets on Puberty and

Boys and Puberty and Girls.
1 As children approach adolescence, their bodies begin to produce chemicals called hormones - that lead to changes in their bodies and emotions. This time of change is called puberty.

2 Puberty occurs early for some people and later for others.

- Age of puberty is influenced by genes, nutrition, physical activity, and illness.

- Girls typically reach puberty at an earlier age than boys do.

\section{At puberty, sexual and reproductive organs begin to mature.}

- For girls, physical changes associated with puberty include beginning menstruation, the development of breasts, growth of underarm and pubic hair, and other physical changes.

- For boys, puberty includes the initiation of involuntary orgasm during sleep (called nocturnal emission or wet dream); production of sperm; the growth of facial, pubic, and body hair; deepening of the voice; and other physical changes. 


\section{Puberty can be both confusing and exciting.}

- Both the physical and social aspects of puberty bring changes in the way young people feel about themselves and about other people.

- Many adolescents become curious about sex and may explore their sexuality by themselves, with a friend, or with a sexual or romantic partner.

\section{As young people reach puberty and begin to develop sexually, they find that} people they know — and the society at large — relate differently to them.

- For those reaching puberty, some cultures practice coming-of-age rituals. Most such rituals are celebrations of growing up. Some, however, may be harmful. [See fact sheet on Female Genital Mutilation.]

- Families and communities often expect adolescents to assume greater responsibilities and sometimes allow them greater freedom.

- Often, families and communities exert great pressure on adolescents to conform to expected gender roles. 
6 Gender roles often sharpen dramatically around puberty. This change is often marked by a growing gap in boys' and girls' equality and opportunities.

[See Unit 2.]

For example:

- Boys are pressured to be brave and strong.

- Boys may experience disapproval if they express certain emotions, such as vulnerability or tenderness.

- Boys are often pressured to become sexually active to prove their heterosexuality. In contrast, in most settings girls who are sexually active meet with social disapproval. [See Unit 3, pages 90-91.]

\section{SEE ACTIVITIES BOOK}

Activity 41

\section{body changes}

Students create books and songs that explain the physical changes of puberty.

\section{SEE ACTIVITIES BOOK}

\section{Activity 42}

\section{puberty: what else to expect}

Students analyze social changes that boys and girls experience during adolescence.
- In some settings, girls find that their freedom is seriously restricted at puberty. Their schooling may end, their style of dressing may be limited, their behavior may be constrained, and they may be assigned additional household duties.

- Girls, in particular, are subject to sexual advances, both well-meaning and harassing.

- For girls in some settings, reaching puberty signals that they are of an age to be married.

- Both boys and girls may experience pressure or stigma related to their sexual or gender identity.

7 Puberty is a time of rapid physical growth, so taking care of one's body is especially important. Young people often face particular health issues at adolescence, including the need for safe physical exercise and proper nutrition. They may also face risks related to the use of drugs or alcohol.

[See fact sheet on Nutrition, Healthy Physical Activity, and Substance Abuse.] 


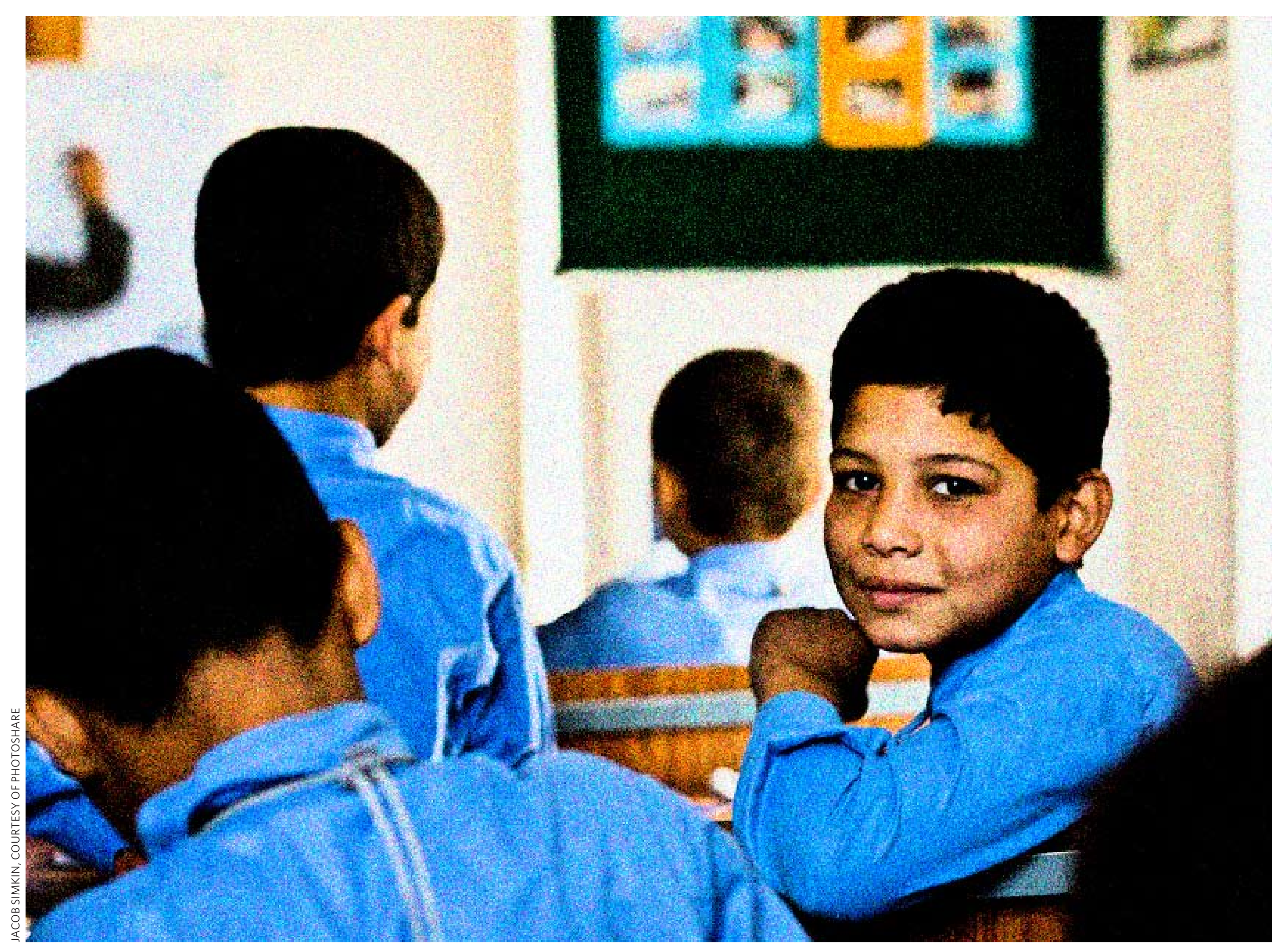




\section{knowing about one's body}

Information and services should ... help [adolescents] understand their sexuality and protect them from unwanted pregnancies, STIs, and subsequent risk of infertility. This should be combined with the education of young men to respect women's self-determination and to share responsibility ... in matters of sexuality and reproduction (Paragraph 7.41, ICPD Programme of Action, 1994).

1 Learning about your body can be exciting and empowering.

2 Knowing about your body has many benefits for your sexual health and well-being.

For example:

- feeling that your body is your own, feeling comfortable with your body;

- for girls, being able to anticipate and manage menstruation;

- being able to figure out what feels good sexually;

- being able to communicate feelings and thoughts about sex and reproduction;

- being able to prevent an unwanted pregnancy;

- being able to recognize the symptoms of certain infections; and

- being able to protect your right to dignity and respect.

\section{SEE ACTIVITIES BOOK}

\section{Activity 43}

fun facts about the body

Through a crossword puzzle and an exercise, students review and learn "fascinating facts" about the body and reproduction. 
3 Society often sends inaccurate, harmful messages about the sexual body to young people; these attitudes may retain their power to hurt into adulthood.

4 Many young people decide by themselves to learn about the body and to share what they learn with their peers.

5 Around the world, young people and adults are working to promote more accurate and positive messages about sexuality and the body. 


\section{sexual and reproductive organs}

See fact sheets on Sexual and Reproductive Systems and unit 3, page 98.
1 Some organs are involved primarily in reproduction, in sexual pleasure, or both.

For example, in males:

- The penis is involved in both sexual pleasure and in reproduction.

- The testicles are essential organs in reproduction and are also involved in sexual pleasure.

In females:

- The uterus is involved only in reproduction.

- The clitoris is the only organ for which the sole purpose is sexual pleasure.

\section{Some other organs also play roles in sex and reproduction.}

For example:

- The skin may respond sexually to touch.

- The brain processes emotions and secretes hormones that affect feelings and sexual and reproductive function.

3 Community standards about sexuality and gender often shape attitudes about parts of the body and may lead to myths.

In some settings, for example, people may not know that:

- sex involves more than just the sexual organs and is about far more than orgasm;

- a torn hymen (the thin membrane of skin just inside the vaginal opening) is not an indication that the girl is no longer a virgin. The hymen may tear as a result of physical activity during childhood;

- the vagina is naturally self-cleansing; "douching" or washing inside the vagina is unnecessary and often harmful; or

- in many settings, penis size appears to be a greater concern among males than among their female partners.

\section{Some people who want to change their gender and sex may use hormones and/or} undergo surgery to alter their sexual organs permanently.

- Such procedures are complicated and costly, but to those who seek it the change is of vital importance.

- Adults who want to change sex should have access to counseling to help make this decision and should be free to decide whether to do so. 


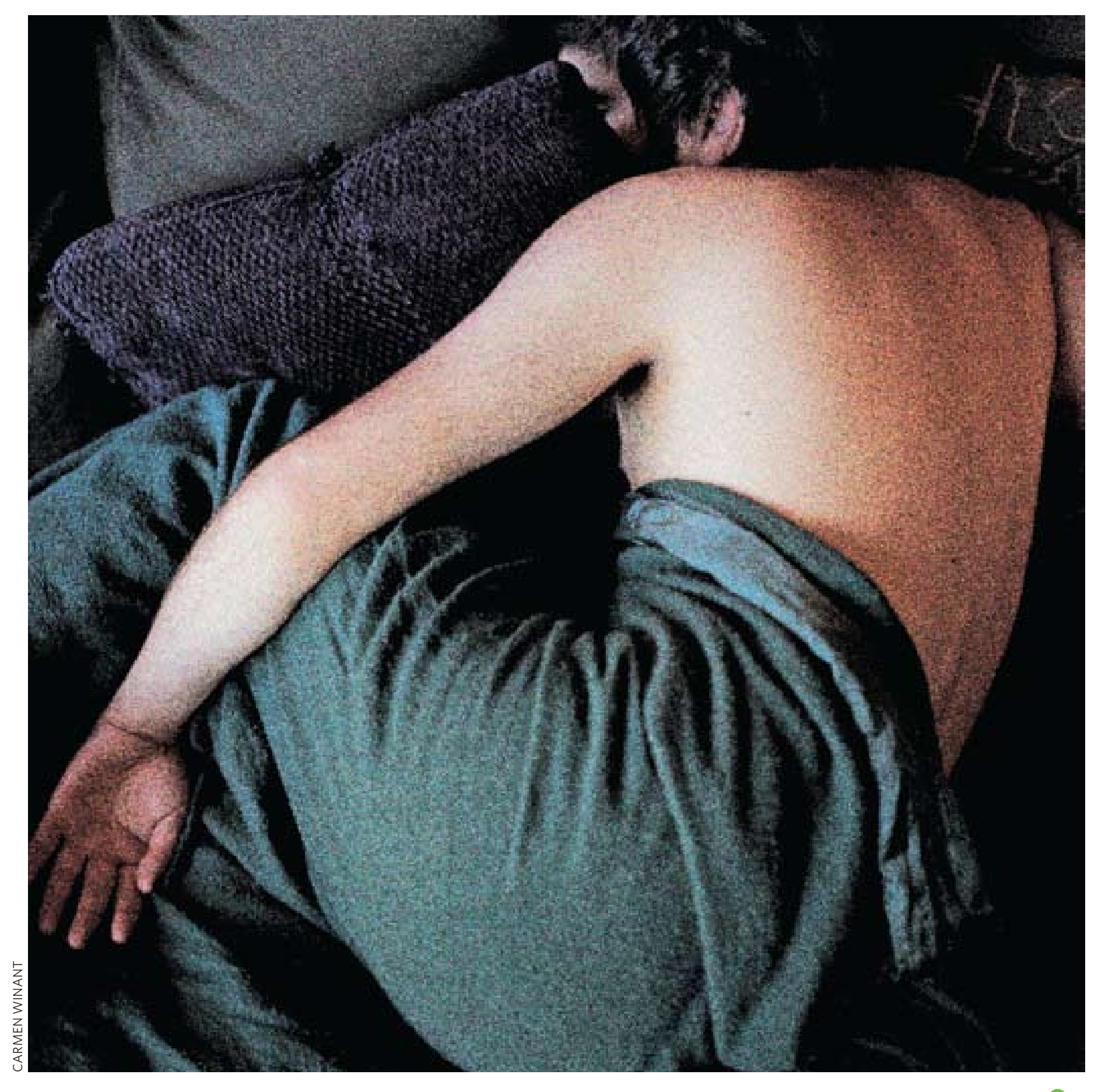




\section{fertility and reproduction ("where babies come from")}

1 A woman or a couple may choose to have children or not. This choice is a basic right.

[For information on preventing or ending unwanted pregnancy, see Unit 7, Part 2.]

2 Biologically, female fertility is the ability to become pregnant and carry a pregnancy to birth. Male fertility is the ability to provide healthy sperm capable of starting a healthy pregnancy.

- A woman's fertility varies over the course of her ovulatory-menstrual cycle [see fact sheet on the Menstrual Cycle]. A man's fertility does not vary on a cyclical basis.

- Both men and women can be infertile or have low fertility. Infertility has many causes, including sexually transmitted infections, illnesses, environmental toxins, and genetic or physical factors. Some of these are preventable.

- Fertility declines naturally with age in both women and men, although this decline takes place earlier in women. [See fact sheets on Infertility and on the Menstrual Cycle.]

\section{Many steps lead to pregnancy.}

[See fact sheet on Reproduction and Pregnancy.]

- Starting at puberty, girls begin to ovulate; that is, they generally release a mature egg with each ovulatorymenstrual cycle.

- Starting at puberty, boys continually produce millions of tiny cells called sperm.

- When a sperm joins with an egg (fertilization), an embryo may be formed. The sex of the embryo is determined by the man's sperm, not by the woman's egg.

- A pregnancy results if the embryo attaches to (is implanted in) the lining of the uterus. It is this embryo that will develop into a fetus if the pregnancy continues. 


\section{Most commonly, a pregnancy occurs through heterosexual intercourse, during}

which the penis enters the vagina and the male ejaculates, releasing sperm.

• People use various names for sexual intercourse, including, for example, "making love" or "having sex." (These terms are also sometimes used for other sexual behaviors.)

- For a viable pregnancy to occur, the following conditions are necessary:

- The female must be near the time in her menstrual cycle when she releases a mature egg from her ovary into her fallopian tube (the process is called ovulation). [Also see Unit 7, page 212.]

- The male must have an erection and must ejaculate inside, or at the opening of, the female's vagina.

- Many sperm must travel up to the fallopian tube, where a single sperm must join with the egg (fertilization), and the fertilized egg must travel down to the female uterus, and become attached to (implanted in) the uterine wall.

- Pregnancy may occur whether or not the woman has an orgasm.

\section{Pregnancy may occur by means other than vaginal intercourse.}

- People who have difficulty conceiving, do not have a sexual partner, or have a same-sex partner, may seek other means of achieving pregnancy.

- Various medical means exist to join an egg and sperm [see fact sheet on Infertility and Assisted Reproduction].

6 Depending on region or country, only 40 to 70 percent of pregnancies result in a live birth. The remaining 30 to 60 percent of pregnancies end in induced or spontaneous abortion or stillbirth. 


\section{when pregnancy continues}

1 Every day, many thousands of women and girls make a choice about continuing or ending their pregnancies.

[See Unit 7, pages 214-217.]

2 For those who continue their pregnancies, pregnancy and childbirth usually take place without major problems. In some cases, however, pregnancy and childbirth may have serious complications, including the mother's or infant's death.

[See the fact sheets on Reproduction and Pregnancy and on Childbirth and Breastfeeding for information about promoting healthy outcomes for mothers and for reducing babies' risks of acquiring HIV and other serious problems.]

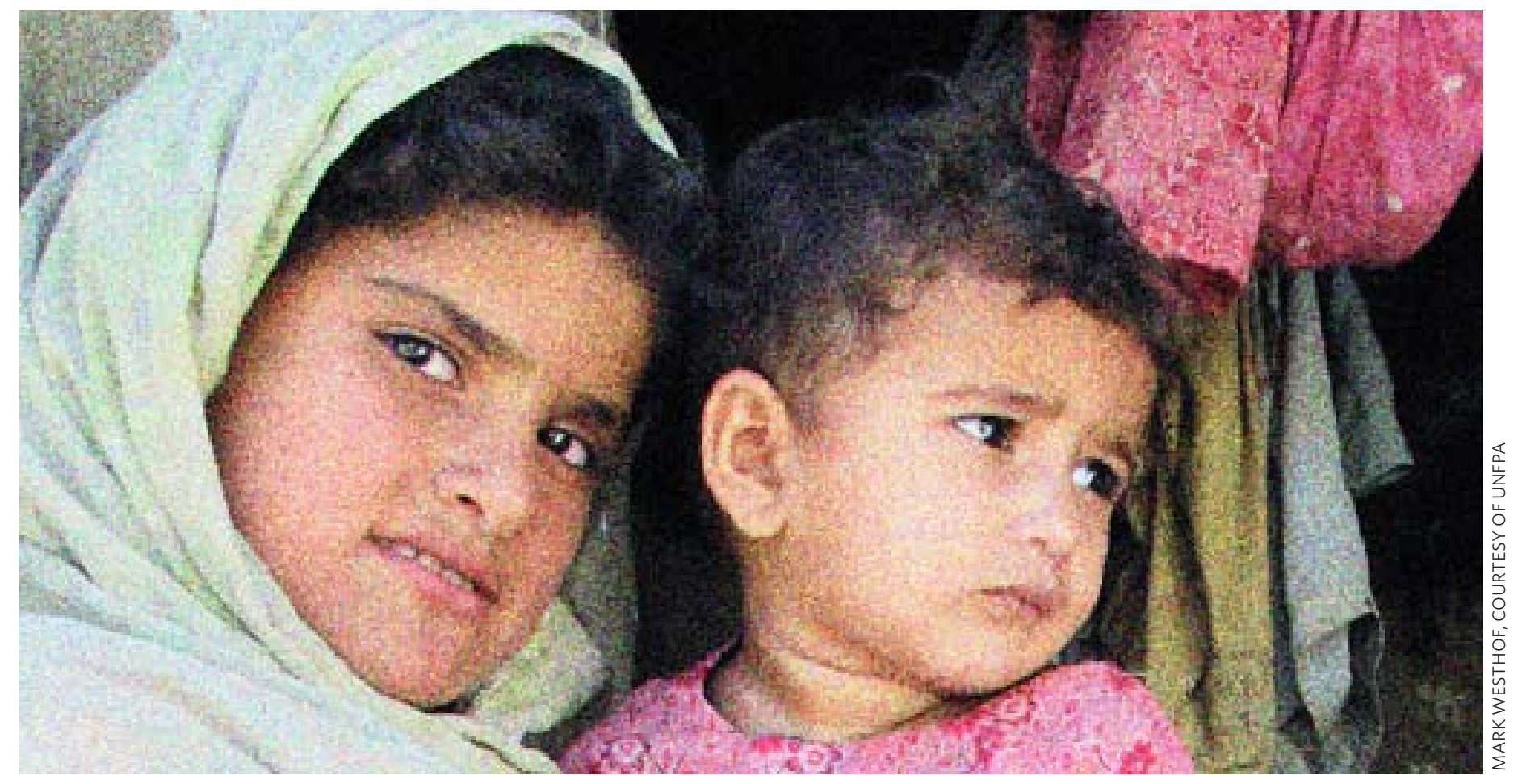

(6) 174 
- Access to adequate health care during pregnancy and childbirth is a basic right, but is often not available.

- Many girls and women suffer acute or long-lasting harm or disability during pregnancy and delivery. This situation is especially likely if they are undernourished, give birth in early adolescence, or if they lack access to emergency obstetric care. One serious problem is that the mother's pelvis may not be large enough to allow the baby to pass through. Without immediate access to surgery, her vaginal tissue can tear open into other parts of her body and cause permanent leakage of urine or feces. This tear is called an obstetric fistula. Fistula can be repaired but surgery for this condition is not widely available. [See fact sheet on Childbirth and Breastfeeding.]

- Worldwide, the lack of access to adequate medical care contributes to more than half a million pregnancy-related deaths among women and girls every year — that is, one death every minute.

\section{Even in settings with greater resources, some practices related to pregnancy} and birth can cause unnecessary harm to the mother and/or newborn. Women's health advocates and many medical professionals have expressed concern about a number of these practices.

Some of the practices that have come under particular scrutiny include:

- unnecessary cesarean-section surgery;

- overuse of painkillers and other drugs during pregnancy;

- preference for infant formula rather than breastmilk; and

- routine separation of newborns from their mothers. 


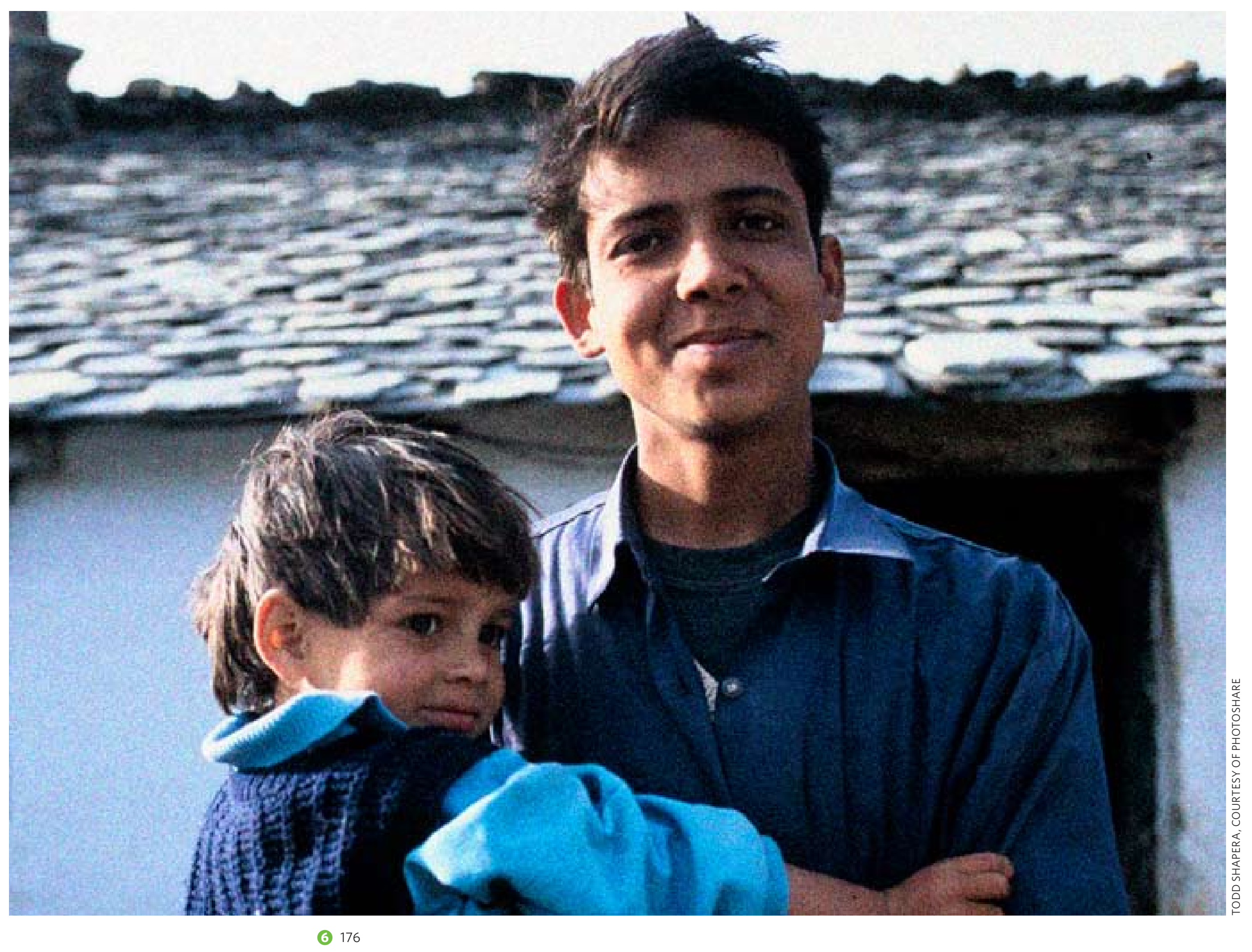


- In many settings, a woman's status may depend in part on bearing children. Particularly where women are achieving opportunities in other areas of life, however, women may feel less pressure to have children.

- Some people believe that pregnancy and childbirth should occur only within the socially sanctioned relationship of marriage. Increasingly around the world many others believe that children can grow up happy and healthy regardless of the form their families take.

- In an increasing number of settings, men are taking a more active role during pregnancy and childbirth. They are encouraging and attending prenatal visits, attending birth classes, being present at the birth, and, importantly, actively participating in infant and child care.

\section{Although not all couples choose to have children, those who want to do so but are infertile (unable to have children) may suffer great disappointment or stigma.}

- Among infertile couples, the woman is frequently "blamed," even though the source of the problem is just as likely to rest with the man.

- If a couple is unable to conceive, in some settings men may seek another wife (or the man's family may seek one for him).

\section{People who have difficulty becoming pregnant can take various steps.}

For instance:

- Women can learn to identify if and when they are ovulating (the fertile time of the cycle; see fact sheet on the Menstrual Cycle).

- Techniques for assisted reproduction are available. Such procedures may be complicated, however, and are costly and not always effective. [Also see fact sheet on Infertility and Assisted Reproduction.]

- Many infertile couples adopt children, as do some people who are fertile.

\section{SEE ACTIVITIES BOOK}

Activity 44

reproduction: more than

a private matter

Students learn about 15

contemporary issues related

to reproduction (from teen

fatherhood to sex selection). They write factual summaries and

personal responses.

\section{SEE ACTIVITIES BOOK}

Activity 45

every minute of every hour:

stories of pregnancy-related death

Students read case studies of maternal death. Through skits and discussion, they explore how these deaths could have been prevented. 


\section{learning about one's body: a global movement}

1 Around the world, people, particularly women and girls, have taken steps to teach themselves and each other about their bodies, including their sexual and reproductive systems and health.

2 In virtually every country, formal or informal groups have formed that offer selfhelp workshops, theater and radio programs, and informational materials about the body.

3 Many groups that begin with a focus on helping people learn about their bodies also advocate for broader social changes.

For example, they work for:

- better sex education in schools and communities;

- an end to cultural practices that are harmful;

- more accessible and more respectful sexual and reproductive health services;

- more effective prevention and treatment of reproductive cancers [see fact sheet on Cancers of the Reproductive System];

- laws protecting sexual and reproductive rights; and

- new community norms that foster men's and women's joint responsibility for sexual and reproductive health. 


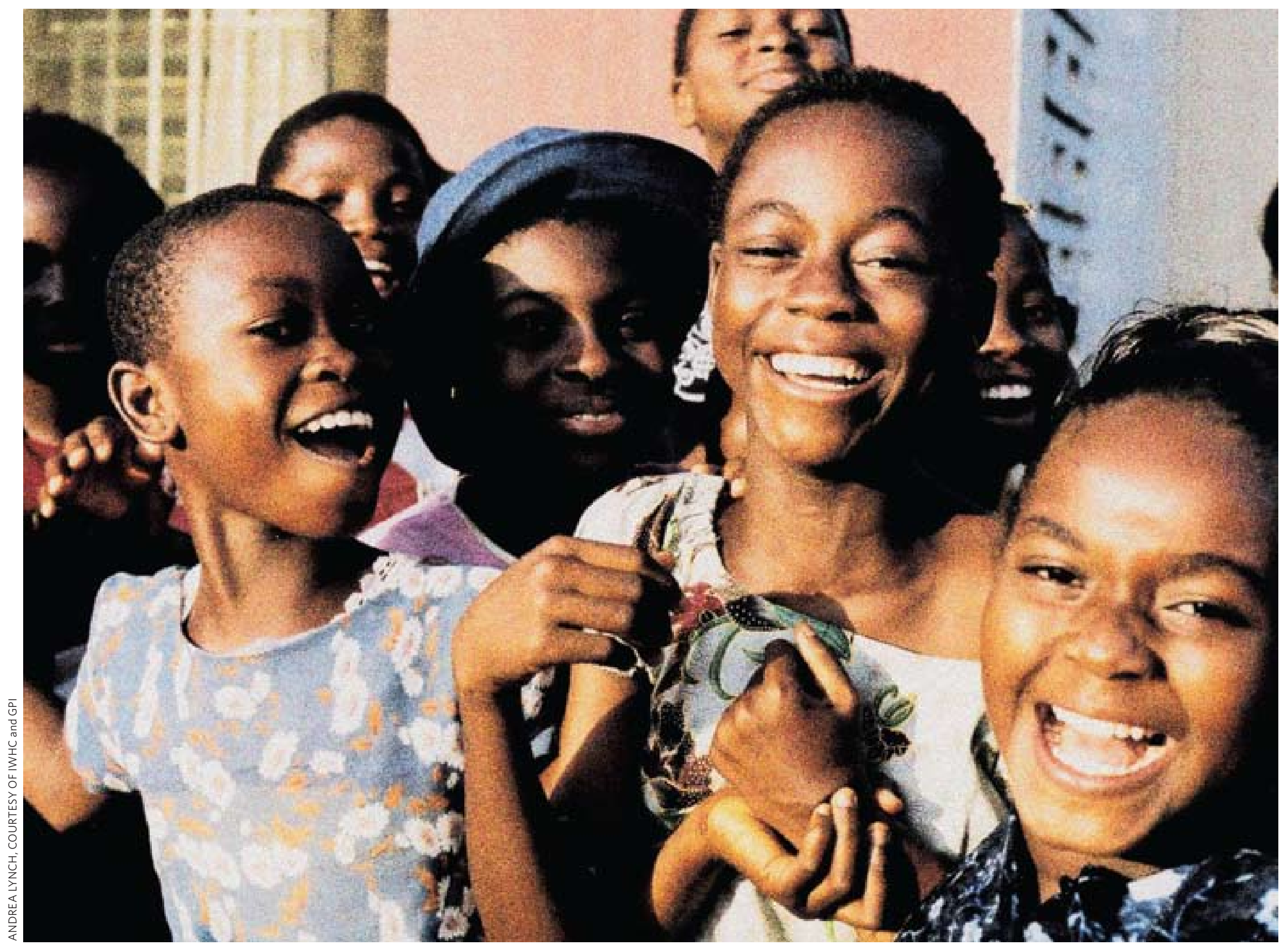




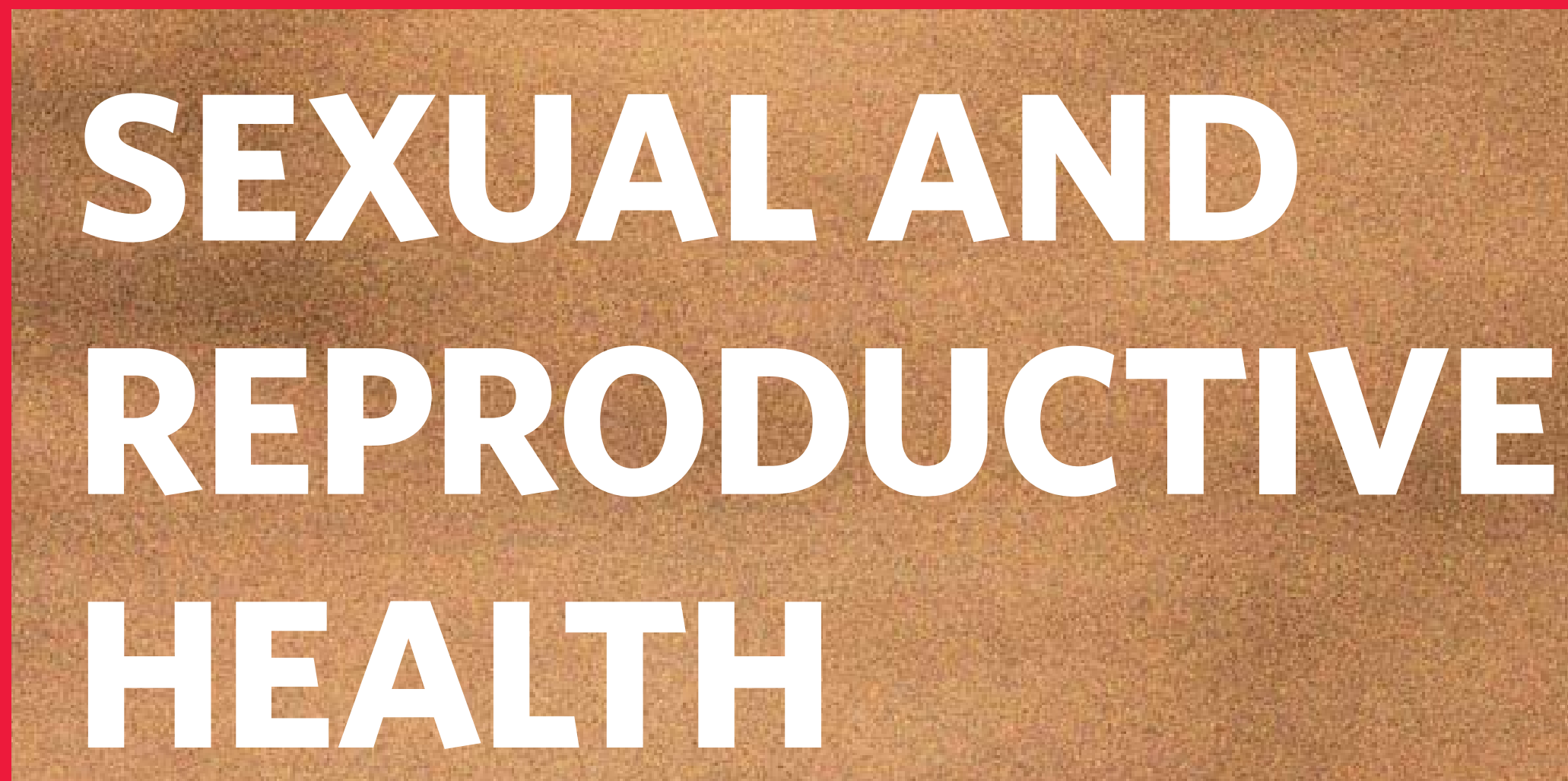




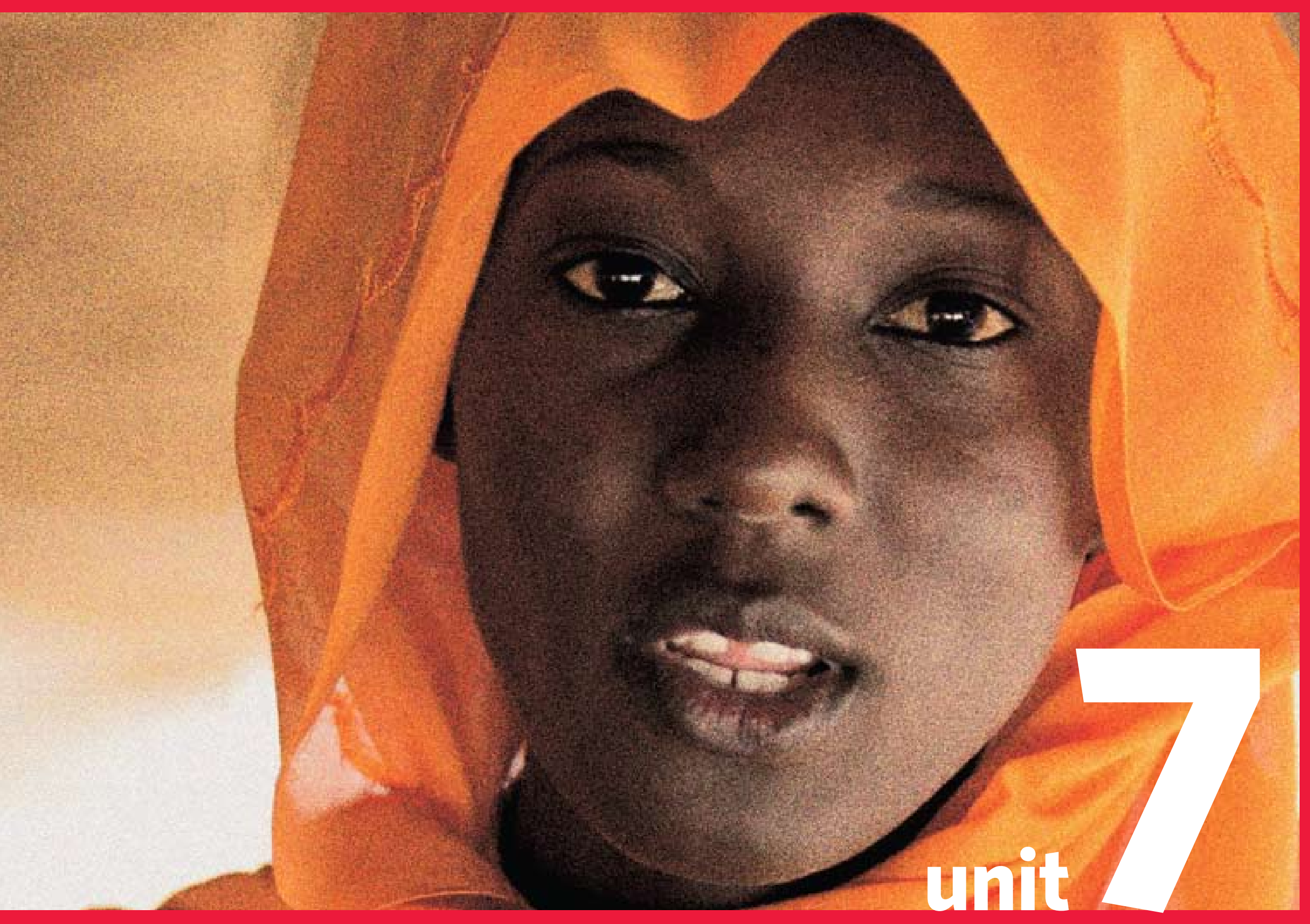




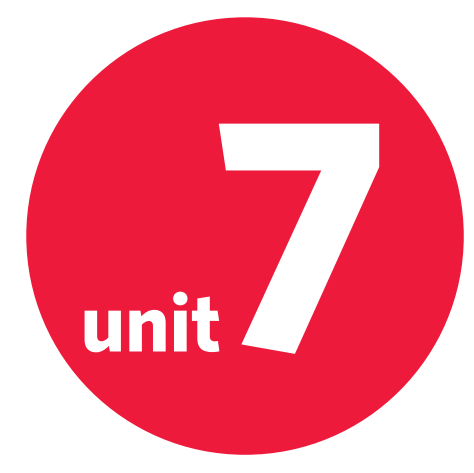

\section{overview}

Sexuality and reproduction can be sources of deep satisfaction, pleasure, and fulfillment in people's lives. Sex may also lead to health problems, however, if both partners do not ensure that they protect themselves, and each other, from unintended pregnancy and infection, including HIV. One key step to improving people's sexual and reproductive well-being is ensuring that they have access to information and services. Another step is to create more just social conditions - including gender equality and respect for people's rights - that enable all people to control the circumstances under which they have sex.

This unit provides vital information to help young people keep their bodies safe and well. 


\section{SEXUAL AND REPRODUCTIVE HEALTH}

This unit covers the final "content" topic in It's All One Curriculum. (Unit 8 is a project-based module for developing and practicing citizenship skills.) Sexual and reproductive health appears last because individual sexual and reproductive health outcomes are often a result of the social and personal factors addressed in the previous units.

In developing curricula or in teaching this material, educators can rely on the accompanying fact sheets in this resource kit. Scientific knowledge and important information in the area of sexual health change continually, however. Therefore, seeking updated and locally relevant information from reliable sources is essential.

Teaching about HIV and AIDS requires great sensitivity, particularly in settings with a high prevalence of the infection.

Try to avoid words like "natural" or "normal" to describe aspects of sexuality that are, in reality, nothing more than cultural conventions or norms that we have adopted.

A number of the fact sheets at the end of this volume provide additional detail on the topics in this unit. 


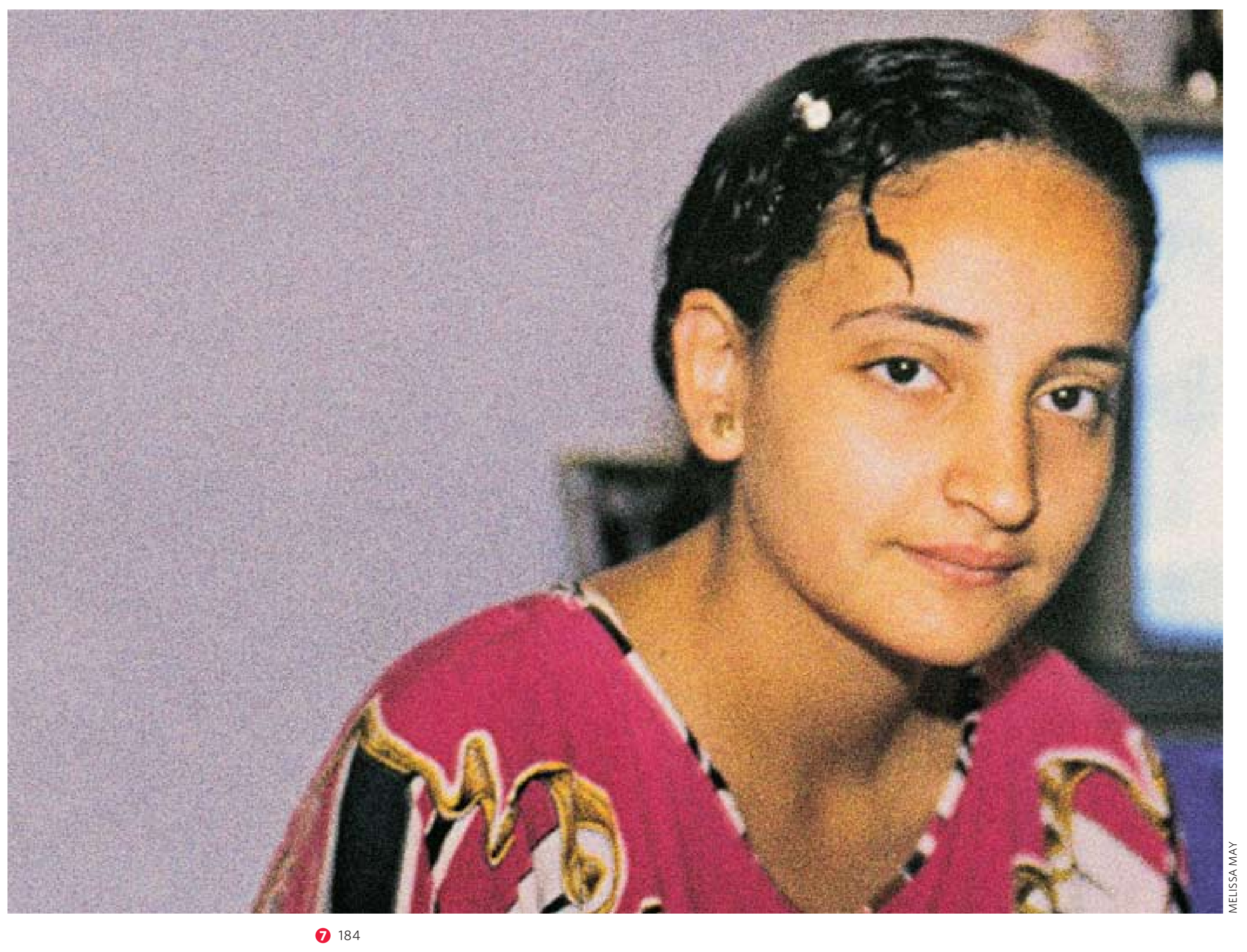




\section{SEXUAL AND REPRODUCTIVE HEALTH}

The material in this unit prepares learners to:

\section{Cognitive Objectives}

Discuss key issues regarding access to sexual and reproductive health services (including for pregnancy and childbirth) in their setting.

Discuss the rights of all people to protect themselves against STIs and HIV.

Explain the asymptomatic nature, and consequences for fertility, of chlamydia and gonorrhea among females.

Name key facts about transmission, diagnosis, consequences, and treatment for HIV and AIDS.

Discuss consequences of HIV and AIDS for families, communities, and countries, and the rights of people living with HIV and AIDS.

Name the primary reasons why people may not use contraceptives even if they do not want a pregnancy. Discuss characteristics of at least three contraceptive methods, including their effect on STls.

Describe at least six personal situations in which a woman might decide to end a pregnancy. Explain why maternal mortality, including from abortion, is largely preventable.

\section{Affective Objectives}

Recognize the role of gender inequality in transmission of STIs and HIV or unwanted pregnancy.

Reflect on their feelings about people's hesitations, and their responsibility, to disclose their STI and HIV status to their sex partners.

Reflect on their feelings about contraceptive and condom use, including how it can affect their sexual relationship (positively or negatively), and about barriers to use that they have experienced or think they might experience.

Explore and discuss their feelings about abortion being safe and legal.

\section{Skill-based Objectives}

Demonstrate knowledge about proper condom use. 


\section{the right to health services}

All people have the right to health care and necessary social services (Article 25, UDHR, 1948; Article 12, CEDAW, 1979; Article 12, ICESCR, 1966; Article 24, CRC, 1989).

Information and services should be made available to adolescents to help them understand their sexuality and protect them from unwanted pregnancies, sexually transmitted diseases and subsequent risk of infertility. This should be combined with the education of young men to respect women's self-determination and to share responsibility with women in matters of sexuality and reproduction (Paragraph 7.41, ICPD Programme of Action, 1994).

1 Every young person needs access to health services as part of having a safe, responsible, and healthy sex life.

2 All people have the right to health services that are accessible, affordable, and of good quality. People have a right to be treated respectfully and to maintain their privacy.

3 Unfortunately, many barriers may keep people from obtaining the health services they need and deserve. Sometimes these barriers reflect discrimination and informal stigma. Sometimes these barriers become formal policies.

- Governments may not provide free or affordable health services in all areas.

- Governments, providers, or pharmacies may withhold access to certain health services and medications. Their actions may be influenced by political or religious beliefs.

- Pharmaceutical companies may charge unaffordable prices for drugs and supplies.

- Some health programs may require young people, particularly girls, to obtain parental consent before receiving contraceptive services. 


\section{Poor quality of care may discourage people from going to available health services.}

For example:

- Clients may have to endure a long wait for services or may not receive the supplies or services they need.

- Some clients (especially if they are unmarried, poor, sex workers, of a racial/ethnic minority, transgender, living in a same-sex relationship, or living with HIV or AIDS) experience judgmental treatment from health providers.

- Adolescents often have real or perceived fears that family or friends will find out about their health care visit.

\section{Gender norms influence use of services.}

- Many young men may feel uncomfortable about seeking sexual health services, especially where such services focus mainly on women.

- Many women and young people lack the decisionmaking power or the money that they need to get to services.

- Some girls and women are prohibited from leaving their homes or villages unaccompanied, even to a health clinic.

6 Despite obstacles, millions of people, including young people, use health services and interact well with their providers.

7 People around the world are organizing successfully to improve the health of their communities.

For example, they:

- establish community health education activities to teach each other about health issues;

- establish sexual and reproductive health services that are especially welcoming to young people, and include counseling, informed consent, and respect for confidentiality;

- educate the community about obstetric fistula and advocate for services to provide surgical repair for women with this debilitating condition (see Unit 6, page 175 and fact sheet on Childbirth and Breastfeeding);

- establish community projects to improve health, such as gardens, water wells, and exercise programs;

- advocate for better health services (including increasing availability of medications); and

- advocate for better health policies and for increased funding for health care. 


\section{PART 1:}

\section{SEXUALYY TRANSMITTED}

INFECTIONS, INCLUDING

\section{HIV AND AIDS}

Governments, international organizations, donors, and NGOs shall undertake gender-sensitive initiatives that address sexually transmitted diseases and HIV/AIDS. ... (Strategic Objective C3, FWCW Platform for Action, 1995). [This should include] . . strategies to end social subordination of women and girls and ... to educate and enable men to assume their responsibilities to prevent HIV/AIDS and other sexually transmitted diseases (Paragraph 108.e, FWCW Platform for Action, 1995). 


\section{about sexually transmitted infections (STIs) and HIV and AIDS}

1 People can experience both positive and negative consequences as a result of sexual activity.

- Positive outcomes include pleasure, intimacy, and (among heterosexual couples) desired pregnancy.

- Negative consequences may include emotional and physical harm; sexually transmitted infections, including HIV; or (among heterosexual couples) unintended pregnancy.

2 Sexually transmitted infections (also called STIs) are infections spread through sexual activity. STIs are preventable.

[See fact sheet on Sexually Transmitted Infections.]

- Some STIs cause symptoms or discomfort. Others do not always have symptoms (especially among females).

- Even when an infection does not produce symptoms, it can have serious health consequences, including endangering fertility or even life.

- Among the STIs that can have serious consequences are: HIV, HPV (genital warts), syphilis, gonorrhea, chlamydia, trichomonas, and herpes.

- Oral sex can result in the transmission of various STIs, including HIV.

- For some STIs, girls are physiologically more vulnerable to infection than boys. Receptive anal intercourse increases risk of infection (for boys and girls). Social factors also affect the likelihood of transmission [see section in this unit titled Why People Don’t Use Protection].

3 People who are sexually active can take steps to reduce their risk of acquiring an STI.

[See following section titled Methods of Protection Against STIs and HIV.]
Refer to fact sheet on Sexually

Transmitted Infections to develop a detailed curriculum.

\section{SEE ACTIVITIES BOOK}

Activity 46

the facts about sexually

transmitted infections (ST/s)

Students make posters displaying important information about STIs, including HIV and AIDS. 
4 One of the most serious infections that people can acquire through sex is HIV, the virus that causes AIDS. AIDS is a major cause of illness and death in many parts of the world.

[See fact sheet on HIV and AIDS.]

- HIV weakens the body's immune system, allowing infections and cancers to develop. Without treatment it eventually leads to death.

- Rates of HIV infection vary across countries and within countries.

- In many places, HIV rates are much higher among young people, especially girls. In many places, men who visit sex workers and men who have sex with men may also be particularly vulnerable to HIV infection.

- HIV may also be transmitted nonsexually, for example, by injecting drugs with a contaminated needle, through transfusion of contaminated blood, or from an HIV-positive woman to her fetus or baby.

5 Some (but not all) STIs are curable. A person who completes proper treatment will no longer have the infection. Taking proper preventive measures can prevent re-infection.

6 Proper treatment can often reduce symptoms and/or dramatically slow the progress of those STIs that cannot be cured (for example, herpes, HIV infection, and HPV).

NOTE: HIV stands for human immunodeficiency virus. AIDS stands for acquired immunodeficiency syndrome. HPV stands for human papilloma virus. See fact sheets on Sexually Transmitted Infections and on HIV and AIDS. 


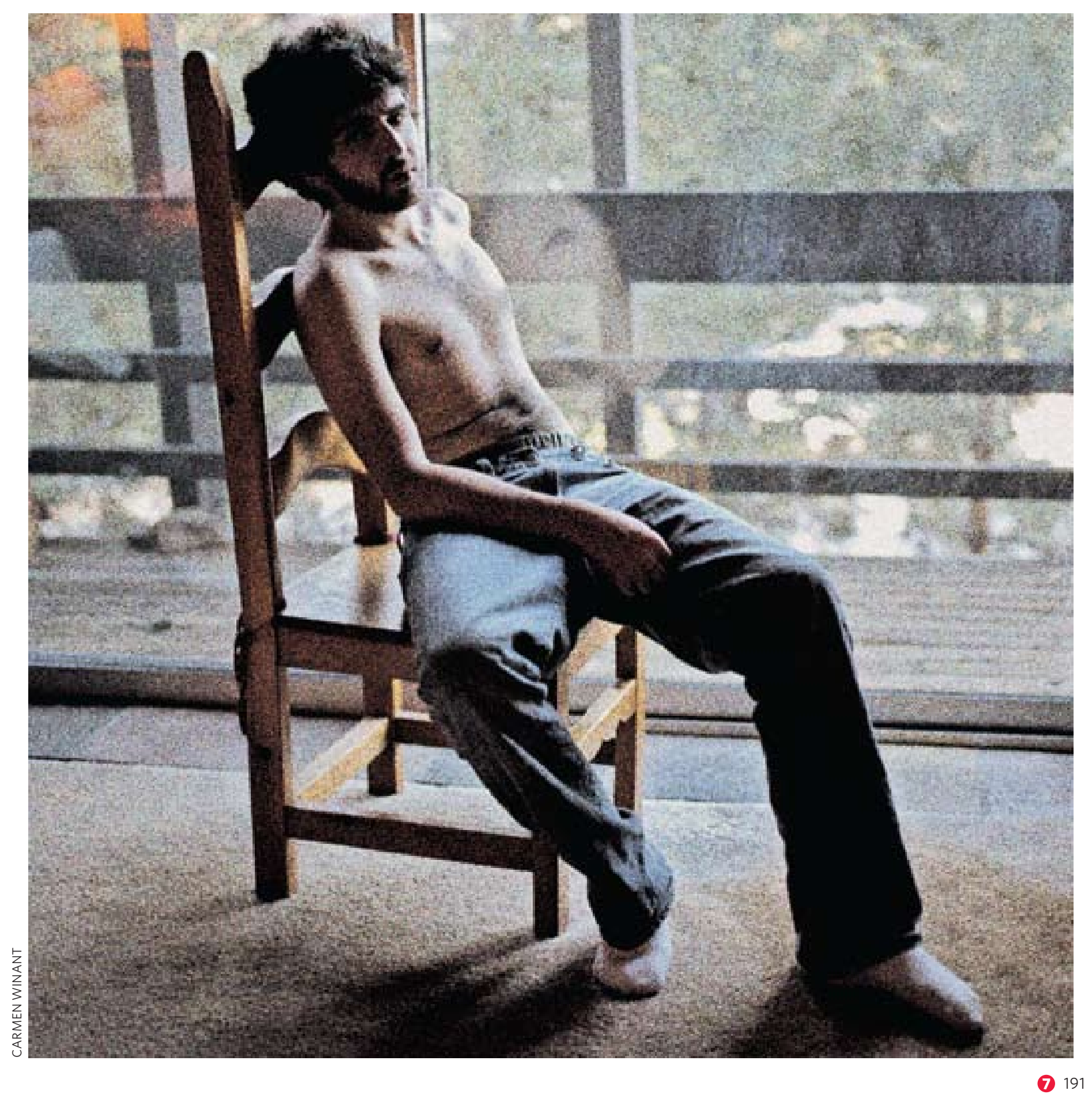




\section{methods of protection against STIs and HIV}

1 All STIs, including HIV infection, are preventable.

2 Every person has the right to protect himself or herself against STIs. There are various ways to protect oneself and one's partners against STIs. This is true whether one's partner is of the same or the other sex.

3 The surest way to prevent an STI is not to have vaginal, oral, or anal sex. Everyone has the right to refuse unsafe sex (or sex that is unwanted for any reason). Many people, however, cannot or do not exercise this right. This situation is especially common among women and girls who lack the power to insist that their male partners use condoms.

4 Both partners can agree to engage in forms of sex (such as mutual masturbation) that do not carry the risk of infection transmission.

5 Both partners can agree to use male or female condoms. 
6 Both partners can practice mutual monogamy. This means not having any sex partners outside their primary relationship and is also known as "being faithful." However, a person can already be infected (even without knowing it), or may not be completely faithful. Hence promising to be faithful does not necessarily eliminate the need for practicing safer sex.

[See following section; also see fact sheet on HIV and AIDS.]

7 A common STI is human papilloma virus (HPV). Many strains of HPV exist; some cause genital warts and others lead to cancer - most commonly, cervical cancer. HPV vaccines can protect both males and females against many of these strains of the virus.

8 Male circumcision offers some protection against HIV for males, but no direct protection for females.

- Having a foreskin on the penis seems to make it easier for various viruses and bacteria — including HIV — to establish an infection in the man.

- Even if they are circumcised, men can still get infected by HIV and can still infect their partners.

- Because circumcision provides no direct benefit to females and provides only partial protection for males, circumcision does not eliminate the need for condoms.

9 New protective technologies are likely to become available in the future. As they do, people have a right to learn about, and to access, such technologies. 


\section{why people don't use protection and why gender equality is key to fighting AIDS}

1 In real life, many people do not use protection against STIs.

2 Some people do not use protection because they lack information, skills, or basic access to services.

For example:

- They do not have accurate information regarding transmission and prevention of STIs, or about proper condom use.

- They do not know that there are condoms for females (as well as for males). Or they may not have access to female condoms.

- They believe that their partner could not be infected.

- They believe that they are not infected.

- If they have a same-sex sexual encounter, either between men or between women, they may not consider it to be "real" sex.

- They lack access to condoms, or they feel embarrassed to ask for them from a provider, pharmacy, or shop.

- They have had sex with someone else and are not sure how to tell their partner that one or both of them may have an STI or HIV as a result.

- They feel embarrassed about discussing condom use with a partner, or uncomfortable about putting on a condom.

3 Some people do not use protection because they did not anticipate that they were going to have sex.

- They get caught up in the desire of the moment but have neither a male nor a female condom.

- They may be forced into having sex. 


\section{Some people do not use protection because they have conflicting feelings about using or discussing condoms.}

For example:

- Some women or couples (including those in which one partner has an incurable STI or HIV) are trying to become pregnant.

- People may want to use protection but also feel that sex is more pleasurable without a condom.

- People may want to protect their partner's and their own health. But they may also be reluctant to admit (or even to ask about) the possibility that either one of them may have had an outside sexual relationship. In some circumstances, for example:

- Telling or asking about an outside relationship carries a risk of conflict or even violence.

- Such outside relationships may be particularly stigmatized (for example, a married man having sex with another man, or a woman having an extramarital relationship in a place where gender norms severely condemn such activity).

- A couples' desire for protection may conflict with religious teachings opposing condom use. 
5 Some people do not use protection because they are in circumstances of unequal social power, including gender inequality.

For example:

- People, particularly girls, may feel pressured by their partner to show their love by having sex without a condom.

- Even if a condom is available, a person may feel pressured by a partner to have intercourse without stopping to put on the condom.

- A significant age gap between partners may make it difficult for the younger person to insist on condom use.

- Within marriage, women and girls are often obligated to have sex or to have a child, even if they feel that it is not safe.

- People (both men and women) who are paid to have sex may be paid extra - or coerced — to have sex without condoms. Girls who accept favors or gifts from older men ("sugar daddies") may be offered more in the way of material goods if they agree to have sex without a condom.

- Initiating a discussion about sex or sexual health may be considered inappropriate or taboo for women and girls.

- Some people feel that raising the issue of condoms implies suspicion of sexual infidelity and may trigger conflict, anger, or violence. Such reactions result in serious harm to many women throughout the world.

- In some settings, men who are infected with HIV wrongly believe that they can be cured by having unprotected sex with a female virgin. This practice is dangerous for the girl and is an extreme abuse of her human rights.

6 Sex that is forced (in addition to being an act of violence) often takes place without condoms; hence, it is more likely to carry a risk of HIV and other STIs. [See Unit 2, pages 70-71 and Unit 3, pages 106-107 for further discussion of sexual coercion.]

7 Despite obstacles, millions of people, including young people, use condoms correctly and effectively. 


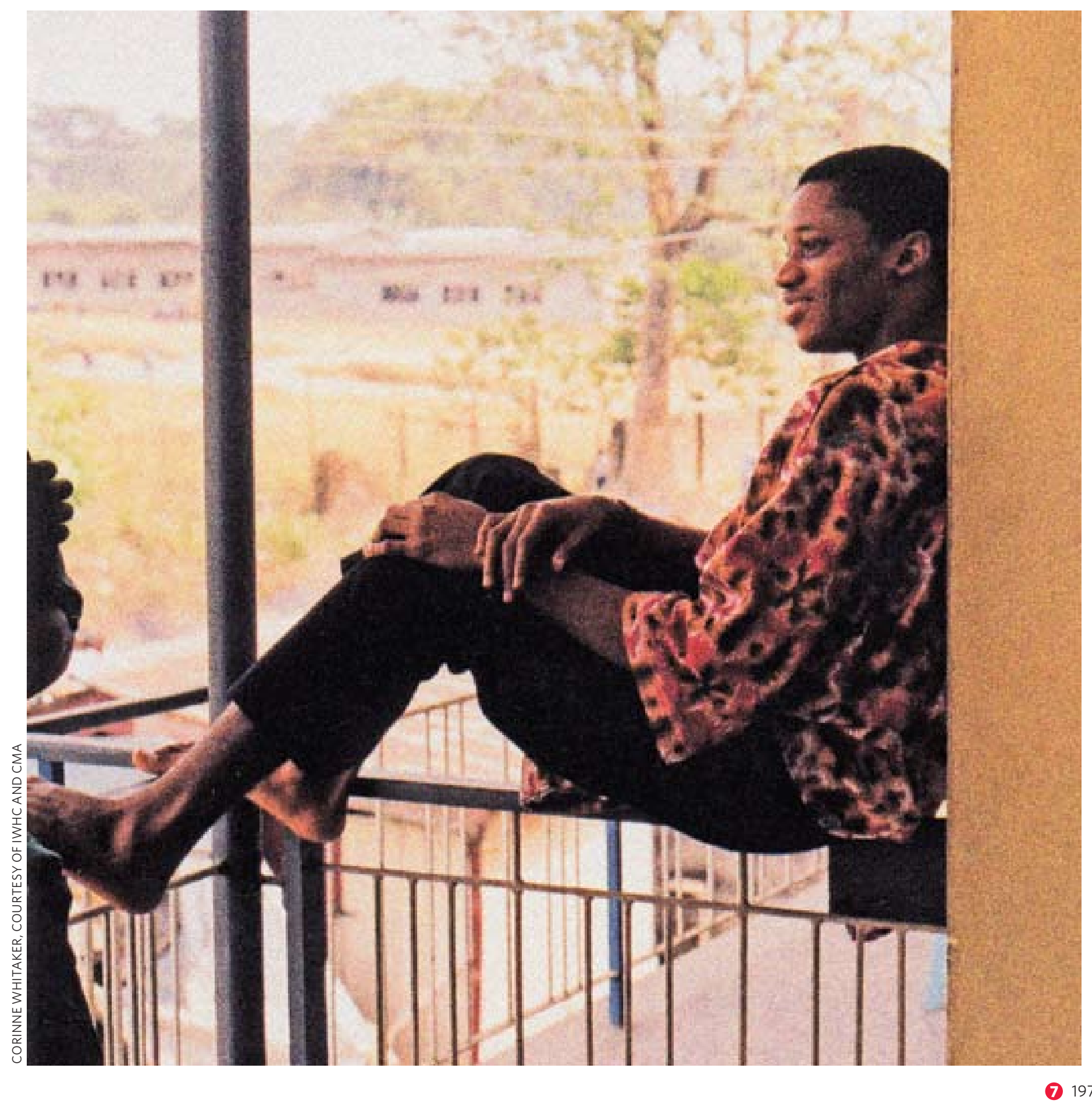

SEE ACTIVITIES BOOK Activity 47

gender and condom use

Students analyze barriers (including gender norms) to condom use and ways to overcome these barriers, and learn how to use a condom.

SEE ACTIVITIES BOOK Activity 48

starting a conversation about sex and safety

Students practice initiating conversations about important sexual safety and health topics. 


\section{living with HIV and AIDS}

1 All people have a right to know their own HIV status and to obtain confidential testing and counseling services. (People also have a right not to be tested.)

2 People living with serious and incurable STIs such as HIV infection can live a long time and can maintain a relatively normal life, including having safe, satisfying, and supportive sexual relationships. However, doing so requires social and health care support and attention to the rights of people living with HIV or AIDS.

3 People living with HIV or AIDS need counseling and support to be comfortable speaking with others about their HIV status.

This support can include:

- group meetings with other people living with HIV and AIDS;

- help in informing and protecting their sex partner(s), including current partners as well as any past partners who may have been infected [see following section];

- emotional support, including assistance in talking with family members; and

- help with ensuring that they have proper nutrition, take their medication, and have access to care.

SEE ACTIVITIES BOOK

Activity 49

AIDS: learning from others

Students listen to the story of a person who is HIV-positive.
4 Some people suffer as a result of telling their partners or family members that they are HIV-positive. Many more find that their partners and family members are understanding and helpful.

5 Any person who is HIV-positive has the right to obtain needed services and treatment.

- Care may include, for example, access to medications, special medical attention during pregnancy or illness, and social services with ongoing counseling support.

- Medical treatment and care for those with HIV and AIDS are costly. Support from governments and international donors is essential for poor people who need to obtain care. 
For example:

- In some countries, people living with HIV or AIDS are barred from employment, housing, or other basic needs.

- Some women living with HIV or AIDS have been unjustly denied access to reproductive health services.

\section{In a sense, families and communities are also "living with" HIV and AIDS. This is} especially true where a relatively high proportion of individuals are infected with the virus.

- In some towns, many of the income earners become too sick to work.

- Millions of people (especially women and girls) are caring for family members infected with HIV.

- In some settings, women are not allowed to inherit property or receive state benefits when their husbands die. As a result, losing one's husband to AIDS may mean losing one's home and means of survival.

- Millions of children have been orphaned because one or both of their parents have died of AIDS.

- Young people must cope with the reality of HIV as they seek to maintain a positive experience of sex and sexuality.

8 Worldwide, groups are working to protect the rights of people living with HIV and AIDS, to support communities coping with the epidemic, and to advance prevention efforts.

Some of their activities include:

- providing and advocating for support of people living with HIV or AIDS, as well as their families;

- assisting children who have lost one or both parents to AIDS;

- advocating for greater access to treatment;

- increasing awareness of HIV and AIDS and ways to prevent transmission of the infection; and

- advocating for, researching, and testing other means of protection against the virus.

How can we ensure that young people living in areas with high rates of HIV can grow up with a positive experience of sex and sexuality? 


\section{rights and responsibilities related to preventing STIs and HIV}

1 Societies and governments have responsibilities to provide health services, respect confidentiality, and protect all people against stigma and discrimination that result from their health status. Each of us has a right to obtain these services and protections.

2 Within our sexual relationships, each of us has the right to protect ourselves from harmful consequences of sexual activity - including infection with STIs and HIV and unintended pregnancy.

3 Within our sexual relationships, each of us has the responsibility to protect our partners from harmful health consequences, including STIs, HIV, and unintended pregnancy. The responsibility to protect our partners becomes particularly important when the possible consequences are very serious.

\section{SEE ACTIVITIES BOOK}

\section{Activity 50}

what do you have to tell? what would you want to know?

Through discussion and creative writing, students consider what responsibility people have to disclose their HIV status to a sex partner.
4 Many people tell their sex partners that they are (or suspect they may be) HIV-positive, even though telling them is not easy.

Some of the reasons that people share this information include:

- They want to protect their partner.

- They wish that a previous partner had disclosed his or her status to them.

- They want emotional support from their partner.

- They are concerned that their partner might find out about their status from a health care provider or from someone else. 

positive, even if condoms are being used.

- They may feel that their sexual relationship should be based on openness and honesty, including about this matter.

- Some people might choose to have sex regardless of their partner's HIV status, whereas others might not want to.

- Some people may want to explore approaches to sexual intimacy that do not carry a risk of transmission [see page 192].

6 In reality, however, some people do not tell their sex partners that they are (or suspect they may be) infected with HIV.

For example:

- They feel that they do not have to tell their sex partners about their HIV status as long as they use condoms, which greatly reduce the risk of transmitting the virus.

- They don't know how to bring up the issue.

- They are afraid of their partner's reaction. For example, they fear that their partner may accuse them of sexual infidelity, become violent, or abandon them.

- They fear that other people will learn about their HIV status, which could lead to stigma and discrimination.

- They lack adequate concern about the welfare of their sex partner.

- They incorrectly believe that they will not infect their partner.

7 A counselor or trusted health care provider may be able to provide support and guidance about how to talk to a partner about one's HIV status. 


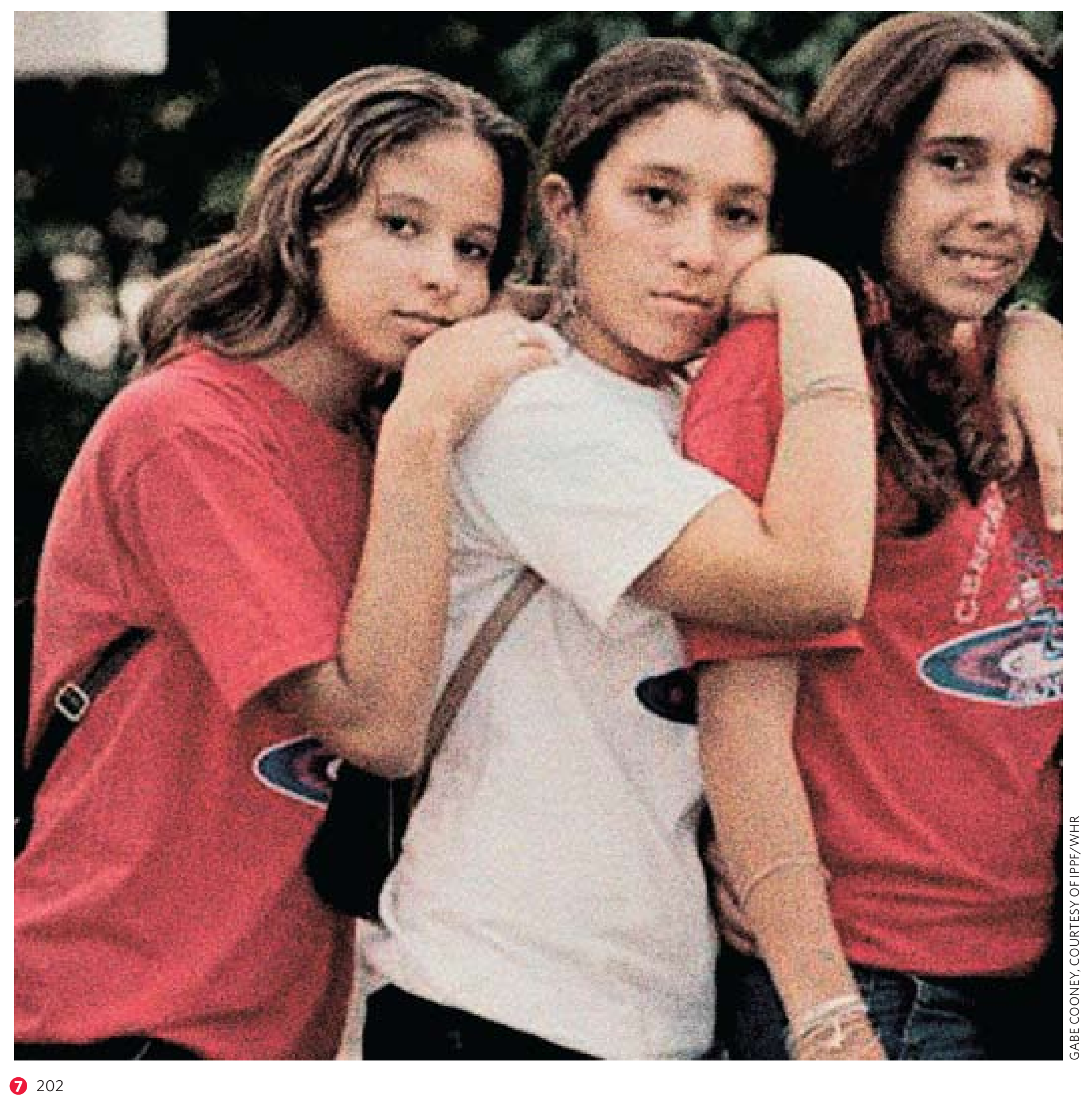




\section{reproductive tract infections (RTIs)}

1 Reproductive tract infections (RTIs) is a general term for infections affecting the reproductive organs. RTIs have three main types of causes.

[See fact sheet on Reproductive Tract Infections.]

2 Some RTIs are transmitted through sex. (In these cases, they are generally called sexually transmitted infections, or STIs.)

[See earlier section, starting on page 189.]

3 Some RTIs result from an imbalance in the organisms normally present in the genital tract.

- This kind of RTI is far more common among women than among men.

- This type of RTI is sometimes caused by practices that are unnecessary (such as douching) or even harmful (such as inserting substances to dry the vagina), or as a side effect of using certain medications.

4 Some RTIs are transmitted or spread by certain medical procedures and treatments.

- This kind of RTI is far more common among women than among men.

- This type of RTI can result from use of medical instruments that are not sterile (cleaned properly) or from pushing an existing infection farther up the reproductive tract during a medical procedure (for example, during the insertion of an IUD). 
5 RTIs may cause such symptoms as itching and vaginal discharge.

6 Many RTIs are easily treated and cured, especially if they are diagnosed early. If left untreated, some can have serious consequences, including infertility or even death (as in the case of pelvic inflammatory disease).

7 Women are more likely than men to suffer serious consequences (including infertility) from a non-sexually transmitted RTI.

8 In settings where the prevalence of RTIs is extremely high, awareness of such infections and treatment is often lacking.

9 In some countries, women have demanded that RTIs be seen as a serious health concern. They have called for investments in RTI education and clinical services. 


\section{PART 2: \\ DECISIONS ABOUT \\ ONE'S OWN FERTILITY: \\ CONTRACEPTION \\ AND ABORTION}

[People have] the right to decide freely and responsibly on the number and spacing of their children and to have access to the information, education and means to enable them to exercise these rights (Article 16.e, CEDAW, 1979; Principle 8, IPCD Programme of Action, 1994). 


\section{about contraception}

\section{Refer to fact sheet on}

Contraceptive Methods to develop a detailed curriculum.
1 A person (or couple) who intends to have heterosexual intercourse but does not want a pregnancy can use a contraceptive or engage in sexual activity other than intercourse.

2 Contraception can be defined as any method used to prevent pregnancy. Different methods are used in different ways and at different times.

[See following section.]

3 Using contraceptives allows many people to enjoy their sex lives without having to worry about unwanted pregnancy. Male and female condoms also allow people to enjoy sex with less worry about sexually transmitted infections.

- Contraceptive use enables many people to have greater control over their bodies, their relationships, and their broader social and economic lives.

- Discussing and using contraceptives can foster trust and mutual comfort.

- Millions of people around the world use contraceptives.

4 Most governments, and most people, recognize the benefits of contraception and the right to use it.

- Most governments and health services provide contraceptive services to any individual who requests them (regardless of age, gender, or marital status); a few do not respect this basic right and refuse care to adolescents, unmarried people, or (in the case of women) those who do not have their husband's consent.

- Some religious groups oppose all forms of contraception, but most religious groups and leaders support the right to use a contraceptive. 
5 International agreements protect individuals' and couples' right to control their own fertility. These agreements also encourage boys and men to share in the responsibility for preventing unplanned pregnancy.

6 In the past, many men expected women to assume the entire responsibility for preventing pregnancy. Nowadays, many males share this responsibility.

For example, a male can share such responsibility by:

- abstaining from sex without contraception;

- communicating with his female partner before having sex;

- educating himself about different contraceptive methods;

- using condoms correctly and consistently;

- where appropriate, using other male methods such as withdrawal or vasectomy;

- accompanying his female partner to a family planning clinic; and

- supporting his female partner in using her contraceptive method.

7 Some people (even if they do not want a pregnancy) do not use a contraceptive because they lack accurate or complete information.

For example:

- People may not understand their risk of pregnancy.

- Many people lack knowledge of the fertile period during a woman's or girl's menstrual cycle.

- Many people lack accurate information about different contraceptive methods that may be available and acceptable to them or about where to obtain contraceptives.

- Providers may have inaccurate or out-of-date information about which methods are appropriate for adolescents to use. 
8 Some people (even if they do not want a pregnancy) do not use contraceptives because they lack access to services where they feel comfortable.

For example:

- Some worry about cost, privacy, and confidentiality in finding and paying for services.

- Many do not have access to a clinic or pharmacy where they can purchase contraceptives.

- Many people - especially ethnic or racial minorities, unmarried young people, and people living in poverty are not treated respectfully by service providers.

9 Some people (even if they do not want a pregnancy) do not use contraceptives because of personal or cultural barriers, including gender inequality.

- Community norms about gender and sexuality make many people — especially, but not only, girls embarrassed to admit that they are planning to have sex or to talk about contraception with their sex partner.

- Some people believe that their partner is taking the responsibility for contraception.

- Some people oppose contraception because of beliefs that they have adopted from their family, community, or religious leaders.

- Many couples experience social pressure to produce a child; the pressure on women to prove their fertility and bear children may be intense.

- Many people - especially, but not only, females - are coerced into having sex that they were not planning to have.

- One partner may oppose using a contraceptive and may rely on pressure, threats, or deception to avoid using one.

10 Some people (even if they do not want a pregnancy) do not use contraceptives because they have not found a method that they are willing or able to use safely. For example, they may be concerned about the side effects (whether real or perceived) or other characteristics of a contraceptive method. 


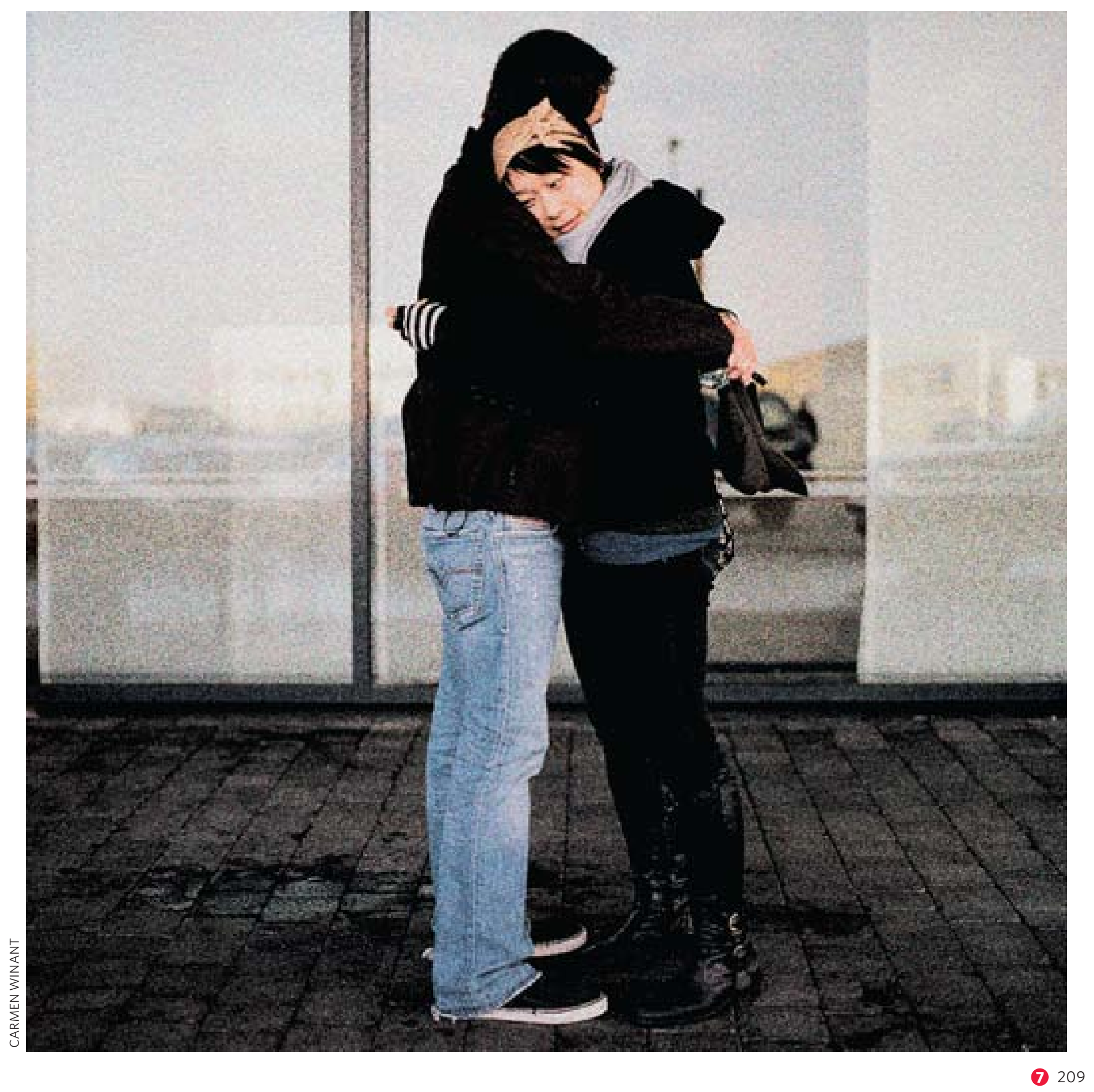




\section{different contraceptive methods}

Refer to fact sheet on

Contraceptive Methods to develop a detailed curriculum.
1 Most contraceptive methods are for use by females; only a few methods are used by the male. There are many methods to choose from. Each person has the right to free and informed consent regarding which method to use. Many couples cooperate in the choice and use of their method.

2 No contraceptive method is perfect, and every method has its own characteristics. Some methods carry medical restrictions.

- Only two methods, the male and female condom, protect against HIV.

- Some, but not all, methods may affect sexual pleasure or performance.

- Some methods are easy to obtain. Others require a visit to a health clinic and may involve a physical examination.

- Methods vary in their effectiveness at preventing pregnancy.

- Some methods carry risks of side effects to the user's health.

- The use of some, but not all, methods may be stopped and started easily.

- Some methods are more satisfactory for people who have sex relatively infrequently.

- Methods vary in their cost and availability.

3 People often try different methods to figure out which one works best for them.

- A health care provider can offer information about the benefits, disadvantages, and side effects of different methods.

- If a person is not comfortable with a method, she or he can change to a different method. 
4 Some people choose contraceptive methods that offer the greatest protection against infection. These methods are inserted or put on each time a couple has sex. These are called "barrier methods" because they create a barrier between the egg and the sperm, making fertilization impossible.

- Condoms (male and female) offer protection against both pregnancy and HIV. They also protect against a number of other STIs, including some that may damage future fertility.

- In many places, young people can obtain condoms free of charge or can purchase them at a pharmacy or at other kinds of stores.

- Some people feel that condoms reduce sexual pleasure. Others do not think so, or feel that this drawback is outweighed by having protection against unwanted pregnancy and STIs (including HIV).

- For extra protection, many couples use condoms in addition to another contraceptive method.

- Other barrier methods, such as the diaphragm and the cervical cap, are used by the female. It is not yet known whether the cap or diaphragm offers any protection against infections.

5 Some people choose contraceptive methods (such as "the pill," hormonal implants, injectable hormones, hormonal patches, the vaginal ring, and the IUD) that are especially effective in preventing pregnancy.

- These methods do not protect against sexually transmitted infections. Combining the use of one of these methods with a male or female condom can offer greater protection against both pregnancy and sexually transmitted infections, including HIV.

- These methods tend to have more side effects. For example, certain hormonal methods reduce interest in sex among some women.

- These methods have more potential health-related complications, although they may also have some health benefits.

- These methods may be more convenient to use.

- These methods may be easier for females to use regardless of their partners' active participation; some may be used even without their partners' knowledge. 
6 In order to avoid an unwanted pregnancy, some women learn techniques to identify which days in their menstrual-ovulation cycle they are most likely to be fertile (to be able to become pregnant). There are a variety of these techniques, which as a group are called "fertility awareness methods." For example, a woman can learn to calculate her likely fertile days, based on her past menstrual cycles. She can also observe changes in her own body, including a shift in body temperature and changes in the texture of the mucus discharge from the vagina.

[See fact sheet on the Menstrual Cycle.]

- Learning to identify the fertile period takes time; a woman has to learn about the menstrual cycle and to practice observing and recording cyclical changes in her own body.

- During the fertile days of the menstrual-ovulation cycle, couples may use a contraceptive method such as the condom, or they may avoid having vaginal intercourse. [See earlier section on the Reproductive System.]

- Each woman's menstrual-ovulation cycle is different. Hormones, illness, and other factors often disrupt the regularity of the cycle.

- Younger adolescents often have irregular cycles that make it difficult to use these methods effectively.

- These methods do not protect against STIs or HIV.

- Many couples find it difficult or inconvenient to use these methods effectively.

7 Some couples prevent pregnancy by agreeing that the male will withdraw his penis from his partner's vagina before he ejaculates (has an orgasm, releasing semen). This is referred to as "withdrawal."

- If used properly and consistently, withdrawal is effective at preventing pregnancy.

- Effective use requires a great deal of control and commitment by the male. For this reason, couples trying to use withdrawal have more unintended pregnancies than users of many other methods. Proper and consistent use is often a challenge for young people.

- Withdrawal does not provide effective protection against HIV (or other STIs). 
8 Some people choose sterilization, a surgical contraceptive method that must be considered permanent. Both males and females can be sterilized.

\title{
9 A woman may obtain protection from pregnancy after she has had intercourse by
} using a method called "emergency contraception."

[See fact sheet on Emergency Contraception.]

- Emergency contraception is useful in cases when the couple did not use a contraceptive, experienced a method failure (for example, as a result of a torn condom), or when the woman was forced to have sex.

- Emergency contraception is fairly effective for as long as five days after having unprotected sex. But it works best if used as early as possible during this period.

- The most common form of emergency contraception contains a specific dose of a hormone used in many oral contraceptives. Emergency contraception pills are often packaged specifically for this purpose. In some places, the method is available without a doctor's prescription.

- Inserting an IUD within five days of intercourse is another option for emergency contraception.

- Emergency contraception is not a method of abortion. It will not end an established pregnancy.

\section{Sometimes contraceptives fail.}

- When they do, some women choose to continue the unplanned pregnancy. [See Unit 6, pages 174-177.]

- Other women choose to end the pregnancy. [See the following section.]

\author{
SEE ACTIVITIES BOOK \\ Activity 51 \\ contraceptive knowledge \\ games \\ Students review information about \\ contraceptive methods by way of a \\ crossword puzzle and a game. They \\ discuss shared responsibility for \\ contraception.
}




\section{unintended pregnancy and abortion}

International agreements affirm the need to recognize and address the health impact of unsafe abortion (Paragraph 106j, FWCW Platform for Action, 1995) and, in settings where abortion is legal, that it should be safe (Paragraph 8.25, ICPD Programme of Action, 1994; Paragraph 106k, FWCW Platform for Action, 1995).

1 Millions of women and girls experience unintended pregnancies. These pregnancies occur for many reasons: because a contraceptive was not available, was not used, was used incorrectly, or was used correctly but failed.

2 Every year, between 40 and 50 million women and girls decide to seek an abortion (to end a pregnancy).

3 Women and girls have abortions for many reasons.

For example:

- They cannot afford or manage to rear a child (whether a first child or another child).

- They don't want to become a parent at the time of the pregnancy.

- They want to finish their education.

- Their relationship with their partner is becoming difficult, or they are not in a stable relationship and do not want to rear a child alone.

- The pregnancy threatens their physical or mental health.

- They became pregnant as a result of sex that was forced or otherwise coerced. 
4 Even in situations where a woman or couple wants to continue a pregnancy, they may end it by abortion for various reasons.

For example:

- The pregnancy may threaten a woman's physical or mental health.

- Genetic, behavioral, or environmental factors may cause serious medical risks (even death) for the fetus.

- The couple is unhappy about the sex of the fetus. This feeling occurs mostly in places where society unjustly places greater value on sons than daughters. [See fact sheet on Sex Selection.]

- Some women or girls are pressured to have an abortion because of their personal or economic situation, their health status, or for other reasons. Such pressure may come from another person (for example, a parent, boyfriend, or health care provider). In countries with coercive population policies, the government may pressure women to have abortions.

5 Various methods exist for performing a safe abortion. Depending upon the stage of the pregnancy and the provider's facilities, methods of abortion include a surgical procedure or medication.

[See fact sheet on Abortion.]

6 Abortion is a simple and safe procedure when provided under proper conditions. These include having a skilled provider, appropriate and sterile equipment, and access to early treatment for any potential complications.

- In general, abortion is far more likely to be safe when it is legal.

- The conditions under which abortion is typically provided vary widely from place to place. Globally, slightly more than half of all abortions are provided in safe conditions.

\section{POINTS FOR REFLECTION}

The majority of women who choose to have an abortion are married and have at least one child, but women who have abortions come from all ages, races, ethnicities, religions, and economic and marital situations. What are some of the circumstances under which a woman or girl might decide to have an abortion?

Abortion is least common in countries that provide sex education as well as broad access to contraceptive services and safe abortion. What are some of the reasons that women in these countries are less likely to have an unintended pregnancy? 


\section{Many, but not all, people and governments support women's access to safe and}

legal abortion.

People and governments may support legal access to safe abortion because they:

- believe that people should have access to all safe medical procedures;

- are dedicated to reducing maternal mortality, including death resulting from unsafe abortion;

- believe that women have a right to control their own lives and that the ability to control their fertility is an important part of that right;

- believe that people should be able to enjoy sexual intimacy and pleasure without reproducing;

- are concerned about population growth and want women to have access to all possible methods to control their fertility; and

- are concerned about the economic effects that result from unsafe abortion (for example, the cost of providing emergency care for women and girls who suffer complications).

People and governments may oppose access to abortion because they:

- hold religious or other personal beliefs that prohibit it;

- believe that women should not have control over their own lives and fertility;

- believe that sex should not be enjoyed separately from reproduction; and

- wrongly think that making abortion safe and legal will increase sexual promiscuity or will increase abortion rates.

\section{SEE ACTIVITIES BOOK}

\section{Activity 52}

walking in her shoes:

the decision to end a

pregnancy

Students read case studies and 
8 Nearly all countries in the world have passed laws that permit abortions under specific circumstances.

- In some places, women have the right to abortion on request, usually up to a specified number of weeks of pregnancy.

- In other places, abortion is allowed only in specified circumstances, for example, to save the woman's life, in cases of rape or incest, or in other situations or conditions.

- Abortion laws are a subject of ongoing debate and change in many countries.

9 Every hour, approximately eight women and girls die (and two hundred become infertile) simply because safe abortion services are not available or accessible. These tragic outcomes are easily preventable.

- Although abortion is a simple and safe procedure when provided under proper circumstances, close to half of abortions are carried out under unsafe circumstances.

- Unsafe abortion is a major public health problem in many parts of the world. It affects women and girls in all walks of life, but especially those living in poverty. 


\section{ADVOCATING}

FOR SEXUAL

HEALTH, RIGHTS,

AND GENDER

EOUALITY 


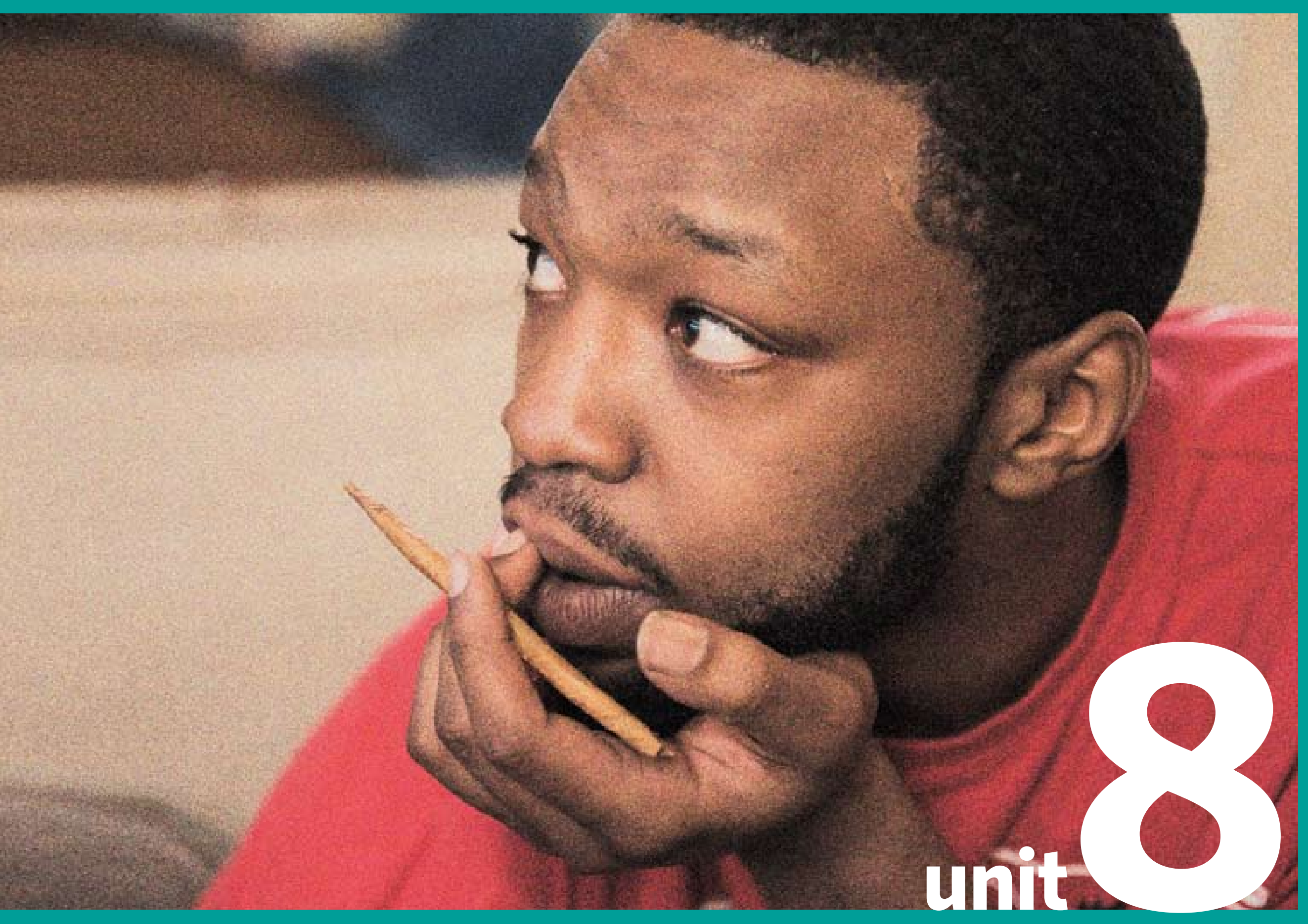




\section{overview}

This special module enables educators to support students with hands-on learning experiences in their own lives, schools, and communities. These experiences focus on achieving change in the areas of sexual health (including HIV and AIDS), human rights, and gender equality. Learners may reflect on their own behaviors. They may discern what they deem fair or unfair. And they may take steps - whether large or small — to make a difference in their own lives and in the lives of others. This kind of personal and civic engagement helps empower individuals as responsible citizens and helps promote democratic culture. 


\section{ADVOCATING FOR SEXUAL HEALTH, RIGHTS, AND GENDER EQUALITY}

This unit helps you guide students undertaking "hands-on" action projects. Even if your students are not able to carry out an advocacy project themselves, you may use the first part of this unit to introduce the topics of advocacy and social change to your students.

Use the material in the preceding units of this book as a reference, so that you can help students think and learn about different issues.

Although this unit highlights particular issues (including gender equality, the rights of people living with HIV and AIDS, and violence), it can be applied to a wider range of social action projects.

Familiarize yourself with at least one advocacy effort in your area. You can draw on this information for concrete examples about why and how people work for social change.

This module includes a number of "thinking questions" that your students may find complicated or personally challenging. Take care to select questions that are appropriate for them.

Seek both encouragement and counsel from others in guiding students through this module.

\section{IF YOU WILL BE TEACHING THE "TAKING ACTION: PROJECT-BASED LEARNING" MODULE:}

Encourage your students to start small. Remind them that change at any level matters. Help them understand how their small acts can connect to larger movements.

Encourage students to work in teams, and ensure that the teams give everyone a chance to participate and feel involved.

Remember: Your first responsibility is to keep your students safe. Although change often requires bold steps, even small steps may feel threatening to others in the community. As your students design their projects, make your own inquiries among leaders in your institution or community about any potential resistance to your students' plans, and seek backing of influential people for students' efforts. Such outreach can help minimize any backlash. Work closely with your students to ensure that they do not take inappropriate risks, and help them select a new topic if appropriate. Consider compiling a list of resources where students can go for help and support. 


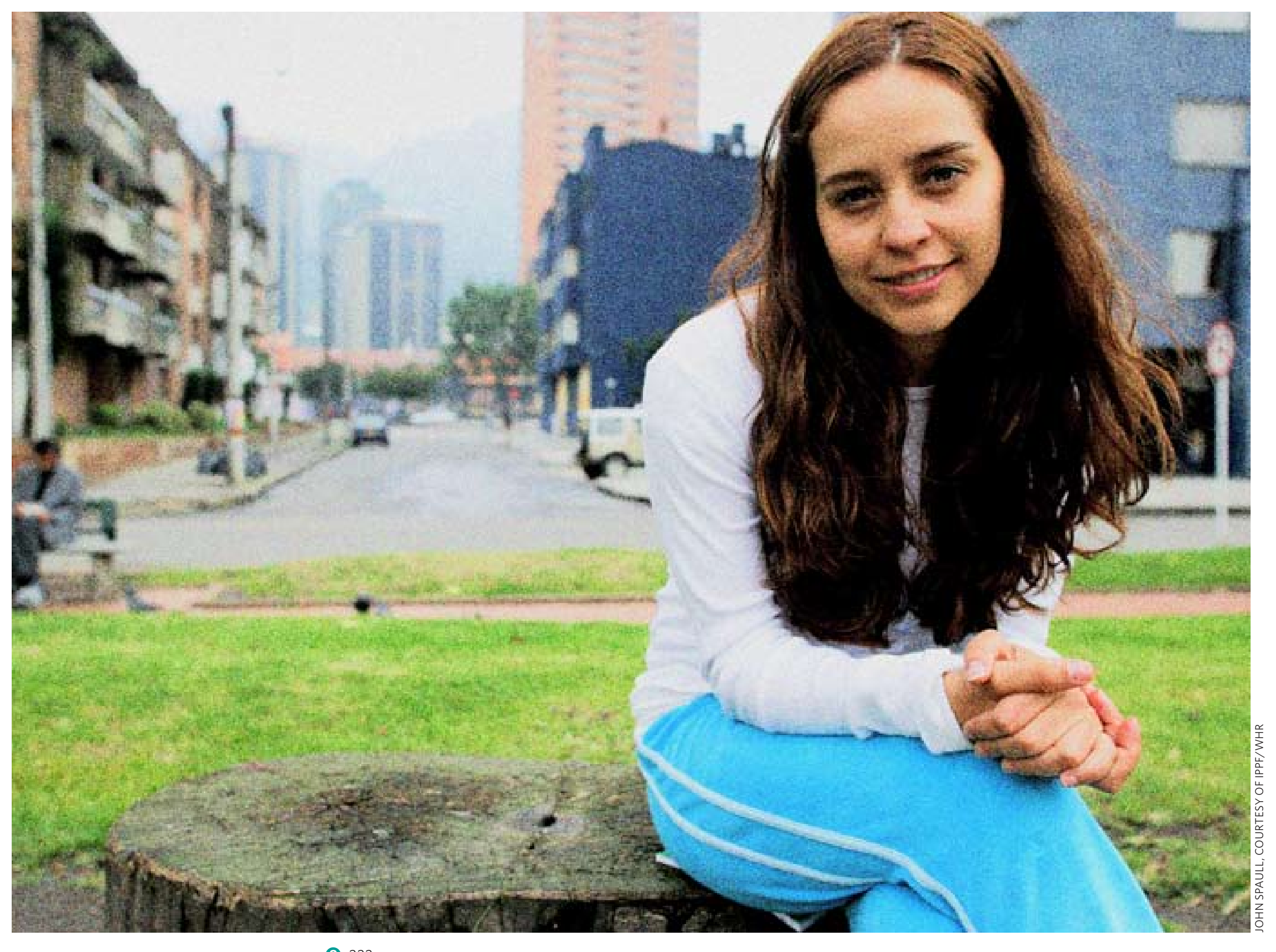

(8) 222 


\section{ADVOCATING FOR SEXUAL HEALTH, RIGHTS, AND GENDER EQUALITY}

The material in this special module prepares learners to:

\section{Cognitive Objectives}

Name at least one way that people can challenge discrimination or injustice in their own lives. Name at least one way that people can challenge discrimination or injustice in their communities.

Name at least one way that people can challenge discrimination or injustice at the national or global level.

\section{Affective Objectives}

Reflect on their own biases and prejudices and motivations to change.

Become sensitized to situations characterized by injustice, discrimination, marginalization, or inequality.

Reflect on their experiences and feelings in trying to promote sexual health, human rights, or gender equality.

\section{Skill-based Objectives}

Research a concern that they have about sexual health, human rights, or gender equality. Develop an action plan to undertake an activity that contributes to a more just world. Implement the steps of this action plan. 


\section{reflecting on our own attitudes}

1 We all hope to develop our full potential as human beings. Our ability to do so may be affected, however, by established social norms and stereotypes. These norms and stereotypes often relate to people's gender, race, age, class, religion, sexual identity, and physical abilities or disabilities.

2 To some degree, everyone absorbs and passes on widely accepted stereotypes. Absorbing discrimination (or oppression) means that we come to believe that the stereotypes and norms are true, even when we are the victims of them. Sometimes people recognize that certain norms and stereotypes are harmful, but doubt that they can change them.

3 You can challenge stereotypes related to gender and other aspects of your own life. To do this, you must have the ability and confidence to identify how these stereotypes have affected your identity, personal development, and choices. 
See the glossary at the end of unit 1 for definitions of some of the terms used in this unit.

\section{All of us can engage in self-reflection and critical thinking about our personal}

opinions, values, and ideas.

Following are some difficult, but important, questions each of us can consider in reflecting about community standards and fairness in the areas of gender and sexuality:

- What adjectives would I use to describe my personal traits? Are these words typically used to describe boys and men or girls and women?

- Do I feel that certain emotions such as anger or gentleness are not appropriate for girls or for boys? What are some examples?

- Do I tend to assume that I should develop (or not develop) certain skills and talents because of my sex?

- Do I tend to assume that boys and girls naturally have different intellectual capacities?

- Do I tend to listen more carefully to someone's ideas if the speaker is a boy or a girl?

- Do I think girls don't really need to play sports as much as boys do? Why?

- Do I consider some sexual behavior acceptable for boys but not for girls, or vice versa?

- Do I hold any stereotypes about the sexuality of people of other ethnic or racial groups? If so, on what basis have I formed these attitudes?

-What do I think about a person who identifies with a different gender than the one he or she was assigned at birth?

- How do I feel about girls having more chores at home than boys do?

- How acceptable is it for a man to be paid more than a woman for the same job?

- As an adult, would I vote for a female president? Why? Why not?

- Would I hire a man to take care of young children? Why? Why not?

- How do I feel about teasing someone I think is homosexual if the teasing is not extreme? Why do I feel that way?

- Do I think that girls and women sometimes are to blame when they are raped? If so, under what circumstances?

- On what basis did I develop these views? Where did I learn to form these attitudes? 
5 We can also ask ourselves about fairness and community standards related to HIV and AIDS. Such questions may be difficult but they are important.

For example:

- Do I hold stereotypes about people living with HIV or AIDS? Where did I learn those attitudes?

- How would I feel if I learned that my sibling was infected with HIV?

- How do I view people who pay to have sex, and how do I view those who sell sex to them? Do I think of them similarly or differently, and on what basis have I formed my attitudes?

-What responsibility, if any, do I have to defend the dignity and rights of HIV-positive people?

- Do I have any responsibility to get an HIV test myself?

- If I am infected with HIV, do I have a responsibility to tell my sex partners, even if we are using condoms?

6 Every day, we make decisions about the way we react to and treat other people. Many times, we make decisions without stopping to think about what is fair or ethical, or about other decisions we could make. Being fair means treating people with equal respect as a matter of personal ethics and human rights. 


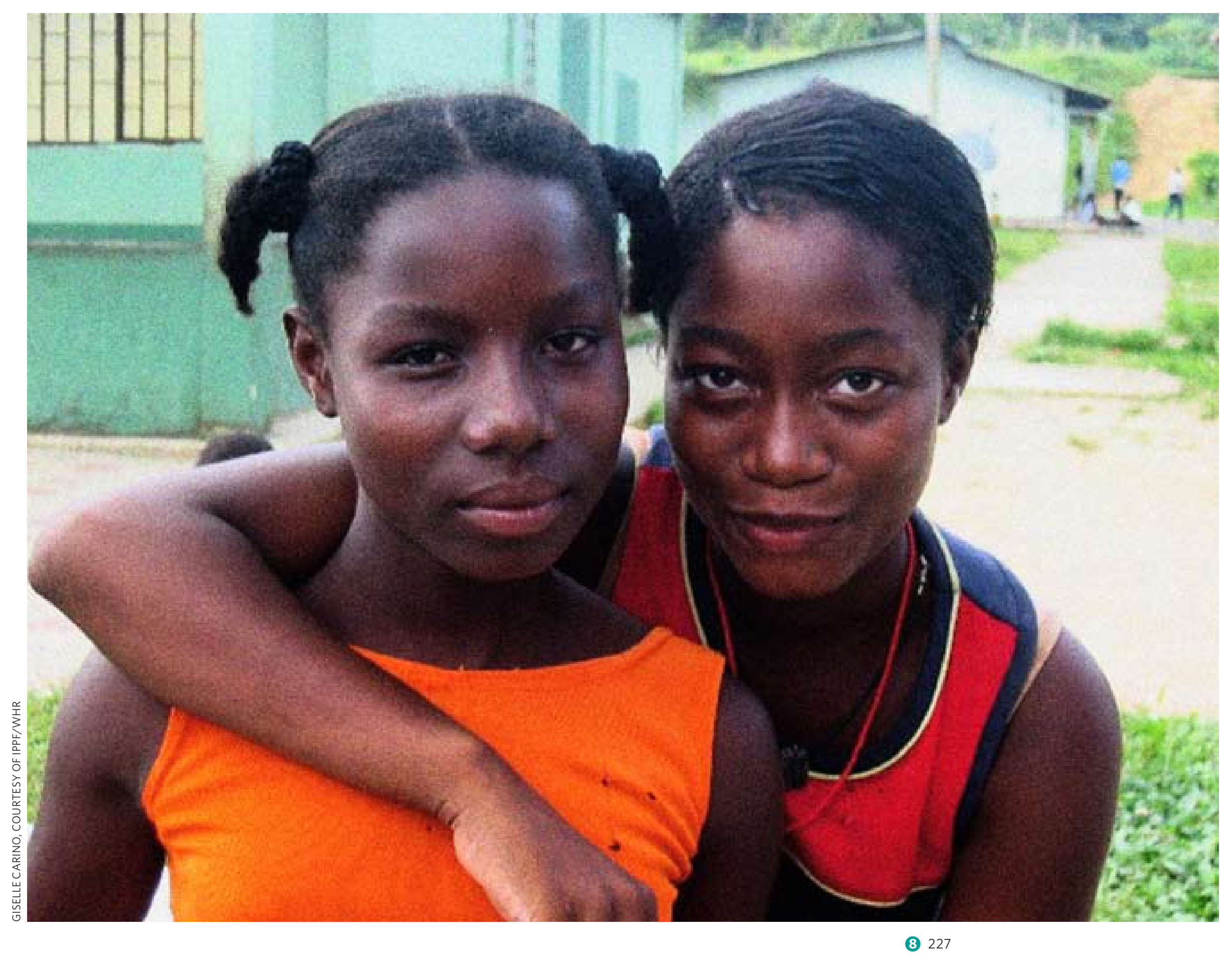




\section{recognizing whether something is fair or unfair}

1 In order to stand up to discrimination, people first must be able to recognize it both within themselves and in the world around them.

2 Recognizing discrimination is not always easy. In some cases, it can be obvious (for example, in a highly derogatory remark or in instances of domestic violence). In other cases, it may be more subtle and harder to notice (for example, ignoring someone's opinion because of her or his sex).

3 One question people can ask themselves when they sense that they may be responding based on stereotypes or prejudice is, "Why am I making this judgment?" Answering this question honestly can provoke useful reflection and can help a person to recognize when discrimination may be at the root of his or her behavior. 


\section{changing the world around us}

1 We all feel some cultural pressure to conform to the "way things are."

- Some people accept things the way they are, even when they are unfair. They may not care. They may not know how to change the situation. Or they may feel that trying to make a change would be too uncomfortable or risky.

- Other people speak out against unjust conditions in their own relationships and families, in their schools, in their communities, and in their society. Some people speak out or act even when their actions might put them at emotional, economic, legal, social, or physical risk.

2 People who believe in social equality can take a number of actions. It is rarely effective to challenge the entire social fabric. Rather, people can contribute toward small but important changes even in highly conservative settings.

3 Making a difference can be exciting and empowering and can build new relationships with other people.

For example everyone can:

- express attitudes, values, and opinions that are consistent with their beliefs;

- respect the human rights of all people;

- act against discrimination; and

- through steps small and large, help change lives every day. 


\section{Individuals can challenge injustices (including gender inequality) that they see in their own relationships and lives.}

For example:

- All of us can stop using degrading language or telling demeaning jokes about people who are different from ourselves. We can also speak up when others do so. People can become more aware of disrespectful or degrading attitudes presented in the media (song lyrics, videos, television programs, comic books, and so forth).

- A girl can decide to make serious efforts to convince her parents not to marry her off at a young age. Her brother can help, and he can refuse to take dowry when he is about to be married.

- A man can ask his parents to stop harassing his wife (their daughter-in-law) and her family for more dowry.

- A person can encourage a parent who is an employer to hire HIV-positive workers.

- An adolescent can pressure his friends who are teasing or bullying someone to stop doing so.

- People can openly embrace family members whose sexuality is outside of the social norm.

- Everyone can become more sensitive to the feelings of people from other backgrounds and situations. Being openminded and listening are crucial traits for developing respectful relationships.

\section{People can also decide to help end injustice that they observe in their communities and in their society.}

For example, they can:

- be supportive of an individual who is being unfairly marginalized; and

- educate people one-on-one and raise their awareness of local injustices. 


\section{People can join local efforts to achieve fairness and equality related to gender and}

sexuality.

For example, they can:

- help ensure that people living with HIV and AIDS are treated fairly in the community;

- convince people in the community to stop circumcising their daughters;

- establish neighborhood watch groups to intervene in instances of domestic violence;

- create safe places where victims of domestic violence can go for help; and

- work to establish sex and gender education in schools.

\section{People can join national campaigns to achieve fairness and equality.}

Such campaigns may include those to:

- help girls stay in school;

- save girls' and women's lives by decriminalizing abortion;

- reform laws that punish people based on their sexual identity;

- advocate for greater government spending to prevent and treat maternal health problems (such as obstetric fistula);

- advocate for enforcement of laws that make spousal abuse and marital rape a crime; and

- ensure enforcement of laws that protect gender equality (including in the face of opposition by conservative or religious movements).

\section{People can support or join movements for social change at the global level.}

For example:

- the White Ribbon Campaign (a movement of men and boys around the world to end violence against women);

- arts and culture campaigns (such as Dance4Life) to raise awareness about HIV and AIDS;

- movements to end trafficking in women and girls [see fact sheet on Sex Trafficking]; and

- youth-led networks for sexual and reproductive rights and services. 
9 Some of the activities that people undertake to bring about social change include:

- Research;

- Educating others, both individually and in groups;

- Educating decisionmakers;

- Contacting and educating journalists;

- Writing and signing petitions and letters;

- Working in electoral campaigns;

- Lobbying elected officials for better laws and enforcement;

- Defending in court the rights of people who have been discriminated against or abused;

- Attending parades and rallies;

- Writing proclamations and position statements;

- Attending protest demonstrations and strikes;

- Picketing and boycotting;

- Creating and performing theatrical and musical pieces to promote awareness;

- Setting up direct services to show what can be done; and

- Organizing training workshops to teach health care providers, police, and others in public life about how to better address a particular issue. 


\section{obstacles faced in advocating for social change}

1 Working for justice can be difficult and hazardous. It often involves questioning public opinion or individuals and institutions with authority and power. In some cases it can carry risk of stigma, imprisonment, or physical danger.

2 Because of these risks, questioning or protesting an instance of discrimination directly is not always possible.

3 If questioning or challenging a specific instance of discrimination is not possible, a person may look for a safer way to respond. However, it is important to remember that what is safe in one setting is not always safe in another setting.

Some of the ways that people (including young people) have responded to discrimination include:

- figuring out a way to lessen its effect on themselves or on others;

- talking about it with a trustworthy and experienced person;

- setting up a Web page or blog; and

- finding a few supportive people and then going to speak to an authority. 


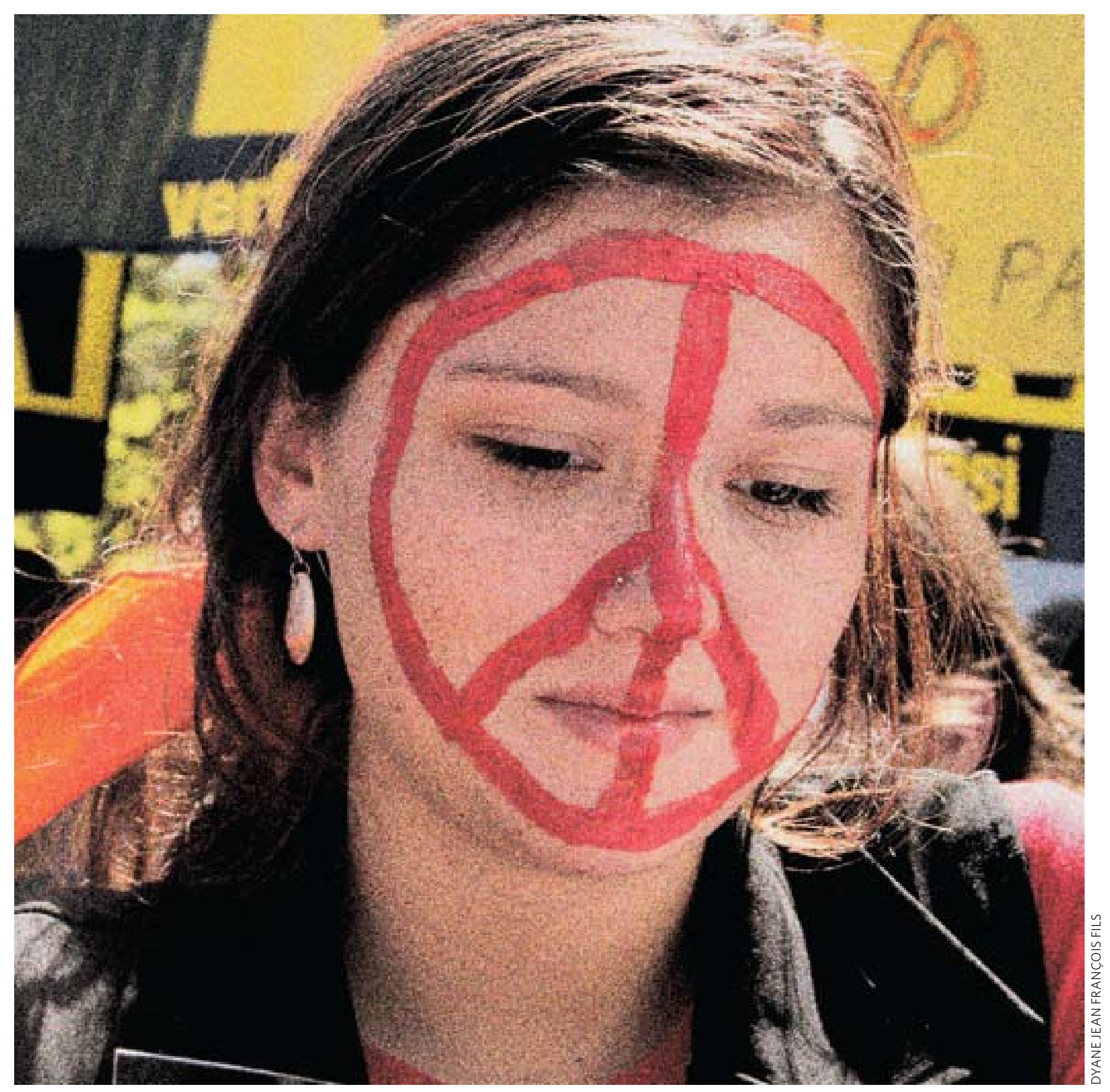




\section{the meaning and power of advocacy in people's lives}

1 People are usually most effective in creating social change if it relates to an issue that they know and care about, often because it affects them directly.

2 People can learn skills for changing the world around them. These skills can be used in many different situations.

3 Whether we work for fairness in our daily personal choices or in organized social campaigns, promoting justice and human rights can give meaning to a person's life and can be personally empowering.

SEE ACTIVITY BOOK

Activity 53

get inspired! creating change

Students select a quote that

inspires them and explore what it would mean to apply the message

of the quote in their own lives. 


\section{taking action: project-based learning}

People can learn skills for changing the world around them, even in the smallest of ways and in the most conservative of settings. These skills can be used in many situations.

Young people can be powerful and effective advocates for change.

The following are important steps for creating social change.

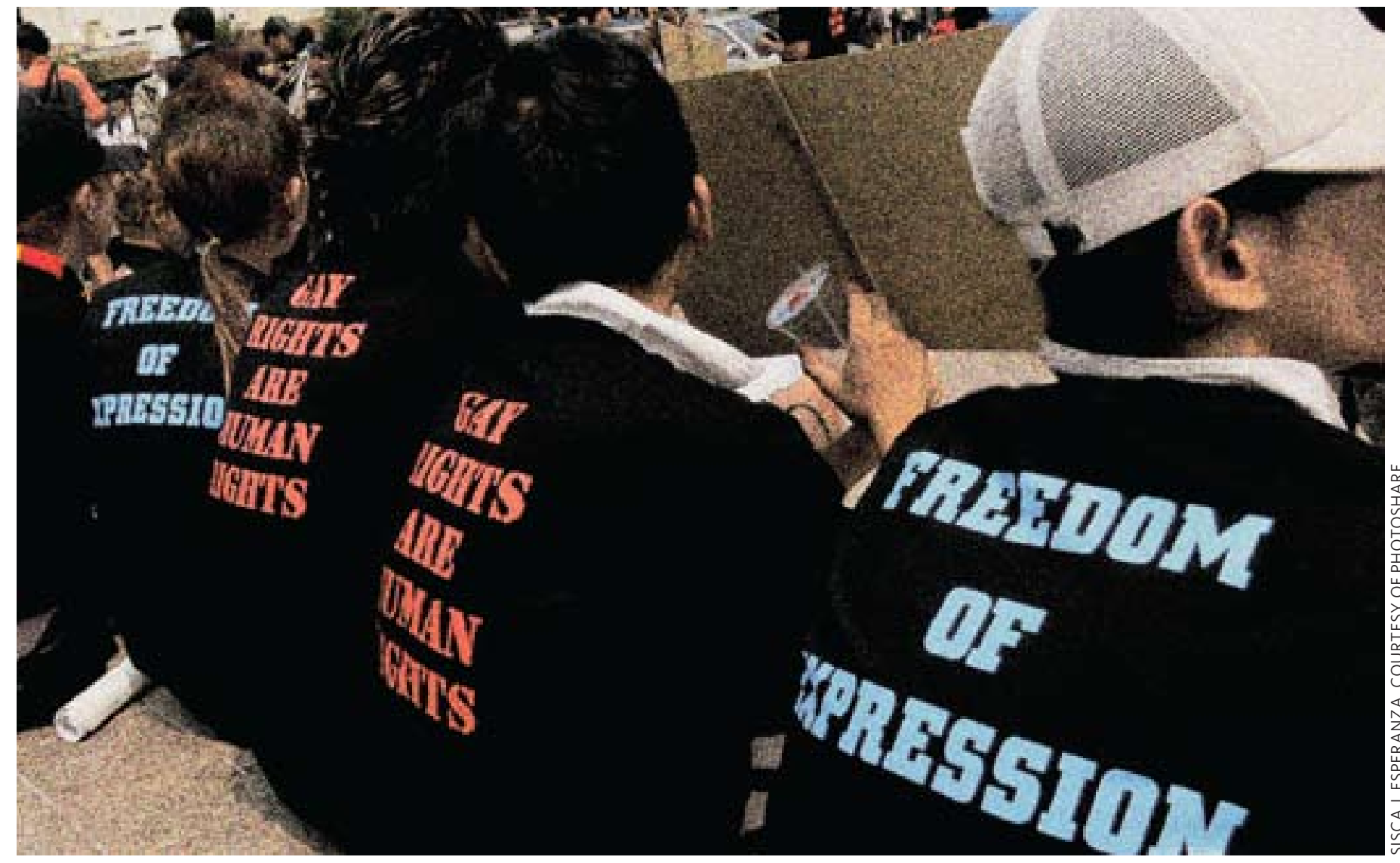


Step 1: Identify an issue or problem that you care about. Think about why you care about this problem. This can be a problem affecting you alone or another person. It can affect a few people, for example, in your family or classroom. It can be a problem that involves all or some members of your community, or even a largescale problem affecting many people in your country or in the world.

\section{Step 2: Gather and analyze information about the problem and who has taken} steps to address it.

For example:

- Gather information about who is already involved in addressing this problem locally or nationally. Figure out how to link yourself to such efforts.

- Talk to other people about how they see the problem.

- When possible, learn more by reading about the problem.

- Identify the underlying roots of the problem.

- Examine what institutions, policies, laws, rules, cultural norms, and resource allocations allow the problem to persist. (You can make a type of "political map" with this information.)

Step 3: Decide what changes you want to achieve. Think about short-term goals and long-term goals. Be imaginative, but also be realistic.

Changes might include:

- changing your own attitudes or behavior;

- increasing knowledge and awareness among the people around you;

- encouraging people to change their behavior and be more responsible about respecting other people's rights;

- changing the rules within a community institution; and

- arranging for certain people to gain access to a program or receive a service they need.

\section{SEE ACTIVITY BOOK}

Activity 54

an issue i care about

Students identify an issue or problem in society that matters to them. 
Step 4: Think about who might be able to help you take steps toward the change you want to see - either by offering advice or by helping you more directly. For example, you might approach a parent, school principal, local community leader, or elected official.

- By talking with other people, you can motivate them to become more supportive or involved. You can benefit from their skills and advice, and you do not need to do everything yourself.

- Pay attention to people's different perspectives.

Step 5: Join an organization or find partners. There is power in numbers!

- Collective efforts — including the voices of people who often go unheard — often receive more attention and are more effective than individual efforts.

- Typically, a person can work more easily for any change — even a small one — if he or she has cooperation and moral support from other people.

Step 6: Identify your key audience (whom you want to reach). As best you can, clarify the message you want to present about the changes you want to see.

Step 7: Brainstorm possible actions that might make the changes happen. Keep in mind the most appropriate way to reach the audience you have targeted.

For example, consider:

- meeting with the school principal or a local community leader;

- writing an article for the school paper;

- hosting a concert or dance to raise money for the change;

- providing educational sessions in the community or in your classroom; and

- getting involved or organizing political participation locally. For example, you can write and distribute leaflets, create and perform a street play, or volunteer for a political campaign that shares your concern and values. 
Step 8: Carefully discuss, study, and compare all possible actions. Then choose those that seem the most achievable and effective. Develop your action plan.

[See Unit 5, pages 151-153.]

Step 9: Consider the barriers you might face in undertaking these actions in your community.

For example:

- You might be ignored.

- You might not be able to obtain all the resources you need.

- You might not have enough allies.

Step 10: Be sure that your actions do not cause harm to you or others. Be sure to ask a trusted adult and other young leaders about risks you may not have considered.

Some potential risks include:

- Social stigma or discipline, at home, at school, or in the community.

- Hostility or even physical harm from someone who is opposed to your actions.

- Financial or legal consequences.

Step 11: Revise your plan, if necessary, to be sure that no harm will come of it. 
Step 12: Identify your opposition. Learn about their arguments and activities. Prepare counterarguments that are accurate and honest.

Step 13: Finalize your action plan.

Step 14: Identify and gather the human and material resources you will need to implement your plan.

Some examples of human resources are:

- people who can help contact the local government;

- people who know how to write a press release;

- people who can help start a website; and

- people who can carry out other tasks involved in delivering your message.

Some examples of material resources are:

- money or donations of food to serve or sell;

- necessary equipment or supplies, which may be borrowed; and

- assistance with travel.

Step 15: Carry out your action plan. 


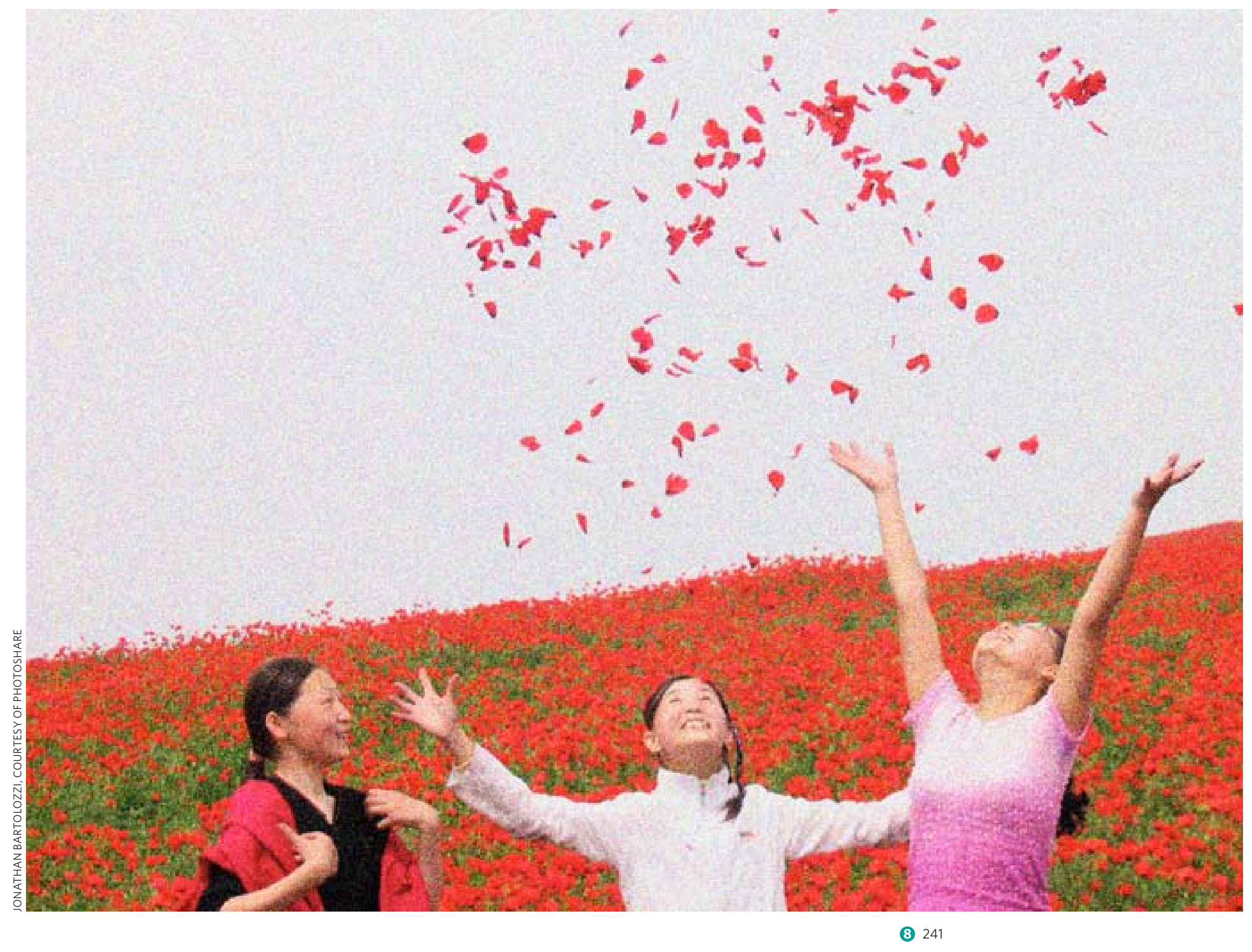


Step 16: Assess the effectiveness of your work in terms of your short-term and long-term goals. Make adjustments. Seek advice and support from others if necessary.

Step 17: Keep working on the problem. Social change is usually a long-term goal.

Change is possible. You can always find something you can do, no matter how small. Do not be discouraged if the problems seem large and overwhelming.

Finally, keep in mind that while you try to change the world around you, you must be fair, respectful, and just in your own everyday actions and interactions. 
"Be the change you want to see in the world."

- Mahatma Gandhi

"It is not required that you finish the work. But neither are you free to abandon it."

- Adapted from Rabbi Tarfon, Mishnah, Avot

"You gotta have a dream; if you don't have a dream, how you gonna have a dream come true?"

— Oscar Hammerstein, "Happy Talk" 


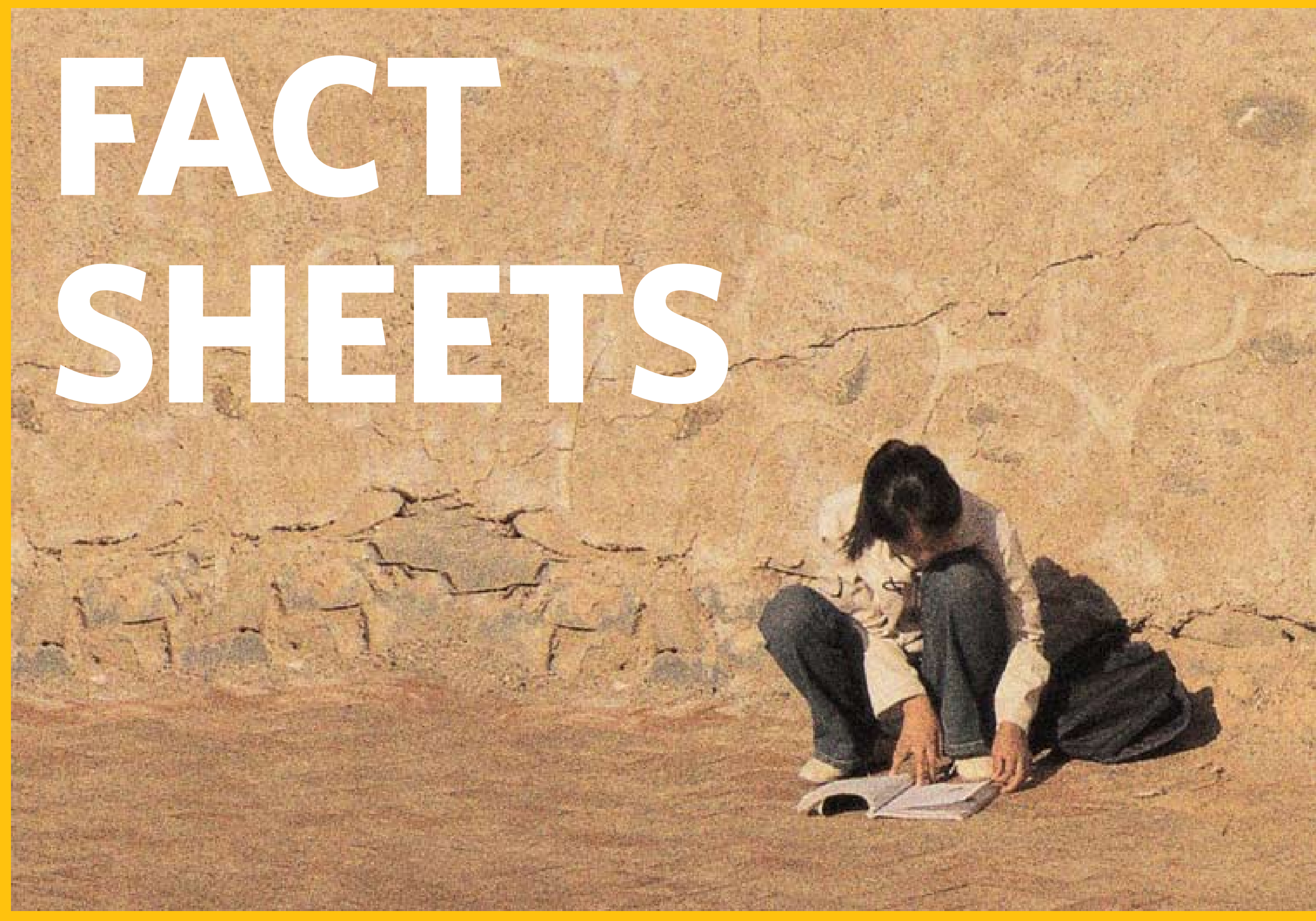


247 abortion

248 anatomy and sexual pleasure

249 cancers of the reproductive system

250 childbirth and breastfeeding

252 contraceptive methods

256 emergency contraception (EC)

257 female genital mutilation

258 HIV (human immunodeficiency virus) and AIDS (acquired immune deficiency syndrome)

260 infertility and assisted reproduction

261 menstrual cycle (also called the ovulatory cycle)

263 nutrition, healthy physical activity, and substance abuse

265 puberty and boys

266 puberty and girls

268 reproduction and pregnancy

270 reproductive tract infections that are not sexually transmitted

271 sex selection

272 sex trafficking

273 sexual and reproductive systems - female

275 sexual and reproductive systems - male

277 sexually transmitted infections (STIs)

279 United Nations agreements

280 violence against women and girls, including sexual violence 


\section{What is abortion?}

Abortion is the ending of pregnancy before the fetus is viable. A pregnancy that ends on its own is called a spontaneous abortion or a miscarriage. Or an abortion may be induced - that is, a woman or girl may seek to end a pregnancy. People decide to seek an abortion for many different personal and health reasons.

\section{How common is abortion?}

Abortion is very common. About one in five pregnancies ends in spontaneous abortion (often before the woman is aware that she is pregnant). A similar number - about one in five pregnancies - ends in induced abortion. Most abortions - whether spontaneous or induced - take place when the pregnancy is eight weeks of gestation or earlier.

\section{What does an induced abortion entail?}

There are two primary methods of induced abortion. One is a brief procedure during which a health care provider uses medical instruments. The instruments are used to suction or remove the contents of the uterus (the blood-rich lining that holds the embryo or, in later abortions, the fetus; this lining is expelled during the menstrual period if the woman is not pregnant). The second method involves taking one or more pills that trigger uterine cramping and the start of menstrual bleeding. By this method, a woman expels the lining of her uterus and with it, the embryo. Occasionally, part of the lining remains in the uterus. In such a case, the health care provider uses medical instruments to complete the procedure (as described above). Both methods are effective if performed under proper conditions.

\section{Is abortion safe?}

When performed under proper conditions, an abortion is a simple and safe procedure. The procedure must be conducted by a trained health care provider using proper equipment, technique, and sanitary standards. Abortion is safest early in pregnancy. When performed during the first half of pregnancy (as virtually all abortions are), it is much safer than having a baby.

In many places, however, abortions are performed by people who lack the necessary skills. Often they are performed in an environment that does not meet minimum medical standards. In these situations, abortion carries great risk. Globally, nearly half of all abortions are unsafe, and nearly all of these (95 percent) are performed in developing countries. The risk is often greatest in rural areas. As a result, nearly 70,000 women and girls die every year from complications of unsafe abortion. These deaths are preventable.

\section{Is abortion legal?}

In most countries, induced abortion is legal under some or all circumstances. Where it is legal, it tends to be safer. Where abortion is criminalized, unsafe procedures are common, and women and girls suffer health complications.

Criminalizing abortion does not make it less common. In fact, some of the countries with the most restrictive abortion laws have the highest rates of abortion.

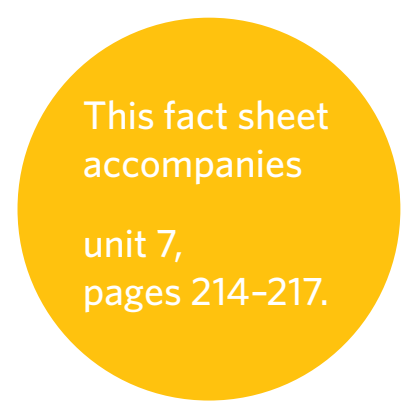



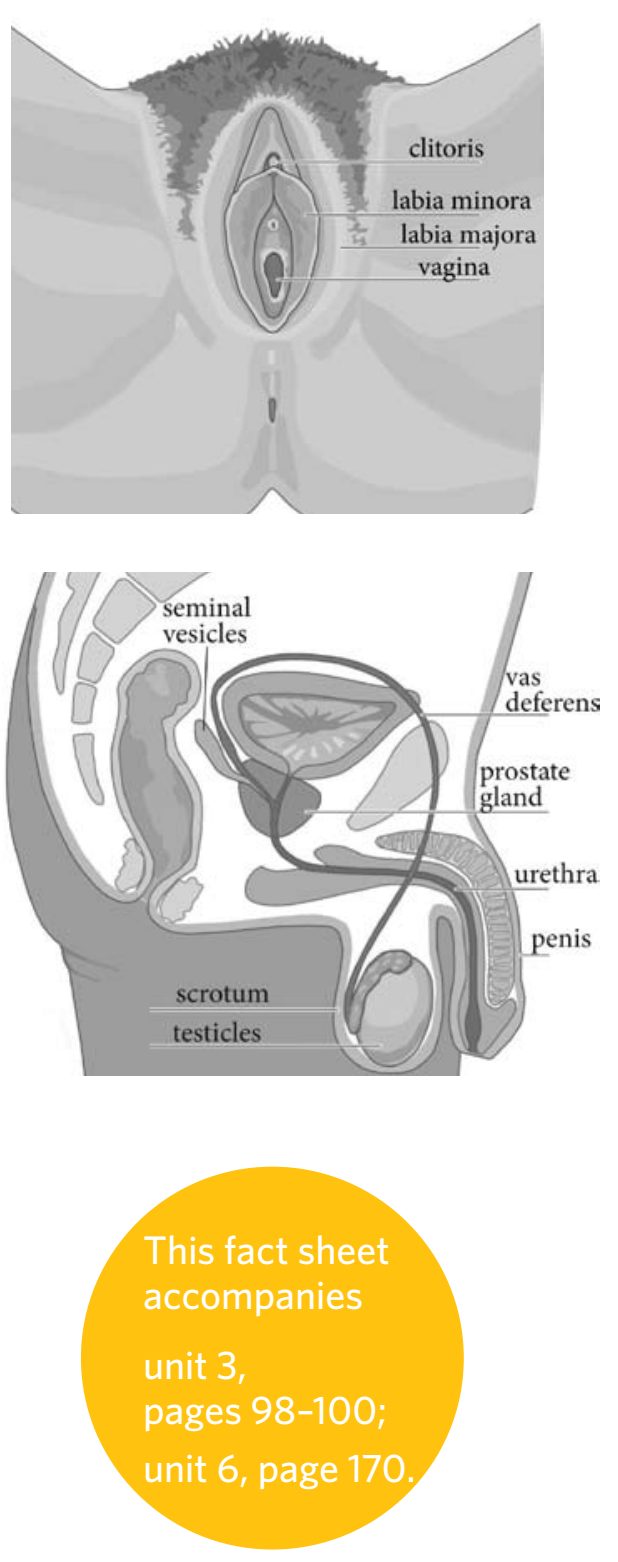

Sexual response is not the same in any two people. It is often affected by past experiences, cultural attitudes, and feelings about one's sexual partner and about the specific sexual situation. Age; physical state (including illness or fatigue); use of alcohol, drugs, or medication; and emotional state (including a sense of comfort or anxiety) may also affect sexual response. These factors are examples of why it is sometimes said that the brain may be the most important organ involved in sexual arousal.

\section{What happens during sexual arousal?}

Sexual arousal refers to the body's response to wanting, anticipating, and participating in sex. It begins with sexual stimulation from, for example, a touch, smell, sight, taste, sound, thought, or fantasy that has erotic meaning to a person. Males are often particularly aroused if the penis or scrotum is touched or stroked. In females, the most sensitive organ is the clitoris. The clitoris is rich in nerve endings, and sexual pleasure is the sole function of the clitoris. Both the penis and the clitoris fill with blood and become more erect in response to arousal; this engorgement increases their size and sensitivity.

Sexual arousal also involves the responses of other organs. Heart rate increases, muscles become tense, blood pressure is elevated, skin may flush, and nipples may become erect. In women, the vagina becomes moister and expands. In men, the scrotum is pulled closer to the body, a gland releases a fluid that cleans the urethra, and the bladder closes so that urine and semen cannot mix. During a sexual experience, the level of arousal can go up and down. Arousal may last for just a few minutes or for several hours.

If sexual stimulation continues, arousal may intensify and lead to orgasm. Just before orgasm, breathing, blood pressure, and heart rate increase. Becoming aroused and reaching orgasm often take longer in women than in men.
Although some women perceive sensitive areas in the vagina (sometimes called the "G-spot"), most women reach orgasm through direct stimulation of the clitoris rather than through intercourse.

\section{What happens during an orgasm?}

Orgasm is a peak of sexual pleasure. It is accompanied by a series of rhythmic contractions in the pelvic area, contractions and sensations of pleasure throughout the body, and a sudden release of sexual tension. With orgasm, the body also releases chemicals called endorphins, which produce good feelings. The experience of orgasm varies greatly among people and from one orgasm to another in the same person. Some women can have more than one orgasm in a relatively short period of time; in fact they may experience the urge to do so. The vagina becomes more lubricated with fluid secretions after orgasm.

In men, orgasm is usually, but not always, accompanied by ejaculation. During an ejaculation, the prostate, seminal vesicles and vas deferens contract, releasing their fluids, which mix with sperm produced by the testicles, to form semen. At this point, men sense that ejaculation is unstoppable. Then, the pelvic muscles contract, pushing the semen out of the penis through the urethra. After ejaculation, men cannot become erect again for a period of time, varying from several minutes to 24 hours. The length of this period increases with age.

\section{What happens when you become sexually excited but do not have an orgasm?}

After orgasm, blood flows back out of the congested organs. Blood pressure and heart rate return to their resting state and muscular tension is released. If a person does not experience an orgasm, the blood congestion may cause temporary discomfort. This feeling goes away on its own, usually in less than an hour, and has no lasting effect. 
Cancers of the reproductive organs may affect both men and women. Some of the more common reproductive cancers are described below.

\section{What reproductive cancers affect women?}

Breast cancer is the most common and deadliest cancer among women in both developed and developing countries, accounting for 1 in 10 of all new cancers worldwide each year. Cervical cancer is the second most common, but is found primarily in developing countries, where, due to limited screening, four-fifths of all cases and related deaths occur. For all types of cancer, early diagnosis and treatment make a cure more likely.

\section{How does breast cancer screening work?}

Screening for breast cancer is performed using examinations and mammography. Women older than 20 should examine their breasts every month to familiarize themselves with their feel and to look for changes. Bloody or pus-like discharge from the nipples or new, hard lumps should be checked by a health care provider. Guidelines for breast cancer screening (clinical examinations and procedures) vary widely, depending on a woman's own risk factors and on local resources. Mammograms are $\mathrm{x}$-rays of the breast that can detect changes that may indicate cancer. However, mammograms do not find all breast cancers and can find changes which further testing determines are not cancer. If a change is found, a biopsy (laboratory analysis) is performed to determine if it is cancer. Eight of ten breast lumps are not cancer. Breast cancer can be treated with surgery, radiation, and/or chemotherapy (drugs).

\section{How can women prevent cervical cancer?}

Most cases of cervical cancer are caused by certain types of human papilloma virus (HPV, see STI fact sheet). HPV can be prevented by vaccination, preferably when a girl is young, before she becomes sexually active. Condoms also reduce the risk of HPV infection. A test (Pap smear) conducted during a pelvic exam can detect precancerous cells or lesions, which can be treated by a simple procedure. If possible, women who are sexually active should be screened regularly.

\section{What is ovarian cancer?}

Ovarian cancer occurs more frequently in women older than 55 and among women living in developed countries. Often, women have no symptoms until the cancer is relatively advanced. Methods to diagnose and treat ovarian cancer are still in the early stages.

\section{What reproductive cancers affect men?}

The male reproductive organ that is most likely to be affected by cancer is the prostate gland. Prostate cancer typically affects older men, and grows slowly. Cancer of the testicle is more likely to affect young men (18-35); however, testicular cancer is less common and can usually be successfully treated if caught early. Men can also learn to do a self-exam to identify abnormal growths in the testicles. Some strains of HPV (not those strains that cause warts) can lead to cancer in the penis or anus.

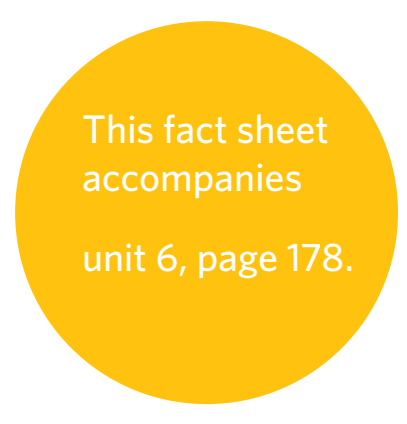




\section{What happens during childbirth?}

When a woman is about to give birth, her body enters a stage called "labor." Labor often begins with one or more of the following: clear or pink-colored mucus flowing from the vagina; amniotic fluid flowing from the vagina; and contractions of the uterus that are perceived as a hardening of the belly. The intensity of the contractions increases during labor. The cervix opens and the uterine contractions help push the baby through the opened cervix and vagina. Labor generally lasts between 5 and 18 hours, but varies among women. It usually becomes quite painful (although the perception of pain varies among women and may depend on the preparation the woman made during antenatal care), exhausting, and can be anxiety provoking. However, many women experience labor and childbirth as a wonderful and incredible experience.

\section{What is a cesarean section?}

Cesarean section, also known as c-section, is a surgical method of childbirth. During this procedure, an incision is made through the woman's abdomen and uterus and the baby is removed. It is usually performed when a vaginal delivery would put the mother's or baby's life or health at risk. Sometimes it is performed for the benefit of the doctor rather than for that of the woman or baby, for example to allow the doctor to schedule a convenient time for delivery. Unnecessary cesarean sections may increase risks to the

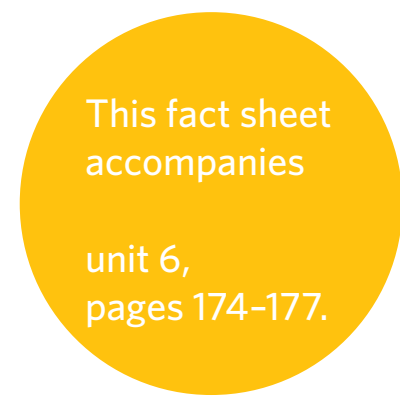

\section{What help do women need when giving birth?}

Wherever a woman gives birth — whether at home, in a health post, or in a hospital — she needs assistance from a trained person such as a midwife or doctor. Proper conditions and access to emergency care are also necessary in case of complications. Conditions and practices related to childbirth vary around the world. In some countries, all women have access to skilled assistance, but in other places most women give birth at home without the help of a trained attendant and lacking proper conditions and emergency backup care. In some places, women in labor also rely on support from other women. In other places, the woman's husband or partner is present and can give her support. Some women give birth alone, without any help.

\section{What are the consequences of giving birth without skilled assistance?}

Because complications occur in about 15 percent of all births, the lack of trained assistance and access to emergency care results in preventable illness and death. Every year, more than half a million women die and 8 to 15 million women suffer serious injury or disability, such as obstetric fistula, from causes related to pregnancy and birth. Nearly all of these deaths occur in developing countries. Almost all of these deaths could be prevented with skilled attendance at delivery and timely emergency obstetric care for complications, use of family planning methods to reduce unintended pregnancies, and access to safe abortion services. 


\section{What is an obstetric fistula and how does it affect women?}

An obstetric fistula is an opening between the vagina and the bladder or rectum, sometimes both, that allows urine and/ or feces to leak continuously. When a woman experiences blocked labor and has no access to a cesarean section procedure, the prolonged pressure of the baby's head on the tissue between the bladder and the vagina or rectum can cause an opening, called a fistula.

In most cases, the baby dies because of the prolonged labor. For the woman, the ongoing smell of leaking urine or feces, or both, is constant and humiliating; many women and girls with this condition are abandoned by their husbands and avoided or shunned by their family, friends, and communities. Untreated, fistula can lead to chronic medical problems, including ulcerations, kidney disease, and nerve damage to the legs.

About 100,000 cases of obstetric fistula occur each year, mostly in sub-Saharan Africa and Asia. Fistulas occur disproportionately among impoverished girls and women, particularly those who have small pelvises, because their growth is not yet complete or has been stunted by malnutrition. Fistulas can usually be surgically repaired at a hospital. However, an estimated two million women are living with untreated fistula.

\section{Why is breastfeeding important?}

Breastmilk is the only perfect food for a baby, especially for a newborn. The first yellow-colored milk, called colostrum, is rich in nutrients and antibodies that protect the baby from diseases and infections. Colostrum also helps to clean the baby's gut. Breastfeeding during the first hour after birth helps the uterus to stop bleeding and the milk to start flowing. In addition, breastmilk is always clean, ready, and of the right temperature. It helps the mother and baby to feel close, and it costs nothing. (The World Health Organization recommends breastfeeding without other food for the first six months of a baby's life. If possible, extend breastfeeding beyond six months in combination with safe and nutritious foods.)

\section{What can a pregnant woman who is HIV-positive do to} reduce the chance of passing the virus to her baby?

A pregnant HIV-positive woman can transmit the virus to her baby during pregnancy, labor, and delivery, and through breastfeeding. If she takes no preventive drugs and breastfeeds, she runs about a 20 to 45 percent chance of transmitting her infection to her baby. Today, however, effective drugs can prevent the transmission of HIV from a mother to her baby during and after pregnancy. An HIV-positive woman who is or wants to become pregnant should seek the advice of a physician about which drugs to take and when. HIV-positive mothers should also speak with their health care providers about appropriate feeding options for their newborn that can reduce the chance of transmission through breastmilk. In areas where a mother may not have regular access to safe water and infant formula, it is better to breastfeed exclusively for the first six months and then to wean abruptly. Combining breastfeeding with commercial formula or starter foods carries the greatest risk of passing HIV infection from mother to child. By taking preventive medicines and following the appropriate feeding guidelines, an HIV-positive mother can reduce the chance of passing HIV to her baby. 


\section{contraceptive methods}

\section{temporary "user-controlled" methods that block the sperm from reaching the egg}

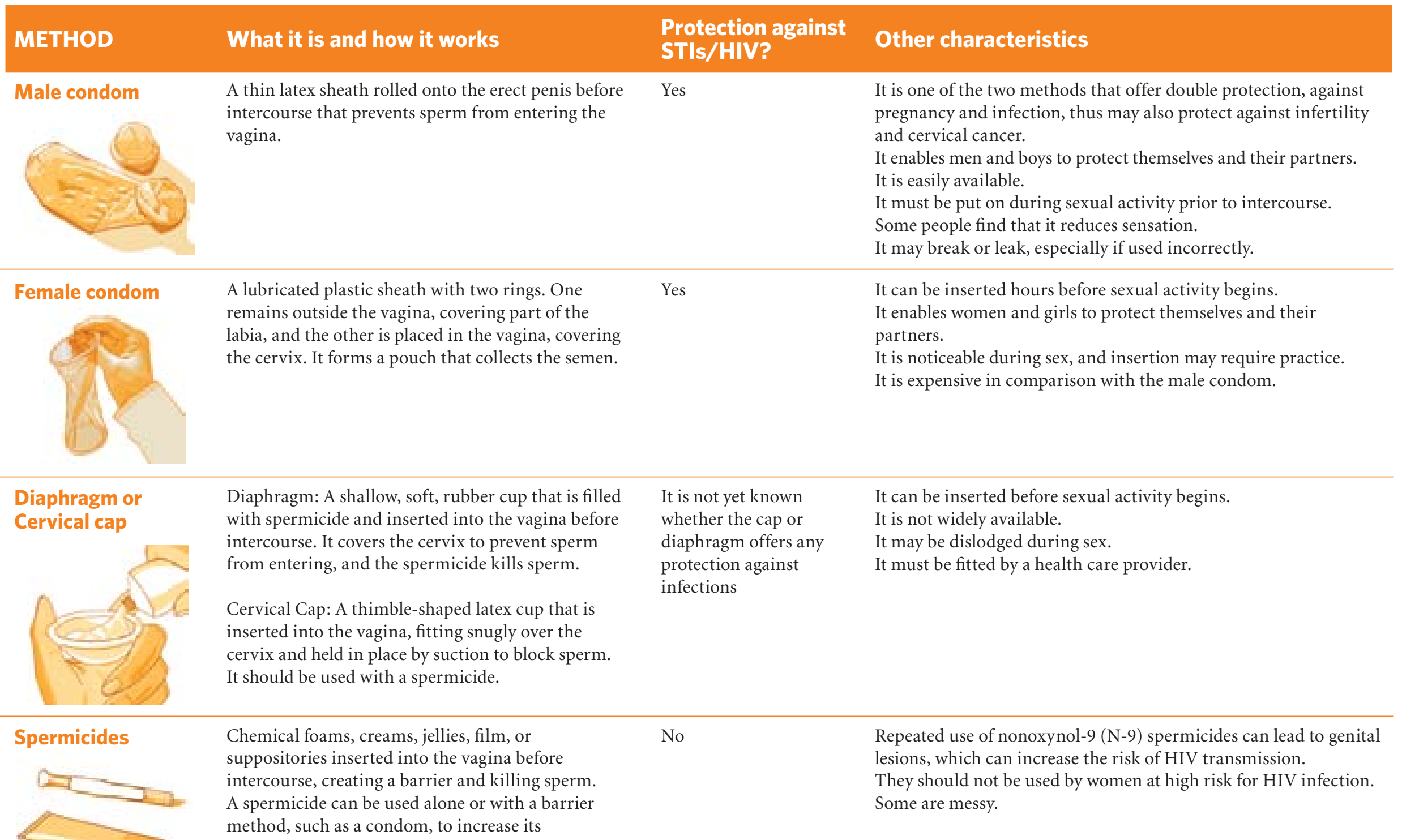

effectiveness.

Note: This fact sheet accompanies the content in unit 7, pages 210-213.

For additional information, including on side effects, effectiveness, and how to use, see <www.who.int/reproductivehealth/publications/family_planning/9780978856304/en/index.html>. 


\section{long-acting methods that work inside the body's system}

\begin{tabular}{|c|c|c|c|}
\hline METHOD & What it is and how it works & $\begin{array}{l}\text { Protection against } \\
\text { STIs/HIV? }\end{array}$ & Other characteristics \\
\hline 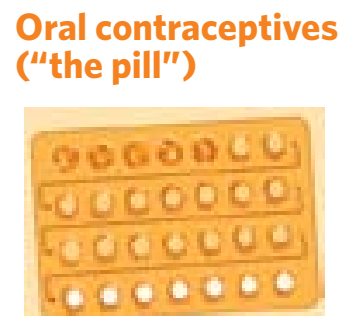 & $\begin{array}{l}\text { Small pills containing synthetic hormones } \\
\text { (estrogen and progestin, or only progestin) that } \\
\text { prevent ovulation and interfere in sperm migration } \\
\text { by thickening the cervical mucus. They are taken } \\
\text { orally every day by the woman for } 21 \text { or } 28 \text { days, } \\
\text { depending on the brand and type. }\end{array}$ & No & $\begin{array}{l}\text { It does not require the woman to insert or apply anything at the } \\
\text { time of sexual relations. } \\
\text { It may reduce menstrual cramps and the risk of certain kinds of } \\
\text { cancer, anemia, breast problems, and pelvic inflammatory disease. } \\
\text { The woman must remember to take the pill regularly. } \\
\text { Typically, fertility resumes quickly after the woman stops taking } \\
\text { the pill. }\end{array}$ \\
\hline Injectables & $\begin{array}{l}\text { An injection given at regular intervals, usually } \\
\text { every one or three months, containing progestin, } \\
\text { a synthetic hormone that prevents ovulation and } \\
\text { thickens the cervical mucus. }\end{array}$ & No & $\begin{array}{l}\text { The method can be used without the knowledge of others. } \\
\text { It does not require the woman to insert or apply anything at the } \\
\text { time of sexual relations. } \\
\text { It may decrease the risk of certain kinds of cancer. } \\
\text { Fertility resumes within a few months after stopping use. }\end{array}$ \\
\hline Vaginal ring & $\begin{array}{l}\text { A thin, soft, flexible ring inserted in the vagina } \\
\text { by the woman. It slowly releases estrogen and } \\
\text { progestin, stopping ovulation and thickening the } \\
\text { cervical mucus. }\end{array}$ & No & $\begin{array}{l}\text { It does not require the woman to insert or apply anything at the } \\
\text { time of sexual relations. } \\
\text { After the woman stops using it, fertility returns immediately. }\end{array}$ \\
\hline Contraceptive patch & $\begin{array}{l}\text { A small adhesive patch applied to the skin that } \\
\text { slowly releases progestin and estrogen through the } \\
\text { skin to prevent ovulation and thicken the cervical } \\
\text { mucus. }\end{array}$ & No & $\begin{array}{l}\text { It does not require the woman to insert or apply anything at the } \\
\text { time of sexual relations. } \\
\text { It is less effective for women weighing more than } 90 \text { kilos (198 lbs.) } \\
\text { than for other women. } \\
\text { After the woman stops using it, fertility quickly returns. }\end{array}$ \\
\hline Implants & $\begin{array}{l}\text { One or two small, soft rods implanted in the woman's } \\
\text { upper arm that release a steady low dose of progestin } \\
\text { over a period of three to five years. Thickens the } \\
\text { cervical mucus and inhibits ovulation. }\end{array}$ & No & $\begin{array}{l}\text { Implants can be removed at any time, but they must be inserted } \\
\text { and removed by a trained provider. } \\
\text { It does not require the woman to insert or apply anything at the } \\
\text { time of sexual relations. } \\
\text { Fertility resumes immediately upon removal. }\end{array}$ \\
\hline
\end{tabular}


Intrauterine devices (IUDs)

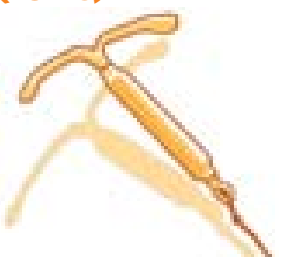

No placed in the uterus by a health care provider

IUDs release progestin (a hormone), while others contain copper, which has antifertility effects. They

keep the sperm from reaching the egg. Some types of

IUDs can work for as long as ten years.
This method does not interrupt sex; it is not noticeable during intercourse.

If an infection is present during insertion, or if the conditions for insertion are not sterile, insertion may lead to pelvic infection and increased risk of infertility.

The body sometimes expels the IUD.

It must be inserted and removed by a trained provider.

\section{"natural methods" - methods that require specific behaviors and an understanding of one's body}

\section{METHOD \\ Lactational \\ amenorrhea method

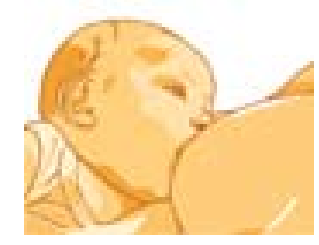

\section{What it is and how it works}

For breastfeeding women only. Breastfeeding causes

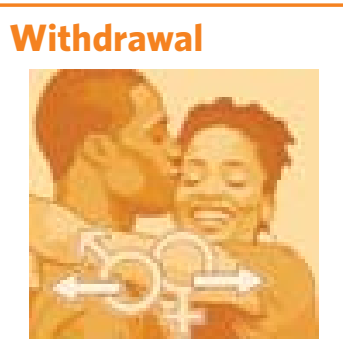

Cervical mucus method of fertility awareness

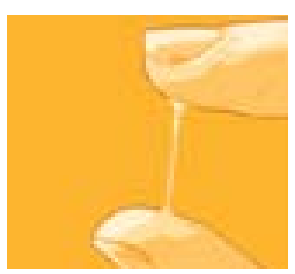

The cervix secretes mucus that can be observed when wiping after urination or on underwear. The type and amount of this mucus changes during the woman's cycle. A woman can learn to tell which type of mucus indicates that she might be fertile and which type indicates that she is not fertile. During fertile days, she can use a barrier method of contraception or she can abstain from intercourse. (See fact sheet on Menstrual Cycle). ovulation. As contraception, this method is effective only during the first six months of breastfeeding or until the woman has resumed menstruation only breastmilk and on demand.
Pulling the penis out of the vagina and away before ejaculating prevents sperm from entering the vagina. This method can be effective if used correctly and consistently.

\section{Protection against STIs/HIV?}

No

This method increases a woman's awareness and understanding of her body.

It allows a woman to predict when she will begin her next menstrual cycle.

It can also help couples who are trying to become pregnant to identify the most fertile days of the cycle.

It is acceptable to religious groups that oppose the use of other methods. It requires time to learn the method, the discipline to maintain daily observation of mucus, and the cooperation of the woman's partner. 


\begin{tabular}{|c|c|c|c|}
\hline $\begin{array}{l}\text { Temperature } \\
\text { method of fertility } \\
\text { awareness }\end{array}$ & $\begin{array}{l}\text { A woman's body temperature rises slightly with } \\
\text { ovulation. By taking her temperature every morning } \\
\text { before getting out of bed or moving around, she can } \\
\text { identify when ovulation has occurred. Ovulation } \\
\text { cannot be predicted, but a few days after ovulation } \\
\text { occurs, the woman knows she is not fertile for the } \\
\text { remainder of the cycle. Until ovulation has occurred, } \\
\text { she can use a barrier method of contraception or she } \\
\text { can abstain from intercourse. }\end{array}$ & No & $\begin{array}{l}\text { A special thermometer called a basal body thermometer is needed } \\
\text { that enables the user to notice slight differences in temperature. } \\
\text { Because the woman's temperature sometimes dips just before } \\
\text { ovulation, the method can help couples who are trying to become } \\
\text { pregnant to identify the most fertile days of the cycle. } \\
\text { This method requires the woman's partner's cooperation. }\end{array}$ \\
\hline $\begin{array}{l}\text { Calendar, Standard } \\
\text { Days, or CycleBeads } \\
\text { methods }\end{array}$ & $\begin{array}{l}\text { Many women have menstrual cycles that are fairly } \\
\text { predictable in terms of how often a new cycle starts. } \\
\text { CycleBeads (used for the Standard Days Method) } \\
\text { and the calendar are two methods that a woman } \\
\text { can use to identify the fertile days during which } \\
\text { she can abstain from sex or use a barrier method of } \\
\text { contraception. }\end{array}$ & No & $\begin{array}{l}\text { This method is most practical for women with regular cycles. } \\
\text { It can also help couples who are trying to become pregnant to } \\
\text { identify the most fertile days of the cycle. } \\
\text { It requires the woman's partner's cooperation. }\end{array}$ \\
\hline
\end{tabular}

\section{permanent surgical methods}

\begin{tabular}{|c|c|c|c|}
\hline METHOD & What it is and how it works & $\begin{array}{l}\text { Protection against } \\
\text { STIs/HIV? }\end{array}$ & Other characteristics \\
\hline $\begin{array}{l}\text { Vasectomy, male } \\
\text { sterilization }\end{array}$ & $\begin{array}{l}\text { A simple, outpatient operation in which the vas } \\
\text { deferens is cut and tied. Sperm then are harmlessly } \\
\text { reabsorbed into the man's body, rather than } \\
\text { entering the semen. It does not change a man's } \\
\text { ability to have sex, feel sexual pleasure, or ejaculate. }\end{array}$ & No & $\begin{array}{l}\text { Vasectomy is not effective until three months after the surgery. } \\
\text { This is a permanent method. }\end{array}$ \\
\hline $\begin{array}{l}\text { Female sterilization, } \\
\text { tubal sterilization } \\
\qquad l+1\end{array}$ & $\begin{array}{l}\text { A surgical procedure to cut and tie (tubal ligation), } \\
\text { or block, the fallopian tubes, preventing the sperm } \\
\text { and egg from meeting. It does not change a woman's } \\
\text { ability to have sex or to feel sexual pleasure. }\end{array}$ & No & This is a permanent method. \\
\hline
\end{tabular}




\section{What is emergency contraception?}

Emergency contraception (EC) refers to methods of preventing pregnancy that can be used after unprotected intercourse has occurred. For example, it can be used after contraceptive failure (such as in cases where a condom breaks), when a method has been used incorrectly, after having sex without contraception, or after rape. EC can prevent pregnancy if taken within five days after unprotected sex, but works best when taken as early as possible within this time period. EC is not abortion.

\section{What methods are used for emergency contraception?}

Pills - Pills containing progestin (a hormone contained in many contraceptive pills) are the most common EC method. As of 2009, the recommendation is to take one pill containing $1.5 \mathrm{mg}$ of this hormone or two pills containing $.75 \mathrm{mg}$ each. The pill or pills may be taken in a single dose or in two doses, the first as soon as possible after unprotected sex and the second 12 hours later. In some places EC comes pre-packaged as two pills. The method is sometimes called the "morningafter pill." Regular contraceptive pills taken for a short time at a much higher dosage than usual can also work, but the dosage depends on the type and brand of pill and must be determined by a knowledgeable health care provider.

IUD - Another emergency contraceptive method is the copper-releasing intrauterine device (IUD), which can be inserted by a trained health care provider within five to seven days after the woman has had unprotected sex. The IUD is not appropriate for women at risk of a sexually transmitted infection, however, and in some countries, it has not been approved for emergency contraception.

\section{How do they work?}

EC pills work by preventing ovulation (see fact sheet on the Menstrual Cycle), preventing an egg and sperm from joining, or preventing implantation, whereby a fertilized egg attaches to the uterus (see fact sheet on Reproduction and Pregnancy). EC does not cause an abortion, because it does not work if the woman is already pregnant.

Copper-releasing IUDs are believed to work by interfering with implantation.

\section{How effective is emergency contraception?}

The effectiveness of emergency contraceptive pills depends on the type of pill that is used and how soon it is taken after having unprotected sex. The sooner the pills are taken after unprotected sex, the more effective they are. Estimates suggest that EC pills are about 90 percent effective in preventing pregnancy. Emergency IUD insertion is 99 percent effective.

\section{Does emergency contraception protect against sexually} transmitted infections?

Emergency contraception provides no protection against sexually transmitted infections, including HIV.

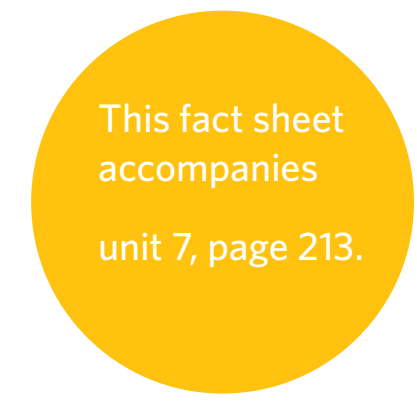




\section{What is female genital mutilation?}

Female genital mutilation (FGM), also known as female genital cutting or female circumcision, refers to the surgical removal of part or all of a female's external genitals. It is performed on girls of different ages, most commonly around the age of seven to ten. It may involve any or all of the following:

- partial or total removal of the clitoris;

- cutting off all or part of the clitoris and the inner lips of the vulva;

- sewing closed the two sides of the vulva, leaving a small opening to allow urine and menstrual blood to pass, a procedure called infibulation; and

- other harmful practices, such as piercing, stretching, or burning the clitoris and labia; scraping or cutting vaginal tissue; or putting corrosive substances into the vagina to cause bleeding or tightening.

\section{What are the health consequences of FGM?}

FGM often has serious physical, sexual, and mental health consequences that vary according to the type of procedure, the conditions in which it is performed, and the physical condition of the girl or woman. Immediate consequences may include infection, bleeding, severe pain, shock, problems with urination, and tissue injury. Excessive bleeding and infection may lead to death. Over the long term, FGM can cause difficulties with menstruation, sexual intercourse and enjoyment, fertility, childbirth, excretion of urine and feces, and with mental health, including fear and depression.

\section{Why is FGM performed?}

The reasons given for the procedure vary, but are often related to tradition and to maintaining prevailing gender norms. As a traditional rite of passage, FGM signifies a girl's acceptance into society and eligibility for marriage. Other specific reasons are to reduce women's sexual desire so that they will not have sexual relations outside marriage; to reinforce cultural identity; to comply with local cultural attitudes about "attractiveness"; and for beliefs associated with religion, although the procedure is not required by any religion.

\section{Where is FGM practiced? How many women are affected?}

FGM is performed in 28 African countries and in several countries in Asia and the Middle East, and among immigrant populations in Europe, Australia, Canada, and the United States. An estimated 100 to 140 million girls and women have undergone female genital mutilation, and about two to three million more girls are at risk each year.

\section{What human rights does FGM violate?}

FGM is a form of violence against girls and women. It violates or jeopardizes the enjoyment of the right to life; the right to physical integrity; the right to the highest attainable standard of health; the right to freedom from cruel, inhuman, or degrading treatment, including physical or mental violence, injury, or abuse; the right to live in dignity, free from gender discrimination; and the rights of the child to development, protection, and participation.

\section{What is being done to end FGM?}

International bodies, governmental agencies, and many nongovernmental organizations are working to end FGM. Many countries and communities have banned it.

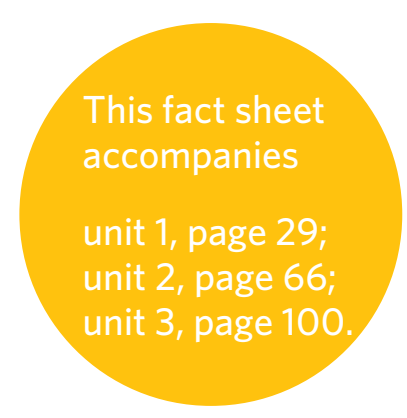


Also see fact sheet on Sexually Transmitted Infections.

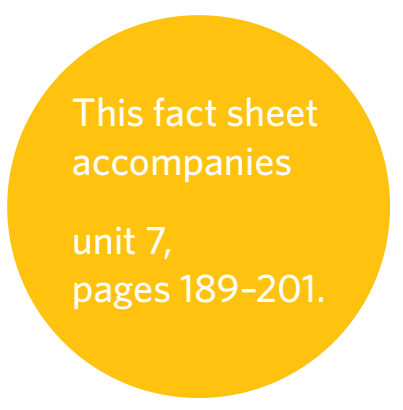

\section{HIV (human immunodeficiency virus) and AIDS (acquired immune deficiency syndrome)}

\section{What is the difference between HIV and AIDS?}

HIV (human immunodeficiency virus) is a virus that attacks and breaks down a person's immune system. When the immune system becomes weak from HIV, the body can no longer fight off illness and may develop serious, often life-threatening, infections and cancers. This condition is known as AIDS (acquired immune deficiency syndrome). People with HIV may also be diagnosed with AIDS if their blood tests show that their cells that fight diseases have fallen below a certain number.

\section{How is HIV transmitted?}

HIV is present in the bodily fluids of persons infected with the virus. A person who is HIV-positive can pass the virus to others through their semen (including the pre-ejaculate), vaginal secretions, breastmilk, or blood. The virus is most commonly transmitted through the exchange of semen and vaginal secretions during sex. HIV is transmitted not only through vaginal or anal sex between a man and a woman; it can also be transmitted through anal sex between two men. Having a sexually transmitted infection can increase the risk of acquiring or passing HIV during sex. HIV can also be passed to others by transfusion of infected blood or by sharing needles with an infected individual for drug or steroid use, body piercing, or tattooing. HIV can also be passed from an HIV-positive mother to her baby during pregnancy, delivery, or breastfeeding. Oral sex also carries some risk for HIV transmission.

Although using contaminated instruments during manicures, pedicures, or shaving may carry a risk of infection, HIV transmission through these routes is highly unlikely. HIV cannot be transmitted by touching, kissing, sneezing, coughing, or by sharing food, drink, or utensils, or through everyday contact at work, school, or home. It is not transmitted by using swimming pools, public toilets, or through insect bites. HIV cannot be transmitted by saliva, tears or sweat. Urine and feces do not transmit HIV if they do not contain blood.

\section{How can HIV be prevented?}

Currently no vaccine or cure for HIV has been developed, so prevention is essential.

Sexual transmission can be prevented by abstaining from unprotected sexual intercourse or by using male or female condoms for every instance of intercourse. Another approach to prevention is to confine oneself to a single sex partner, that is, to be "faithful" or monogamous. This approach works only if both partners are truly monogamous and if both partners are HIV negative. Unfortunately, many people are unaware that they — or their partner — are already infected with HIV; the only way to be certain is to be tested for HIV. Moreover, no one can guarantee that his or her partner will never have another sex partner. For these reasons, the "be faithful" approach carries risks for many people. For men, circumcision offers some protection against HIV, but it does not eliminate the risk of infection. For women there are currently no known direct benefits of male circumcision. Therefore, circumcised males should still use condoms.

Needle transmission from sharing an infected needle can also be prevented by using only new or sterile needles for all injections or skin piercing.

Mother-to-child transmission — Pregnant women should always be tested for HIV. HIV-positive pregnant women can take preventive medicines to reduce the chance that their baby will be infected with HIV during pregnancy and birth. Transmission of the virus from mother to baby can also occur after delivery through breastfeeding. HIV-positive mothers must seek the advice of a health care provider in order to prevent transmission of the infection during pregnancy and delivery, and also to learn appropriate feeding options for their newborn. [See fact sheet on Childbirth and Breastfeeding.] 


\section{Can HIV infection be cured or treated?}

HIV infection cannot be cured, but it can be treated. The current treatment for HIV is called antiretroviral therapy (ART). ART is a combination of drugs that reduces the level of HIV virus in the blood and slows down the destruction of the immune system. ART has improved the quality and length of life for many individuals with HIV. These drugs also reduce illness and death due to AIDS, the most advanced stage of HIV. Not all people respond equally to the drugs. Without treatment, however, a person infected with HIV generally progresses to AIDS within one to ten years of becoming infected. Without treatment, a person with AIDS may live less than a year.

\section{How can a person know if he or she - or his or her sex partner - has HIV?}

The only way to know if you have been infected with HIV is to take an HIV test. The only way to know if your sex partner is HIV-positive is if he or she takes an HIV test and shares the result with you. Millions of people who are HIV-positive feel and look completely healthy, have no symptoms, and have no idea that they are passing the virus to others.

The HIV test detects special cells (called HIV antibodies) that are present if the person is infected. Tests can usually detect HIV antibodies within six to eight weeks of exposure. In rare cases, it may take as long as six months for the antibody level to be detected by a test.

A positive HIV test means that the person has HIV antibodies and is infected with the virus. If the first test is positive, a second, different test is conducted to confirm the results.

A negative HIV test means that the person is not infected with HIV. Or it may mean that he or she is infected but has not yet made enough HIV antibodies to test positive. Someone who tests HIV-negative but suspects that he or she was recently exposed to the virus should take the test again in a few months.

\section{Why should people be tested for HIV?}

Being tested for HIV is important for many reasons.

Obtaining a negative test result can bring enormous relief to a person. It can also encourage that person to practice safer sexual behavior in the future. Those who test HIV-positive can begin to seek care and treatment. Treatment can improve the quality of life and significantly prolong the life of an HIV-positive person. Those who are tested can also inform and protect their sex partners. For a woman who is - or would like to become - pregnant, knowing her HIV status is important so that she can take action, if necessary, to reduce the risk of transmission to her baby. [See fact sheet on Childbirth and Breastfeeding.]

What support do people living with HIV and AIDS need?

When people find out that they are HIV-positive, they may feel frightened, confused, and depressed. Being infected with HIV is life-changing, and it takes time to adjust to the knowledge. People living with HIV need a strong emotional support system, which may include parents, their spouse or partners, other family members, friends, counselors, social workers, other people living with HIV and AIDS, or religious or spiritual leaders. They need to find a doctor who is caring, respectful, and knowledgeable about HIV and AIDS, and to have access to medical treatment when they need it. They need to learn as much as possible about HIV and AIDS, and how to protect their own health and that of their sex partners. To stay as healthy as possible, they need to eat well, exercise regularly, rest adequately, avoid smoking and drinking too much alcohol, and avoid using recreational drugs. Most important, by always practicing safe sex, they can protect themselves from other sexually transmitted infections and avoid infecting others with HIV. 


\section{infertility and assisted reproduction}

\section{What is infertility?}

A couple is said to be infertile if they do not become pregnant after having unprotected sex regularly for a year, even if they have had children before. About one in ten couples has trouble becoming pregnant.

\section{What are the main causes of infertility and what can be done to protect against it?}

Although infertility is often blamed on the woman, about half the time the man is infertile, or both partners may contribute to the problem. The main causes of female infertility include blocked tubes (for example, from an untreated STI or another condition, such as endometriosis) and hormonal problems. The main causes of male infertility are problems with producing enough healthy sperm (which can be the result of various factors). To protect against infertility caused by STIs, use a condom when a pregnancy is not desired. Age may also be a factor. People, particularly women, become less fertile as they age. Women's fertility declines significantly beyond the age of 35 .

What is the first course of action for fertility problems? First, the couple should determine the woman's fertile time and have sex when her mucus is abundant, clear, slippery, and stretchy. They should treat any health problems, eat and rest well, and avoid tobacco, drugs, alcohol, and caffeine. The man's semen can be examined at a clinic to determine if he has sufficient sperm, and his scrotum can be examined for presence of a varicose vein that may affect sperm production. The woman can be examined to see if she has a condition or an infection that can be treated.
What other treatments are available for infertility?

Other treatments depend on the cause of the infertility. If the woman is not producing eggs, fertility drugs may help. If a tube is blocked or if there are other conditions, surgery may help. If a man has a varicose vein in his scrotum that is affecting his sperm, surgery may correct the problem.

\section{What is assisted reproduction?}

Assisted reproduction is the use of various advanced techniques to aid fertilization. Artificial insemination involves inserting male semen into the woman's vagina when she is ovulating. In-vitro fertilization involves joining eggs and sperm in a laboratory dish, and inserting the resulting fertilized egg or eggs in the woman's uterus. Another practice is "surrogacy" in which couples arrange with a "surrogate mother" that she will carry a pregnancy for the woman (usually by means of in-vitro fertilization), when the woman is unable to do so herself. Such complicated techniques of assisted reproduction are extremely expensive.

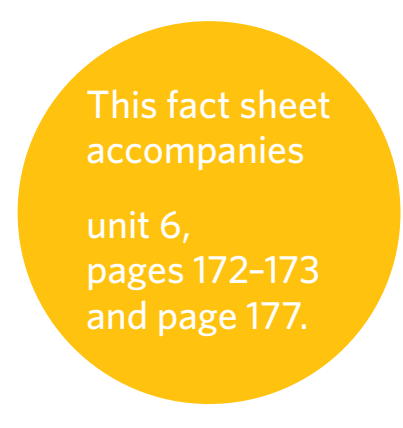




\section{menstrual cycle (also called the ovulatory cycle)}

\section{What is the menstrual or ovulatory cycle?}

At puberty, girls begin to experience cycles of fertility. Unlike males, who are fertile continuously from puberty onward,

females can become pregnant only during certain days of the cycle. The length of the cycle varies from person to person but is generally about one month. During each cycle, the female body goes through many changes. The most obvious part of the cycle is menstrual bleeding, also called menstruation or the "period."

We often think of menstruation as the climax of the cycle, but menstruation is just one part of an amazing array of changes that take place during the cycle. These changes are the body's way of preparing for a potential pregnancy. They include producing mucus at the cervix, growing and releasing an egg, and changes in the lining of the uterus. These changes are controlled by hormones (natural chemicals produced by glands in the body and carried in the bloodstream).

These hormonal changes affect many parts of the female body, and also how women feel and function. Knowing about these changes can give a girl or woman a sense of greater comfort and control regarding her own body. A woman can learn simple techniques for identifying when she is ovulating and when her menstrual period is due.

\section{What changes does the body go through during the cycle? Before ovulation}

Menstrual bleeding - Menstruation, or menstrual bleeding, signals the beginning of a new cycle. During menstruation, blood and tissue are shed by the uterus and flow out of the vagina. The first day of bleeding is designated as "day one" of the cycle. Bleeding usually lasts between four and six days.
Dryness - After menstrual bleeding ends, the vagina may feel dry because hormone levels are low and the cervix is producing little or no mucus.

Thick mucus discharge/thickening of the uterine lining - After a few days, as her body releases more hormones, the woman (or girl) may notice a vaginal discharge of mucus. At first, this mucus is cloudy-white or yellowish and may feel sticky. At the same time, although she cannot detect it, the lining of her uterus begins to thicken and an egg (also called the ovum) "ripens."
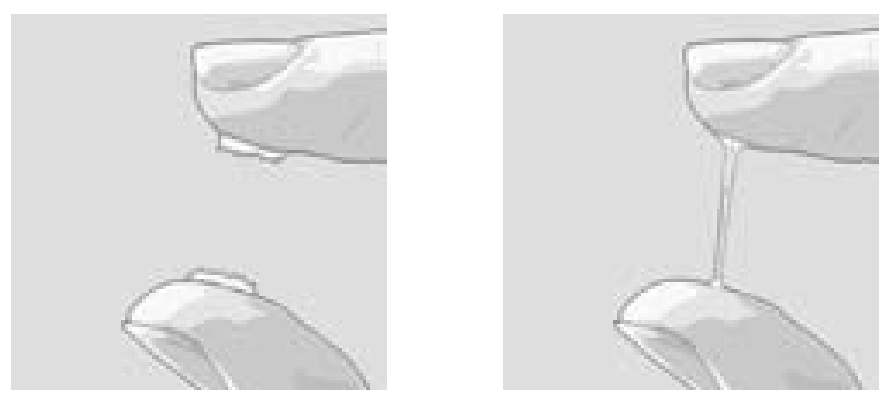

\section{Ovulation}

Clear mucus/ovulation - As the egg ripens, the mucus becomes clearer and slippery, often similar to raw egg white. Often it can be stretched between the fingers. This clear mucus nourishes sperm and helps them to move toward the egg. At this time, a woman's sexual desire may also increase. The release of the egg from the ovary is called ovulation. The days just before and around the time of ovulation are the time when a girl or woman can become pregnant. These are sometimes called her "fertile days."

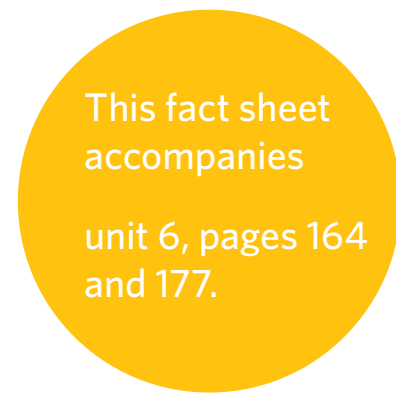


The female body goes through other changes around this time as well. For example, some women experience an increase in sexual desire and in their sense of well-being for a few days. And some feel a twinge or slight discomfort on one side of their abdomen at about the time the egg pushes out of the ovary.

\section{After ovulation}

Postovulation - After ovulation, the egg can live for one day. The mucus again becomes thicker and creamy or sticky. For the next 14 days (more or less), hormones keep the thickened lining of the uterus in place. The body temperature also rises slightly.

Menstrual Bleeding - If no pregnancy has occurred at the end of the 14 days, the hormone levels fall. The lining of the uterus sheds, and the body temperature falls back down. This shedding is menstruation, and a new cycle begins. (If a pregnancy occurs, the body continues to produce hormones to keep the thickened lining of the uterus in place for nine months.)

\section{How long is the ovulation-menstrual cycle?}

During the first year or two after menarche (the first menstrual period), the length of time from one period to the next may vary. Several months may pass between periods. Even for adult women, the length of the cycle may vary from one woman to the next. It may also vary from cycle to cycle for any one woman. It can be affected by things like travel, stress, depression, malnutrition, and illness. Most commonly, however, women begin a new cycle every $24-36$ days.

The part of the cycle from the beginning of menstrual bleeding until ovulation may vary a great deal. It can be as short as a couple of days or as long as several months or more. Most commonly, it lasts between one and three weeks. In contrast, the part of the cycle from ovulation to the next menstrual period does not vary; it is always close to 14 days.
In other words, once ovulation occurs, a girl or woman knows that - unless she has become pregnant - her menstrual period is due in 14 days.

\section{Which are the fertile days of the cycle?}

The fertile period includes the day of ovulation and the five previous days. Sperm can survive in the female genital tract for as long as five or six days, and the egg (if it is not fertilized) survives for as long as 24 hours. Predicting the fertile days is difficult, however, because the first phase of the cycle (from menstruation to ovulation) is the part that may vary widely in duration. Some women learn how to observe the changes in their mucus (and in their body temperature) so that they can tell when they are likely to be ovulating. Some women also feel a slight pain when they ovulate. Many women and girls use such "fertility awareness" techniques to have a better sense of when their menstrual period is due. Knowing which days are the fertile ones can be useful for women who are trying to become pregnant and for those who want to avoid pregnancy. Using fertility awareness techniques correctly, however, requires thorough instruction, followup, and careful ongoing observation. [Also see fact sheet on Contraception for more information about fertility awareness techniques.]

\section{For how long do women have menstrual or ovulatory cycles?}

As women enter mid-life, their hormone levels change. Eventually they stop releasing eggs and menstruation also ceases. This phase, called menopause, also signals the end of fertility. The age of menopause varies by woman and differs in different settings, but typically it begins in the mid-40s in developing countries and in the early 50 s in developed countries.

[Also see fact sheet on Puberty and Girls.] 


\section{nutrition}

Why is nutrition particularly important during adolescence? Adequate nutrition is particularly important during adolescence because it is a time of rapid growth. Girls who bear children and breastfeed during adolescence require considerable extra nutrition.

\section{What are the main causes and consequences of nutritional problems?}

The lack of access to enough nourishing food is the main cause of nutritional problems. These problems are made worse when food is distributed unequally within families, for example, when sons receive more nourishing food than daughters, or when wives and daughters are fed last. Inadequate nutrition impairs learning capabilities. It lowers resistance to infections. It leads to maternal and infant health problems and, in many cases, to death. It may result in weak or brittle bones among those who are middle-aged or elderly.

Other nutritional problems are more common in developed countries. Eating too much of foods that are rich in fat and sugar leads to obesity and contributes to numerous health problems, including diabetes, hypertension, and heart disease. Compulsive dieting is also a problem for many people, especially where the media create and promote unrealistic ideals of body size and appearance. Eating disorders such as anorexia (compulsive undereating) and bulimia (usually vomiting, but also taking laxatives, after eating) may lead to serious illness and even death. These disorders are more common among girls.

\section{What can be done to improve nutrition?}

Ways to improve nutrition include:

- learning about the nutritional content of foods and making healthy choices;

- petitioning markets or fast-food outlets to provide affordable, healthy options;
- organizing farmers' markets to make local fresh food available to residents of inner cities;

- promoting fair distribution of food among all family members;

- supporting accurate and clear labeling of food products; and

- monitoring fast-food advertising practices.

\section{physical activity}

\section{Why is physical activity important?}

A healthy amount and type of physical activity helps protect against diseases such as obesity, diabetes, certain cancers, and high blood pressure, and improves psychological wellbeing. Sports are also a source of social interaction and fun. For girls, participation in sports or exercise programs can foster development of a positive body image and provide opportunities for building friendships, spirited group activity, and public recognition of achievement. Adolescent girls who engage in sports may have better social and health outcomes - including better academic performance and fewer unintended pregnancies - than those who do not.

\section{How do stereotypes affect participation in physical activity and sports?}

Everyone deserves an equal opportunity to engage in sports or physical activity, regardless of skill level, sex, physical ability, or economic status. However, girls, people with disabilities, and people living in extreme poverty often lack opportunities to participate in sports. Gender bias has resulted in fewer exercise and sports opportunities for girls. Examples include school team sports offered only to boys; less access to, or inferior, facilities and equipment for girls; and less recognition and funding for girls' and women's sports. Such discrimination is a violation of girls' rights. Fortunately, community advocacy and legal changes are starting to address these inequalities at the local, national, and international level, and biased attitudes and beliefs are starting to change.

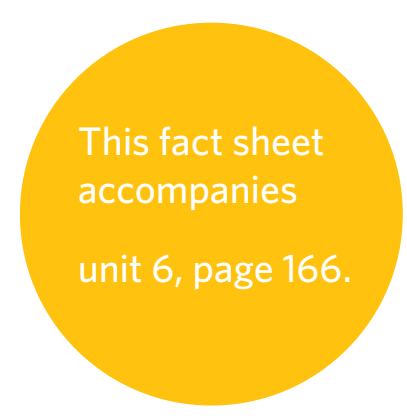




\section{What types of physical activity can have negative effects on health?}

Work that includes long hours of strenuous activity, such as carrying heavy loads or engaging in tasks that require repetitive motions such as bending, can be harmful. Unsafe conditions may also make work-related physical activity more dangerous, for example, working where you have to breathe toxic substances or working in extreme heat. Many sports, particularly contact sports, also carry a risk of injury.

\section{substance abuse}

\section{What drugs do people use and why do they use them?}

Apart from medications, drugs people use for recreation

include alcohol, tobacco, caffeine, marijuana, inhalants (such as gasoline, glue, cleaning fluids), cocaine, and heroin. Drugs affect the mind and body, sometimes permanently. Some are more dangerous than others, and their effects differ by individual. Alcohol and tobacco are the most commonly used drugs worldwide. In recent years, girls' and women's use of tobacco has increased dramatically in some countries. People use recreational drugs for many purposes, including:

- to reduce anxiety in social situations;

- to appear mature and confident;

- to avoid feeling or dealing with problems, including boredom and loneliness;

- to fit in socially or have fun;

- to stimulate their minds or stay awake

- to enhance sensory perceptions or feel "high";

- to reduce appetite or avoid eating (to lose weight);

- to relax or sleep; and

- to cope with trauma.

\section{What is addiction?}

When people use a drug regularly, they can become dependent on or addicted to it. Many drugs can be addictive, including some medications, such as painkillers, diet drugs, or sleeping aids, and people may become addicted without recognizing that they are. Many people find it difficult or impossible to stop using a drug once they are addicted to it. Overcoming an addiction requires determination, strong willpower, belief in oneself, and a supportive environment, often including professional treatment or involvement in a treatment program.

\section{What serious problems can result from using or abusing}

\section{drugs?}

Adolescents' substance abuse is a major public health problem in many countries. Drug use leads to numerous serious problems, including:

- causing accidents while driving under the influence of alcohol or other drugs;

- behaving in ways that lead to regret as a result of poor judgment and lowered inhibitions from drug use;

- having sex without protection against STIs, HIV, or pregnancy, as a result of diminished judgment; - acquiring HIV or hepatitis from sharing needles while injecting drugs; and

- overdosing on a drug to the point of poisoning and death.

Addicts may resort to desperate, degrading, or illegal measures to obtain the money to buy drugs. People who smoke cigarettes, chew tobacco, or spend a lot of time near those who smoke, may develop cancer or other life-threatening diseases. A pregnant woman's use of some drugs, both legal and illegal, can harm the fetus. 


\section{puberty and boys}

For boys, puberty usually begins between the ages of 10 and 13, a couple of years later than it begins for girls. Boys typically finish puberty in their late teens or early twenties, when skeletal growth is complete.

\section{What changes do boys experience during puberty?}

Like girls, boys may find that their feelings and interests change during puberty. Physical changes also occur. These changes are different for every person but typically occur in this order:

- The testes and penis grow larger.

- Pubic hair begins to grow; it gradually increases in amount and becomes coarser and curly.

- The voice begins to change and deepen, usually gradually but sometimes suddenly.

- About a year after the testes begin to grow, a boy may begin to experience ejaculation (release of a white milky fluid called semen from the penis).

- Underarm hair grows and sweat changes scent to adult body odor.

- Facial hair develops.

Boys also experience a growth spurt and muscle growth. Skin becomes oilier, increasing the likelihood of acne, a skin condition. About half of boys experience slight temporary breast growth, which disappears in a year or two.

\section{What causes erections?}

Erections occur throughout life. An erection is caused by blood filling the spongy tissue in the penis as a result of sexual stimulation; lifting or straining; dreaming; being cold; wearing tight clothing; feeling fear or excitement; or having a full bladder on waking. An erection may have no apparent cause, especially during puberty. Boys often get sudden or spontaneous erections, sometimes many times a day. These are the result of high or changing levels of the hormone testosterone.
Having an erection without ejaculating may cause a temporary feeling of "heaviness" but is not harmful in any way. If an erect penis is not touched, the erection will subside by itself.

\section{What happens during ejaculation?}

Prior to ejaculation, the Cowper's glands release a drop or two of fluid through the tip of the penis. This is called preejaculate, and it cleans the urethra. The pre-ejaculate alone does not contain a sufficient number of sperm that are strong enough to cause pregnancy (unless sperm from a recent ejaculation are still present). HIV may be present in the preejaculate, however.

Full ejaculation involves the release of semen, which typically contains hundreds of millions of sperm in a teaspoon of fluid. Usually, but not always, ejaculation comes with a wave of pleasurable release known as orgasm. Once a boy can ejaculate, he can cause a pregnancy.

\section{What are wet dreams?}

Men regularly have erections during sleep, and about 80 percent of males occasionally ejaculate. This kind of ejaculation is called a nocturnal emission or "wet dream." Wet dreams are common during puberty, but adult men may also have them. A boy or man who masturbates or has regular sex is less likely to have wet dreams.

Wet dreams (and masturbation) are not harmful in any way. They may release tension and be a source of pleasure. Nor do wet dreams (or masturbation) "waste" sperm. The testes are continuously making new sperm, and wet dreams are one way the body rids itself of stored sperm.

[Also see fact sheet on Sexual and Reproductive Systems Male.]

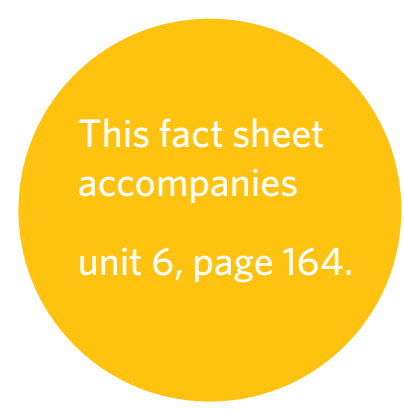


For girls, puberty begins between the ages of 8 and 13, about two years earlier than for boys. Girls typically finish puberty between the ages of 16 and 17 or around the time that their skeletal growth is complete.

\section{What changes do girls experience during puberty?}

Changes at puberty differ from person to person. Although they may vary in timing, sequence, and speed, girls' bodies typically develop in this order:

- Breast growth begins, often on only one side at first. Full development takes about two years.

- Pubic hair begins to grow, gradually increasing and becoming coarser and curly.

- Inside a girl's body, the surface of the vagina thickens and the uterus and ovaries increase in size. [See fact sheet on Sexual and Reproductive Systems — Female.]

- The first menstrual bleeding, menarche, usually occurs two to three years after breast development begins. Many girls have irregular periods for the first couple of years. Once a girl ovulates, she can become pregnant. [See fact sheet on the Menstrual Cycle.]

- Underarm hair grows and sweat changes, resulting in adult body odor.

- The cervix starts producing mucus that is discharged from the vagina. This mucus is normal and is a sign of natural changes related to fertility and menstruation.

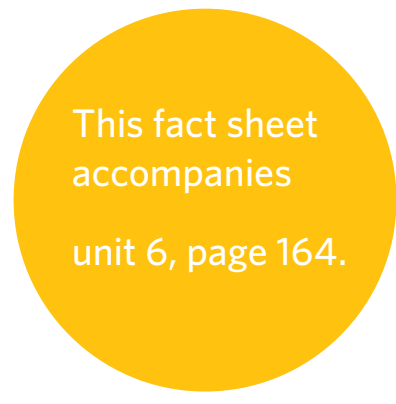

Girls also experience a growth spurt, their pelvis and hips widen, fat tissue increases, and the skin becomes oilier, increasing the likelihood of acne.
As with boys, girls' interests and feelings may also change with puberty. In the days before menstruation, girls commonly experience strong feelings of different kinds, for example, joy, sadness, sensitivity, and anger.

\section{Managing menstruation}

Menstruation is natural and part of being a healthy female. Having one's first menstrual period can be an exciting event, especially if the girl knows what to expect. Unfortunately, many girls worry or are afraid when their first period comes because no one has explained to them what it means and requires. Some parents may feel embarrassed to talk about it. Or the girl may have absorbed messages from her culture or religion suggesting that menstruation is somehow unclean. Menstruation, however, is part of the body's means of renewing itself and maintaining fertility.

During menstruation a girl can generally engage in all of her regular activities. Bathing during menstruation is important. The vulva should be washed with water and mild soap to remove any blood that is left.

How women take care of their menstrual flow varies in different settings. Many women use pads to absorb the blood. In some places, women buy pads that can be thrown away after use. In other places, they employ reusable pads made from folded cloth; these must be washed thoroughly after each use with soap and water. Having a private place to change or wash pads (both at home and at school) is important. 
Many women and girls use tampons instead of - or in addition to - pads. A tampon is a small mass, made of cotton (or other absorbent material), and often shaped like a finger to fit comfortably into the vaginal canal. Tampons are inserted into the vagina to absorb the menstrual blood. Tampons must be changed at least twice a day. Leaving a tampon in for more than a day can cause a serious, even deadly, infection. (Inserting any unclean object into the vagina can also cause a serious infection.)

The amount of menstrual bleeding - the menstrual flow varies from day to day and by person. Bleeding may be heaviest during the first days of the period. Some girls and women also experience pain — abdominal cramping — during these days. In some cases, these cramps are strong and include nausea. A mild painkiller such as ibuprofen helps. Taking a bath, or placing a plastic bottle or hot water bottle filled with warm water on the lower belly or lower back, may also help.
A few days before their menstrual period begins, some girls and women may experience one or more kinds of discomfort. These include sore breasts, constipation, tiredness, pimples, and strong feelings that are harder than usual to control. Other months they may experience, some, other, or none of these. Many girls and women find that their premenstrual discomfort and their menstrual cramps tend to decrease if they exercise regularly throughout the month.

Girls commonly have questions or difficulties with menstruation. They may find that speaking with a health care worker, female relative, or friend is helpful.

[Also see fact sheet on the Menstrual Cycle and fact sheet on Sexual and Reproductive Systems — Female.] 


\section{reproduction and pregnancy}

\section{How does pregnancy occur?}

Before a pregnancy can occur, an egg and a sperm must join. This event is called fertilization. Fertilization can occur only during the fertile phase of a woman's menstrual cycle. [See fact sheet on the Menstrual Cycle.]

During the woman's fertile phase, one of her two ovaries releases an egg. This event is called ovulation. Within minutes, fingerlike projections (called fimbria) at the ends of the fallopian tube begin moving to surround the egg and draw it into the tube. Also during the fertile phase, the woman's cervix moves into a position that eases the sperm's entry from the vagina. The cervix secretes a large amount of clear cervical mucus. This mucus provides nourishment to enable sperm to survive for several days. The mucus also provides an environment that helps sperm swim upward toward the fallopian tube, to reach the egg.

During sexual intercourse, the sperm are ejaculated near the cervix. They enter the cervix within seconds. If the woman is fertile, some sperm may reach the egg in the fallopian tube within five minutes, while other sperm can survive in the clear ("fertile-type") mucus in the cervix. In this way, for up to five days after ejaculation, sperm continue to exit the cervix and are available to fertilize an egg. Hence, a woman who ovulates several days after she has unprotected sex is likely to have sperm remaining in her cervix, and these sperm may still be able to reach the fallopian tube and fertilize the egg.
Once ovulation occurs, however, fertilization must occur within 24 hours because the egg can survive for only that long. Fertilization takes place in the fallopian tube. Once a sperm has fused with the egg, it creates a barrier to other sperm. The fertilized egg continues down toward the uterus, propelled by tubal contractions and by the cilia (little hairlike projections within the tube).

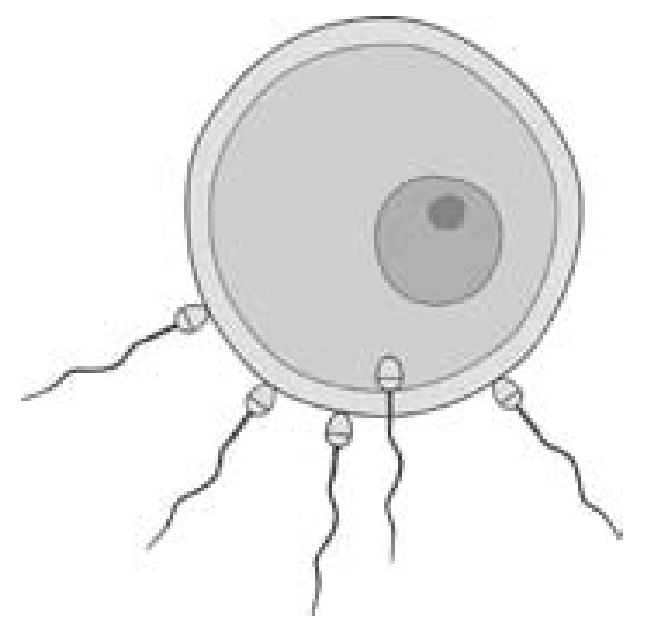

What happens after fertilization?

In the fallopian tube, the fertilized egg, or zygote, begins to divide and grow, as it moves toward the uterus. This journey takes about five days. After it has divided once, it is called an embryo. Within two days of reaching the uterus, the embryo attaches or implants itself in the lining of the uterus. Implantation is the beginning of pregnancy. 


\section{How can a woman tell if she is pregnant?}

Early signs of pregnancy differ from woman to woman and between pregnancies. They include:

- a missed period;

- tender or swollen breasts;

- sensitive nipples;

- frequent urination;

- unusual fatigue;

- nausea and vomiting;

- cramps;

- feeling bloated;

- changes in appetite; and

- feeling unusually emotional.

Pregnancy can be confirmed with a pregnancy test, which may be performed by a health care provider or purchased from a pharmacy. Some women who have learned how to detect when their body is ovulating can predict fairly well which day menstruation is due; therefore, they may be aware of a pregnancy as soon as their period is late.

\section{What happens during pregnancy?}

After implantation, the embryo (at this stage called a blastocyst) also gives rise to an amniotic sac and a placenta. The sac provides a protective fluid environment for the growing fetus. The placenta provides the fetus with nutrients and oxygen from the mother, and carries out waste products. An umbilical cord connects the placenta to the fetus.

Human pregnancy lasts 38 weeks after fertilization (about 40 weeks from the last menstrual period). Pregnancy is divided into three periods of about three months each, called trimesters.
During the first trimester, until the twelfth week, all of the major organs and structures of the body are formed: the brain, heart, lungs, eyes, ears, arms and legs. After the eighth week, the embryo is called a fetus. Women commonly feel nauseous during the first trimester; the nausea is sometimes called "morning sickness."

During the second trimester, from the 13th to approximately the 27 th or 28 th week, the fetus grows rapidly, and usually around the 19th week, the woman can feel fetal movement. Most women begin to put on weight during the second trimester.

In the third trimester, the fetus continues to gain weight, and its movements become stronger and more frequent.

\section{What can women do to promote a healthy pregnancy?}

If a woman or girl chooses to keep her pregnancy, it is particularly important for her to avoid taking unnecessary medications, drugs, and alcohol. Taking the recommended vitamins and mineral supplements (especially iron and folic acid) is very important (including before pregnancy, if possible). She should also visit an antenatal-care provider, from whom she can get medical checkups and can learn about her pregnancy, potential danger signs, and childbirth. Women infected with HIV should take anti-HIV medication to prevent the fetus from becoming infected and to maintain their own health. Treatment with anti-HIV medicines during labor and delivery is critical for reducing the risk of transmitting HIV to the baby. 


\section{What are reproductive tract infections?}

Reproductive tract infections (RTIs) have three main causes: - sexual transmission [see the fact sheets on STIs and HIV];

- when bacteria are accidentally introduced or spread to the uterus during a medical procedure, such as IUD insertion or during childbirth); and

- overgrowth of organisms normally present in the vagina. The most common such infections, which are known as endogenous infections, are candidiasis and bacterial vaginosis.

\section{What is candidiasis?}

Candidiasis, also called yeast infection, candida, or thrush, results from an increase in yeast naturally present in the vagina. Signs include a thick white discharge; intense itching or redness of the vulva and vagina; and vaginal irritation during sex. Sometimes a woman may have candidiasis but have no symptoms. The infection can be treated. Women whose immune systems are weak, who are pregnant, or who are taking antibiotics are more likely to develop candidiasis. Men occasionally have itching and discomfort from candidiasis. People can also have candidiasis infections in other moist parts of the body.

\section{What is bacterial vaginosis?}

The vagina normally hosts both "good" and "bad" bacteria living in equilibrium. Bacterial vaginosis (BV) develops when an abnormal increase in harmful bacteria occurs that affects the biochemical balance of the vagina. The most common symptoms are thin gray, white, or yellow/green discharge; a bad odor, especially after sex or during menses; or vaginal itching and soreness. More than half of women with BV, however, do not have any symptoms at all. BV is treatable. Although it usually causes no complications, it can be serious, leading to increased susceptibility to HIV and other STIs, pelvic inflammatory disease [see STI fact sheet], and, among pregnant women, increased risk of preterm delivery or low birth weight.

\section{What can be done to decrease the occurrence of reproductive tract infections that are transmitted by means other than sex?}

Women should avoid vaginal douching; the use of internal vaginal "drying" or "tightening" herbs, agents, or products; and the unnecessary use of antibiotics. After using the toilet, women should always wipe from front to back (from where the urine comes out toward the anus) to avoid spreading germs from the anus into the vagina or urinary opening. Synthetic (polyester) underwear and tight pants that restrict air circulation should be avoided.

\section{How do reproductive tract infections result from a} medical procedure?

RTIs may also be caused when a nonsterile instrument introduces bacteria into the uterus, or when an instrument carries an existing vaginal or cervical infection into the uterus where it can spread. Such RTIs can be caused by procedures such as abortions or IUD insertions, or during childbirth. If left untreated, a serious condition called pelvic inflammatory disease may develop. Medical services must maintain sterile conditions during such procedures. Testing for (and treating) existing infections before inserting an instrument through the cervix is essential. 


\section{What is sex selection?}

Sex selection is the practice of testing for the sex of a fetus during pregnancy and choosing to keep or abort the pregnancy according to the test results.

\section{Why do people practice sex selection?}

The main reason people practice sex selection is because they live in a society where sons are valued above daughters. In some settings, sons carry on the family lineage and name, inherit family property, provide income to the family, support parents in their old age, and perform parents' burial rites. Daughters in these societies, on the other hand, are expected to leave their birth families to live with their husband's family. Government policies that restrict the number of children that a woman may have contribute further to the decision to abort a female fetus.

In societies where boys are preferred to girls, many women are under extreme pressure to bear sons. Giving birth to a son enhances a woman's status. Failing to produce a male heir may cause a woman to suffer blame, abuse, or even abandonment. In some situations, a pregnant woman may even be coerced into having a test to determine the sex of her fetus and then aborting the fetus if it is female.

\section{How is sex selection accomplished?}

A number of procedures - originally designed to help monitor a pregnancy — allow health care providers to identify the sex of a fetus. In some settings, these procedures are now widely used specifically to identify fetal sex, with the intention of aborting the fetus if it is female.
Prior to pregnancy: In some cases, fertility specialists can enable parents to select a baby's sex prior to pregnancy. Special techniques are used to separate the male and female sperm within a sample of semen. (A baby's sex is determined by the father's sperm, not by the mother's egg.) Only sperm that are of the desired sex are used - either by artificially inseminating the woman or through in-vitro fertilization.

During pregnancy: Several procedures exist to identify fetal sex during pregnancy. One of these procedures is ultrasound, which uses sound waves to generate a rough image of the fetus on a computer. Another such procedure is amniocentesis (inserting a needle into the amniotic fluid surrounding the fetus and analyzing the fluid). A third procedure is called chorionic villus sampling (removing and analyzing a sample of placental tissue).

After pregnancy: Some couples take drastic measures after childbirth. An infant girl may be given up for adoption, abandoned, or killed because she is female.

\section{What are the consequences of sex selection?}

Sex selection results from (and perpetuates) gender discrimination. In places where it is common, such as parts of China and India, it has resulted in vastly greater numbers of boys compared with girls. As a result many young men in such settings are unable to find a wife. Even where it is outlawed, sex selection continues to be practiced. It remains a serious concern among many women's rights advocates and governments.

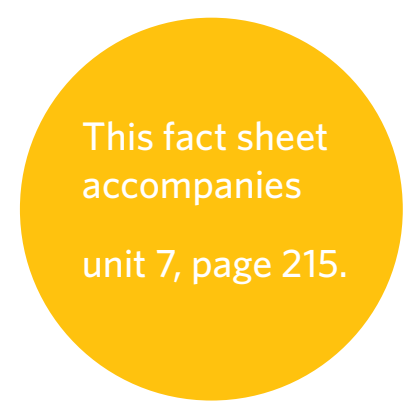




\section{What is sex trafficking?}

Sex trafficking is the recruitment, transport, sale, or purchase of human beings in order to exploit them sexually through prostitution, pornography, stripping, live sex shows, sex tourism, or forced marriage. Most victims of sex trafficking are girls and young women. Coercive tactics, including deception, fraud, intimidation, isolation, threat and use of physical force, and debt bondage (being forced to pay back debts with direct labor instead of money or goods), are used to lure and control victims. Some girls and women are sold into the sex trade by parents, husbands, or boyfriends.

\section{How widespread is sex trafficking?}

The precise extent of sex trafficking is unknown because trafficking is illegal, generally hidden, and therefore, difficult to track. Moreover, varying definitions of sex trafficking complicate efforts to establish the number of people affected worldwide. It is a rapidly growing global industry, however, reported in every region of the world. It generates enormous profits and has links to organized crime.

\section{What are the consequences of sex trafficking?}

Victims often endure degrading and brutal treatment and conditions on a daily basis, including starvation, confinement, beatings, rape (including gang rape), forced drug use, forced abortions and sterilization, threats of violence to themselves and their families, and threats of exposure of their circumstances to family and friends. Health consequences include physical injuries (for example, broken bones, concussions, burns, and vaginal and anal tears); drug and alcohol addiction; sexually transmitted infections, including HIV infection; miscarriages; and infertility. The victims' extreme physical and emotional trauma can result in acute psychological reactions, such as mind-body separation, posttraumatic stress disorder, and suicidal thoughts. Victims are at risk of premature death from homicide, suicide, drugs and alcohol, and HIV.

\section{What can be done to prevent sex trafficking?}

Addressing the many consequences of sex trafficking requires measures to prevent it, to deal with the perpetrators, and to care for the victims.

Preventive measures include:

- empowering women;

- providing educational, vocational, and employment opportunities to women and girls;

- undertaking education campaigns directed at potential victims;

- training teachers, youth workers, or others to identify girls at high risk of being sold and working with their families and communities;

- adopting legislation and providing education to reduce the demands that foster trafficking; and

- establishing cooperative preventive programs among sending, receiving, and transit countries.

Measures to deal with perpetrators include:

- strengthening laws and sanctions and their enforcement;

- establishing police divisions dedicated to finding and arresting the perpetrators; and

- developing comprehensive witness-protection mechanisms.

Services for victims must address their immediate needs: protection, medical care, legal redress, housing, employment, and counseling. Victims of trafficking should not be penalized, criminalized, or arrested. They should be assisted without conditions, regardless of their legal status or documents. Governments must prioritize and allocate sufficient resources to combating sex trafficking, and, over the long term, address its root causes, particularly poverty and gender inequality and discrimination. 


\section{What are the sexual and reproductive systems?}

The sexual and reproductive systems share some but not all organs. The sexual system consists of those organs involved in sexual activity and pleasure, whereas the female reproductive system consists of those involved in pregnancy and birth.

\section{What are the parts of the female sexual and reproductive systems and their functions?}

The vulva consists of all the visible external genital organs of a woman (see illustration below).

The clitoris (\#1 in the diagram) is a small organ, shaped like a flower bud with a bit of tissue forming a small "hood." The only function of the clitoris is to give girls and women

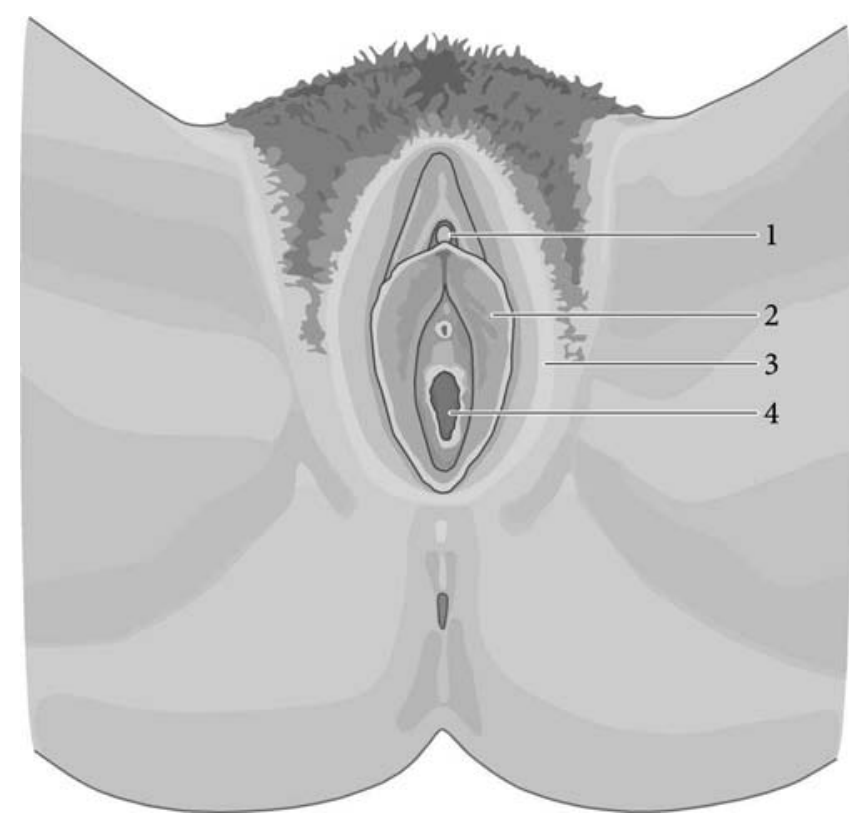

sexual pleasure; it contains a rich network of nerve endings for sensation. During sexual arousal and during orgasm, the clitoris (and the genitalia in general) engorge and fill with blood, causing the clitoris to become erect. Women may feel vaginal contractions during orgasm.

The labia majora or outer lips (\#3) cover and protect the vaginal opening. The labia minora or inner lips (\#2) also swell during sexual arousal.

The vagina (\#4) is an elastic canal, leading from the vulva to the cervix and uterus. When a woman is sexually aroused, the vagina produces lubrication. It has few nerve endings and is therefore not highly sensitive. In vaginal intercourse, the penis penetrates the vagina. If the man ejaculates, semen enters the vagina and travels through the cervix into the uterus and fallopian tubes, where fertilization can occur if an egg is present. Menstrual blood leaves the body through the vagina, as does the baby when it is born. The vagina cleans itself and does not need to be washed out. Women should not insert substances to dry or tighten the vagina; such substances can be harmful.

The hymen (not shown) is a thin membrane that may stretch across part of the vaginal opening. The hymen can be easily torn during sports or other physical activity and can be stretched open if a girl uses tampons. Therefore, a torn or stretched hymen does not indicate that a girl or woman has engaged in sexual intercourse.

The cervix (\#5) is the lower part of the uterus that extends into the top of the vagina. An opening in the cervix, called the os, connects the vagina and uterus. Menstrual blood passes out of the uterus through the os; and semen passes through it to the uterus. The cervix produces a secretion (cervical mucus) that aids sperm in entering the uterus. The cervical

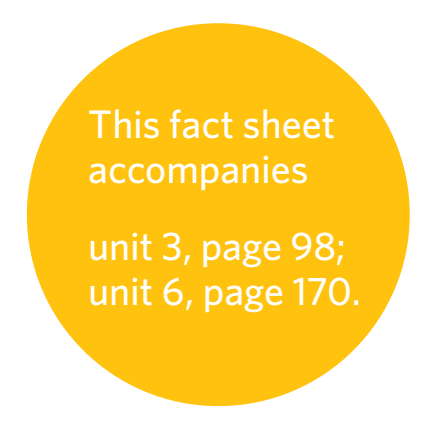




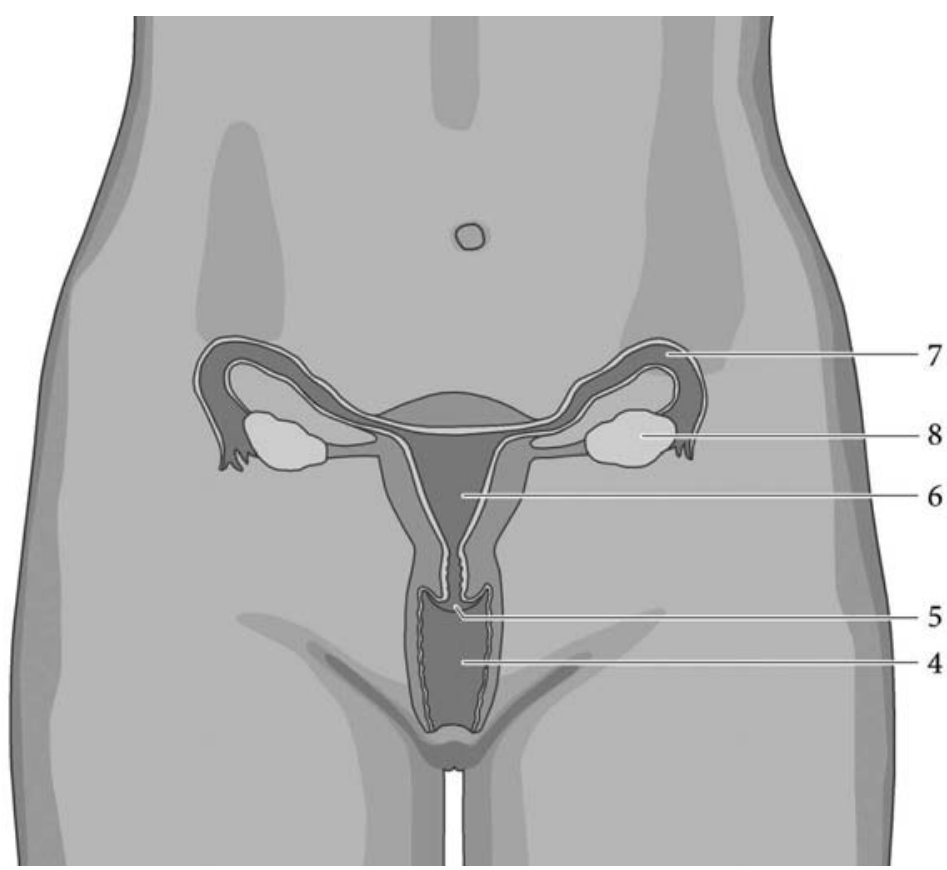

mucus changes during the menstrual cycle; women can learn to identify the fertile period according to the characteristics of the mucus. During childbirth, the cervix stretches, allowing the baby to pass through.

The uterus (\#6) is a hollow, muscular organ that rests above the bladder. It is shaped like an upside-down pear. Its lining (called the endometrium) thickens with blood and tissue

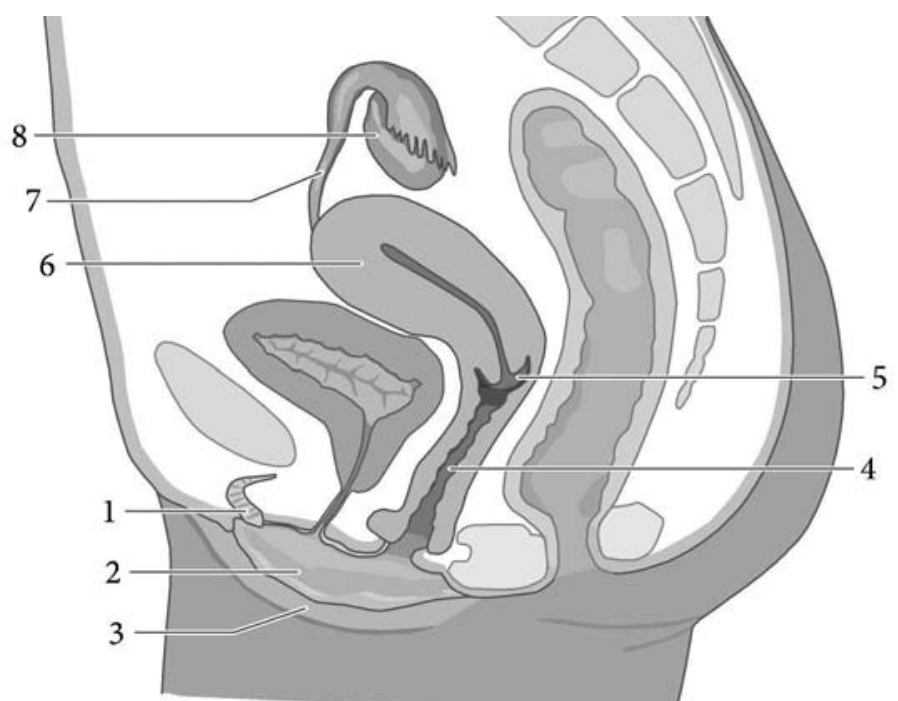

during the first part of the ovulation-menstrual cycle. If no embryo implants itself, the lining breaks down, becoming the menstrual flow. If an embryo implants itself, a fetus develops in the uterus.

The fallopian tubes (\#7) are two narrow, 4-to-5-inch-long tubes through which the egg travels from the ovary to the uterus and in which the egg may be fertilized.

The ovaries (\#8), two organs, each the size of an almond or a grape, store the immature eggs in follicles, produce and secrete female hormones (estrogen and progesterone), and produce and release mature eggs. 


\section{sexual and reproductive systems - male}

\section{What are the sexual and reproductive systems?}

The sexual and reproductive systems share some, but not all organs. The sexual system consists of those organs involved in sexual activity and pleasure. In males the reproductive system includes those organs that produce, store, or transport sperm for reproduction.

\section{What are the parts of the male sexual and reproductive} systems and their functions?

The penis (\#1) has several functions. It is involved in sexual feeling; in this function it corresponds to the clitoris in the female. The penis may fill with blood and become hard and erect in response to sexual stimulation. The reproductive function of the penis is to deliver semen into the vagina. The third function is the excretion of urine (see urethra below). The end of the penis is covered by a layer of skin called the foreskin. In many populations, the foreskin is removed through a procedure called male circumcision.

The testicles (or testes) (\#2), two ball-shaped glands inside the scrotum, produce sperm and the male hormone testosterone. The scrotum and testes are sensitive to touch and can be a source of pleasure.

The scrotum (\#3), a loose bag of skin, holds and protects the testicles. When cold, it is pulled up tight toward the body to keep the testicles at the right temperature to produce sperm.

The urethra (\#4) is a tube that runs from the bladder through the penis. The urethra is the passageway through which semen (a mixture of seminal fluid, prostatic fluid, and sperm) travels out of the body during ejaculation; urine also passes out of the body through the urethra. A valve at the bottom of the bladder closes when the penis is erect to prevent urination during ejaculation.

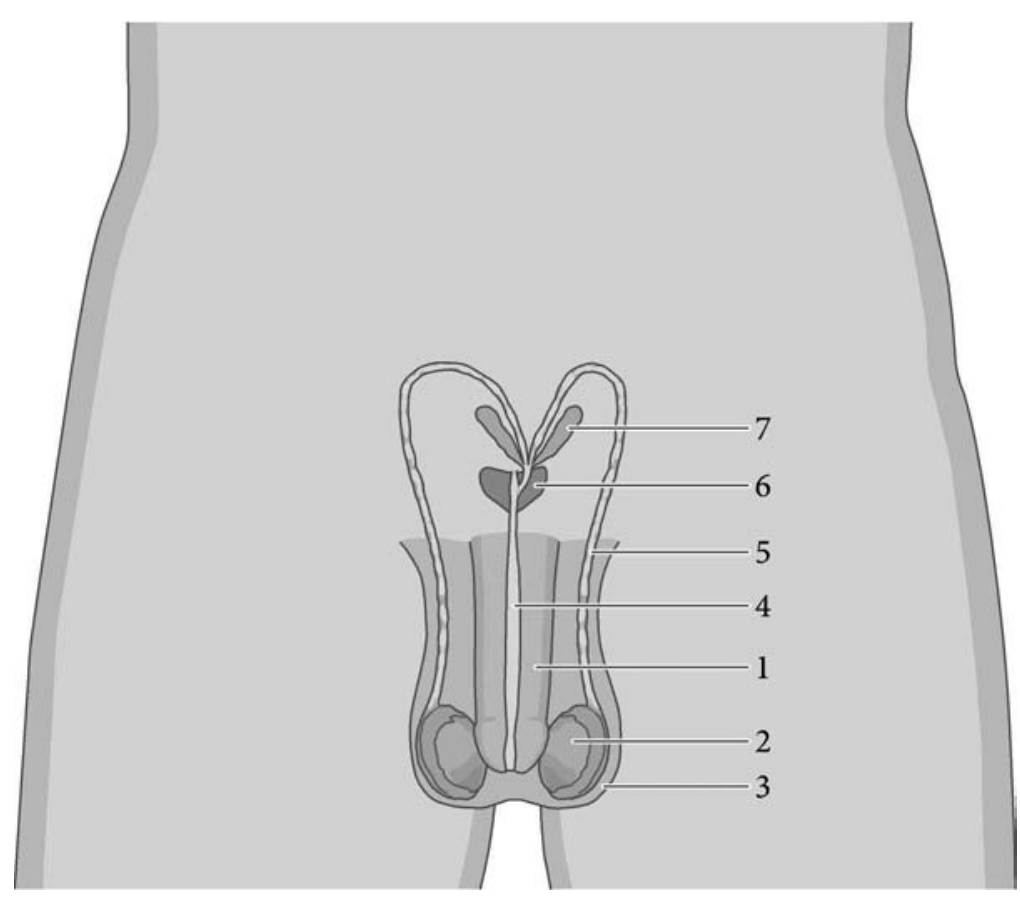

The epididymis (not numbered, but visible) is a highly coiled tube that sits on top of each testis and stores sperm as they mature until they are ejaculated.

The vas deferens (\#5) are two long thin tubes that carry the sperm toward the urethra. They contract during ejaculation.

The prostate gland (\#6) produces a fluid that makes up part of semen and helps sperm to move. Many men find stimulation of the prostate to be sexually pleasurable.

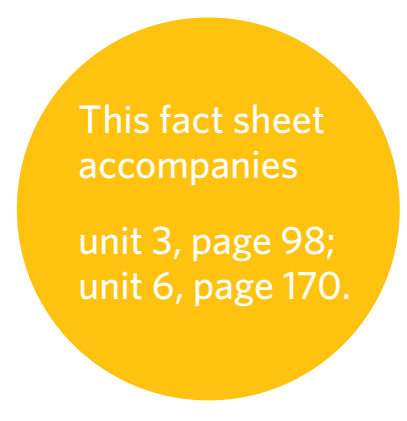


The seminal vesicles (\#7) produce much of the fluid that ultimately becomes semen. This fluid nourishes the sperm.

The Cowper's glands (not shown) produce a thick alkaline fluid, called pre-ejaculate, that neutralizes the acid in the urethra before ejaculation.

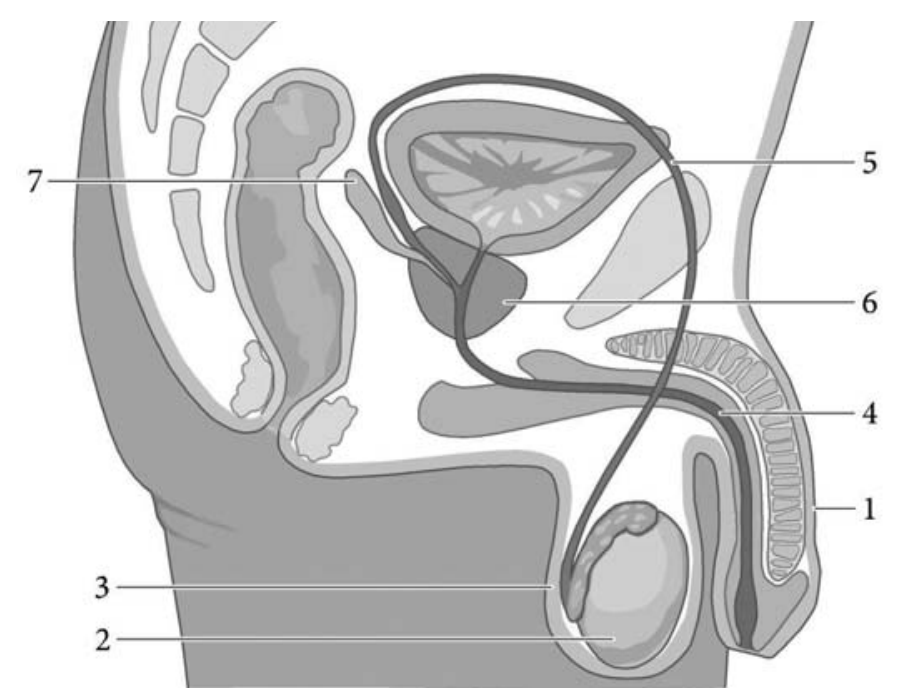




\section{sexually transmitted infections (STIs)}

\section{What are sexually transmitted infections?}

Sexually transmitted infections (STIs) are infections passed primarily by sexual contact, including vaginal, oral, and anal intercourse. A variety of different organisms may cause an STI (see following chart). Certain parasites such as pubic lice and scabies also may be transmitted by sexual contact. STIs are part of a broader group of infections known as reproductive tract infections, or RTIs. [See fact sheet on RTIs.]

\section{Are these infections transmitted only through sex?}

Some STIs can be transmitted by skin-to-skin contact. Some are transmitted through the exchange of bodily fluids. Some can be passed to a baby before it is born, during childbirth, or via breastfeeding.

\section{What are the consequences of STIs?}

STIs can have serious health consequences for men and women (see following chart). Many common STIs are difficult to detect among women, however, and some have more serious consequences for women than for men. For example, the spread of chlamydia or gonorrhea to the upper reproductive organs is a common cause of infertility among women. Infection with certain STIs increases the likelihood of acquiring or transmitting HIV infection. Some, but not all, STIs are curable. Others, such as HIV, are not. Early treatment eliminates or reduces the consequences of most STIs.

\section{How can people prevent acquiring or transmitting STIs?}

- Find out if you have an STI by being tested by a health care provider.

- If you have an STI, obtain treatment, and notify all of your recent sex partners so that they can also be tested.

- Find out whether your partner has an STI, and if so, make sure that he or she is tested and treated.

- Talk with your partner about ways to be sexually intimate that do not involve the risk of transmitting an infection.

- Use male or female condoms and avoid sexual contact that allows transmission of an infection. Condoms protect against most STIs (including HIV). They do not protect against all STIs.

- Obtain a vaccination for those STIs that can be prevented. At the present time, a vaccine exists for hepatitis B and human papilloma virus (HPV).

\section{When should a person obtain an STI test?}

A person is at risk of acquiring an STI and should be tested if he or she has one or more of the following:

- symptoms of an STI;

- a sex partner who has an STI, or who has signs of an STI;

- more than one sexual partner;

- a new partner in the past three months;

- a partner who has or may have other sex partners; and

- a partner who lives elsewhere or travels often.

Early testing is important. A person diagnosed with an STI can obtain treatment and can help their recent partners to be tested as well. A couple should not resume sexual activity until both partners have been tested and have completed any necessary treatment. Because some STIs do not show up in test results right away, a repeat test may be necessary.

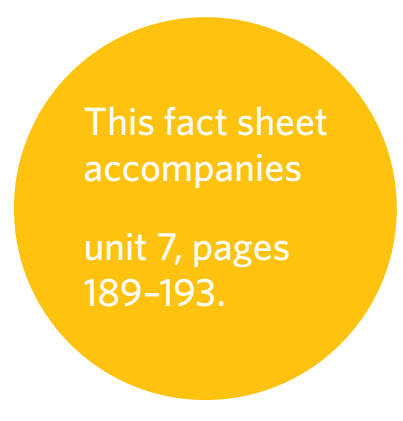




\begin{tabular}{|c|c|c|c|c|}
\hline STI & Symptoms for women & Symptoms for men & Can it be cured? & Is there a vaccine? \\
\hline Chancroid & \multicolumn{2}{|c|}{$\begin{array}{l}\text { Painful sores on the genitalia; swollen lymph nodes on the groin. } \\
\text { Women are often asymptomatic. }\end{array}$} & Yes & No \\
\hline Chlamydia & $\begin{array}{l}\text { Most women are asymptomatic. } \\
\text { Women who do have symptoms } \\
\text { might have abnormal vaginal } \\
\text { discharge or a burning sensation } \\
\text { when urinating. }\end{array}$ & $\begin{array}{l}\text { Often asymptomatic. Men with } \\
\text { symptoms may have a pus-like } \\
\text { discharge from their penis } \\
\text { or burning sensation when } \\
\text { urinating. }\end{array}$ & $\begin{array}{l}\text { Yes. Left untreated, it can lead to pelvic } \\
\text { inflammatory disease (PID) among women, } \\
\text { which may lead to infertility. Complications } \\
\text { among men are rare. }\end{array}$ & No \\
\hline Gonorrhea & $\begin{array}{l}\text { Most women are asymptomatic; } \\
\text { abnormal vaginal discharge or } \\
\text { burning sensation when urinating. }\end{array}$ & $\begin{array}{l}\text { Men often experience discharge } \\
\text { or burning when urinating. } \\
\text { Some men have no symptoms. }\end{array}$ & $\begin{array}{l}\text { Yes. Left untreated, it can lead to PID among } \\
\text { women, and may lead to infertility among both } \\
\text { women and men. }\end{array}$ & No \\
\hline Hepatitis B & \multicolumn{2}{|c|}{$\begin{array}{l}\text { Some people experience flu-like symptoms, jaundice, and } \\
\text { dark-colored urine; others experience no symptoms. }\end{array}$} & $\begin{array}{l}\text { Although no medicine has been found that } \\
\text { cures hepatitis B, in many cases the body clears } \\
\text { the infection by itself. Occasionally it develops } \\
\text { into a chronic liver illness. Small children and } \\
\text { infants are at a much greater risk of becoming } \\
\text { chronically infected. }\end{array}$ & Yes \\
\hline $\begin{array}{l}\text { Herpes (herpes } \\
\text { simplex virus) }\end{array}$ & \multicolumn{2}{|c|}{ Recurrent episodes of painful sores on genitals or anus. } & $\begin{array}{l}\text { No, but symptoms can be controlled through } \\
\text { treatment. }\end{array}$ & No \\
\hline $\begin{array}{l}\text { HIV (human } \\
\text { immunodeficiency } \\
\text { virus) }\end{array}$ & \multicolumn{2}{|c|}{$\begin{array}{l}\text { HIV generally has no symptoms in its early stages. HIV usually leads } \\
\text { to AIDS. People with AIDS may suffer various infections, cancers, } \\
\text { and other life-threatening ailments. }\end{array}$} & $\begin{array}{l}\text { No, AIDS is a chronic, ultimately fatal } \\
\text { disease, but treatment (antiretroviral therapy) } \\
\text { dramatically slows the progress of the disease. }\end{array}$ & No \\
\hline $\begin{array}{l}\text { Human papilloma } \\
\text { virus (HPV) }\end{array}$ & \multicolumn{2}{|c|}{$\begin{array}{l}\text { HPV can be asymptomatic. Some strains cause genital warts. Others } \\
\text { cause cancer. This includes head, neck, and anal cancer; penile cancer } \\
\text { in men; and — most commonly — cervical cancer in women. }\end{array}$} & $\begin{array}{l}\text { No, but symptoms can be controlled through } \\
\text { treatment. Some cancers secondary to HPV are } \\
\text { treatable. }\end{array}$ & $\begin{array}{l}\text { Yes. HPV vaccines can protect } \\
\text { both males and females against } \\
\text { many strains of the virus. }\end{array}$ \\
\hline Syphilis & \multicolumn{2}{|c|}{$\begin{array}{l}\text { Begins with one or more painless sores on the genitals, rectum, or } \\
\text { mouth. The second stage may produce skin rashes, lesions on mucus } \\
\text { membranes, fever, and malaise. The latent stage begins when these } \\
\text { symptoms go away. }\end{array}$} & $\begin{array}{l}\text { Yes, if treated in its early stages. Without } \\
\text { treatment, infection remains in the body. } \\
\text { The late stage of syphilis includes damage to } \\
\text { internal organs and can be fatal. }\end{array}$ & No \\
\hline $\begin{array}{l}\text { Trichomoniasis } \\
\text { (trichomonas or trich) }\end{array}$ & $\begin{array}{l}\text { Women may experience frothy, } \\
\text { yellow-green vaginal discharge } \\
\text { with a strong odor. May also cause } \\
\text { itching or discomfort during } \\
\text { intercourse and urination. }\end{array}$ & $\begin{array}{l}\text { Men are usually asymptomatic; } \\
\text { sometimes mild discharge or } \\
\text { slight burning with urination or } \\
\text { ejaculation. }\end{array}$ & Yes & No \\
\hline
\end{tabular}


How are United Nations treaties and agreements reached? First, the United Nations (UN) calls for a global conference. The next step is a planning meeting involving senior country representatives, technical experts, and people from nongovernmental organizations (NGOs). They negotiate the content of a written document. NGOs have no official role or vote, but are often active in shaping the content of the documents. The UN holds the official conference where countries' representatives finalize and approve the negotiated documents. These documents may be in the form of treaties (which are legally binding) or of nonbinding declarations or action programs or platforms. In either case, countries can choose to sign the document, promising to comply with and implement it. When a country ratifies a treaty, that country becomes legally bound by it.

\section{How do United Nations treaties and agreements make a difference?}

Countries issue regular reports on how they are (or are not) complying with a human rights treaty. Violations of human rights treaties can often be addressed in national courts or, in some cases, by United Nations or regional human rights bodies. Many NGOs use international agreements as a basis to advocate for better laws, policies, and programs in their countries. They may also assume responsibility for monitoring their governments' compliance. International aid or trade agreements are also sometimes tied to a country's respect for certain human rights conventions.

\section{What are some of the most important official human rights documents?}

The Universal Declaration of Human Rights, adopted by the UN General Assembly in 1948, recognizes the principle that "all human beings are born free and equal in dignity and rights" and outlines the human rights guaranteed to all people. It includes rights related to life and security, personal freedom, economic, social, and cultural freedom, education, and work, among others. Together with the International Covenant on Economic, Social and Cultural Rights and the International Covenant on Civil and Political Rights, it makes up the International Bill of Human Rights.

The UN Convention on the Rights of the Child (CRC), adopted in 1989, aims to protect the individual rights of children including the right to protection from violence, to the highest attainable standard of health, and to education, among others. The CRC outlines the rights and responsibilities of families and governments to ensure these guarantees.

\section{The Convention on the Elimination of All Forms of}

Discrimination Against Women (CEDAW), adopted in 1979, recognizes women's rights and lays out an agenda to end discrimination against women in every sector of society. The rights addressed include political participation, health, education, employment, marriage, family, and equality before the law. The Fourth World Conference on Women (FWCW), held in Beijing in 1995, refocused efforts to achieve women's equality and adopted a Platform for Action. Themes included the empowerment of women, poverty, the girl-child, and violence against women.

\section{The International Conference on Population and}

Development (ICPD), held in Cairo in 1994, adopted a Program of Action laying out priorities to address population and development issues, including sexual and reproductive health, education, human rights, the environment, migration, and HIV and AIDS. The goals of the ICPD include universal access to reproductive health care and education, especially for girls, and the reduction of infant, child, and maternal mortality. This document has been an important tool for advocates and governments that seek to protect reproductive rights.

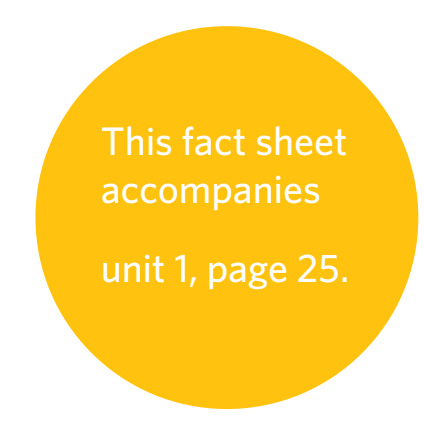




\section{violence against women and girls, including sexual violence}

\section{How widespread is violence against women and girls?} Sadly, violence against women and girls (sometimes called gender-based violence) is very widespread. It is a major public health and human rights issue. Worldwide, rates of such abuse vary widely. In most settings, however, between one-third and two-thirds of women are beaten, coerced into sexual activity, or otherwise abused by an intimate partner during their lifetime. Hundreds of thousands of women and girls are trafficked across borders annually. Roughly 140 million women and girls have undergone female genital mutilation and another 3 million are at risk annually in Africa. In the next decade, more than 100 million girls in developing countries will marry as children. In every war zone, violence against women, including systematic rape, has been reported during or after armed conflicts.

\section{What are the consequences of violence against women?}

The health consequences include:

- serious pain and injuries, such as broken bones, burns, black eyes, cuts, bruises, headaches, and abdominal and muscle pain, sometimes enduring for years;

- mental health problems such as depression, anxiety, and eating disorders;

- sexual dysfunctions, including painful sex, lack of desire, and fear of sex; and

- reproductive health problems, including miscarriage, STIs and HIV infection, unplanned pregnancy, and increased sexual risk-taking among adolescents.

Severe injuries, intentional homicide, and suicide related to violence all contribute to female mortality rates. In a community, violence against women can perpetuate the false belief that men are better than women. Gender-based violence creates a climate of fear and insecurity in families, schools, communities, and workplaces.

\section{What are some effective strategies for addressing violence against women?}

Changing attitudes and conducting other prevention efforts, including:

- engaging men in efforts to change cultural attitudes about masculinity and violent behavior;

- integrating gender education, including information about gender-based violence, into formal and informal education;

- introducing campaigns, such as the annual 16 Days of

Activism to End Violence Against Women;

- educating women and girls about their legal rights;

- other activities to empower women and girls; and

- ending child marriage, which puts many girls in

relationships in which they are at risk of violence.

Providing services: Women who experience violence and their children need access to various services, ideally in one place.

They may need hotlines, counseling, support networks, shelters that meet safety standards, legal services, and health care, including emergency contraception for rape victims.

Providing training: Trained health care providers can help detect abuse and assist victims by offering medical, psychological, and legal support and referrals.

Changing laws, including:

- demonstrating political commitment through statements from high-level government officials, backed by action and the commitment of resources;

- enacting and implementing laws that address violence against women, and evaluating the application of these laws;

- developing guidelines and protocols and providing systematic, mandatory training for police, prosecutors, and judges;

- establishing specialized courts and police units; and

- enacting vigorous arrest and prosecution policies and appropriate sentencing.

Expanding knowledge: Research and documentation of violence against women and girls increase recognition of the problem and the commitment to address it. 

